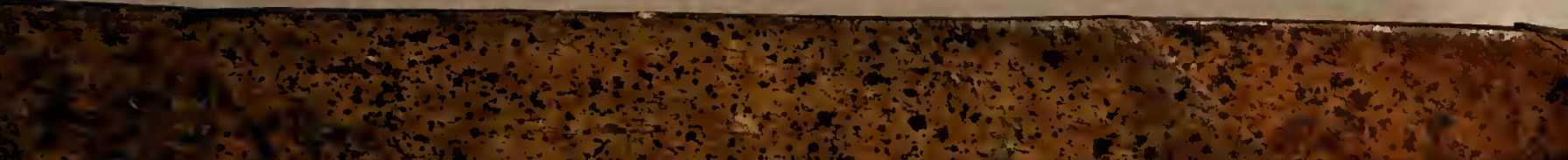

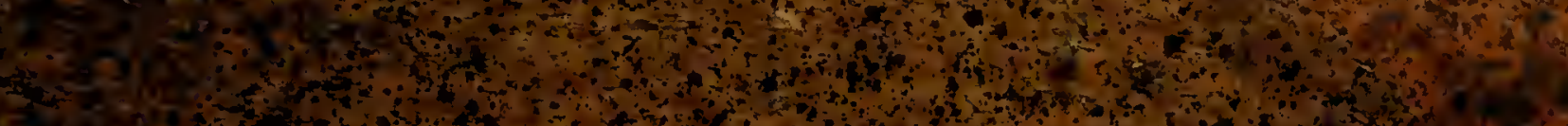

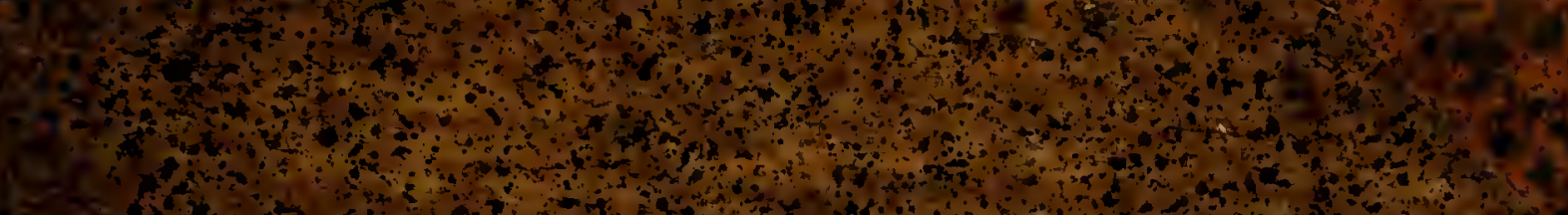

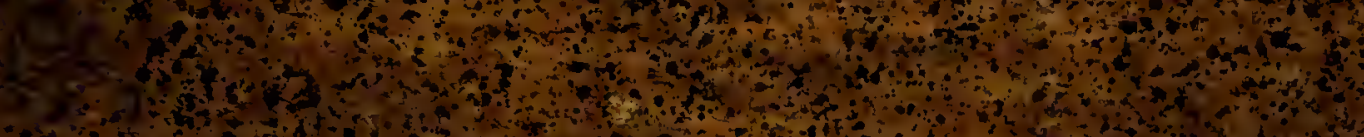

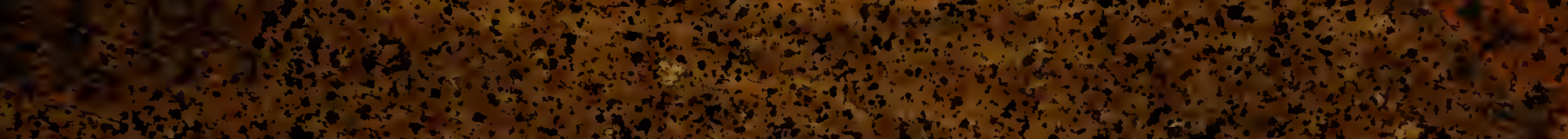

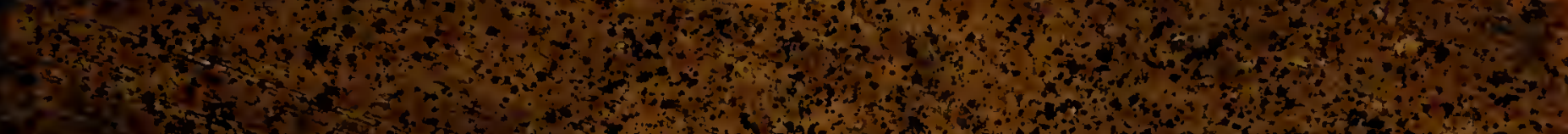

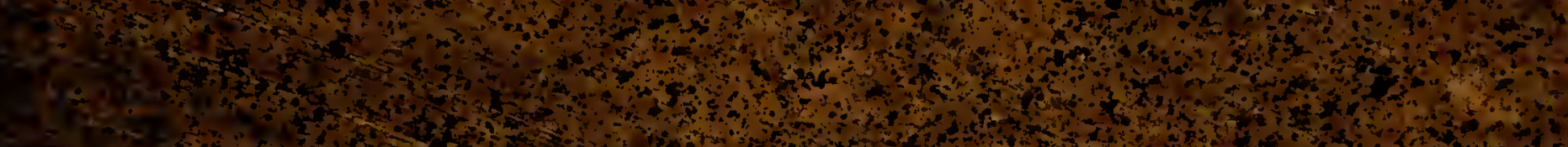

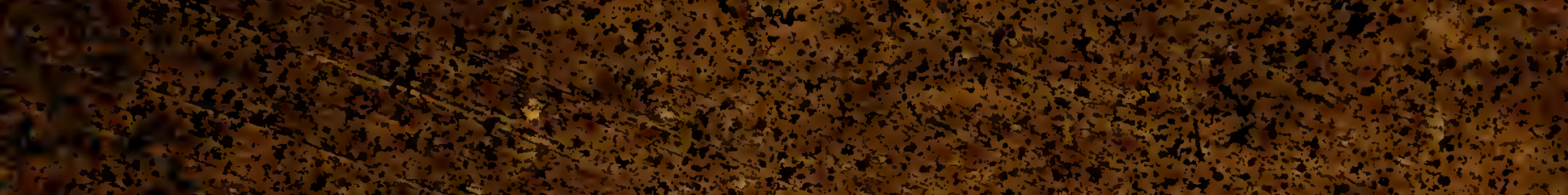
1
30

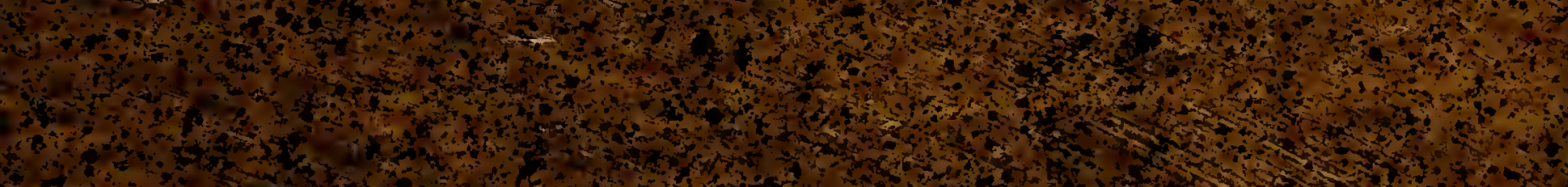

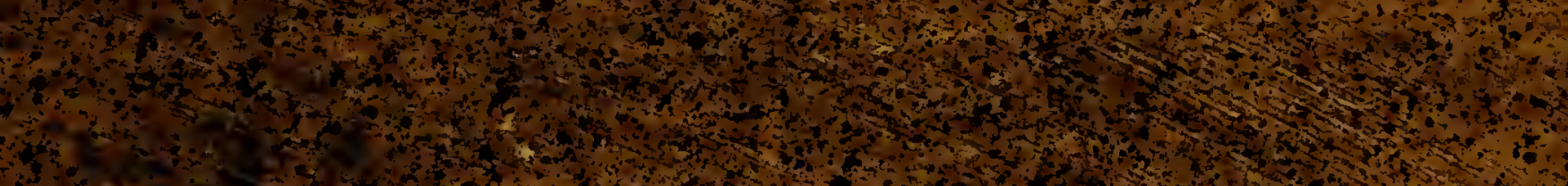

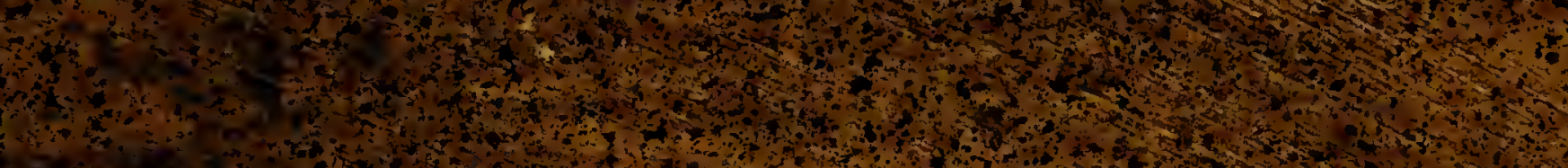

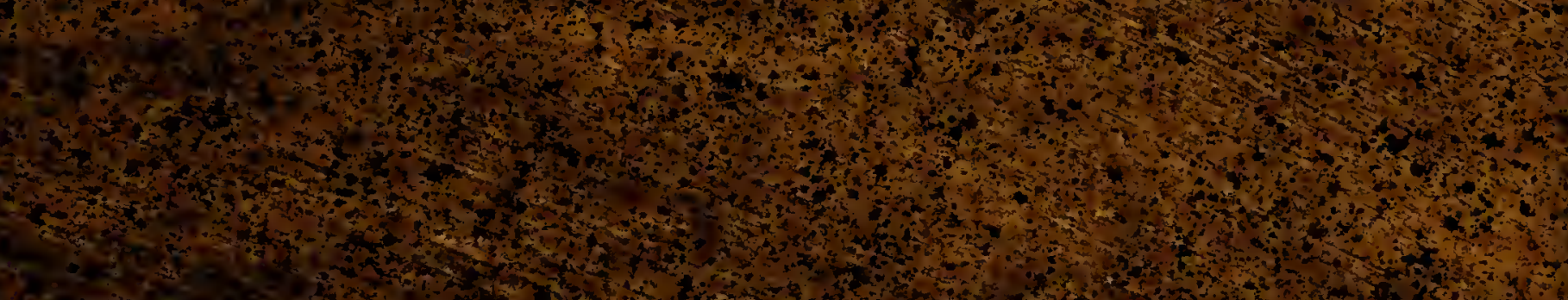

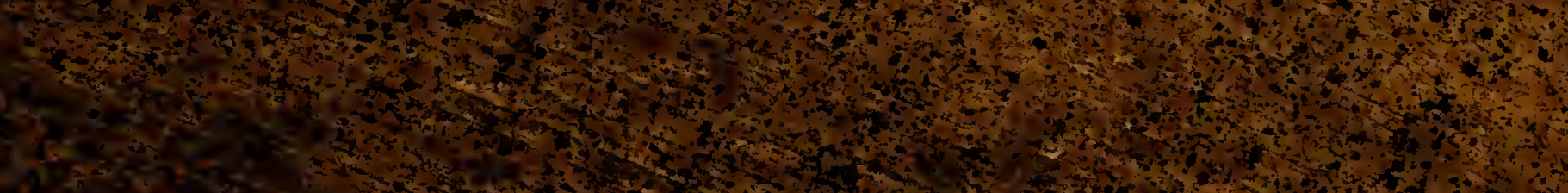

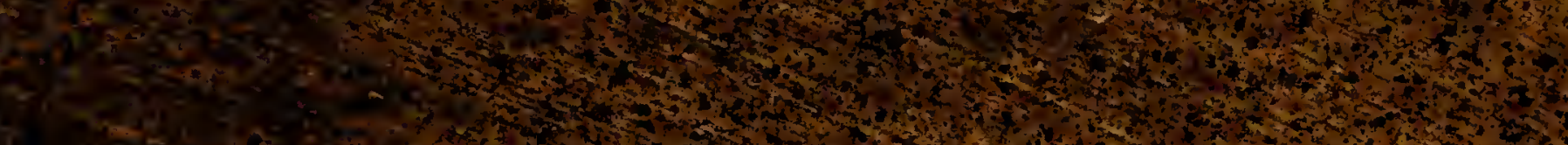

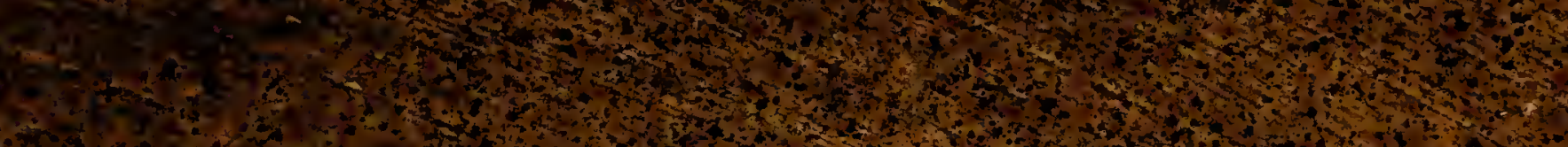

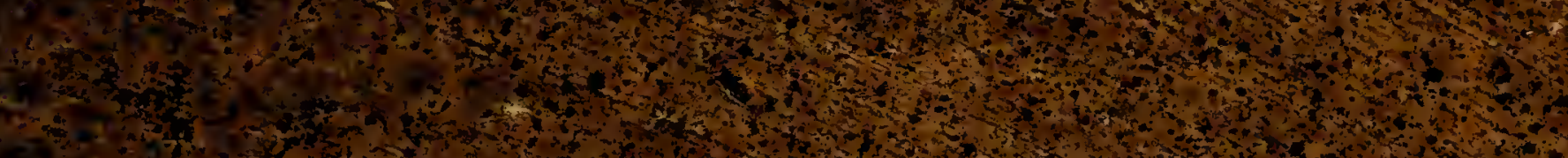

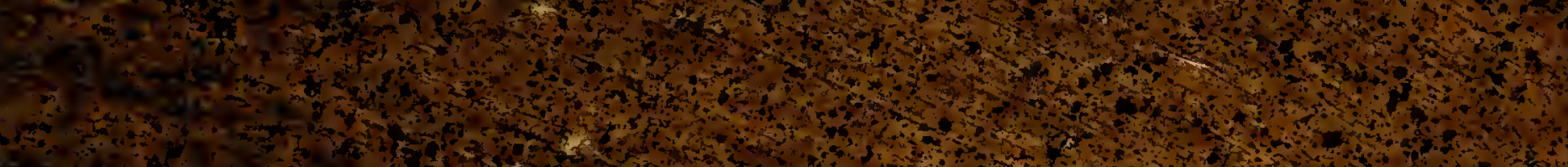

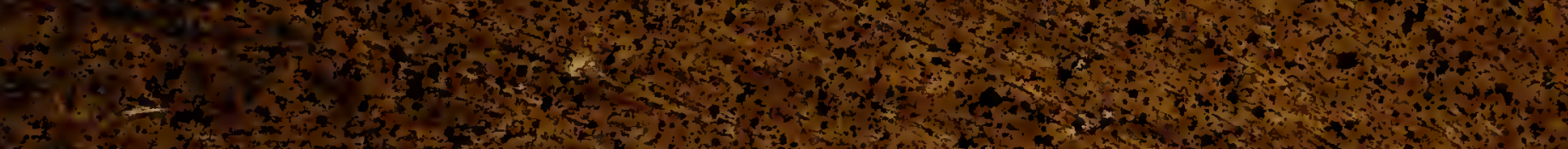

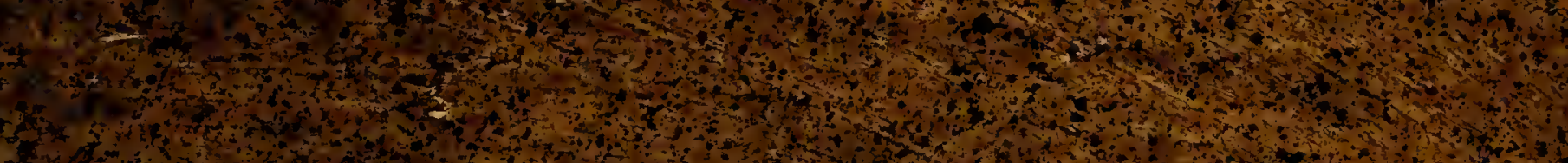

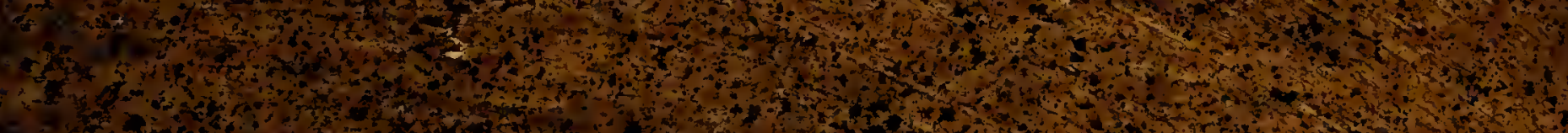

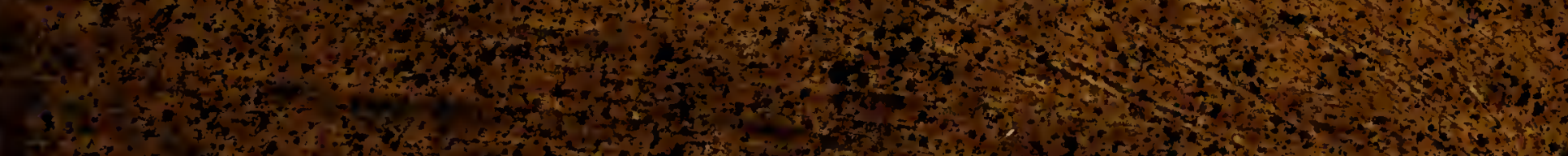

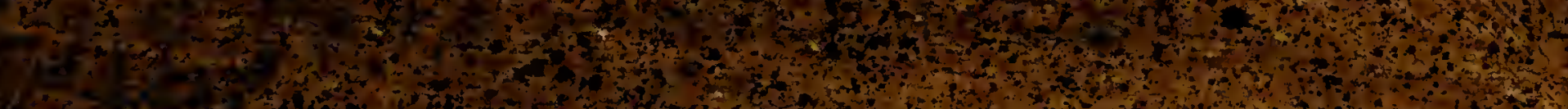

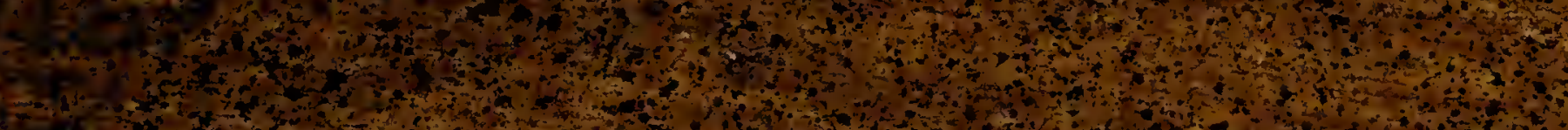

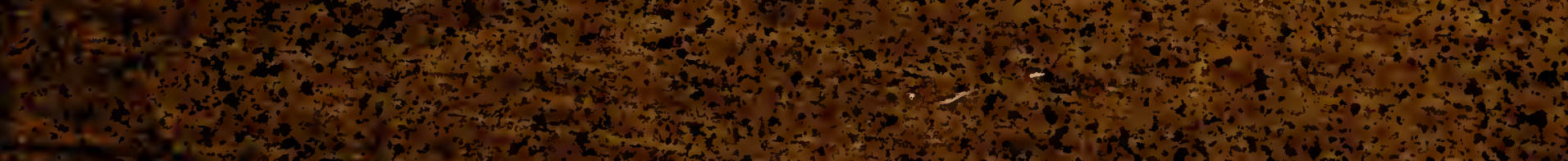

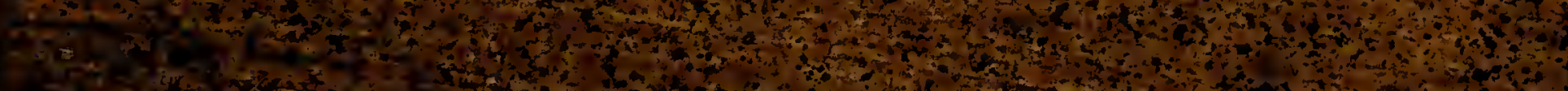

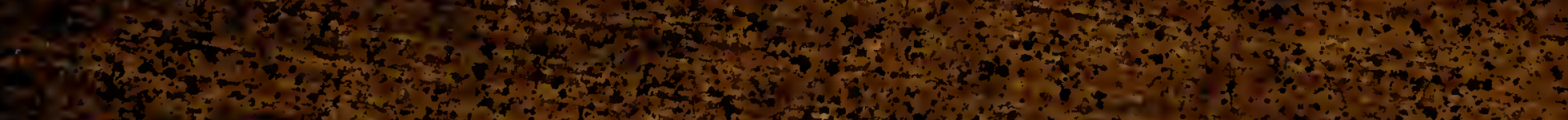

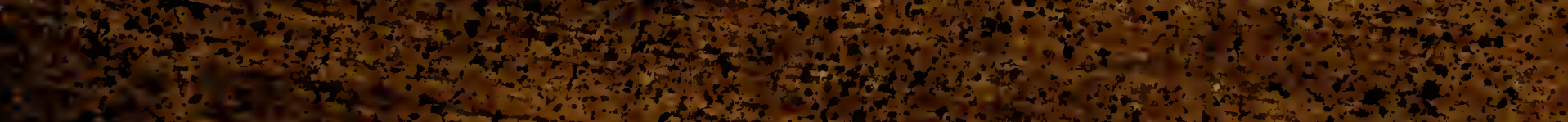

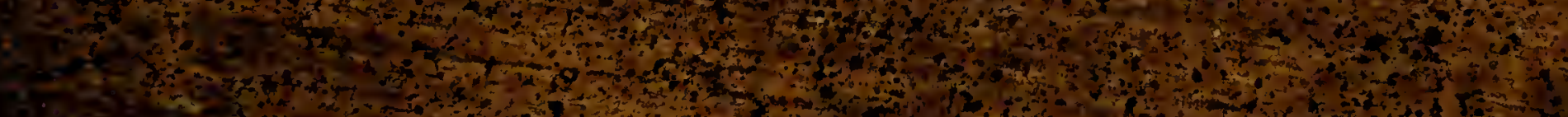

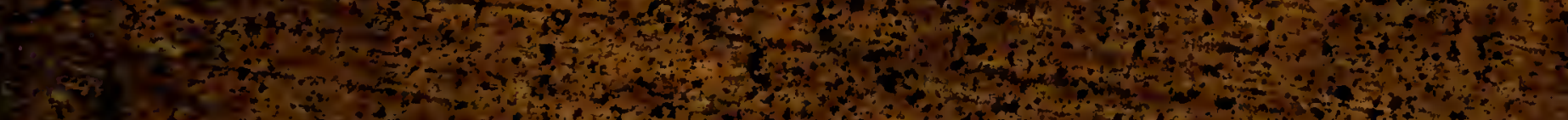

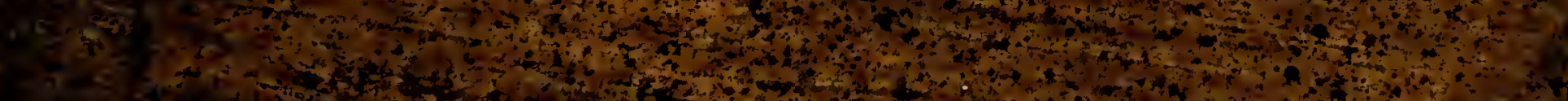

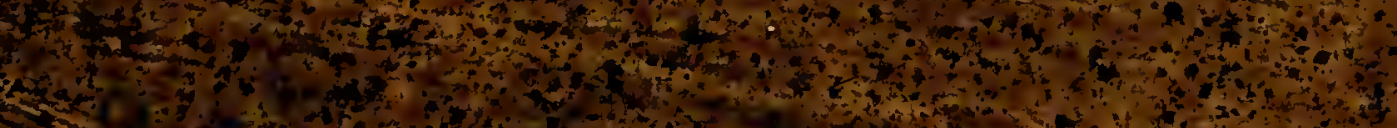

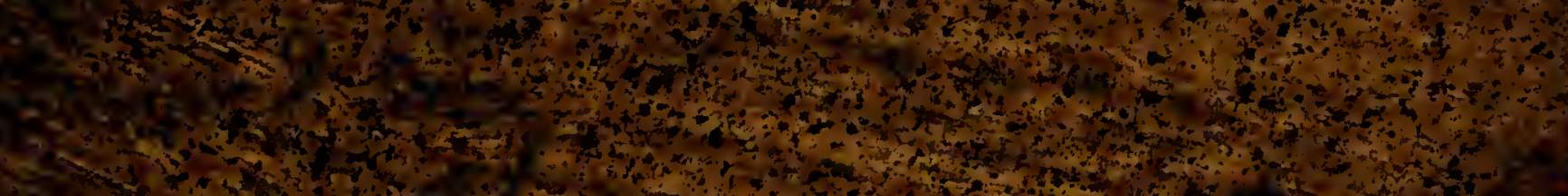

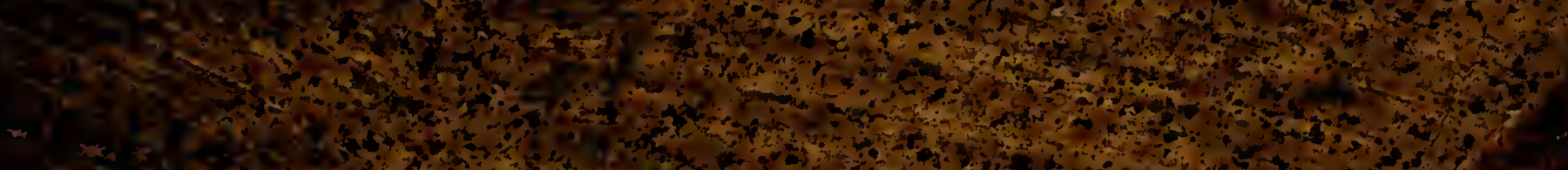

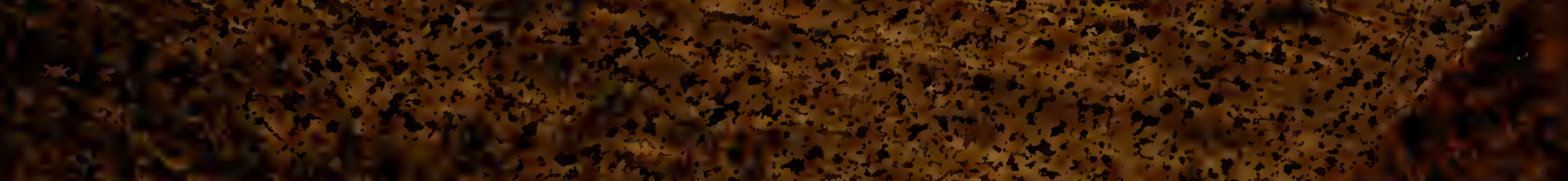
5. Cor

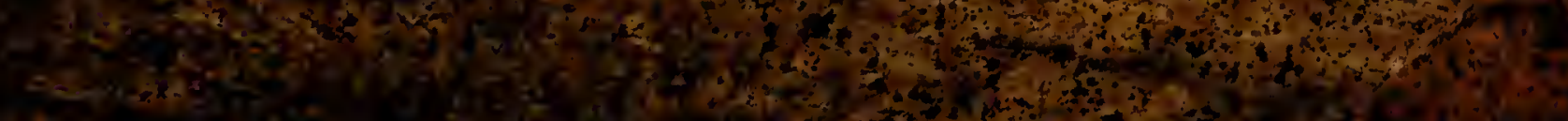




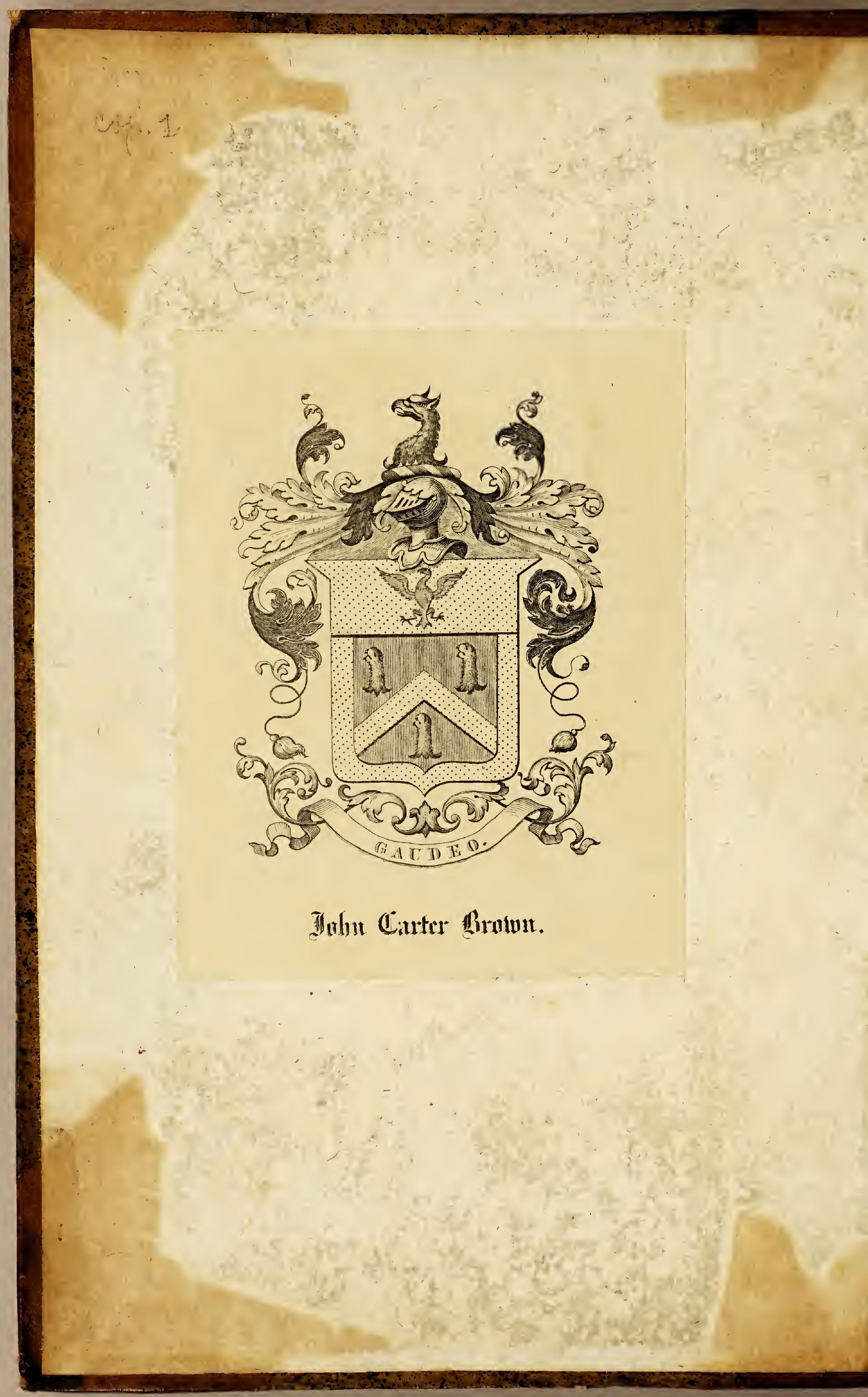





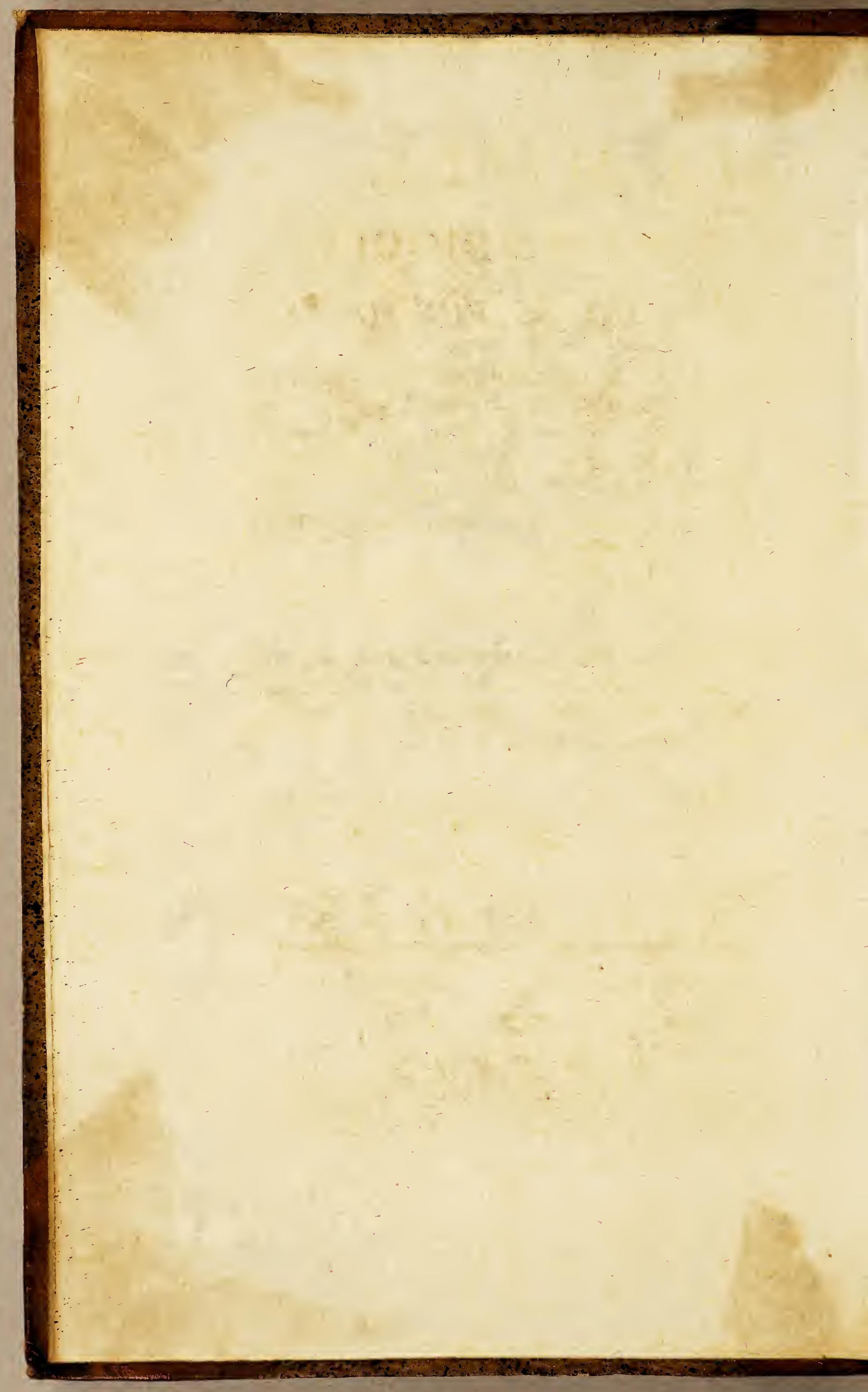


M É M O I R E S PHILOSOPHIQUES,

\section{HISTORIQUES, PHYSIQUES,}

Concernant la découverte de l'Amérique, fes anciens Habitans, leurs mœurs, leurs ufages, leur connexion avec les nouveaux Habitans, leur religion ancienne $\&$ moderne, les produits des trois règnes de la Nature, \& en particulier les mines, leur exploitation, leur immenfe produit ignoré jufqu'ici;

\section{Par Don ULLOA,}

Lieutenant-Général des Armées navales de l'Efpagne, Commandant au Pérou, de l'Académie Royale de Madrid, de Stockolm, de Berlin, de la Société Royale de Londres, Esc.

Avec des Obfervations \& Additions fur toutes les matières dont il eft parlé dans l'Ouvrage.

$T R A D U I T$ PAR $M$. ***

\begin{tabular}{lllllllllll}
\hline & $\mathrm{O}$ & $\mathrm{M}$ & $\mathrm{E}$ & $\mathrm{S}$ & $\mathrm{E}$ & $\mathrm{C}$ & $\mathrm{O}$ & $\mathrm{N}$ & $\mathrm{D}$ \\
\hline
\end{tabular}

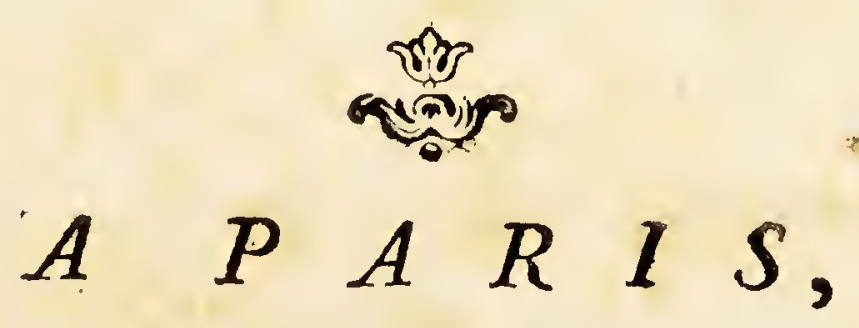

Chez Bu Is s o N, Libraire, Hôtel de Mefgrigny; rue des Poitevins, $\mathrm{N}^{2}$. I 3 .

I 787 . 


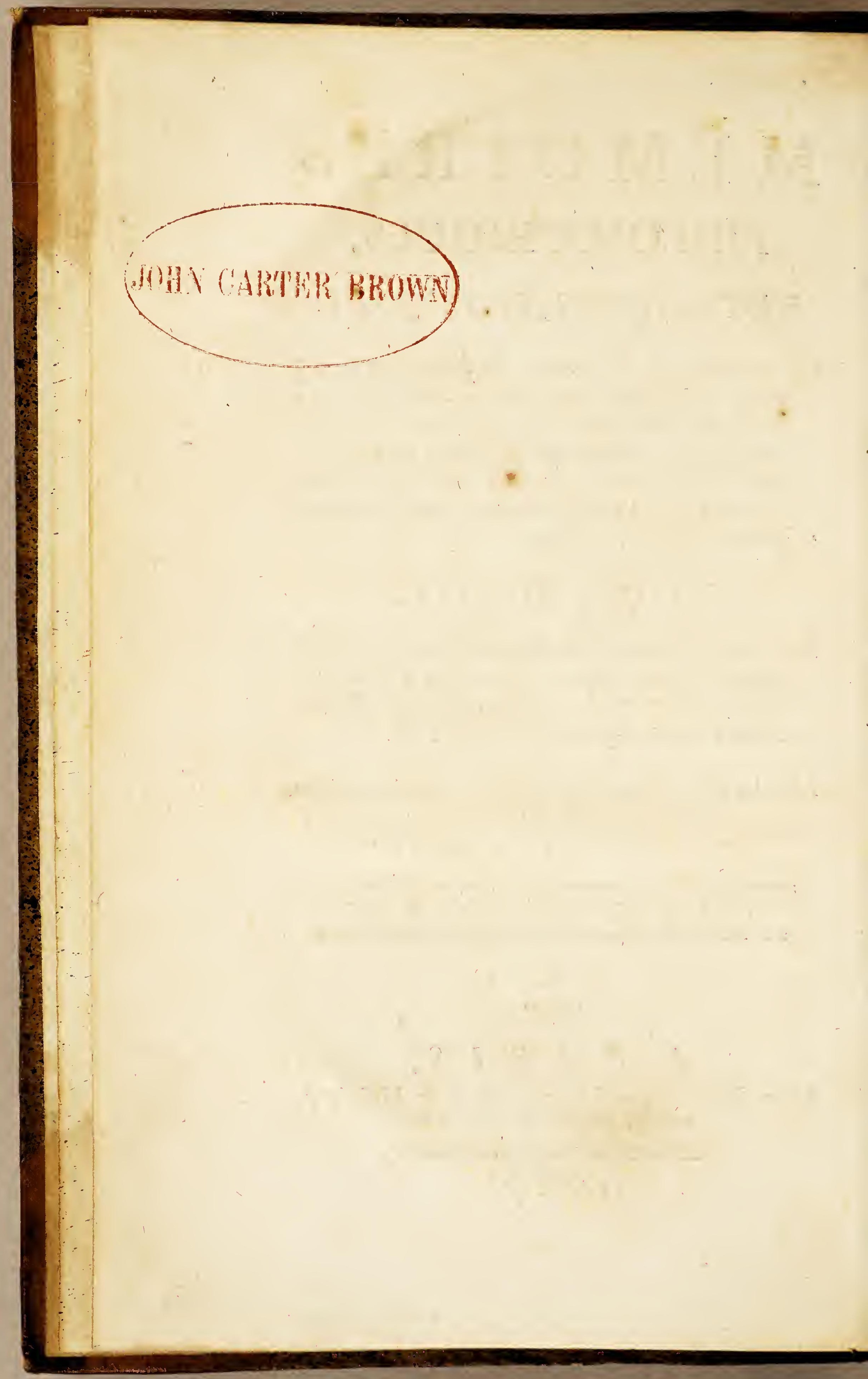




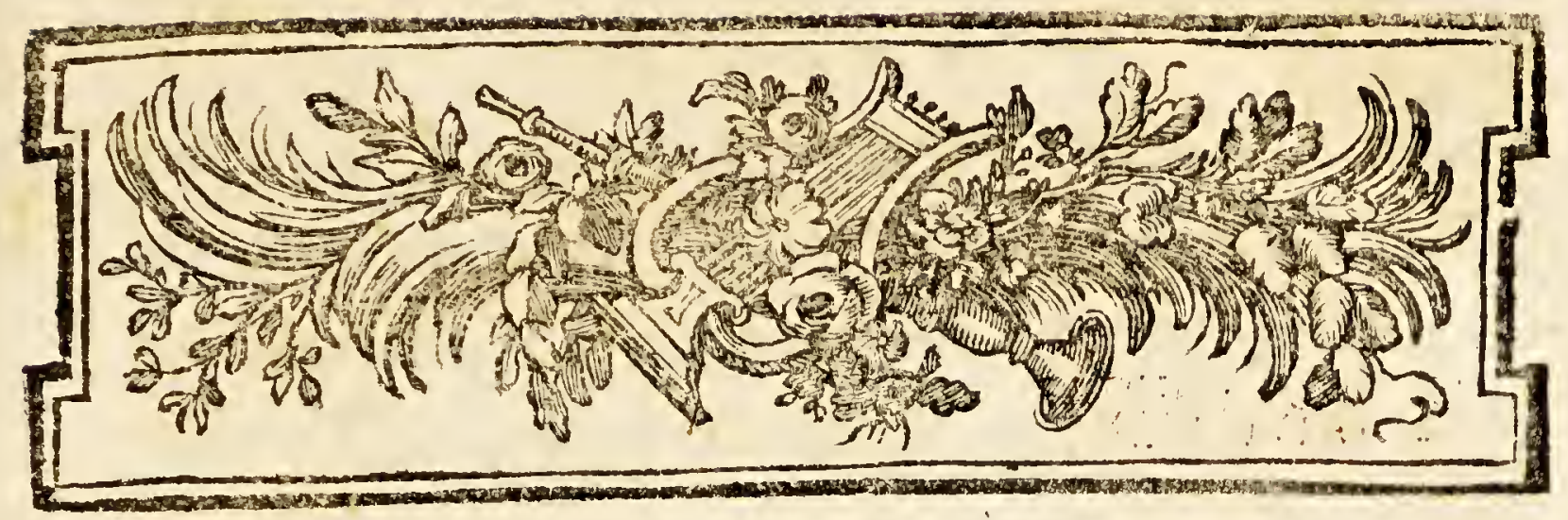

MEMOIRES PHILOSOPHIQUES, HISTORIQUES, PHYSIQUES.

\section{DISCOURS DIX-SEPTIEME.}

Des Indiens indigènes des deux parties de l'Amérique; de leurs mours, contumes $\&$ ufages.

U Ne curiofrté naturelle nous porte à connồre fur-tont les habitans des différentes contrées de la terre, leurs contumes, leurs ufages, leurs inclinations. Ce defir vient fans doute de ce que tous les hommes ayant une même origine, il leur paroit bien extroordinaire qu'il y ait tant de difíérence dans la manière d'être \& de penfer de toutes les Nations. En effer, on ne peut guère fe perfuader au premier abord qu'ils aient tous une même origine, lorfquon réféchit fur cette différence; elle eft même in confidérable dans Toine 11 . * A 
plufieurs Nations, qu'elle femble en faire des efpèces d'hommes qui jamais n'ont eu rien de commun, même à leur fouche. La couleur, les traits du vifage, la forme du corps, \& fur-tout les mœurs, le genre de vie, les habitudes, ont montré par-tout des variétés étonnantes. On peur cependant réduire ces variétés à trois principales, à l'égard de la couleur. On comnoîr des hommes blancs, des noirs \& des rougeâtres : mais ces couleurs fe fubdivifent chacune en prefque autant de nuances différentes qu'il y a de Régions, d'Etats \& de Provinces fur le Globe. On remarque entre le blanc \& le noir toutes les nuances oppofées qu'on peut fuppofer de l'un à l'autre extrême; de forte qu'en prenant ces deux termes, on peut dire que la différence eft du jour à la nuit. Le rouge tient un milieu entre ces deux couleurs, différant autant de l'un que de l'autre : c'eft la couleur des Indiens. Quoique ces hommes n'y attachent aucun avantage, ils fe nomment vers le Nord les hommes rouges, pour fe'diftinguer des deux autres efpèces. On a cherché la caufe de ces couleurs, \& on a pretendu l'afigner; mais, bien loin de l'avoir trouvée, on n'a produit rien que d'illufoire à cet égard. Les mêmes raifonnemens qu'on avoit avancés pour la prouver fe font détruits d'eux-mêmes: mais, ourre que le froid \& la chaleur des climats n’en 


$$
D I X-9 \text { E F } T \text { I I E } M E \text {. }
$$

font pas une raifon fuffifante, jamais ils ne ferviront non plus à expliquer d'une manière fatiffaifante la diverfité de la contexture \& des traits; car on remarque, à cet égard, autant de variétés que dans les couleurs de la peau.

Les Indiens ont naturellement une couleur qui tire fur le rouge; nais étant très-fouvent expofés au foleil \&s au vent, cette couleur devient obfcure. Or, il eft conftant que ni le froid, ni la chaleur, ne produifent à cet égard aucune variation fenfible; c'eft pourquoi les Indiens de la partie haute du Pérou fe confondent avec ceux de la partie baffe. On fe méprend aufi fur la couleur de ceux qui habitent les pays appellés Vallées, en les confondant avec ceux d'autres contrées plus chaudes. Il en eft de même à l'égard de ceux qui habitent la partie méridionale depuis le qua rantième degré vers le Sud, \& de ceux de la partie feptentrionale, depuis le quarantième degré, \& au-delà, vers le Nord; car on ne peut, à la couleur, diftinguer ceux - ci des Indiens qui font vers l'Equateur. En général, il eft fort difficile de déterminer de quelle partie font tous ces Indiens lorfqu'ils fe trouvent enfemble; leur couleur naturelle reçoit des rayons du foleil, du froid, de l'air, une teinte qui la rend d'un rouge obfcur: or, c'eft la couleur générale de tous ces peuples, comme je l'ai dit. 


\section{4}

$D$ I $S$ C O U R S

On remarque moins de différences entre les races Indiennes, qu'entre les autres; comme, par exemple, entre les Nègres, les uns ont le nez applati, les tuniques des yeux épaiffes, les lèvres prominentes \& groffes, \& de la laine pour cheveux. Il en eft d'autres auffie noirs; mais leur vifage eft modelé comme celui des Blancs, furtout à l'égard de la bouche, des narines, des yeux; \& ils ont les cheveux plat's, quoique fort épais. Il en eft auffi de rougeâtres, \& d'une autre nuance rouge beaucoup plus claire, tirant fur la couleur des Mulâtres.

Quant aux Indiens, leur conleur ne varie prefque point, malgré la différence qu'on remarque dans la forme $\&$ les traits de leur vifage; différence fort fenfible, \& qui femble en diftinguer la race : comme un front très-petit, couvert en partie de cheveux jufqu’aux extrémités, ou à l'interRice des fourcils, les yeux petits, le nez. pointu, mince, courbé jufqu’à la lèvre fupérieure, la face large, les oreilles grandes, les cheveux noirs, plats, épais; la jambe bien faite, le pied petit, le corps épais, bien mufclé \& robufte; la face fans barbe, à moins qu'ils ne foient vieux; alors ils en ont un peu, mais jamais aux joues. Quoique cette forme générale varie, les individus confervent cependant un air de race, qui empêche de les confondre avec les Mulâtres, 
qui s'en rapprochent à certain point par la couleur.

Quand on a vu un Indien de quelque contrée que ce foit, on peut dire qu'on les a vu tous, quant à la couleur \& à la contexture externe. Mais il n'en eft pas de même à l'égard de la taille; elle varie felon les pays. Ceux des hautes contrées du Pérou font de moyenne taille: on les trouve un peu plus grands dans la partie baffe, quoique de peu de chofe. Mais ceux qui habitent les parties méridionales depuis le trentefixième degré vers le Sud, les Cayes de la Floride, la partie du Nord depuis le trentième degré vers le Nord; enfin ceux qu'on a connus le long du Mifrifipi, dans le Canada \& vers la partie de la Nouvelle-Efpagne, ont une haute taille \& un beau corfage. Or on ne peut attribuer cette différence ni au froid, ni à la chaleur, puifque l'on éprouve au Pérou les deux excès de ces températures, au même degré que dans des climats très - éloignés de l'Equateur, ou trèspruches.

Les rapports font encore plus fenfibles quant aux ufages, aux contumes, au caractère, au génie, aux inclinations, aux autres particularités : car on y remarque en tout une aulli grande reffemblance que fi les pays les plus éloignés n’en faifoient qu'un. 
Toutes les nations Indiennes ont un plaifr fingulier à fe peindre le corps en rouge : elles fatisfont ce goût avec les terres de cette couleur. La mine de Guancavelica n'avoit anciennement au Pérou d'autre ufage que celui-là, \& le cinabre qu'on en tiroit fervoit de peinture. Celles de la Louyfiane, du Canada, ont aufli une extrême paffron pour fe peindre Fe corps; voilà pourquoi le minium y eft la marchandife la plus recherchée.

Il paroîtra fingulier que ces gens étant naturellement rouges, aiment tant à fe peindre avec cette couleur : mais ces gens ne font à cet égard que ce qui fe pratique en partie chez les nations les plus cultivées de l'Europe, où l'on employe différentes matières pour faire mieux fortir la blancheur de la peau, \& la couleur rouge des parties où il doit y en avoir naturellement. Les Indiens du Pérou ont, il eft vrai, renoncé à cette coutume; mais elle étoit commune chez eux avant la conquête, \& c'eft encore celle des nations Indiennes qui ont confervé leur liberté. Les nations de la partie du Nord employent aufi le blanc, le noir, le bleu \& même le verd, outre le rouge qui eft la couleur dominante.

La parure que les Indiens de la Louyfiane \& des valtes pays qui s'étendent vers le Nord trouvent dans ces couleurs, eft pour eux une affaire d'auifi grande importance que les habits \& les 
acitres ajuftemens parmi les nations policées : ils appellent cela maśtacher, \& ils y mettent tous leurs talens pour le faire avec toute la délicateffe \& la prolixité imaginable. C'eft en cela qu'on reconnoît leur patience : en effet c'eft la feule chofe pour laquelle ils foient actifs \& toujours prêts. Cette opéracion exige cinq ou fix heures de leur tems, c'elt-à-dire une matinée entière, \& jamais la femme du plus haut rang n'a tant confulté fon miroir à fa toilette, qu'ils le font en fe peignant. Ces couleurs font appliquées avec un art quii demande de l'adreffe. Ils tirent à la racine des cils, au-deflus des paupières, deux ligines auffi fines qu'un fil; ils en font autant aux lèvres, aux ouvertures des narines, aux fourcils, aux oreilles, \& en fuivant toutes leurs courbures. Quant au refte de la face, ils y placent différentes figures dans lefquelles le rouge prédomine, \& que les autres couleurs font fortir davantage. Le cou reçoir auffi en partie fa parure. D'ordinaire ils étendent fur leurs joues des couches affez épaiffes de vermillon. Ils ont befoin du tems que $j$ 'ai dit pour imaginer \& tracer ces lignes avec délicateffe, \& avec la perfection qu'ils y voyent. Comme ces figures ne correfpondent pas toujours à leurs idées, ils les effacent, après y avoir pris beaucoup de peine; \& en tracent d'autres qu'ils jugent benucoup plus belles. Le plaifrir, la fariso $A_{4}$ 
faction qu'ils trouvent dans cette parure, après s'être mactachés, les raviffent au point que le miroir ne leur fort plus des mains, \& qu'ils ne ceffent de fe réjouir à regarder leur figure. Ils laiffent le refte du corps dans fon état naturel, de même que la tête, \& n'ont aucun habit : à l'exception de ce qu'ils appellent cache-cul, ils vont tous nuds.

Les Indiens courageux \& confidérés fe diftinguent des aurres, en ce qu'ils fe peignent des figures fur le corps : ils y introduifent la couleur en fe picotiant la peau; \& cet ornement eft d'autant plus étendu, qu'ils ont fait de plus grands exploits. Les uns ne fe peignent que les bras, les autres les bras \& les jambes; ceux-ci les cuiffes, ceux-là depuis la ceinture jufqu'au haut du corps; \& ce font les plus valeureux guerriers. Ainfi les figures ou peintures vont toujours en augmentant avec les exploits \& la renommée.

Ces guerriers pórtent aufil des plumes fur la tête en forme d'aigrette; ils s'en parent même les bras en forme de bracelets, \& les jambes au-deffus de la cheville du pied; ce qui eft pareillement une marque diftinctive \& une preuve de valeur. Voilà pourquoi on n'en voit pas à ceux qui ne font pas guerriers.

Le penchant à l'oifiveté eft égal dans ceux de la Louyfiane, du Canada, dans ceux du Pérou 
D I $X-S$ E P T I E M E.

\& des parties civilifées ou fauvages de l'Amérique méridionale. L'unique exercice de ceux qui font indépendans, eft la chaffe, la pêche; ce qui eft aufi commun aux nations voifines du Paraguai, dans les plaines de Buenos-Ayres. Les femmes s'y occupent à faire quelques femailles de mais \& de citrouilles, qu'elles écrafent pour en préparer un aliment à leur manière : elles préparent auffi les boiflons ordinaires, prenant en même tems foin de leurs enfans, car les pères ne s'en inquiettent pas.

Les Indiennes de tous les pays foumis de l'Amérique méridionale font ce qu'elles appellent le urcu; (mot qui fignifie chez eux élévation.) Cet urcu confifte à rejetter les cheveux (depuis le milieu de la tête) fur le front, \& à les couper en rond depuis les oreilles jufqu'au-deffus des yeux, de forte que le front \& les fourcils en foient couverts. Cet ufage fe voit auffi chez celles du Nord. Les unes \& les autres lient le refte des cheveux par derrière, en forme de petice queue; \& toutes font fi reffemblantes à cet égard, qu'on penferoit qu'elles fe font modelées les unes fur les autres. Cette uniformité donne lieu de croire, que cet ufage vient de la première race qui s'eß répandue dans ces valtes contrées.

Cet ufage ne fe remarque pas chez les Indiens. Ceux de la parie haute du Pérou portent les 
cheveux longs \& flottans, ce qui eft pour eux un ornement à leur idée. La plupart de ceux des bas pays les coupent, à caufe des chaleurs : ce en quoi ils imitent les Blancs, ou les Efpagnols. Ceux de la Louyfrane fe les arrachent jufqu'à la racine, depuis le vertex jufqu'au bas du front, afin d'avoir ainfi un front bien étendu, que la Nature leur a refufé. Ils coupent le refte fort court, afin qu'en guerre l'ennemi ne puiffe les faifir par-là, ni arracher aifément la chevelure quand ils tombent en fon pouvoir; car c'eft une marque de triomphe chez eux que d'apporter la chevelure de l'ennemi. L'enlevement d'une chevelure eft une opération horrible. Quand il s'agit d'arracher celle des Européens, qui portent ordinairement les cheveux longs, ils cernent la peau tout autour. de la tête, paffent les doigts entre le cuir chevelu \& le crâne, \& arrachent enfuite avec violence le cuir avec les cheveux. Quoique cette opération foit des plus cruelles, on a cependant vu des gens y furvivie: mais fi le vaincu n'a pas de cheveux, l'opération devient plus difficile $\alpha$ infiniment plus douloureufe, parce qu'il n'y a pas affez de prife.

En général ces Indiens font très-inhumains au Pćrou, civilifés ou fauvages, \& à la Louyfrane: la feule différence qu'il y a, c'ent que ceux qui font civilifés \& affujettis, fe trouvent foumis aux 
loix du Gouvernement, qui les empêche de fuivre leur inclination naturelle: mais on leur voit faire, à l'égard des animaux, des chofes qui ne laiffent aucun doute fur leur barbarie-naturelle.

Lorfqu'on donne un combat de Taureau, leur plaifir eft de courir à fix ou huit contre l'animal avec des lances garnies de longues pointes de fer, \& de le percer tous en même tems où ils peuvent l'atteindre, de manière à l'abattre fur le champ. Aufîtôt ils en coupent le mufle, la queue, \& des morceaux de la cuiffe, qu'ils dévorent même avant que l'animal foit mort. On les voit toujours difpofés à quelqu'acte de cruauté que ce foit : la gaieté qu'ils montrent dans ces actions prouve combien cela leur plaît. Il eft naturel d'en conclure que fi ces gens vivoient dans leur ancienne liberté, comme ceux de la Louyfrane, de la Floride, \& des parries les plus méridionales, ils fe comporteroient envers les hommes comme ils le font envers les animaux : mais ce qu'il y a de plus remarquable en ceci, c'eft qu'ils font cruels de fang-froid, fans montrer la moindte colère, ni même en avoir aucun motif; \& ils agiffent comme fi leur action n'avoit pas l'ombre de cruauté.

On a obfervé qu'ils n'ont ni barbe, ni poil en aucun endroit du corps dans toutes les contrées 
qui s'étendent du Nord au Midi; ce qui diftingue cette race de toutes les autres nations.

Ils ont la peau épaiffe, la chair dure, \& paroiffent moins fenfibles que les autres nations du Globe. On peut citer pour exemple l'opération de la pierre. Un Opérateur fut vingt-fept minutes à faire cette opération à un Indien, fans ceffer de travailler; tandis qu'ordinairement on la fait. en quatre ou cinq minutes. Mais la pierre étoit adhérente, elle échappoit de la tenaille lorfqu'on la tiroit, deforte qu'on fut obligé d'introduire $\&$ de retirer plufieurs fois l'inftrument. Pendant ce tems-là, cet Indien ne montra aucun figne de la douleur extrême que caufe cette opération; il fe plaignit feulement de tems en tems, mais foi. blement, comme s'il n'eut fenti qu'une légère incommodité : enfin on eût la pierre après bien du travail. Deux jours après, l'Indien demanda à manger, \& le huitième il quitta le lit, fans éprouver aucune douleur, quoique la plaie ne fût pas encore totalement fermée.

On les voit auffi peu fenfibles dans tous les cas de fractures, de bleffures, \& de tout autre accident; ils guériffent très - facilement, \& femblent ne jamais éprouver autant de mal que les autres nations. Après avoir examiné les crânes qu'on tira des anciens tombeaux, on leur trouva 
plus d'épaiffeur que cés os n'en ont ordinairemeut; car il y avoit fix ou fept lignes de la table externe à l'interne. On remarque aufli la même chofe à la peau dans les opérations chirurgicales: celle des cadavres tirés des tombeaux avoit autant d'épaifleur.

On doit conclure de-là que leur organifation eft plus groflière \& plus forte; ce qui la rend moins fenfible. La facilité avec laquelle ces gens fupportent les peines \& la dureté des climats, en eft une autre preuve. Les habitans de la haute partie du Pérou, qui font bergers ou pâtres, vivent fur les punas, où le froid \& les neiges règnent prefque continuellement. Quoiqu'ils ne foient que très-peu vêtus, ils s'accoutument à cette dure température, fans en éprouver d'incommodité. L'habitude y fait fans doute beaucoup; malgré céla ils n'y tiendroient pas toujours fans inconvénient, fi la texture \& l'épaiffeur de leur peau ne les garantiffoit de l'impreflion que la température pourroit faire fur leurs pores.

Ceux de la partie du Nord leur reffemblent a cet égard: ils réfiftent au froid, aux gelées de l'hiver; faifon pendant laquelle ils chaffent également, fans fe couvrir d'aucun habit. Quoiqu'on leur voye une mante de laine fur les épaules, ou la peau d'un animal, elle n'embraffe pas tout le corps; il paroît même qu'ils s'en fervent plutôt 
comme d'une parure que pour fe garantir du froid; en effet, ils en portent auffi pendant les chaleurs les plus fortes, lorfque les autres hommes, blancs ou noirs, ne peuvent fouffrir fur le corps le vêtement le plus fin de foie ou de laine. Ils la quitrent même lorfqu'ils vont à la chaffe, pour ne pas en être embarraffés en paffant dans des bois remplis de ronces \& d'épines, qui s'attachent, difent-ils, à ces mantes ou peaux, au lieu qu'elles gliffent fur la peau de leur corps.

En tout tems ils vont tête nue, fans rien avoir qui la garantiffe des rayons du foleil, ni des frimats, \& l'on ne voit pas qu'ils en fouffrent la moindre incommodité, bien loin d'éprouver les coups de foleil funeftes, qui, dans la Louyfrane, tuent promptement les individus des autres races. L'habitude contribue beaucoup à ces avantages; mais la vigueur \& la robufticité en deviennent bien plus confidérables, lorfque cetre habitude eft celle de conftitutions aufi fortes \& auffi peu fenfibles naturellement.

Les Indiens de l'A mérique méridionale fe diftinguent entr'eux par les habits modernes; car ils ne portent pas tous les mêmes. Il faut en excepter ceux de Quito, qui s'habillent comme ils le faifoient du tems de leurs anciens Rois. Ceux des Vallées, \& de la partie haute du Pérou, s'habillent en partie à l'Efpagnole : ils portent au 
D I $X-S$ E P $T$ I E M E.

lieu de chapeau un bonnet de gros drap, lourd. $\&$ double, qui ne les incommode même pas quand ils vont dans des pays chauds, \& dont ils fe paffent fans peine dans les climats froids lorfqu'ils ne l'ont pas. Ils n'en portent même pas tous habituellement; ils vont pieds nuds, jambes nues, fi l'on en excepte des alpargates ou fandales, que plufieurs font de peaux de bouf, \& qui exhalent une odeur abominable lorfqu'elles font mouillées à leurs pieds; car ils ne les quittent pius, ni pour les laiffer fécher, ni pour dormir, dès qüils les ont chauffées, à moins qu'elles ne foient toutes déchirées. On voit parlà leur malpropreté, \& combien ils font peu dégoûtés des chofes les plus fales \& les plus impures.

Les Indiens font naturellement portés à s'enivrer; ils préfèrent toujours les liqueurs les plus fortes. Ceux du Pérou faifoient encore ufage du Chica, il y a quelques années; mais l'intérêt des Propriétaires qui ont des vignes dans la partie baffe, fur-tout dans les vallées d'Ica, Pifco, Nafca, a fait introduire chez ces Indiens l'ufage de l'eau-de-vie, qui les détruit vifiblement. On remarque le même penchant dans nombre des Nations fauvages qui habitent au Nord de l'Ainérique depuis la Floride \& le Miffifipi, jufqu'aux terres connues les plus reculées vers le 
Nord. Elles y ont été accoutumées par les Anglois de la Nouvelle-Angleterre d'un côté, \& de l'autre par les François de la Louyfiane \& du Canada. Mais c'elt une boilfon qui les fait périr peu-àpeu : auff a-t-on remarqué que chaque Nation étoit actuellement beaucoup moins nombreufe.

Le penchant décidé que ces Sauvages ont à Poifiveté \& à la fainéantife, les a rendus exceffifs dans l'ufage des boiffons fpirituenfes. Ia pafion qu'ils ont pour ce poifon agréable eft telle, qu'ils bravent tous les dangers, furmontent tous les obftacles, \& commettent tous les. crimes, s'ils ont l'efpérance de s'en procurer. On a vu plus d'une fois, dans la Louyfrane, l'Indien le plus affidé \& le plus raifonnable en apparence, ruer perfidement fon mârre qu'il accompagnoir à la chaffe ou en voyage, pour lui voler un Hacon d'eau-de-vie qu'il lui avoit vu : il attendoir que fon maître fut endormi pour faire le coup, $\&$ l'on trouva le flacon vide à côté du cadavre.

On apperçoit fouvent dans les chemins, fur la partie haute du Pérou, des Indiens morrs de leur ivrefle: ces gens, hors d'état d'aller plus Join, s'endorment fur la route, le froid les faifit, \& ils y reftent. Mais ces trittes exemples quion rappelle à leurs femblables, les avertifemens qu'on leur donne fur les dangers de ces liqueurs meurtrières, ne peuvent les en détoumer, ni les 
D I X-S E P T I E M E。

garantir de leur perte. Les femmes ne buvoient pas avec leur mari dans le royaume de Quito; ellos les accompagnoient feulement, pour tâcher. de les ramener en cas qu'ils fuffent ivres : mais au Pérou; les femmes boivent comme les hommes, \& ils fe mettent dans le cas de ne plus pouvoir fe fecourir réciproquement. Ce qu'il y a de plus affreux dans cette conduite, eft que les femmes êtent leurs enfans du fein pour leur donner de ces liqueurs qu'elles boivent, \& les accoutument ainfí à l'ivrognerie, même avant l'ufage de raifon.

Dès qu'une fois ces Indiens ont commencé a boire, ils ne connoiffent plus de bornes; ils boivent jufqu'à ce qu'ils tombent ivres; \& privés de tout fentiment. En vain veut-on les féparer, ils font la plus grande réfiftance, \& fe remettent à boire avec la phrénéfie qui les y porre : ils font, à cet égard, comme dans leurs autres habitudes; de véritables frères dảns tous les pays; fans que les diftances les plus éloignées y faffent la moindrè différence. On s'apperçoit plus qu'ailleurs de ces excès à Guancavelica, (vu le grand nombre des Indiens qui y travaillent aux minés ) au Potof, $\&$ dans les autres grandes mines. Il eft d'ufage d'y payer le dimanche à ceux qui ne font pas Mitayos, ce qu'ils ont gagné pendant la femaine: Quant aux Mitayos, on leur paye moitié, réfer-s, Toms $I I_{\text {s }}$ 
vant le refte pour la fin du tems quils font obligés de travailler. Ce paiement fe fait par les mineurs à quarre ou cinq heures de l'après-midi; ce qui fait une fomme de dix mille pefos ou environ, à Guancavelica, \& dont quatre mille font dépenfés le foir on pendant la nuit pour de l'eauce-vie : conféquemment on y travaille peu jufqu'au foir du lundi, vu l'ivreffe dans laquelle fon les Indiens : à peine leur refte-t-il même un denier pour payer les dépenfes qu'ils font pendant la femaine; \& l'on remet au dimanche fuivant à payer les alimens qu'on a confommés pendant ce tems-là. On a vu même un Indien boire pour fept pefos d'eau-de-vie, c'eft-à-dire, la quantité de douze ou treize flacons ou limetas, fans en éprouver d'autre inconvénient que fon ivreffe, tant il avoit une forte conftitution.

Le chica les enivre par la grande quantité; mais il n'en réfulte pas les funeftes effets de l'ean-de-vie. On devroit, fans contredit, en défendre l'ufage dans ces contrées, comme d'un véritable poifon; \& faire attention à la vie de ces peuples, dont la diminution ne peut être que srès-préjudiciable à ces royaumes; car ce font eux qui font tous les travaux les plus pénibles des mines, qui labourent les terres, gardent les troupeaux; fans parler de nombre d'autres circonftances qui les rendent abfolument nécelfaires. 
Si l'ivrognerie devient une caufe de deftuction parmi les Indiens, \& de perte réelle pour ces royaumes, elle n'occafionne pas moins de dommage par les rixes, les débats, les émeutes qui s'élèvent parmi ces gens, dont la tête eft troublée. Ces rixes fe terminent fouvent par les fcènes les plus affreufes. Quoiqu'ils n'aient pas d'armes, le fang ne conle pas moins : on fe bat à coup de pierres, de bâtons, \& quelquefois à coup de couteau; de forte que le dimanche qui devroit être uniquement confacré à la paix \& a aux devoirs de religion, eft un jour où tous les gens font maniaques, en fureur, fe compent le vifage, fe caffent la tête, jufqu'à ce qu'entièrement abbatus par leur ivreffe, ils tombent fans aucun fentiment au miliei des rues $\&$ des chomins, \& ne re relèven qu'après leur ivrelre.

Si les Sauvages du Nord tuent les Blancs \& les Nègres, ou s'ils font fi cruels les uns envers les autres, même en paix, on ne doit attribuer cela. qu'à l'ivreffe qui en fait des furieux, d'autant plus portés aux excès, qu'ils ne refpectent naturellement rien, ne craignent rien. Ceux mêmes qui leur fourniffent ces boiffons, ne peuvent être trop en garde contre leurs violences; car c'eft la véritable caufe des guerres qui s’allument entre les différentes nations de ces barbares. Comme il eft de règle parmi eux que la peine égale l'of-

\section{B 2}


fenfe gui a été faite, ils ne renoncent au feht ment de la vengeance que quand ils ont la tête de l'aggreffeur ou du meurrier. S'ils ne peuvent avoir farisfaction fur le champ, la guerre fe déclare, \& la vengeance va jufqu'à l'extinction de la nation ennemie, s'il eft pollible. Dans tous les traités de commerce qu'on fait avec eux, leaude-vie eft toujours le principal objet, fans quoi ils n'entreroient dans aucun atrangement, tant ils font accoutumés à cetie liqueur. Il faut toujours qu'il y ait de l'eau-de-vie dans les préfens quion leur fait, pour les déterminer à une alliance; mais en même tems on les rend furieux; $\&$ on les porte à commettre les plus horribles atrocités. C'eft, difent-ils, le lait de leurs amis; tant ils ont de paffion pour cette liqueur, qu'ils comparent avec le lait de leurs mères. Il en eft de même des nations barbares du Chili, \& de toutes celles qui ont des liaifons avec les Efpagnols dans les parries méridionales du Pérou; leur paffion exceflive pour l'eau-de-vie ne leur fait reconnoitre pour amis que ceux qui leur en donnent; mais en cédant à leur defir, on leur en domne le muins qu'il eft pollible.

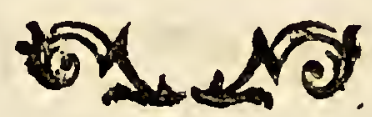




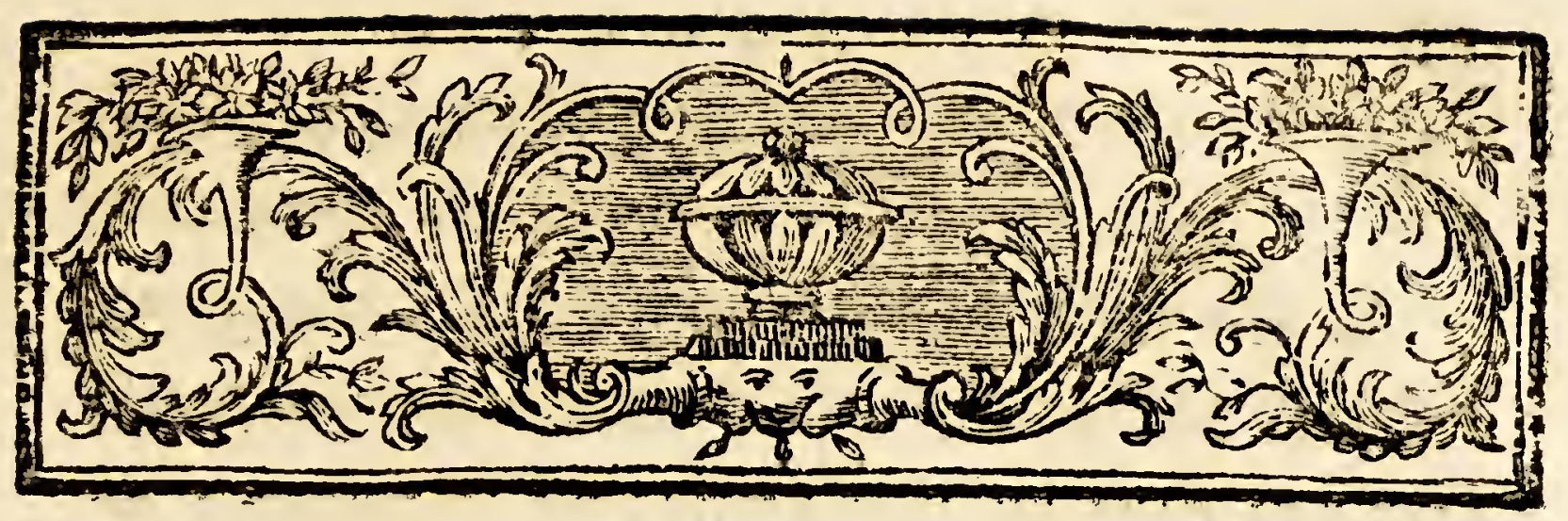

\section{DISCOURS DIX-HUITIEME。}

Continuation des détails relatifs au caractère aux maurs des Indiens; comparaifon des uns $\xi$ des autres.

$\mathbf{L}$

Es Indiens fone moins à craindre par leur. valeur que par leur perfidie, \& par la rufe avea laquelle ils commettene leurs attentats. Victorieux par furprife, ils font cruels à l'excès, ne connoiffent aucin fentiment de compaltion. Leur cruauté eft toujours accompagnée de fang froid; teur plaifir eft le carnage; mais vaincus, ce fon les gens les plus lâches, les plus puffllanimes. qu'on puiffe voir. Dans le premier cas, ils on un fouverain plaifir à répandre le fang des malheureux qu'ils furprenneno au dépourvu : dans le fecond, ils cherchent à fe difculper, shumiliene jufou'à la dernière baffeffe, comdamnené euxmêmes leur furie, prieñ, fupplieat, \& fe monrrent dans toure leur conchire les plus lâches des: hommes. Cę coutrafte ent celui qui doit réfultes

B 3 
de la lâcheté \& de la perfidie qui font le caractère de ces barbares.

Ce que les Hifroriens de la conquête nous difent des actions héroiques de ces Indiens, doit ctre pris dans un fens figuré, ou le caractère de ces nations n'eft plus le même qu'à cette époque. Cé qu'il y a de certain, c'eft que les nations de la partie feptentrionale vivent dans la même liberté quautrefois, fans avoir été affujettis par aucun conquérant étranger: elles confervent les mêmes ufages, les mêmes coutumes, \& fans avoir eu aucun motif de changer de caractère. C'eft ce quion voit chez ces peuples, comme chez ceux du Pérou \& de toute l'Amérique méridionale, foit foumis, foit libres \& indépendans. Il eft impollible d'atribuer à l'affujettiffement ce caractère des. Indiens du Pérou, nì̀ ce qu'ils ont changé de maîtres pour être foúmis à une nation étrangère, $\mathrm{ni}$ à toutes les autres circonftances qui peuvent en être réfultées. Comme ils n'ont changé ni de langue, ni d'ufages, ni d'inclinations, il n'eft pas pomble qu'ils aient pris un autre caractère, fur-tout fi l'on fait attention qu'ils n'ont rien de celui de la nation dominante depuis l'époque de la conquête. D'ailleurs, ils ne fon pas fi affujertis quon le penferoit; ils vivent dans leur peuplade avec une entière liberté, gouvernés par leurs Curacas ou Caciques, comme 
ils vivoient auparavant. Cequ'il y a encore de plus particulier, eft l'uniformité qui fe tronve entre ceux qui font foumis aux conquérans, \& ceux qui ne le font pas, tant dans ces pays que dans les contrées les plus éloignées.

Il n'y a pas d'exemple que ces Indiens aient fait face d'homme à homme, ou plurieurs, en nombre égal, à toute autre nation, foit aux Européens, foir aux Nègres de l'A frique. Ils ne fe font jamais expofés à les attendre, étant même fupérieurs en nombre; mais, malgré leur peu de courage, ils font à craindre : il eft même fouvent arrivé qu'un petit nombre de ces barbares. a mis en déroute un plus grand nombre de foldats en troupe-réglée; cependant ce n'a été quien les furprenant dans des terreins couverts de bois, où ils fe cachoient à la faveur du branchage épais. C'eft ainfi qu'ils ofent attaquer un corps de foldats, ne faifant jamais leur décharge que lorfgi'ils font sûrs de leurs coups. Auffi-tôt ils fe retirent fans être apperçus, ni laiffer aucune trace: du chemin qu'ils ont pris. Il n'en faut, fans doute, pas davantage, pour répandre le trouble \& la confufuon dans la troupe qui fe voit attaquée fans. favoir le nombre des ennemis, ni connoîrre les embufcades où il s'eft placé. Telle eft leur manière: de réitérer les attaques; \& roujours ils tirent de manière à ne pas perdre un coup. Comme on $\mathrm{B}_{4}$ 
ne voit point les aggreffeurs, la confufion, la crainte font prendre la fuite, \& l'on échoue dans l'encreprife qu'on a faite.

Ils font extrêmement habiles \& rufés dans ce genre de guerre; ils ne confidèrent pas le tems giuils ont à refter dans une embuche, pourvu. qu'ils aient l'avantage qu'ils fe promettent en ne portant que des coups sûrs, \& ils exécutent leur deffein avec toute la réflexion requife pour une réufite completre. Tantôt ils fe cachent à la fayeur des bois \& des broffailles, tontôt ils fe tapiffent fur terre, où ils fe couchent tellement à plạt, quion ne peut les appercevoir.

Les, Indiens du pays appellé Natchès, dans, la Louyfrane, formèrenc le complot d'égorger en une nuit tous les François qui y avoient formé mne Colonie. Ils l'exécutèrent, malgré la bonne. intelligence qui paroifoit fubfrter entreux \& ces Européens. Ils, gardèrent un fl grand fecret, qu'on ne furrien de ce complot que quand le coup. fut porté, Un feul François eut le bonheur d'échapper à la faveur de la nuit, pour apprendre le maffacre quion avoit faic des autres. Il fut auffi favorifé par un fentimene de pitié que quelques, Indiennes eurent pour lui : par ce moyen il évita la rrife defincé à laquelle toute la Colonie avoic éré condamnée. Les Indiennes étoient dépofitaires. tu fecret. La Nation des Natchès avoit appellé ic 
D I $\quad \mathrm{X}-\mathrm{H}$ U

fa confpiration les autres Indiens de ces contrées, même à une très-grande diftance. On avoit ar $r_{-1}$ rêté le jour auquel tous devoient fondre fur les Colons françois, \& ne pas y laiffer un feul homme en vie. Le jour précis avoit été marqué par un paquet de baguettes plus ou moins gros felon l'éloignement, avec injonction d'en ôter une tous les. jours, deforte qu'à la dernière tout le monde fue prêt à attaquer dans le plus grand filence. Les paquets ayant été ainfi diftribués, celui des Natchès. refta entre les mains de la femme qui en étoitdépofitaire. Touchée de commifération, foit par fa propre fenfibilité, foit d'après les réflexions. que firent les autres fermmes fur la trifte fène où toụs les François devoient être exterminés, elle ôta en un jour trois ou quatre baguettes, \& abrégea par-lì le tems où fa Nation devoit agir. Dès que les Natchès eurene examiné le faifceau, \& qu'ils fe furent apperçus que le terme étoit arrivé, ils exécutèrent fẹuls le carnage, fans at tendre les autres Nations qui avoient encore plufieurs baguetres à ôter, ce qui les empêcha d'avoir part à certe boucherie, Mais on ne tarda pas a s'appercevoir de la conjuration, \& l'on prit les mefures néceffaires pour être fur la défenfive, \& empêcher que le malheur ne s'étendît plus loin. Sans cerie méprife, qui far dûe à le rufe àvar. 
tageufe des femmes, tous les Européens y étoient exterminés.

Ce fur ainfi que les Indiens de la province de Macas, au royaume de Quito, détruifirent la riche ville de Logrogno, la Colonie de Guamboya, \& fa capitale Sevilla del oro, tous endroits fort peuplés, de forte qu'on ne fait même plus en quel pays étoient ces Colonies, ni ou fe trouvoit cette grande quantité d'or dont cette ville a eu le furnom. Les Arauques \& les Tucupelès ravagèrent de même, au royaume de Chili, limpériale, \& autres lieux de fes dépendances; les peuplades dés millions des Chuncas, dans le Gouvernement de Tarma; les Colons du Dariel, dans le royaume de Terre-ferme; \& plifieurs autres établiffemens; qui ont été les fanglans théâtres de leur barbarie. Ces complots fe forment partout de même, chez ces barbares : le fecret y eft inviolablement gardé : on fe rend ponctuellement à l'heure indiquée pour l'exécution; \& tous. font également d'accord fur les cruautés qui s'y commetrent. C'eft de fang froid qu'ils maffacrent, \& fans fe laiffer toucher par aucun fentiment de pitié. Les mâles fur lefquels ils fe jettent font autant de victimes : quant aux femmes, ils les: enlèvent \& les gardent, comme le triomphe de leur perfile atrocité, pour s'en fervir au befoin. 
Je ne m'arrêterai pas à peindre ici ces cruautés \& ces ravages, ni fur ce fecret qu'ils gardent; car toutes les Nations fe comportent de même dans de femblables circonftances : ainfi il n'y a rien d'extraordinaire; mais ce qu'il y a de fingulier, c'elt que le grand éloignement qui fépare piufieurs de ces Nations, ne les rend pas moins cruelles les unes que les autres, \& que toutes fuivent la même marche dans les excès de leur barbarie. On ne dira pas, fans doute, que cette cruauté vient de ce que ces Indiens font affujettis à des maitres étrangers, puifque ceux qui font répandus dans le vafte territoire de la Louyfrane \& de la Floride, ne font ni efclaves, ni foumis, \& qu'ils ont confervé toute leur indépendance. Ce qu'il y a de vrai, c’eft que ces peuples qu'on trouve fi bornés dans toutes les chofes qui demandent de l'intelligence, foient fir rufés, fi réfléchis lorfqu'il s'agit de barbarie, de perfidie, d'intérêt, de pillage, \& du butin qu'ils en peuvent tirer. Ceux du Chili, de Quito, de Tarma, tous les autres en un mot, ne leur cèdent en rien : on diroit qu'ils ont tous été inftruits dans une même école; \& le fecret eft pour eux, dans toutes les circonftances, une chofe facrée, qu'ils ne violent pas, à quelque prix que ce foit.

Ces Nations ne comprent pas les jours, \& ne 
les réuniffent pas par femaines; $c^{\prime} \in$ ft toujours pour eux le même jour : ils re connoiffent que les lanaifons pour objet fènfible, s'inquiettent peu de fe fatiguer la mémoire au moindre calcul : voilà pourquoi, lorfqu'il s'agit de faire une convocarion, ils ont recours à leurs paquets de baguettes, dont ils chargent les meffagers: ces bagueties fon de niême nombre que les jours qui doivent s'écouler jufqu'à celui où ils doivent exécuter leur. deffein : ainfir cela lignifie, à tel jour.

Il n'eft pas inutile de dire que l'infulte, ou le zort qu'on fait à un individu ou à une nation, devient une caufe commune, même aux nations les plus éloignées: c'eft pourquoi ni alliance, ni amitié, ni fervices réciproquement rendus, ne les arrêtent plus à l'égard de la nation qu'il s'agit d'attaquer : tuus les fervices font oubliés, plus de bonne foi On voit par-là, combien peu l'on doit fe repofer fur leur parole, \& qu'il faut toujours vivre avec eux dans une défiance continuclle, puifqu'il n'eft pas pollible de fe repofer fur l'amicié, pour fe croire à l'abri de toute conjuration.

Sils rencontrent quelqu'un fans défenfe, 'ils. l'attaquent avec audace \& impitoyablement, pour lui ôter ce qu'il a, \& fe vêtir de fa déponillo. 1!s re comportent de même à l'égard des habitar đons qu'ils voiene çloignẹ́s des peuplades ou des 
villages : ils en approchent d'abord avec, aftuce \& prompritude, fautant par deffus les murailles fans bruit, on s'introduifant fans être vus. La première chofe qu'ils font, eft d'afrafliner les gens endormis; enfuite, alfurés de leur butin, ils volent tout ce qu'ils trouvent; mais s'ils voient que l'on peur leur faire réfiftance, ils fe retirent avec le même filence qu'ils font entrés, \& remettent le coup à un autre moment plus favorable.

Si l'on prend un Indien du Nord ivre, \& qu'on le metre dans un corps de troupes réglées, il y tient ferme tant que fon ivreffe dure, \& qu'il fe voit bien foutenu : c'eft ce qu'ont obfervé les François \& les Anglois; mais fi l'une ou l'autre de ces deux circontances celfe, il prend la fuice, \& va fe mettre en embufcade. Les Indiens foumis du Pérou, qui écorchent quelques mots Efpagnols; font allufion à ceci, en difant animo (en élevant le ton für la dernière fyllabe) lorfqu'ils boivent de l'eau de-vie, pour fe aonner de la hardieffe dans les émeutés, faifant entendre par-là quils prennent du courage. Ces Indiens qu'on appelle civilifés, n'èn font pas muins fujets à caufer des émeutes fubites, dans lefquelles ils fe réuniffent en grand nombre, \& atraquent à coups de pierres, avec d'horribles clameurs; mais pour peu qu'il fe réuniffe de monde, ils tournent le dos, prenpent la fuite, \& fe recirent au hazard, de diffé- 
rens côtés, pour faire accroire qu'ils n'ont pas caufé de trouble.

La mauvaife foi de ces barbares, la facilité avec laquelle ils fe foulèvent, l'inclination qu'ils ont pour nuire \& caufer tout le dommage qu'ils peuvent, n’a que trop juftifié la prudence \& la fageffe du gouvernement des Indes Efpagnoles, qui- n'a pas voulu que les Indiens foumis \& civilifés, euffent des armes, ni qu'ils en connuffent le maniement : par ce moyen, on les tient dans la fubordination \& aux travaux qui doivent les occuper, comme font les mines où ils doivent refter chacun pendant cerrain tems, \& tous les travaux manuels. Si l'on s'écartoit de ce principe; il feroit fort difficile de les maintenir dans l'obéiffance, comme le prouvent les divers foulèvemens \& les. émeutes qui furviennent inopinément dans les provinces, à la moindre caufe: on auroit donc tout à craindre de ces féditions; fi elles venoient à fe fortifier.

Les François \& les Anglois fe font conduits tout différemment avec les Sauvages du Nord; ils leur ont donné des armes, leur ont appris à s'en fervir, pour en tirer plus d'avantage du commerce des pelleteries, pour en augmenter même leurs armées dans le befoin, \& s'en fervir les uns contre les autres: mais on s'en eft fait des ennemis armés, \& plus à craindre; car dès qu'on 
leur refufe ce quils demandent, ils prennent les armes contre ceux mêmes qui les leur ont fournies: ils font des incurfions, commettent toutes fortes de violences dans les colonies, les obligent à recourir à leur amitié, en extorquant des préfens \& des gratifications avec lefquels on ne peut cependant jamais compter fur l'amitié de ces perfides. C'eft toujours pour le plus offrant que font leurs fervices : les préfens; les fervices paffés font auffi-tôt oubliés; c'ent pourquoi l'on a pour maxime principale dans ces contrées-là, de s'en ménager l'amitié, en ne leur donnant jamais le moindre fujet de plainte; ou sils fe plaignent, on tacha de les appaifer par des préfens, quelque mal fondées que foient leurs plaintes.

Ces gens dorment peu, veillent une bonne partie de la nuit : leurs divertiffemens, dont l'ivrognerie eft toujours inféparable, fe continuent autant de nuit que de jour. Quand ils fe fentent fatigués, ils fe couchent à terre, \& dorment : s'ils fe reveillent, c'eft pour recommencer à quelque tems que ce foit, même lorfque tout le monde eft à repofer : il courent alors de côté \& d'autre, fans but, fans réflexion, fans être arrêtés par le travail qu'ils ont néceffairement à faire. Ceux qui vivent en liberté dans le Chili, dans les plaines de Buenos-Aires, dans les autres pays des mon-: 
堂等

Dis $c$ o v $R$ s

ragnes, \& ceux de toutes les parties du Nord depuis la Floride; ont auffi la même coutume, quoique ceux ci foient obligés de chercher leurs alimens à la chaffe ou à la pêche.

On voit par ces détails, que ces peuples menent une vie peu différente de celle de la brute; 1'ayant aucun but déterminé dans leurs opérarions, dormant peu, \& paffant la plus grande partie de la nuit à courir çà \& là. Le même rapport fe fait appercevoir dans leur manière de fe repofer, ou de fe placer quand ils ne travaillent pas. Ceux des pays les plus chauds s'étendent dans leurs hamacs, qu'ils font eux.mêmes; mais la plupart fe couchent par terre, pêlé-mêle, fans diftincion de fexe ni d'âge: On peut préfumer ce qui doit en arriver parmi des gens qui fe rapprochent fi près de l'animal dans toutes leurs actions.

Ajoutons à cette groflicereté \& à cette barbarie, la fphère infiniment étroite de leurs notions \& de leurs idées; car j’ai déja prévenu qu'ils ne comptoient point les jours, ni ne diftinguoient les femaines: les différentes phafes de la lune leur indiquent feulement la fin d'un période quelconque; mais ils ne s'occupent pas du nombre des jours qu'il contient. Les froids de l'hiver \& les chaleurs de l'été, ou la fonte \& la difparition des glaces \& des neiges, font pour eux la révo- 


$$
\text { D } \mathrm{I} X-\mathrm{H} \text { U I T I E M E. }
$$

Itition d'une année, fans que cependant ils en comptent les lunes; à plus forte raifon ne fongent-ils pas à faire aucune divifion dans les moindres mefures du tems \& des faifons. Lorfqu'on demande à quelques vieillards des plus civilifés du Pérou, quel âge ils ont; ils ne s'en forment l'idée que par le nombre des Caciques qu'ils ont connus; encore cette idée eft-elle fort confure chez eux. Quelquefois même ils ne fe rappellent que les plus anciens de ces chefs, parce que c'eft de leur tems qu'il's'eft paffé des évènemens particuliers dont ils ont confervé le fouvenir; mais quant aux $\mathrm{Ca}$ ciques poftérieurs, ils les ont abfolumen onbliés.

On obferve la même ftupidité daus les. Indiens qui ont confervé leur liberté primitive. On ne les voir jamais chercher à fe fixer dans la mémoire les èvènemens paffés, ni fuivreravec précifion lordre des chofes qui en ont étéles conféquences s leur imagination fe fixe uniquement fur te préfent, \& mêmé fur ce qui lés touche de plus prè̀s.

- On auroit lieu d'être furpris de cette Atupiaté, fi om ne fiappercevoit au mêne degré dans ceux qui reçoivent des inftruations, \& dalis ceux qui n'ont point été inftruits. En effet, les Indiens affujettis du Pérou qui font continuellement parmi les Efpagnols; qui ont des Curés ocoupés à leur donner des idées de religion, de mours;

Tome 1I. 
qui fréquentent toutes les claffes de la fociété font auffi indifférens, aufi fupides, que ceux qui ont toujours vécu dans leur anciemne barbarie au milieu des bêtes féroces.

Cette ftupidité devient fingulièrement frappante, lorfqu'on compare les Indiens avec les Nègres d'Afrique. Après avoir paffé quelques années dans ces contrées, les. Nègres acquièrent avec moins d'inftuction, \& comme d'enx-mêtmes, la faculté de compter les jours, les années, \& des notions infiniment plus étendues que ces Américains. Tout efclaves que font les Nègres, ils fe croient de beaucoup fupérieurs à ces barbares, qu'ils méprifent fouverainement, comme autant de gens incapables du moindre difcernement.

Les Péruviens confervoient, du tems des Incas leurs fouverains, la mémoire des faits les plus notables : ils avoient à lifi certain ordre civil dont parlent les hiftoriens de la conquête. Cet état civil étoir dû aux foins de ces fouverains, \& à l'ordre qu'ils avoient établi parmi les Indiens de leụr dépendance sar ce moyen ils les obligeoient de vivre d'après certains puincipes réflét chis : cette civilifation donne, fans doute, lieu de préfumer que ces légillateurs fortoient d'une race plus inftruite \& plus civilifée que le refte des Indiens, race dont il paroîr ne plus exifter aucun individu. 
En général, les Indiens vivent long-tems, quoi qu'il ne foit pas poffible de connoître au jufte le nombre de leurs années; mais leur âge avancé fe connô̂t à deux fignes diftinctifs, aux cheveux blancs \& à la barbe. Ils n'ont guère de cheveux blancs avant foixante-dix ans ou environ: la barbe ne leur pouffe qu'à foixante; ils en ont même très-peu; ainfi l'on préfume qu'ils ont plus de cent ans lorfque tous leurs chevenx \& leur barbe ont totalement blanchi. On demandoit à l'un de leurs vieillards qui paroiffoir extrêmement âgé : quèl âge astu ? J'ai plus de vinge ans, répondit-il. On le lui demanda d'une autre manière, en lui rappellant quelques circonfconftances. "Mon Machu, dit-il, me parloit des "Incas dans ma jeuneffe, \& il ayoit va ces 3) Princes. s, Selon cette réponfe, il falloit que du Machu à cet Incas, il fe fût paté deux cens trente deux ans aut moins. Le Machu étoit fon aïeul, \& celui à qui l'on parloit alors, paroifloir av oir plus de cent vingt ans, car outre la blancheur de fes chevenx, il avoit le corps tout courbé, mais fans fe fentir en tien des maux qui accompagnent la vieilleffe. Ceci fe palfa en 1764 .

Cette longue vie, toujours accompagnée de la meilleure fanté, eft une conféquence du peu d'occupation d'efprit de ces gens-là , de leut vie animale, de ce qu'ils ne font agités ni par des

$\mathrm{C}_{2}$ 
defirs violens, ni par des craintes; de leur orga nifarion plus groflière, plus robufte que celle des autres nations. Si ces Indiens ne fe détruifoient point par les guerres qui règnent prefque toujours entre cux, par un efprit aveugle de vengeance, fi outre cela, l'ivrognerie n'étoit pas chez eux portée à l'excès, ce feroient des peuples qui pourroient jouir complétement de tous les avantages de la liberté \& de lindépendance, \& qui ne feroient pas expofés à périr de bonne heure.

Quelques nations Indiennes du Pérou ont coutume de fe percer les oreilles dans tout le contour du pli externe, afin de les avoir plus grandes; c'eft chez eux une parure à leur idée : cet ufage fubfifte jufques vers le fleuve Maragnon, chez les Indiens qu'on a nommés Orejones, ou grandes oreilles, à caufe de cette coutume. D'autres fe font des trous aux ailles cartilagineufes du nez; aux lèvres, au menton, pour y paffer de petits brins de bois, longs d'un quart de vara, \& fembläbles aux aiguillons d'un port-épic : cet ufage eft aufi répandu chez les nations du Nord. Cette conformité prouve que ces ufages ont été introduits par les premières peuplades de ce continent, \& qu'ils remontent aux tems les plus reculés. On ne voit pas fans étonnement, cette conformité d'ufage \& de parure parmi les nations du Nouveau-Monde, quoique féparées par de 
D I $\mathbf{X}-\mathrm{H}$ U I T I E M E.

intervalles immenfes, tandis que les nations de l'Ancien-Monde ne font pas appercevoir la même régularité. Il faut donc que les ufages du nouveau Continent, introduits par les premiers hommes qui l'ont peuplé, s'y foient confervés fans aucune variation, tels qu'ils étoient à la première. époque.

Les Indiens de la partie feptentrionale prennent une autre femme, quand celle qu'ils ont eft devenue vieille. Cet ufage eft général chez eux; mais. la femme ne fort pas de la famille; elle refte à la hutte pour avoir foin des perites femailles, broyer le mais, \& préparer le boire \& le manger felon leur ufage : ainfi elle devient la fervante des autres. La jeune accompagne le mari à la chaffe, à la pêche, \& rapporte à la hutte le gibier ou le. poiffon qui a été pris. Chacune a foin des enfans qu'elle a, jufqu'à ce qu'ils foient en état de fe paffer de leur mère. Quand ils font grands, ils quittent la famille. Les vieilles font chargées du. foin de la hutte pendant qu'on eft à la chaffe: on leur confie cette garde comme pour les laiffer repofer, puifqu'elles ne font plus affez fortes pour foutenir les fatigues des courfes \& de la pêche.

Les Indiens foumis du Pérou n'ont pas. la même liberté; car le moindre écart quils fone fur ce point eft févèrement puni : mais s'ils ne 
prennent pas une feconde femme plus jeune, ils font bien l'équivalent; car ils en changent, en prennent une qui fe trouve libre, \& abandonnent la première. Ils n'ont aucun fentiment de honte. à cet égard: les précautions qu'on prend, les, avertiflemens des Curés, le foin des Corrégidors ne peuvent empêcher cet abus en totalité; en effet. on ne leur connoît ni délicatẹffe ni difpofition naturelle à recevoir aucun avis. Ainfi l'on doit: préfumer que s'ils avoient la même liberté que les autres, ils en feroient autant. Les vieilles que ceux du Nord réforment, n'en marquent aucun. reffentiment; elles fe rendent fans répugnance $a_{\text {. }}$ la contume qu'elles voient admife, \& qui parmi ces barbares a force de loi.

La néceflité \& la nature femblent avoir concouru à difpóntion de leurs huttes \& de leurs. logemens. La fructure en eft fort fimple, conforme à leur foible intelligence, \& combinée de manière à les garantir de l'intempérie de l'air \& des faifons, lorfqu'il ent néceffaire. On voit par ces domiciles réunis, que les individus de chaque nation ont cherché à fé rapprocher, malgré la barbarie de leurs ufages \& leur état groffer : ils forment donc des peuplades à leur manière, $y$ vivent \& y font leur principale réfidence. Les huttes des Indiens font rondes, \& de la hauteur d'un homme, ou peu moindres; les murs font élevés, 
verticalement, \& couverts en haut par un comble pyramidal de branchage. Ils élèvenr dans le consour intérieur un échafaudage (ou tablette), fur la furface duquel ils jettent les peaux des animaux qu'ils ont pris à la chaffe : c'eft aufi là qu'ils dorment. Au milieu eft un foyer. Il n'y a d'autre ouverture que la porte, qui même n’a que la largeur $\&$ la hauteur néceffaires pour y entrer : c'éft par-la que fort en partie la fumce \& en partie à travers les branchages qui forment le comble. Les. matériaux de ces hurtes font, ou de la boue délayée \& des pierres, ou du bois dont les inerfrices font remplis de cetre boue ou argille, lorf qu'ils n'ont pas de pierres à leur difpolition.

Ils pratiquent intérieurement quelques niches: dans le mur. Ces cavités ont une demi-vara de haut fur un quart de large, \& un pied de profondeur, \& reffemblent à celles qui fe voyent au Pérou dans les pa!ais des Incas. C'eft-là qu'ils ferrent le peu de chofes dont ils fone ufage. Chaque famille à fa hutre faite de même, quoiqu'il $y$ en ait de plus grandes les unes que les. autres.

Chaque peuplade a auffi une hutre commune avec les mêmes échafaudages tout autour, incér rieurement; elle eft beaucoup plus grande que celles des particuliers, \& de forme quariée; ou en parallélogramme. Cetue hutre leur fert à $s^{2} a f$

$\mathrm{C}_{4}$ 
Cembler, \& à délibérêr für lés intérêts communs, fur le tems où ils iront à la chaffe, à la pêche. On y réminit ceux qui doivent aller parbandes; les quartiers y font diftribués; on y fixe le tems où il faudra être de retour; on y avife aux moyens de faire avec sûreté des incurfions fur les Colonies des étrangers, \&à tout ce qu'on devra y opérer d'avantagenx pour la peuplade. C'elt encore dans cette hutre quils fe raffemblent pour boire, pour leurs diverumfermens publics, leurs danfes : ils ont au haut de la hutte un grenier ou ils ramaffent le mais, les calebaffes de leur récolte. Les huttes font bâties au hafard, fans. laifer d'intervalles réguliers pour former des rues. \& des places ; c'eft ordinairement près des rivières qu'ils bâtifrent.

- Ies Indiens civilifés du Pérou bâtiffent de nême, \& ont auffi une hutte commune dans chaque peuplade, pour s'affembler, \& traiter leurs affaires particulières : cependant ils ne peuvent le faire que par Majordomie, à la tête de laquelle eft un chef qu'on y établit. Lorfque ces affemblées font maintenues dans de juftes bornes, dè manière à prévenir tous les abus \& les excès, elles deviennent avantageufes. On les tient ainf pius facilement dans l'obéiffance; on leur y propofe des matières dont ils peuvent $s^{2}$ occuper; ce gui les détourne äu nipins du penchant quils ont 


$$
\text { D I } \mathrm{X}-\mathrm{H} \quad \mathrm{U} \text { I } T \text { I I E } \mathrm{M} \text { E. }
$$

au mal, ou les prive des moyens qu'ils pourroient inaginer pour le faire.

Les Juges \& les Curés font, malgré cela, fort attentifs à ces affemblées; ils ont foin qu'il n'y foit fuggéré aucune idée de trouble ou de foulèvement, ni aucun autre avis dont les conféquences deviendroient dangereufes. Pour cet effet, ils ont toujours certain nombre de ces Indiens affidés, afin d'être inftruit de ce qui s'y paffe. Dès qu'on foupçonne qu'ils s'écartent de ce qui leur eft permis, ces Juges ou ces Curés s'y rendent, les féparent, font punir avec prudence \& modération les auteurs des mauvaifes fuggeftions. Cetre attention fuffit pour diffiper les complots. Si l'on apprend quelque chofe de plus grave, on prend les précautions requifes, \& les châtimens font plus févères.

Il eft impoffible de faire renoncer ces peuples à leurs anciens ufages; on ne le tenteroit qu'en courant de plus grands rifques. Si on leur interdifoit abfolument toute alfemblée connue, ils iroient en tenir de nuit dans des endroirs éloignés; \& il feroit très-difficile d'être inftruit de leurs délibérations.

J'ai déja fait voir que le travail des mines n'eft en rien préjudiciable aux Indiens du Pérou. Si les Mitas quion oblige de travailler montrent fi peu de boune volonté pour ces ouvrages; cela ne 


\section{2}

D I $s$ C O U R $s$

vient que de l'indolence, de l'inertie naturelle ces peuples, \& de leur répugnance pour toutes. fortes de travaux. En effer, $\mathfrak{f}$ on les laiffoit mấtres de leurs actions, ils ne s'occuperoient jamais. que de leurs perites femailles, comme ceux qui ne font pas affujettis.

Les Mitas convoquées pour les travaux de la campagne \& la garde des troupeaux, ne diminuent pas plus l'efpèce de ces races Indiennes, lorfque tout s'y paffe dans l'ordre \& avec la régula. rité prefcrite par le Gouvernement. Ces gens ne fe trouveroient pas plus mal des travaux qu'on exige. d'eux dans les manufactures, fi on les traitois avec moins de rigueur, fi on leur impofoir des tâches plus proportionnées à leurs forces, enfin fi le falaire qu'on leur paie éroit fuffifant pour les. faire mieux fubfifter. Mais les maîtres ne confidèrent que leur propre utilité, \& non le bien de ces ouvriers, qu'ils traitent même avec inhumanité; de-là réfulte la diminution de ces individus. Le feul remède qu'on peut apporter à ces abus, feroit d'affranchir ces Indiens de tout travail d'obligation, \& d'employer des gens libres pris dans ce grand nombre de Métifs fans emploi, fans occupation, \& dans d'autres Caftes. Il faudroit menacer de prifon perpétuelle, de la part des Magittrats, ceux quineferuient pas occupés, \& que les gens chargés de les infpecter n'euffent 


$$
\text { D I X-H U I I I E M E. }
$$

pas la liberté de les faire châtier, comme ils le jugent à propos. Mais on devroit fe conduire en ceci de même que dans toutes les manufactures de l'Europe. Il eft conftant que ces châtimens font inévitables parmi ces peuples: cependant rien n'empêche que ces peines ne foient modérées. Ces châtimẹns fuffiroient pour vaincré leur $\mathrm{ca}$ ractère réfractaire, $\&$ ce penchant abfolu qu'ils ont pour l'oifiveté \& le défordre. Non, les mầtres quils fervent ne devroient pas non plus les châtier, encore moins les maltraiter, au lieu de les faire corriger avec prudence par ordre de la Juftice, afin de les améliorer. Les peines infligées. de cette manière ne pafferoient jamais les bornes, \& leur feroient plus d'impreffion; ils n'auroient pas de reffentiment de la violence qu'ils éprouvent, parce qu'ils font les plus foibles; la forme judiciaire les convaincroit mieux de leurs torts: mais on s'en fait autant d'ennemis : or ils n'ont été que trop fouvent fort dangereux.

On voit donc quil 'n'eft pas avantageux que les maîtres aient ce pouvoir defpotique, comme on le croit généralement; outre que chacun eft intéreffé à ménager les infrumens de fa fortune. Il eft cependant vrai qu'on eft, pour-ainfi-dire, forcé d'être toujours en guerre avec eux, tant pour l'intérêt particulier des mâtres, que pour les faire même penfer aux travaux qui les re- 
gardent perfonnellement, comme leurs femailles communes, \& les autres occupations qui concernent leurs vêtemens. La raifon ne leur fait rien entreprendre; aucun avis ne détermine leur volonté; tout échoue contre leur penchant à l'oifiveté, \& c'eft malheureufement ce qui oblige de recourir à la force pour lès porter au travail, \& les réunir en Mitas afin de les tenir occupés.

Le travail qu'ils font en un jour égale à peine celui qu'un médiocre travailleur de l'Europe feroit en une demi-journée : ce ne font pas les. forces qui leur manquent, mais leur extrême indolence les tient comme engourdis. Ceux qui font reftés dans leur état primitif, vivent de la. pêche \& de la chaffe. La chaffe devient pour eux. une occupation de néceffité indifpenfable. Quant à la pêche, c'eft une autre occupation qui ne demande pas de raifonnement, \& où il n'y a d'autre intérêt que ce qui peut fatisfaire le goût : d'ailleurs, ces exercices ne font pas continuels. Il n'y a rien à faire pour eux tant qu'ils ont à manger: les viandes fe gardent plufieurs jours, \& pendant ce tems ils fe livrent à l'inäction \& au repos.

Les Indiens conquis font les femailles en commun. Tous ceux de la Paroiffe fe réuniffent; hommes, femmes, enfans, \& forment ce qu'ils appellent Chaco ou affemblée. Six ou huit hommes de nos contrées Européennes pourroient faire 
D I $\bar{X}-\mathrm{H} U$ U I T I E ME:

en un jour, \& fans fe fatiguer, l'ouvrage que 1,s gens font entre foixante ou foixante-dix : ils portent avec eux une provifion de boiffon, leurs Hûtés, leurs tambourins : ils travaillent, boivent, mangent au fon de ces infrumens, fe repofent tour à tour, \& tout le travail fe réduit à un jour ou deux de divertiffement. Ils fe comportent de même, lorfqu'ils font la moilfon; de forte que la meilleure partie de la récolte fe trouve confommée pendant ces jours-là; mais jamais ils ne fe réuniroient fans l'attrait de la boiffon \& de la danfe.

Quiconque ne connoît point par expérience le caractère, les inclinations, le génie, le penchant deces Indiens, s'imagineroit peut-être que c'elt une tyrannie que de les obliger ainfi à travailler, furtout aux mines; mais ce feroit une erreur. Chaque nation a par toute la terre fes loix, fa forme de gouvernement, enfin l'ordre relatif, qui dérive naturellement de fon génie national, pour le maintien de la tranquillité \& du bonheur public; mais les rapports des Indiens de l'Amérique font hors de la fphère du refte des hommes, par Ia différence de leur caractère \& de leurs inclinations.

L'ufage immodéré de l'eau-de vie en détruic plus dans un an, que les mines en cinquante, Jans mêne en excepter ceux qui y périffent par 


\section{DIscous}

des accidens extraordinaires, par les écroulemenis des terres. Ce font fur-tout les fabriqus, qui les détruifent, car on les y traite avec inhunianité, malgré les vifites qu'on fait de tems en tems à ce fujetr; vifites qui ont toujours été inutiles, puifque ces mauvais traitemens n'ont jamais ceffé.

Ces races Indiennes fe croient pourtant des hommes plus fins \& plus habiles que les Européens. Les Indiens qui peuplent les vaftes contrées du Nord, ceux qui font foumis \& civilifés au Pérou, les plus fauvages même, font d'accord à cet égard; tous s'imaginent qu'il ne peut pas exifter une nation auffi intelligente qu'enx cette idée préfomptueufe vient de leur perverfité, de leur amour-propre \& des bornes de leurs notions. Sils, font furpris dans quelques-unes de leurs trames, ils. difent que les Efpagnols ou Viracochas, veulent en favoir autant qu'eux. Ceux de la Louyfiane. $\&$ de toutes les contrées adjacentes, font perfuadés que les Européens ne peuvent les égaler en génie, confondant le génie \& lintelligence avec l'aftuce; car ils font toujours occupés de tromper fans qu'onis'en appercoive, \& de n'être jamais furpris; auffi ont-ils le plus vif reffentiment, \& ne pardonnent-ils jagriais lorfqu' on manque à ce gu'on leur a promis, tandis que de leur côtéils ne connoiffent ni bonne-foi, ni loyalté : \& l'on 
peut être sûr qu'ils feront faux bond dans l'occafion la plus urgente. Les menfonges ne leur coûteront rien lorfqu'il s'agira de s'excufer. On cherche à êrre en paix avec éux, pour fe garantir de leurs incurfions; mais ils ne la demandent pas : ils font redoutables par leur liberté, \& par la rufe, avec laquelle ils attaquent au dépourvu. Toujours defporiques dans leur manière de penfer $\&$ d'agir, ils ne veulent jamais entendre parler de fubordination. On les gagne par des préfens, pour fe mettre en garde contre leurs cruautés \&z leurs pillages; mais ils ne donnent jamais rien : voilà ce qui leur donne cette haute idée d'euxmêmes, \& pourquioi ils penfent être plus habiles, plis intelligens, splus fins que ceux gui recherchent leur amitié, les craignent, \& leur marquent des égards.

- Le menfonge \& la fourberie font deux défaúts aufi náturels chez eúx que l'ivrognerie. Incapables de rougir lorfqu'ils font furpris en contravention, ils cherchent moins à s'innocenter qu'à fe tirer d'affaire par d'autres menfonges, au rifque même de ne pas réuflir : tels font les principes inerronés \& futiles fur lefquels ces peuples fe fondent, pour fe croire infiniment fupérieurs à toutes les autres nations.

Les Sauvages libres qui traitent d'affaires publiques avec les Européens, tiennent, felon leur 
48 DIśCOUS DIX-HUITIEME:

idée, des difcours pompeux, fublimes, mais dans lefquels il n'y a ni ordre, ni méthode; \& ne parlent que par figures \& comparaifons. C'eft ordinairement le foleil, fa lumière, fa chaleur, fon cours, qui leur fervent de premier terme; \& tous ces raifonnemens à perte de vue, font ac $\rightarrow$ compagnés de geftes démonftratifs aufii ricicules: Ils" font très-longs à̀ difcourir, répétant fouvent la mềme chofe: enfin ils pafferoient un jour entier à parler, fi on ne les interrompoit pas : ils réfléchiffent beaucoup à ce qu’ils vont dire, pour ne faire mention que de ce quils ont envie d'obtenir.

C'eft encore fur cette manière de parler prés fomptuetufe, qu'ils fondent ce prétendu favoir cette habileté par laquelle ils penfert être audeffus de tous les peuples de l'Europe, car ils forit perfuadés que ceeft cette grande éloquence qui- leur procure ce rqu'ils demandent. Les Indiens foumins parlent de même: ils font loirgs, fatiguantis, ennayeuxiàl'excès, ne fachant jamais finir ; en un mor, fi la langue étoit la même dans le Nórd \& dans le Pérou, on diroit que ce ferót le mêne homme qui eût parlé:

UISCOURS 


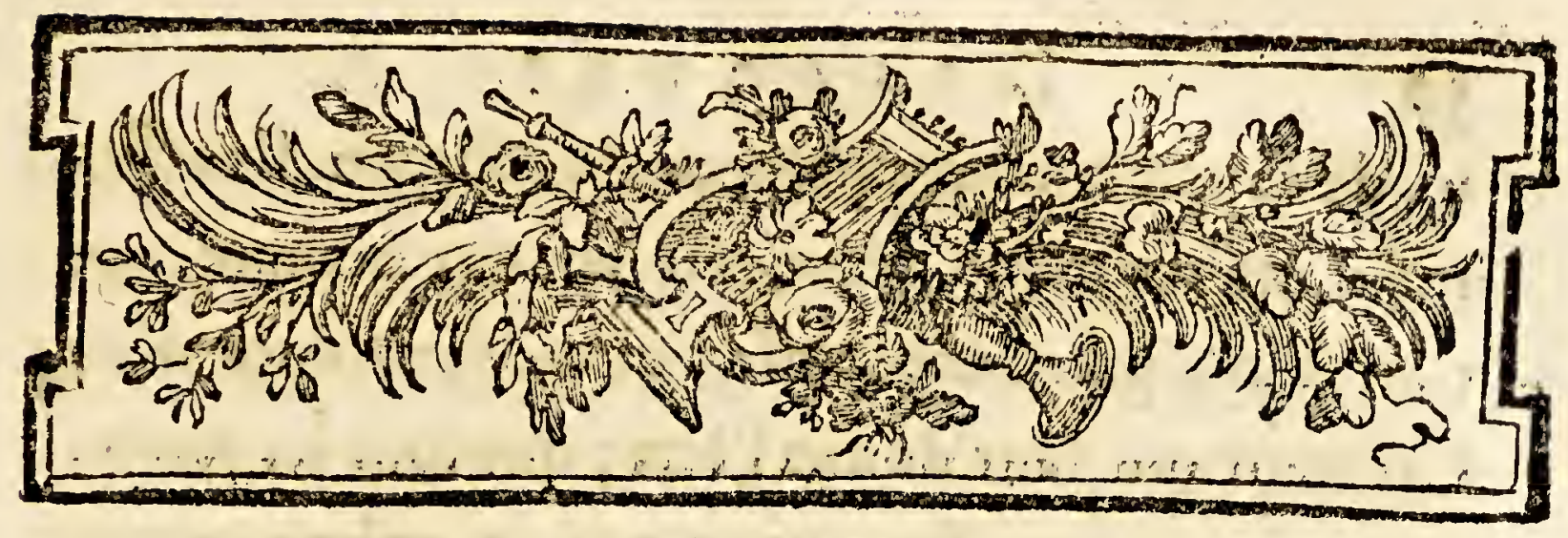

\section{DISCOURS DIX-NEUVIEME.}

De la Religion des Indiens Occidentaux, de leurs fépultures; de leur diminution, \& des Caftes dies Métifs.

LEs Indiens de l'Amérique méridionale, fou mis à l'Empire des Incas, adoroient le Soleil, \&c lui avoient bâti des temples dont on voit encore des reftes; mais on ne fait fi les Indiens indépendans de ces Princes; \& vivant fans ancun principe apparent de civilifarion, rendoient un culte à cet aftre, ou à aucun autre objet déterminé. Ils font fuperfitieux dès les tems les plus reculés, à ce quil paroît. Le hafard, les circonfancés leur font révérer les chofes les plus viles qui le préfentent à eux, quoíqu'ils ne leur rendent pas un culte formel. On remarque la même chofe chez différentes Nations du Nord. Plufieurs François y ont vécu dix à douze ans dans le deffein d'apprendre leur langue. Les relations que ces Européens nous en ont données, nous apprennent que ces Sauvages n'ont pas la moindre idée de iit, Tome $1 I_{0}$ 


\section{jo

ni de ce qui a une apparence de religion. Ils affirment qu'ils n'ont découvert en eux aucune nom tion d'une première caufe, ni de l'exiftence d'un Créateur qui leur donna l'être; que tous les jours, toutes les heures font pour eux un même tems; qu'on ne leur voit jamais faire ni prières, ni facrifices, ni rien qui tienne de l'adoration. On peut donc conclure qu'étant fuperftitieux comme je l'ai dit, ils n'attribuent aucun évènement à la volonté d'un Etre fuprême, ne fuivant d'ailleurs d'autre loi que leur propre volonté : ils ne connoiffent même pas la loi naturelle dans fes rapports exacts.

Certe manière de vivre fans principes, fans loi qui s'oppofe à leurs paffions, fans frein qui arrête leur impulfion vers le crime, à corrompa nombre d'Européens établis dans ces contrées. Séduits par le mauvais exemple, ils ont fuivi le même genre de vie, ont oublié toute religion: ils fe font conformés en tout aux ufages de ces barbares: ils fe font retirés au loin dans les campagnes avec leurs efclaves ou leurs domeftiques, vivant fans fonger au Créateur à qui nous devons notre exiftence, tout ce que notis avons, \& un jufte tribut de reconnoiffance \& d'hommages pour tous fes bienfaits.

Les Indiens civilifés du Pérou connoiffoient une première caufe, du tems de leurs Incas. Quoique 
D I X - N E U V I E M E.

leurs temples fuffent dédiés au Soleil, \& qu'ils lui rendiffent un culte, ils n'ignoroient pas qu'il y eût un autre Etre plus puiffant, qui n'étoit pas obligé de faire un cercle continuel pour donner l'être \& la vie à toutes les chofes. Ils confacroient leurs offrandes au Soleil, commè à une divinité plus connue, lui rapportant les biens \& les avantages réfultans de fa lumière \& de la chaleur qu'il répandoit fur la terre. Cette doctrine leur avoit été enfeignée par leurs Souverains; mais les autres Nations Indiennes non-civilifées ne l'ont poino connue.

Les Indiens foumis du Pérou ont certains lieux confacrés, fur-tout à la cime des montagnes : ils les appellent Mochader. Le vulgaire prétend qu'ils y vont pratiquer un culte idolâtre, qu'ils y invoquent le diable, avec lequel ils ont de fréquentes conférences. On voit dans ces lieux des tas de pierres à côté du chemin, \&amoncelées par les Indiens. Chacun a foin d'avoir une pierre en main lorfqu'il y paffe, la pofe fur le tas qui lui appartient, \& en fait comme une offrande par un ufage fuperfitieux. Les Payens des anciens continens en faifoient autant pour leur dieu Mercure, plaçant ces tas de pierres au milieu des carrefours où les chemins fe cröifent. Le mot mochader vient peut-être de muchar, qui fignifie baifer. 
Toutes les nations fe font accordées fur les égards qu'on doit avoir pour les morts; \& les Indiens ne fe font pas écartés de ces idées. C'eft ce que l'on voir par leurs tombeaux, ou huacas. Ils avoient mêne des lieux particuliers pour la fépulture : on en trouve dans la Louyfrane qui font en tout femblables aux tombeaux du royaume de Quito \& du Pétoul. Il s'en trouve deux, à cent lieues au-delfus de la Nouvelle-Orléans, fur le chemin qui va des Opeluzas aux Natchitocas, dans tune habitation qui a le nom de Richard, près de la Punta cortada; la forme eft celle d'une tombe, qui s'élève en ovale fur une fuperficie plane: Comme ces monumens fe trouvent près des maifons de l'habitation, on ne pent dourer que ce ne foient des fépulcres, qui ont fans doute été ceux de quelques Indiens de la plus grande confidération parmi leurs compatriotes. En effet, on voit qu'il a fallu beaucoup de monde pour les faire. On amonceloit donc la terre qu'on tiroit d'ailleurs pour élever ces monticules, qui font même affez gros. Il faut encore obferver que les Indiens de cette nation n'ont pas coutume d'inhumer leurs morts de cette manière, ni de laiffer de pareils monumens pour la poftérité.

Lufage de ces Indiens eft d'élever une efpèce de fépulcre, formé de rofeaux mis à côté l'un 
de l'autre, \& d'y placer le cadavre. Hs font ces. tombeaux à l'un des côtés extérieurs de la peuplade, \& les élèvent à la hauteur de deux varas. au-deffus du fol, ne leur donnant qu'un peu plus de longenr que le cadavre. Le fépulcre eft foutenu par des pilliers de pierre; it a un vara de large à-peu-près, \& autant dẹ haut, depuis l'extrémité des pilliess. Ils mettent à côté du cadavra différens comeltibles, comme des épis de mais, \& les alimens quils en préparent; ils fufpenden au pilier qui tient le milięu du fépulcre (du côté de la tête) \& en-delzors, plufieurs des chofes dont le défunt fe fervoit. Mais on y voit fur-tout des touffes de cheveux fans être treflés; ce fon fans doute ceux des femmes qui vivoient à la mort de leurs maris, \& qu'elles ont dépofées là en figne de leur trifteffe. On y remarque une de ces touffes qui paroît êrre une chevelure entière coupée au-deffus du nosud qui l'attachoir, au lieu que les autres touffes ne font que comme des toupets très-minces. La plus groffe paroît done âtre l'offrande que confacra la dernière femme du défunt: les autres font probablement les offrandes des vieilles qu'il avoit réformées : on ne voit même que deux ou trois de ces petirs, toupets.

C'eft dans cette fépulture qu'ils laiffent ląs cadavres, pour être confumés par le laps du rems. Il dojs s'en exhaler, dès l'abord, une trèss

D 3 
mauvaife odeur à travers ces rofeaux, à moins qu'ils ne les embaument avec de la réfine de pin ou du cyprès, pour en modérer la puanteur. On ne fait pas ce qu'ilsyfont des os lorfque les chairs en ont été détruites; it eft problable qu'ils les brûlent pour ne pas les lailler jonchés fur terre.

On voit donc que ces Indiens fuivent un ufage reçu généralẹnent dès lẹs tems les plus reculés, en gardant les cadavres de lecurs ancêtres, on en leur rendant certains devoirs. On voulut fans, doute empêchẹ que les morts ne devinffent la pâture des bêtes, ou qu'ils ne furfent dévorés. en terre par les infectes quelconques. Les Egyptiens garautiföient les morts de toute corruption avec des baunies \& des rétines, les enveloppoient de différens linceuils, \& les dépoforent ainfi dans, les niches ou fépulcres, qu'ils avoiẹnt préparés pour les conferver.

Mais la coutume de placer des comeltibles à côté dụ mort, femble indiquer que ces Indiens. croyent que l'efprit ne meurt pas avec le corps, \& qu'ils ont, à certain point, une idée de l'immortaliré de l'ame; car, pourquioi leur donneroient-iks cẹs vivres? ce feroit une pure cérémoinie qui n'auroit aucun but. Quelle que foit la manière dont ils penfent à cet égard, il n'eft pas facile d'en être éclairci; car ce qu'ils en difen ne prefonte aucune notion diftincte. 
D I $X-N$ E U. V I E LA E.

La fépulture étoit différente dans quelques. contrées de la partie baffe du Pérou, fur-tour parmi les peuplades des vallées de Las capillas, \& des pays adjacens. Au lieu de fuivre l'ufage de la Louyfiane, ces peuples avoient leur fépulture dans leur propre maifon, \& chacun fe faifoic une efpèce de pantéon à fa manière. On deftia. noit à cela une des pièces du logis d'environ quatre ou fix varas en quarré; cependant cette étendue varioit à la volonté du maître, ou felon fon état \& fa dignité. Le tombeau fouterrein éroit pratiqué dans un des coins ou angles de la pièce; on lut domnoit trois varas de long fur deux de large, \& une \& demi ou deux de profondeur; la forme en étoir ovale. Les parois qui reftent de ces tombeaux font une maçonnerie de. pierres \& d'argile; ils étoient couverts de branchages non élagués; cela fervoir de folive, \& l'on. mettoit par deffus des rofeaux \& une terre brute jettée au hafard, ce qui formoit un tois folide pour ces pantéons. ou tombeaux.

I1 paroît que cette pièce n'avoit pas d'autre ufage : la porte qui en fermoit l'entrée n'avoit de haut que les trois, quarts d'une vara, \& deux tiers de large : il éroit donc fort difficile de s'y introduire \& d'en fortir. Quoique les autres portes de la maifon foient très-petites, elles ont cependant une vara de haut, \& une demi-vara ow.

D 4 
deux tiers de harge. On cbferve dans l'intérieur diferentes niches, ou perites armories pratiquées duns le mar, comme je lai dit des Indiens de la Eouyliane. Cer ufage elt aulf le même au Pérou; néanmoins il n'y en a pas dans les pièces deftinées a la fépulzure: on a vu qu'elles y étoient inutiles, fans doute.

Le nombre des crânés quon rrouve dans ces rombeaux eft affer confidérable; car on en a vik fufqu trence \& quatante : les uns dhommes faits, les aures de perfonnes phus petires; on a mêne trouvé des reftes de fquelettes. On peut aifément fe former une idée de l'ancienneté de ces peuplades par le nombre de ces crânes, car chaque homme narié ou vivant avec une femme; avoit fa hatte, \& chaque hutte le lieu de fa fépulture En fuppofant done fix perfonnes par famile, \& quit en mourut quatre tous les vingtcinq ans, cela feroit deux cent cinquante ans. Telle feroit Pantiguté de ces peuples avant l'époque de la conquêtet.

On fait quil a regné au Pórou treize Incas. jufqu'ì Hualcar, qui eft le dernier, \& celni fous: kequel finit leur enpire. En excluant ce dernier, on trouvera encore deux cent cinquante ans a partager entre les douze autres, fron fuppofe. que, Hun dans l'autre, ils aient régné chacun vingtun an. Cetre fuppofition n'etr afurémente 
D I X-N E U V I E M E.

pas exagérée; mais on doit encore fuppofẹ que ces peuplẹs ñont pas été civilifẹ́s dès lẹs premiers. tems des. Incas, \& que leurs villages. ou habitations, leurs tombeaux, n'ont pris de forme régulière que depuis qu'ils ont été foumis à ces princes, \& tirés de leur état de barbarie : l'époque de leur antiquité remonteroit donc encore. plus haut.

On trouve dans plinfieurs fépulcres les vêtemens dont ils fe fervoient; ils font de coton, blancs, tiflus comme les dẹfcendans les font à préfent, avec quelques ornemens de différęntes couleurs. On y trouve aufli de la laine d'Alpaque: comme on n'y voit point d'os de cet animal, on préfume que ces Indiens ne mettoient alors dans les tombeaux que des peaux d'Alpaque, les mêmes fans doute qui leur fervoient pour dormir avant la mork.

Toutes ces circonftances nous montrent l'uniformité ou la différence qu'il y a à cet égard parmi les Nations Indiennes répandues dans ces valtes contrées.

On croit affez généralement dans ces contrées que plufieurs Nations Indiennes, plus réfolues, plus couragenfes que les autres, ne pouvant fe foumetre à un joug étranger, prirent le parti défefpéré de s'enterrer toutes vives, pour fefouf: traire à la fervitude, voyant quil n’y avoir plus 
moyen de défendre leur liberté. Suppofé que cela foit, \& que ceux des Vallées fe foient diftingués par ce coup de défefpoir, cela ne prouvera pas. que la coutume d'enterrer les morts dans les maifons n'ait pas fubfité parmi ces Sauvages. Les ventiges qu'on en voit, la folidité des murs, le prouvent fuffifamment : d'ailleurs, on ne voir pas quel autre ufage indiqueroient ces reftes, \& il n'y a aucun endroit habité parmi ces nombreufes peuplades, où l'on n'en rencontre quelques veftiges. On dira petut ĉtre que ces gens ayant leurs tombeaux à côté d'eux, cette circonftance les détermina à prendre ce parti défefpéré. Mais il faudroit qu'il en für au moins refté quelques individus, qui auroient fermé ces fćpulcres communs, les auroient recouverts de terre, \& auroient enfuite applani le fol dans la pièce qui eft au-deffus, de forte qu'il feroit refté tel qu'on le voit aujourd'hui.

Ies Indiens du Nord ont l'ufage de leur cra lumé, qui eft une pipe dont le thyau a une vara de long : il fert en même tems à tous ceux d'une mêne compagnie; chacun tire la fumée du tabac à fon tour. Ce calume eft auffi chez eux un moyen dont ils fe fervent pout fe faluer, comme un verre de vin chez les Européens. L'ufage du tabac y elt cependant fort modéré. Les Indiens du. perou, fur-totic cenx de la partie haute, nen 
D I $X-N \quad E \quad U$ V I E $M E$.

font pas d'ufage. Quelques pays de la partie baffe en ufent, mais peu. Il efe ćtonnant que le tabac, étant une production de ces contrées, ne foir pas. d'un plus grand urage parmi les Indiens, tandis. quil eft devenu fi nécelfaire en Europe; \& que d'ailleurs il y a tant de monde qui en ufe, que c'eft une des parties les plus confidcrables du revenu des Princes; c'ert mâme la plus atfurée. Les Indiens en ufent feulement avec la pipe, au lieu qu'en Europe on le prend en poudre, on le mâche, \& on le brûle avec la pipe; ce qui en rend la confommation fi confidérable.

Le calumé, ou la longue pipe dont fe fervent les Indiens du Nord, eft ornée d'ouvrages de différentes coulẹrs, \& enjolivée de diverfes plumes. Les Orientaux ont auffi de femblables pipes, qu'ils préfentent, par politefle, aux perfonnes qui leur rendent vifite; ils y joignent du café, \& autres boiffons : ainf ces peuples s'accordent avec les Indiens à cet égard, fans sêtre jamais connus, \& nonobftant l'intervalle immenfe qui les fépare. Cet ufage vient donc d'une origine commune, quelqu'éloignée qu'elle foit de notre âge. Le Godet, ou le pavillon de la pipe où l'on met le tabac, na pas tout-à-fait la même forme. que celles des Européens; la forme du tuyau. diffère aunt.

Il n'elt pas certain que l'urage du tabac ait éré 
60

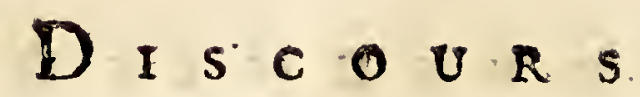

introduit en Europe par la découverte de l'Améa rique; car il étoit très-ancien en Orient avant qu'on mît le pied dans le Nouveau-Monde. It étoit prefque impofible quil ne fe répandît de lOrient en Europe par le commerce de la Méditerranée avec le continent de l'Afie; commerce que faifoient les V'énitiens avant que les Portugais euffent doublé le Cap de Bonne-Efpérance en 1487. On peut feulement affurer que, depuis la découverte de l'Amérique, l'ufage du tabas eft devenu général, tel qu'on le voit à préfent, \& que c'eft depuis ce tems-là qu'on en a varié liufage, \& la différente manière de le fabriquer. Quant à l'ufage du chocolate, il a paffé des Indes Occidentales en Orient, \& l'on a ainfr multiplié à nombre d'autres égards, les befoins journaliers.

11 eft conftant que le nombre des individus Indiens diminue de jour en jour, \& dans toutes les parties de l'Amérique; foit par les ravages horribles qu'y fait la petice vérole; foit par l'ufage excelfif des liqueurs fortes, \& le penchant que ces peuples ont à s'eniv rer; foit par le chagrin qu'ils ont de fe voir foumis à des nations étrangères, \& obligés de travailler contre leur inclination à l'oifiveté foit par d'autres caufes moins. évidentes, quoique toutes celles ci fufifent pour les déruire.

On peut dire des Indiens de l'Ile de Caba, 
We Saint-Domingue, de la Jamaíque, \& de plus fieurs autres de ces parages, ce qu'on dit de l'or \& de l'argent : Eft-il donc bien vrai qu'il y air eu là, avant la conquête, des Indiens en aufi grand nombre qu'on l'a dir, vil qu'à peine il en refte quelques - uns. Il n'y en a plus dans l'lle de la. Puna, qui eft à l'embouchure du fleuve Guayaquil, ni dans toutes les Intes de la côte de Panama. On a obfervé la même diminution dans les différentes peuplades qui fe trouvoient aux gorges de la partie baffe du Pérou, dans les vallées de Las Capillas, dans le Topara, à Luná-Guana, $\&$ dans plufieurs autres pays. Les ruines que l'on voit encore du grand nombre des huttes qui exiftoient du tems du paganifme de ces peuplades, prouve combien il devoit y avoir d'habitans. A chaque quart de lieue on rencontre des reftes des anciennes habitations, dans lefquelles on voit en: core la forme des maifons, les rues qui traverfoient la peuplade, de forte qu'il n'y manque que le toit; mais tout cela ne préfente que l'image de la défolation.

Les nations limitrophes des colonies Européennes établies dans la Louyfrane, celles qui font du côté de la Nouvelle-Angleterre, ont fouffert une fi grande diminution, qu'elles fe trouvent chacune réduites à douze ou quinze familles, quoique beaucoup plus nombreufes avant l'éra 
62

D I s c o U R s

bliffement des Européens. Cette diminution fi prompte, donne lieu de préfumer qu'elles s'éteindront entièrement comme les autres. Les nations de la partie haute ne font pas fi confidérablement diminuées, quoi qu'on n'y voie pas autant d'individu, fur-tout dans lesbourgades qui faifoient la réfidence de leurs Caciques, \& qui étoient le chef-lieu de la Nation.

A mefure que les races Indiennes s'éteignent, les pays fe peuplent d'Européens \& des.Caftes qui viennent de l'Afrique : cependant les Nègres ne s'y maintiennent pas en anffi grand nombre quils devroient, fil l'on confidère combien l'on en a tranfporté dans ces contrées. On doit fans doute attribuer cela aux durs travaux qu'on en exige, à la fervitude, qui doit faire chez eux le plus affreux contrafte avec la vie oifeufe \& indépendante qu'ils menoient dans leur patrie. $11 \mathrm{fem}$ ble que la principale occupation des Européens,

- foir actuellement de tranfporter des hommes des dcux parties de l'Ancien-Monde dans le Nouveau, \& de le peupler ainfi, tandis que d'un autre côté; ils tirent tous les produits de celui-ci, fur - tout l'or \& l'argent, pour les faire paffer à l'autre. partie oppofée du globe.

Si l'on réfléchit donc aux cliangemens que ces contrées ont fubis pendant les trois premiers: fièt cles qui fe font écoulés depuis quion en a fait la 
D I X I N E U V I E A E E

déconverce, on peut fuppofer qu'il reftera peu d'Indiens civilifés pendant le même efpace de tems, \& que le mélange, ou plutôt la confufion des Caftes Européennes, Africaines, Indiennes, peupleront enfin ces pays d'une race bâtarde, qui riendra de toutes les autres, fans reffembler en rien aux races primitives d'où elle fera dérivée. Ce Monde réellement nouveau pour les nations qui ne le connoiffoient pas, le fera encore une fois dans ceux qui le peupleront, comparé avec les autres parties du Globe.

Les bourgades des peuples du Pérou font compofées en grande partie de Métifs, réfultans du mélange des Européens \& des Indiens : de ces races en naiffent d'autres, qui fe différencient par degrés. La race que nous appellons des $Z_{a m-}$ bos, elt déja très-répandue dans la partie bafle: elle vient du mélange des Indiens \& des Nègres. On voit peu d'individus de cette efpèce dans la partie haute, parce qu'il y va peu de Nègres; le climat y eft trop froid pour eux : celle des Métifs provient, comme je l'ai dit, des Indiennes \& des Européens, par des accouplemens licencieux; mais il eft rare qu'un Indien ait affaire avec une Européenne. Ces Métifs propagent aufi leur race entre eux. Quant aux Mérifs procréés d'une Indienne avec un Européen, fa naiffance lui donne une qualité que n'a pas celui qui vienc 
$r_{4}$

Dis O O U R

d'ứn Indien avec une Européenne, car la loi a ordomé que ces Métifs fuivroient la condition du père; ainfi le fecond cas eft déshonorable pour la mère \& pour l'enfant, qui refte dans l'efclavage de fon père. Le premier eft, en vertu de fá naiíiance; difpenfé de tout tribut, ce qui n'eft pas accordé au fils d'une Européenne \& d'un Indien : cette prérogative favorife la propagation des races mixtes, \& les multiplie en même tems qu'elle diminue les races Indiennes pures : d'ailleurs c'eft un déshonneur pour une Mérive de s'allier avec un Indien, de même qu'un Métif eft méprifé lorfqu'il s'allie avec une Indienne.

Il en eft de même à l'égard de la race des $Z$ ambos, quoiquon exempte plus rarement de tributs la première génération. Il eft vrai que la couleur des Zambos eft à ce premier degré femblable à celle des mulâtres; cependant ils ne font pas tout-à-fait exempts de tributs : ils en font affranchis au fecond degré, parce qu'alors ils ne s'allient pius avec les Indiens, ou très-rarement: ce mélange produit donc un grand nombre de familles qui viennent des Indiennes; mais la diminution des Indiens en el auffi la conféquence; \& elle eft d'autant plus confidérable, que ces mélanges font plus nultipliés. Les Indiens font cependant de la plus grande importance pour ces royaumes, comme je l'ai déja dit; on devroit 
D I $X-N$ E U V I E M E:

donc prendre tous les moyens de conferver leurs races, puifqu'on ne peit les multiplier; ce fut toujours l'intention du gouvernement. L'expérience a cependant prouvé qu'on n'avoit pas pris des moyens fuffifans pour arriver à ce but, \& qu'il feroit avantageux que les travaux de l'agriculture, des mines, des manufactures, des métiers, \& autres, fe fiffent indiftinctement par les Européens comme par les Indiens. En prenant ce parti, les familles Indiennes ne diminueroient pas fi fenfiblement. Il n'y a que les colonies Efpagnoles où les blancs dédaignent ces travaux : dans les colonies des autres nations, \& par toute la Nouvelle-Angleterre, ce font les blancs Européens qui s'en occupent indiftinctement, comme ils le font en Europe : c'eft par ce moyen que ces colonies font très-peuplées, les terres en valeur, \& les familles riches par les produits du fol.

Il ne feroit pas difficile de réuffir, fi le gouvernement prenoit les méfures nécelfaires, \& agiffoir avec chaleur \& fermeté pur faire exécuter à fon gré les ordres qu'il auroit donnés. Sans porter la moindre atteinte aux loix juttes \& fages en vertu defquelles tout s'exécute, on parviendroir à faire difparoître ce grand nombre de vagabonds oififs qui fe répandent par-tout, \& ne font rien d'utile pour la fociété : leur bras de. Tome $I I$. E 
66 DISCOURS DIX-NEUVIEME. viendroient alors d'un avantage commun, l'exploitation des mines prendroit une nouvelle vigueur, par le nombre de ceux que l'appas du gain y attireroit, \& qui s'occuperoient des manipulations néceffaires; il fe formeroit de nouvelles familles, dont les individus fe fixeroient, \& l'on réaliferoit dans nos colonies la maxime qui a guidé toutes les autres nations Européennes pour la population de leurs colonies, que nous voyons dans l'état le plus floriffant.

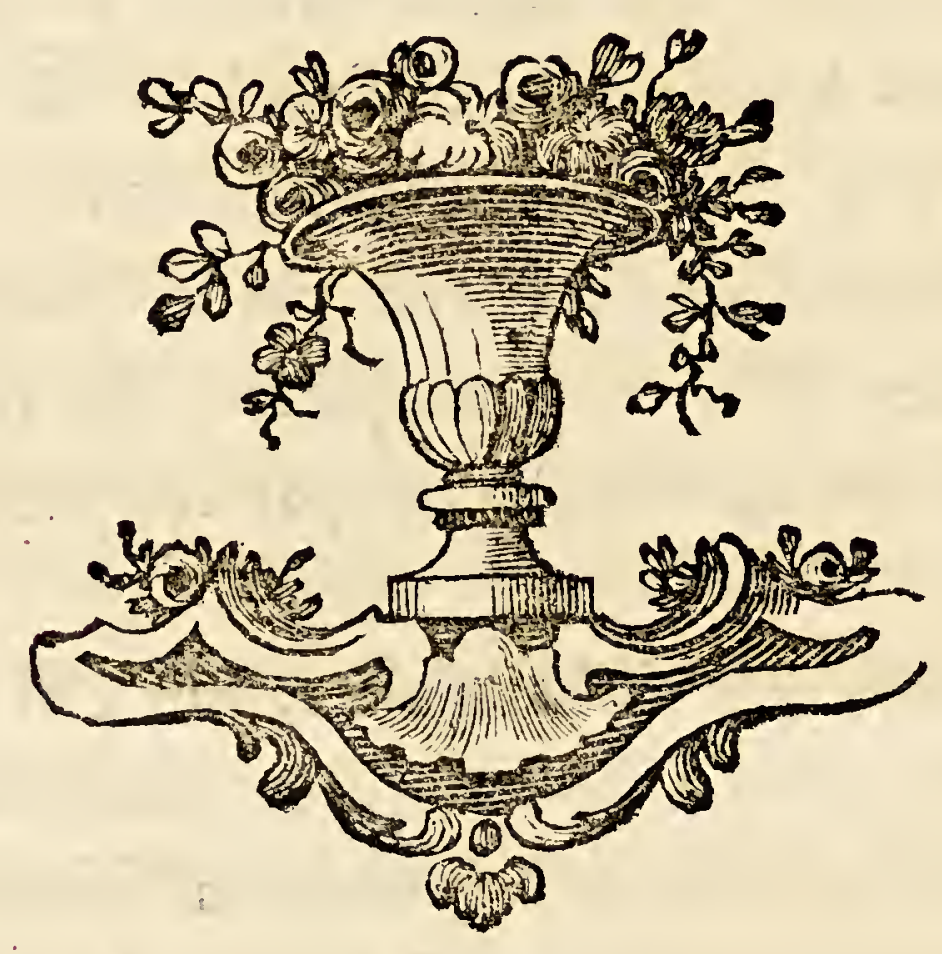




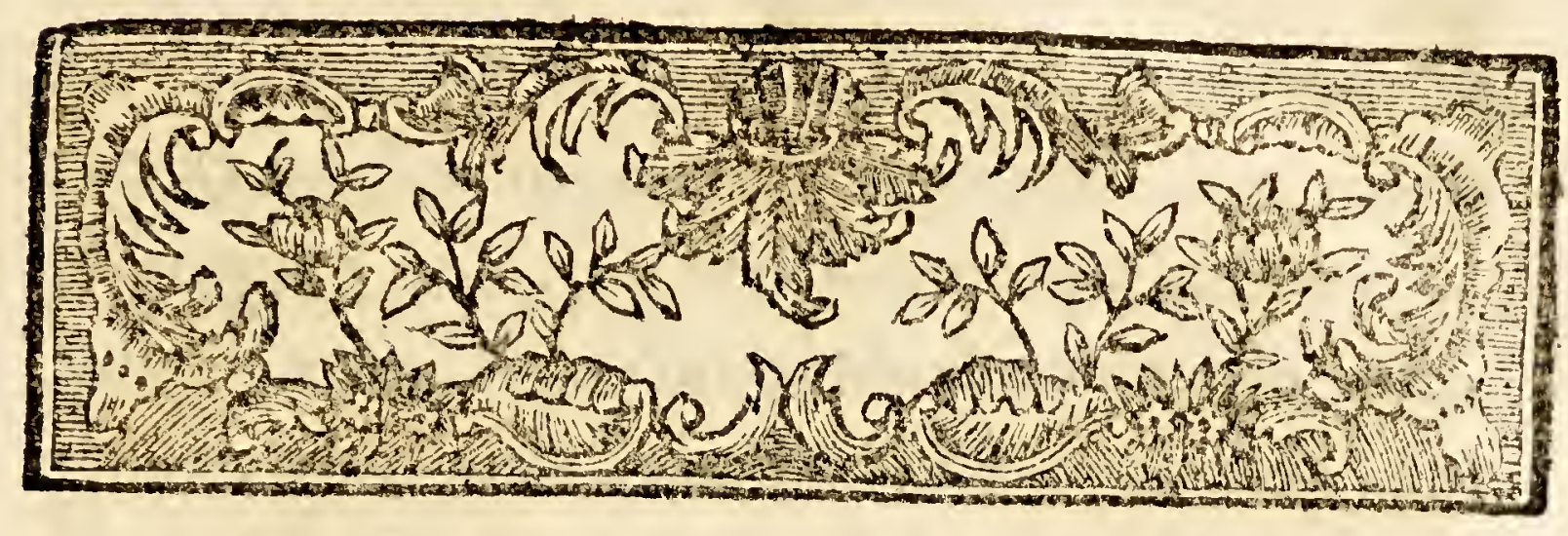

\section{DISCOURS VINGTIEME.}

\section{De l'antiquité des Indiens Occidentaux, E des chofes qui s'y font confervées.}

Es monumens qu'on trouve au Pérou, antérieurs à la conquête, font des édifices, des murs dans les tombeaux ou Huacas, \& différentes chofes qui étoient à l'ufage de ces peuples, comme des uftenfiles, des inftumens nécelfaires à leurs travaux, des figures de leurs idoles, qu'ils portoient ordinairement comme amulettes : néanmoins ceux qui vivent actuellement en liberté dans ces contrées Méridionales \& dans le Nord, ne paroiffent pas s'en fervir dans ce deffein : on ne voit même pas qu'ils forment des figures humaines ou d'animaux avec aucun but.

Ces anciens monumens des Indiens foumis aux Incas, nous donnent une afrez grande idée de ce qu'étoient alors ces peuples, \&z du degré de civilifation où ils étoient arrivés. On voit parmi les peuples civilifés, une culture, ou un degré de perfection qui les diringue de ceux qui ne l'é-

$E_{2}$ 
toient pas, fans cependant avoir anéanti en eux les penchans propres à leur race : on y apperçoit cette différence fenfible qu'il y a entre l'homme, abandonné à la barbarie, à la pareffe, à l'oifiveté, \& l'homme fubordonné aux loix d'une autorité plus éclairée, qui lui donne des connoiffances, développe fes idées, fa raifon, par les infructions qu'elle liii fait entendre.

Les Indiens civilifés du Pérou vivoient en peuples formés avec ordre \& régularité, même avant d'être fubjugués par les Incas : leurs bourgades étoient diftribuées de manière à pouvoir jouir de toutes les commodités requifes pour leurs ufages: on y reconnoiffoit cet avantage qu'on avoir fur les autres nations de la même race, qui fe contentent encore aujourd'hui du néceffaire abfolu, fans toutes ces formalités; mais ces formalités ne font pas contraires à ce que j'ai dit dans le difcours précédent fur l'inclination particulière \& le penchant que ces nations ont pour l'oifiveté , car le caractère naturel d'une efpèce d'hommes ne doit pas être confondu avec le plus ou moins de perfection qu'ils donnent aux chofes qui font à leur ufage, ou indifpenfables : c'eft ainfí qu'on voit que les bêtes ont plus, les autres moins d'inftinct à faire leurs nids, à former le lieu de leur repos \& de leur retraite.

On voit au Pérou d'affez grands reftes des pa- 


$$
\checkmark \text { I N G I I E M E: }
$$

lais des Incas. La forme \& la folidité de ces édifices étoient bien différentes de celles de tous les autres ouvrages que les Indiens faifoient avant d'être affujettis à ces Princes: on y apperçoit les progrès qu'ils firent alors, certaines règles, \& de l'ordre dans la diftribution; il y a même de la magnificence \& des ornemens.

On peut donc réduire les habitations ou maifons de ces Indiens à trois claffes : la première fut celle des cabanes ou huttes circulaires, que la néceffité leur fuggéra dans les tems les plus reculés, \& dont j'ai déja parlé ; telles font en général celles qu'on voit fur les Punas \& chez les nations de la partie du Nord, nations reftées fauvages \& fans culture: la feconde fut celle dont on voit les ruines parmi les anciens peuples du Pérou : la troifième fut celle des édifices qu'on éleva d'après les règles \& la diftribution que. montrèrent les Incas.

On remarque toujours quelques rapports dans ces trois claffes, quoique la forme des bâtimeñs ait varié, foit dans. la hauteur, foit dans lescomparrimens intérieurs. J'ai fuffifamment expofé les édifices de la première claffe; c'eft la forme ordinaire de toutes les habitations des peuples qui font reftés dans leur état de barbarie par toute: la terre.

Il n'y a pas de provinces au Pérou qui ne pré-

$$
\text { E } 3
$$


fentent prefque par-tout des reftes des anciennes bourgades : ainfi le pays devoit être très-peuplé avant la conquête. Les parties qui ont été les plus peuplées, font, à ce qui paroît, les vallées de Las Capillas ou Guanquina, Guanca-Conachi, \& Topara, comme je l'ai déja dit; auff voit-on depuis Capillas jurqu'à Topara, dans un efpace de quatre à cinq lieues, en allant vers la chaine de montagnes, les reftes de quinze à vinge bourgades. Si l'on prend le chemin oppofé qui mène à la mer, en fuivant la même direction, l'on n'apperçoit aucune peuplade dans ces pays; il n'y a que quielques huttes éparfes çà \& là, ou des cabanes de jonc, très-diftantes l'une de l'autre, habitées par des Mulâtres ou des Métifs. 1 Les bourgades étoient en général fur la pente des montagnes qui forment ces vallées. Quoique ces vallées foient affez étendues, ces peuples ne $s^{\prime} y$ plaçoient point; ils préféroient des lieux plus élevés qui dominaffent fur les environs, foit pour repouffer plus facilement l'ememi qui leur auroit fait la guerre, foit pour n'être pas expofés à être furpris, foit pour $\mathrm{y}$ avoir un air plus ouvert \& moins chargé des vapeurs qui s'élèvent des plaines que traverfent les rivières : ces plaines leur paroiffoient moins falubres que le haut des collines. C'étoit dans les bas lieux qu'ils faifoient leurs femailles. 
L'étendue de ces bourgades varioit; elles avoient ordinairement depuis trois cents pas de long, jufqu'à fix cens; c'étoient les plus grandes. Elles fuivoient le plan de la vallée; la largeur étoir de quatre-vingt à cent pas, à-peu-près : les huttes occupoient tout cet efpace. A quelque diftance de-là, \& vers la cime de la montagne, on voit encore des reftes de fortereffes, au moins près des plus grandes bourgades. Il paroît que ces forts avoient été conftruits par ordre des Incas, lorfqu'ils eurent foumis ces peuples; car ils dominoient fur la bourgade. Ils ont la même forme que ceux qui ont été bâtis par ordre de ces Souverains : ce font trois murs avec des terre-plains, qui s'élèvent par érage l'un plus haut que l'autre, felon la pente que la montagne peut avoir de bas en haut. Ces muirailles fuivent l'inégalité du terrein en dehors, \& l'on voit quili y a eu un foflé aut pied de chacune.

La diftribution des maifons ne fe préfente pas bien diftinctement; on voit néanmoins qu'il y avoit troís ou quatre pièces habitables, dont une étoit deftinée à la fépulture, de la manière dont je l'ai expofé. Les portes en font étroites, petites, n'ayant qu'une vara de haut ou un peu plus, \& deux tiers de large; c'eft la feule ouverture qui y foit pratiquée, comme dans celles dont j'ai fäit mention: ces gens n'avoient pas l'ufage des fencetres. $E_{4}$ 
: Il y a des niches pratiquées intérieurement dans l'épaiffeur de la muraille; elles ont deux tiers de vara de large, un de hauteur, \& un quart de profondeur. Ordinairement ils en faifoient deux à la diftance d'une vara \& demie ou de deux; c'étoit l'ufage général de toute la race Indienne. On voit la même chofe dans les huttes de la Louyfiane \& de tout le Nord, tant pour le local que pour la grandeur \& le nombre de ces niches; il femble que ce fut autant pour l'ornement que pour. la commodité d'y ferrer le peu d'effets de ces habitans.

Leurs murs fon de terre appliquée contre des claies : mais ils ne les faíoient pas comme en Europe. Leurs claies fe prolongeoient dans toute ta longueur du mur : s'il étoit trop long, ils faifoient ces claies \& le mur en deux ou trois parties: Les couches n'ont pas non plus la mêmo hauteur : il y a beaucoup de variation à cet égard; l'une a trois pieds, \& celles qui fe trouvent deffus oudeffous ont ou deux pieds, ou un pied. La hauteur n'eft pas la même dans toute la longueur, car d'un côté c'eft une couche de deux pieds ou un peu plus, enfuite elle baiffe peu-à peu, de forte que ces couches vont fe terminer l'une dans l'autre; mais ce qui manque d'élévation d'un côté , eft fuppléé par la couche qui eft immédiatement deffus ou deffous. 
Ces murs, qui ne font compofés que de quatre ou cinq couches, ont deux varas, ou denx \& demi de haut : comme il n'y a plus de toit, on ne peur au jufte en déterminer l'ancienne élévation; cependant fi l'on en juge par les porres \& par la hauteur qu'on remarque à la plupart de celles qui fubfftent encore, on doit croire que l'élévation actuelle étoit la hauteur régulière. Le toit étoit pofé fur ces murs, \& correfpondoit à la figure quarrée ou oblongue du plan de la hutte : l'épaiffeur des murs a un peu moins d'un demi vara. On ne peut voir fans étonnement que ces murs fe foicnt confervés jufqu'à préfent, fans avoir plus de force qu'ils en ont, \& fans: couverture. Dans d'autres contrées, ces murs étoient faits avec de la terre gâchée \& formée en efpèces de briques. Ailleurs on en voir qui font de pierres, liées avec une terre argilleufe. Enfin. on en faifoit de bois, de rofeaux, felon les matériaux qu'on avoit à fa difpofition, \& conformément au climat de la contrée.

On voit la même manière de bâtir dans la partie haute du Pérou, dans les endroits où il $y$. avoit des bourgades \& des peuplades : cependant il s'y trouve auffi d'autres bâtimens plus fimples, en forme ronde, comme étoieitr ceux des pays actuellement dépeuplés. On pratiquoit aufi des tombeaux fouterreins, mais avec plus d'appareil 
que dans les vallées : ils ćtoient enduits intérieur ment d'un crépi dur, brillant \& très-poli, qui les rendoit impénétrables à l'humidité \& aux infectes; ce qui montre le foin qu'ils avoient de conferver les morts.

Entre les grands édifices qui atteftent la magnificence \& la richeffe des Souverains du Pérou, l'on remarque fur-tout celui de la vallée de Pachacamac, nom qui fignifie le Dieu inconnu; fuprême, invifible, ou le Créateur. Cet édifice eft près du: village de Lurin, à cinq lieues de Lima. On n'en voir que les ruines, \& quelques parties qui font éncore fur pied. Il eft divifé en trois parties; favoir, un palais, une fortereffe $\&$ un temple ou lieu de prières. Tout groflier que paroît avoir été cet édifice, on y apperçoit.un air de grandeur \& de magnificence, qui attefte celle des Souverains qui l'ont fait bâtir.

On voir aufí près de la mer, à la fin de la vallée de Pachacamac, les veltiges d'un palais bâti anciennement fur un haut terrein fablonneux; les murs, vus en-dehors, ont encore quatre à cinq pieds d'élévation, quoique moins hauts en dedans: on y reconnoît plufieurs habitations. S'il n'étoit pas circonfcrit par une enceinte circulaire, à laquelle font liés les compartimens intérieurs \& fans apparence de rues, on le prendroit plutôt pour une bourgade que pour un palais, car ila 
plus d'une demi-lieue de circuit; cependánt il paroît que cette enceinte ne formoir qu'un édifice. Il eft impolible de fe former une idée des compartimens qu'il y avoit, vu les morceaux confidérables d'adoyes (ou briques crues) qui ont été détachées des murs, \& accunulées çà \& là par des gens avides, dont l'intention étoit de découvrir des tombeaux, \& de s'en approprier les richeffes qu'oń difoit y avoir été cachées. En effet, quelques perfonmes y en avoient trouvé d'affez confidérables.

La fortereffe eft à fix cens pas environ de ce palais, fur un mont de fable, comme l'édifice précédent, mais plus près de la mer : elle eft auffi faite avéc des adoves, commele palais, \& préfente trois murs plus larges que ceux de ce palais, à trois hauteurs différentes, de manière que l'intérieur domine fur l'intermédiaire, \& celui-ci fur celui du dehors. Chaque muir a un terre plein ou une efplanade très-large; ils font affez élévés, \& même plus que cetix qui reftent au palais : ils ont un quart de lieue de circuit, \& occupent toute la cime du mont avec une partie du contour de $f_{a}$ pente. On y diftingue encore les chambres ou appartemens qui y étoient, \& les loges qui probablement étoient des corps-de-garde pareils à ceux qu'on avoit pratiqués dans les fortereffes de 
pierre qu'avoient fait éléver les Incas fur d'austres terreins.

Le temple de Pachacamac eft à une demi-lieuc de la fortereffe, au milieu de la pente d'un mont fort élevé, \& au Sud de la vallée. Les murs extérieurs fubfiftent encore dans leur entier, ou peu s'en faut : mais l'intérieur a ćté extrêmement dégradé par les gens avides, qui cherchoient des tombeaux. L'extérieur a cette magnificence qu'on remarque aux autres ouvrages, \& tout en eft auffi folide; mais la hauteur furpaffe celle des autres édifices : du haut, on découvre avantageufement toutes les plaines de la contrée.

Il y a donc plufieurs choles à remarquer ici. Les groffes briques dont les murs font faits, l'élévation du local, la grandeur des édifices, \& $\&$ les difficultés qu’il y a eu à vaincre pour exécuter ces travaux.

Les adoves, ou briques; font plus groffes que celles qu'on employoit ordinairement; elles ont deux tiers de vara de long, un demi de large, \& un quart d'épaiffeur. Pour les faire, il a fallu prendre la terre dans la vallée; car les terreins élevćs fur lefquels font bâtis les édifices, ne font que des fables très-fecs. La matière eft un mélange de terre \& de fạble gấchés enfemble; elles font extrêmement dures, quoiqu'on ne les ait pas 
fait cuire. On n'y voit aucune lézarde; le tems ne les 2 pas fait fendre ni éclater; celles qui font amoncelées à terre, où elles font expofées à l'humidité des brouillards \& des givres, font auffi intactes. On préfume de cette réfiftance que les conftructeurs avoient quelque procédé particulier pour les durcir après les avoir faires, de manière qu'elles ne fe fendiffent point. C'eft un fecret qu'on ne connoît plus dans le pays; car celles qu'on fabrique actuellement n'ont ni la même denfité, ni la même dureté : elles font aufi plus petites.

Il paroît affez fingulier que l'agréable vallée de Pachacamac étant tout près, \& fertilifée par une rivière de même nom, ces anciens Indiens n'aient pas préféré d'y bâtir le palais \& le temple; \& qu'ils aient mieux aimé des fables arides \& des monts, où rien ne récrée la vue. On peut préfumer qu'ils ont voulu les placer dans des endroits plus sûrs, afin d'éviter la furprife, préférant la confervation de leurs Souverains aux commodités \& à l'agrément : d'ailleurs, ces emplacemens font dans un local plus pur, expofé à tous les vents, \& par conféquent moins fujer aux maladies. Dans les bas-fonds de la vallée, l'air eft chargé de vapeurs qui s'exhalent de la rivière, \& ainfi moins falubre que fur les hauteurs, où foufflent tous les vents qui font ordinaires fur ces côtes.

Ils ne pouvoient guère donner plus de grandeur 
à ces édifices, comme on le voit par le valte contour qui borne l'épaiffeur exrraordinaire des murs extérieurs. L'antiquité ne nous a lairlé en ce genre aucun monument dont l'épaiffeur des murs puiffe êrre comparée avec celle-ci ; car elle excède celle qu'on donne actuellement aux murs des fortificarions. Or, on ne voit cela ni dans aucuns des palais les plus pompeux, ni dans les édifices publics qui reftent de l'antiquité.

La furface liffe \& uniforme qu'on leur a donnée, femble indiquer que le deffein des confructeurs étoit d'en prolonger la durée jufques dans l'avenir le plus éloigné, \& de les garantir des évènemens dont ils éroient fufceptibles de leur nature. En effer, ils auroient duré nombre de fiècles, fi la cupidité des richelles qu'on y croyoit cachées, ne les ent fait démolir. C'eft ainfi qu'on a anticipé la ruine éloignée qu'en avoient pu prévoir les auteurs. Il ve refte donc plus que ces parties difformes dans leurs proportions pour perpétuer le fouvenir de ces édifices, \& indiquer comment ils avoient été diftribués intérieurement.

Les adoves qu'on employa étoient innombrables, \&x devoient être montées du fond de la vallée, qui en eft à une demi-liene. On avoit donc à effuyer la fatigue qui réfultoit de la dirtance \& de la pente des montagnes, pour les placer enfuire à leur hauteur refpesive. Oure cé 
travail, il falloit encore apporter de l'eau pour lier ces matériaux. Quel nombre de perfonnes ne devoient pas y être employées! On n'y voir pas d'indices de puits; fans doute que ces peuples ne connoiffoient pas cette invention : aucune de leur peuplade ne peut le faire préfumer: quand ils l'auroient eue, le local la rendoit inutile. Il eft donc à préfumer qu'ils prenoient de l'eau à la rivière : c'étoit la plus proche; mais la commodité de cette eau n'étoit pas exempte de toute difficulté, vu la quantité immenfe qu'il en falloit pour tous les travailleurs occupés à ces édifices, \& qui devoient former une efpèce de peuplade à proportion que les bâtimens augmentoient. Il falloit donc un très-grand nombre d'Indiens uniquement occupés à fournir de l'eau.

Mais ceci nous indique en même tems la proportion de tous les autres befoins, $\&$ combien ces pays devoient être peuplés avant la conquête; car il ne faut pas oublier ce que j'ai dit de la lenteur des Indiens, ni ignorer que le tranfport fe faifoit prefque tout fur le dos. Malgré cela, ils furent en aflez grand nombre pour exécuter ces ouvrages, \& vaincre les difficultés qu'on paroît avoir multipliées, dans le deffein de rendre ces ouvrages plus merveilleux.

On découvre une affez grande quanticé d'offemens \& de crânes humains dans les ruines \& 
80 $D x \leqslant c \circ U R S$

les décombres : les crânes ont même encore leurs cheveux. On déterre auffi çà \& là des vafes qui étoient alors d'ufage. Il y a même un grand filet déchiré par lambeaux, \& pourri en partie : c'étoit fans doute pour pêcher. Le fil eft fait de pita, plante du pays: ce font les feules chofes qui y reftent, depuis qu'on en a tiré quelques objets de curiofité, \& autres de certain prix, en foullant \& en démoliffant. Il fe trouve encore des gens qui s'occupent de ces recherches, \& qui par conféquent continuent les démolitions.

Suivant les traditions \& les connoiffances qu'on a de tous ces tems-lì, le palais, le temple \& la fortereffe, étoient les plus grands ouvrages qu'on voyoit en ce genre dans ces contrées-là. Il eft facile de le préfumer par leur valte érendue, leur maffif, \& la folidité de la conftruction; car ce font des monumens faits pour montrer de la grandeur, du pouvoir, de lapplication aux srandes chofes, fans goût il eft vrai, mais avec un génio beancoup moins borné que celui des Indiens en général; car toutes leurs idées fe bornent aux chofes de pure néceflité : jamais ils ne conçoivent rien de grand, d'éclatant.

On ne fait pas avec certitude quel fut l'auteur de ces vaftes monumens : on croit généralement que c'eft l'ouvange des Incas, $\&$ certains indices femblent le perfuader. Mais on oppofe à certe

opinion 
$V I N G T I E M E$.

opinion, que le culte du dieu Pachacamac étoit déja étabii clans la vallée, \& le temple bâti lorfque les Incas en firent la conquête. On peut fuppofer qu'ils l'ont agrandi \& embelli, puifque ceux qui ont écrit l'hiftoire des Incas, difent que ces princes comnoifroient ce dieu, qu’ils le révéroient intérieurement, comme une des divinités fuprêmes. Cependant ils croyoient qu'il étoir inutile de lui rendre extérieurement les mêmes hommages qu'au foleil \& à la lune, parce que $\mathrm{Pa}_{\mathrm{a}}$. chacamac étoit invinble.

Cuifmancu, prince qui régnoit fur certe vallée $\&$ fur toutes les autres du voinnage, avoit regardé Pachacamac comme le premier des dieux, l'auteur \& l'adminifrateur de toutes chofes; c'ent pourquoi il lui avoir, dit-on, élevé le remple qui étoit dans cette vallée : ainfi l'auteur en feroic Cuifmancu, fi même ce ne font pas fes ancêres qui l'ont fait bârix. Néantnoins la grandeur des bâtimens, la méthode, l'ordonnance, la fructure, préfentant, à l'exception des matériaux, tous les mêmes rapports que ceux qui ont été confruits par ordre des Incas, il y a lieu de préfumer que celui dont les veftiges font le fujet de ces détails, eft un de leurs ouvrages, ou qu'au moins ils le rebâtirent \& l'agrandirent.

Il n'eft pas inutile de rappeller ici ce que j'ai dit fur la capacité, le difcemenent \& les, inTome II. 
82

$D$ I $s, C$ O U $R \mathrm{~s}$

ventions des anciens Indiens, d'après ce quie nous en rapporte l'hiftoire, \& ce qu'on en voit dans les monumens : comparons-les avec les Indiens modernes. Les anciens avoient donc une religion, un culte idolâtre, \& faifoient des facrifices : les Indiens actuels ont peu d'idées de religion, \& font fi indiférens fur cet article, qu'on ne peut abfolument croire qu'ils aient quelque culte intérieur. Il y a même dans le Pérou de très-grandes nations indépendantes, qui ne mènent qu'une vie purement animale, \& nê font pas diftinguées de la brute. Lorfqu'on leur parle de culte intérieur, de foumiffion à un être fpirituel, ces gens extravaguent, regardent cels comme très-inutile, comme une rêverie fans but, fans objet déterminé.

Plufieurs perfonnes ont penfé que l'état de barbarie où font ces peuples, leur irréligion, venoient de ce que la race des Indiens ayant été jettée dans ce continent, elle y porta avec elle les ufages de lidolâtrie, dont le foleil étoit le principal objet. Or, ce culte fe bornant à l'extérieur, if y prit d'autant plus aifément racine, \& ces peuples furent ainfi portés aux feules démonftrations extemes. L'idolâtrie s'y propagea donc; leurs idées religieufes ne furent plus manifeftées que par des fêtes, des danfes, l'ivreffe; ce qui devoit leur plaire infiniment plus que de s'occuper de 
réflexions, \& de l'exercice des facultés intellectuelles, exercice qui leur eft fi indifférent. C'cte ainfi que s'eft abruti le peuple primitif, conduit dans ces contrées par des vues particulières de la Providence, comme l'ont été dans les iffes les plus éloignées les nations qui les habitent. Mais les chefs de ces Indiens voyant les individus fe multiplier, craignant auffi les troubles, les féditions, occupèrent les fujets furabondans aux ouvrages dont on voit encore des reßtes. Les Incas fe réglèrent fur cette prudente conduite, \& cherchèrent à les occuper de même, pour éviter les mêtmes inconvéniens。

On doit donc croire que les Incas ont contribué à la conftruction des édifices de Pachacamac $\&$ de différens autres, quoiqu'en difent les hiftoriens; voila pourquoi ils font fi femblables a ceux de Cuzco, du royaume de Quito \& 2 , d'aurres pays où s'étendoit leur domination. En effet, toutes les circonfances prouvent cette opinion. Les compartimens, autant quion peut les reconnoître, les loges ou corps-de-gardes, la manière de pofer les adoves, tout enfin rappelle les mêmes conftructions. D'ailleurs, le Prince de Pachacamac \& de Rimac, ne pouvoit occuper un palais de cette forme monftrueufe; mais il convenoit aux Incas \& à toute leur fuite. L'hiftoire ne nous apprend pas quaucun autre Soum 
verain de ces contrées eût une famille \& me fuite, pour lefquelles il fallût abfolument un édifice de cette grandeur.

On voir à Herbey, fur la rive méridionale de la riviète Cagnête, un palais qui reffemble un peu au précédent; il eft à $23 \frac{1}{2}$ lieues de Pachacamac, \& fort étendu; la longueur eft de quatre cens pas, fur une largem proportionmée. Ce palais fe trouve à la courbure que fait la rivière; il eft contruit ( $\mathrm{I}$ ) d'arbres de même hauteur que les autres : les murs ont encore la même élévation qu'anciennement; mais l'intérieur eft tout renverfé, tout dégradé : on y a aufli cherché des tombeaux.

Il s'eft auffi confervé des pans de murs entiers fur le chemin qui va de Cuzco à Lima: on en voit de diftance en diftance, affez éloignés les uns des autres, fans qu'il y ait une feule breche; ni aucune marque du pouvoir du tems: les parties qui en font ruinées, l'ont été par ceux qui en ont pris des adoves pour bâtir ailleurs; mais ces dégradations font modernes.

Il faut bien dintinguer dans les Indiens les opérations de l'efprit \& de l'entendement, de tout ce qui n'eft que main-d'cuvre $\&$ induftrie méchanique; ou autrement, il ne faut pas con-

(I) Tcxte arboles : ne feroit-ce pas adoves? 
fondre chez eux ce qui exige du raifonnement \& de la réflexion, avec ce qui fe borne aux opérations des fens. Dans le premier cas, on ne voit chez eux que ftupidité, manque de difcernement. \& d'intelligence : aufi quelque chofe qu'on puiffe leur dire pour leur faire connoitre la droite raifon, \& diftinguer tout ce qui s'en éloigne, ils. font incapables de rien fentir, \& de comprendre ce qui réfulte néceffairement ou accidentellement de telle ou telle mauvaife opération. Voilà pour quoi ils agiffent toujours fans réflexion, \& fans penfer plus loin qu'au moment actuel. Ils ne font pas plus intelligens ni plus intéreffés lorfqu'on leur parle de religion, comme je l'ai dit; ils. écoutent affez tranquillement, mais rien ne leut fait impreffion, ne pique leur curiofité, Ainfi ils entendent tout ce qu'on leur dit fur la vraje re: ligion comme toute autre chofe indifférente pour eut; leur volonté eft auffi peu déterminée à l'embraffer quauparavant : ils ne peuvent fe formet une idée d'une vie éternelle après celle ci.

$\mathrm{Si}$ on leur demande de convenir d'une chofe, ils le font fans difficulté, mais prêts à nier tout; fi on leur dit de le faire. Qu'on leur dife que le Diable eft mauvais : ils répondent que cela peur être, mais qu'il ne leur a jamais fair de mal. Sir on leur dit que tel Saint eft bon : ils répondenc que cela peut être. Qu'on leur dife tout le cono $\mathrm{F}_{3}$ 
traire, ils en conviemnent de même; ce qui prouve que ni l'une ni l'autre affertion ne fait imprefion fur leur efprit.

Ils ne defirent ni n'attendent rien dans ce monde, que ce qu'il leur faut pour le jour même, mais fur-tout ce qui peut fatisfaire leur palfion pour l'ivrefre. Quant à l'autre vie, ils en ont $\grave{a}$ peine la moindre idée: d'ailleurs, il ne faut, fuivant eux, aucun mérite pour y paffer. Mais on ne peut décider de quelle manière ils la conçoivent, ni quel ent l'objet de l'idolâtrie de ceux qui font civilifés. On ne voit pas qu'ils faffent de facrifices, ni d'offrndes, ni même aucun autre acte extérieur, d'après lefquels on foir en état de fe former une idée de la fupertition qu'ils confervent de tems immémorial. Tout eft égal pour eux dans toutes les claffes de la fociété, \& dans l'autre monde comme dans celui-ci.

Uniquement occupés des objets qui les environnent, \& bomant là toures leurs actions, ils montrent cependance certaine indultrie en plufieurs chofes : mais il n'y a en cela rien de particulier qui prouve quelques lumières \& de l'intelligence. En effet, hous voyons des animaux faire des ouvrages fi artifement difpofés, qu'on a de la peine à les imiter; on ne les fait même jamais auth parfairs qu'eux : la roile de l'araignée, les cocons des infectes, les loges dẹs caftors, les nids de 
différens oifeaux, \& autres ouvrages des animaux, décèlent l'inftinct le plus indufrieux, quoique dicté par la néceffité. La raifon paroîc infiniment moins développée dans les travaux des Indiens : tout y eft grofler, fans combinaifon, fans variété, fans aucun degré de perfectiona Quand on a vu une de leurs cabanes ou huttes, on les a vues toutes; il femble que la raifon n'y; ait eu aucune part. Les Indiens du Nord font quelques figures fur les peaux quils préparent comme celles de chamois; mais ces figures font celles des objets qu'ils ont fous les yeux : ils y mettent tanc de tems, travaillent avec tant de patience, qu'il faut néceffairement qu'ils s'apperçoivent de leurs erreurs, ayant tonjours les mêmes objets fous les. yeux. Voilà les règles qu'ils fuivent en travaillant, règles qui ne font nullement fuggérées par un efprit de combinaifon, mais qui fe préfentent machinalement : ce qui prouve qu'ils font mat tériels en tout.

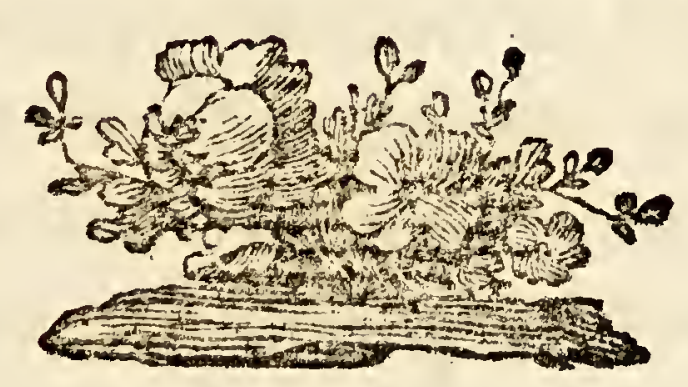




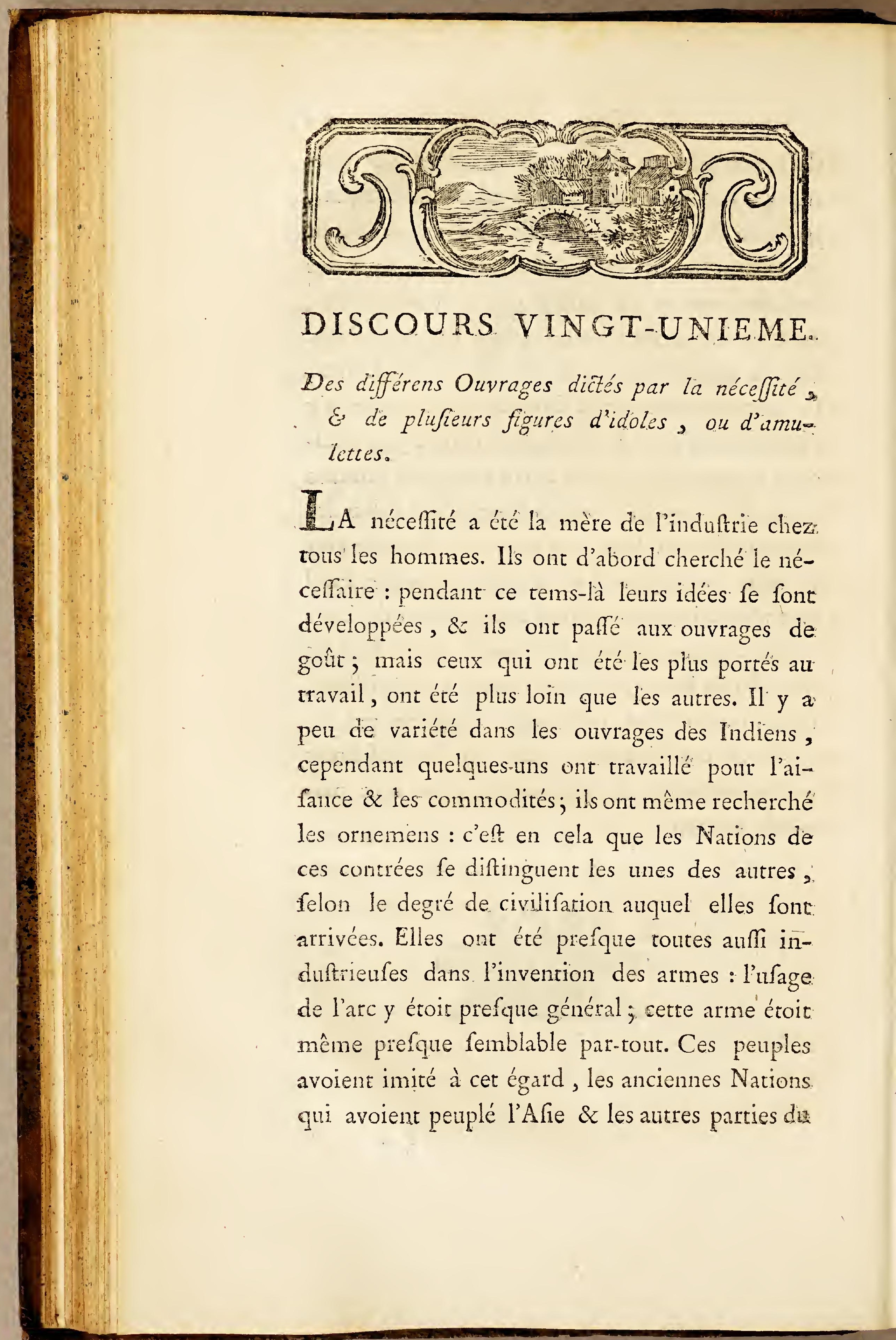


DISCOURS VINGT-UNIEME

Monde : on peut donc en inférer que certe arme avoit une même origine, \& que ce fut une des premieres dont on fe fervit: on en inventa d'autres par la fuite.

Les Indiens civilifés du Pérou ne connoiffent plus cette arme; ceux du Nord en font quelque ufage, mais affez rarement : ces Sauvages fe font faits au maniement de l'arme ì feu, dont les Anglois \& les François leur ont appris à fe fervir : ils montrent, il eft vrai, à leurs enfans à tirer de l'arc, \& ils y font fort adroits; mais ces. enfans le quittent dès qu'ils font grands, \& pren-i nent les autres armes: les Sauvages qui vivent loin des Européens dans la partie éloignée dut Nord, \& qui n'ont aucun commerce avec eux ? ceux qui ont confervé leur indépendance dans les vaftes pays des deux Amériques, ne connoiffent que l'arc, tant pour la chaffe, la pêche, que pour la guerre, \& ils s'en fervent avec beaucoup. d'adreffe. Ces arcs font faits d'un bois dur, fouple; les cordes font de boyaux d'animaux : ils prennent pour les flèches un autre bois dur \& lourd, dont ils durciffent la pointe au feu, où îs y enchaffent des morceaux aigus de cailloux. Is fe fervent auffi de lances longues de plus de deux varas, minces, \& du même bois que celui des flèches : ils les jettent très-légèrement, \& avec adreffe. 
Les Indiens civilifés du Pérou ne fe fervent que de pierres, qu'ils lancent avec la main, fans fronde, \& frappent le but avec sûreté : cette Nation eft bien différente de ce qu'elle étoit. autrefois, quant à la promptitude avec laquelle elle fe procuroit les chofes néceffaires, étant fous. la domination de fes Seigneurs naturelsa

On remarque fur-tout des haches de cuivre parmi les pièces d'antiquité que l'on a trouvés. dans ces contrées. D'un côté, elles ont un tranchant, \& de l'autre une pointe aiguë: dans le: milieu eft l'oil où s'infere le manche : ce manche n'a de longueur que ce qu'il faut pour être manié d'une feule main: c'étoit fans doute une. des marques de la fouveraineté, \& une arme offenfive dont fe fervoient les Rois: ces haches repréfentoient le fceptre par lequel la puifíance fouveraine eft figurée; \& dans un autre fens, c'étoit l'emblême de la jutice: le nombre qu'on en trouve fait cependant préfumer que lẹs autres. chefs de la Nation s'en fervoient auffi, comme revêtus d'une partie du polivoir fouverain pour gouverner les peuples : les Offriers chargés du commandement des armées \& des expéditions militaires, les Princes du fang royal, avoient aufi des haches où étoient figurées les margutes de leurs difinctions \& de leur emploi:

On trouve encore d'autres pièces en forme. 
d'étoiles, dont le diamètre pris d'une pointe à l'autre, eft de cinq à fix pouces. Il y en a de deux matières, \& de quatre formes différentes: la première eft le cuivre: celles de ce métal ont le diamètre mentionné; il y a au milieu un trou d'un pouce \& demi de large pour y introduire le manche; la circonférence eft divifée en fix parties égales; cinq de ces parties font l'étoile : la fixième eft le tranchant de la hache; les pointes en font rondes \& tranchantes.

La feconde efpèce elt de même grandeur que la première, \& de la même figure; mais avec cette différence, qu'il n'y a pas de tranchant; elle a fix pointes rondes en forme d'étoile.

La troifième diffère de la précédente, en ce que les fix pointes qui font l'étoile, ne font pas rondes, mais en forme de feuilles tranchantes des deux côtés, \& l'extrémité de cette étoile a un pouce d'épais, ou un peu plus à l'œil du manche : l'épaiffeur diminue jufqu'aux pointes, qui ne font pas aiguës, mais un peu circulaires.

Ia quatrième efpèce eft comme la feconde; excepté qu'elle eft de pierre fort dure \&r de couleur obfcure. Il eft étomnant que ces peuples n’ayant l'ufage ni du fer ni de l'acier, puifqu'ils ne les connoiffoient pas, aient pu donner à ces infrumens la perfection quion y voit, \& y pra*iquer un ail de forme circulaire parfaite, ce qui 
92 D I S C O U R s

a fans doute demandé beaucoup de patience, $e^{2}$ n'a pu être fait que par un frottement long-tems; continué.

Il paroî́ que la première efpèce étoit la marque de la fouveraineté : les autres étoient celles. des Gouverneurs ou autres Officiers fupérieurs, qui s'en fervoient auffi pour armes offenfives dans la guerre, comme il étoit d'ufage dans l'antiquiré de fe fervir de la maffue : leur figure \& leur grandeur prouvent affez qu'elles n'étoient definées qu'à charger l'ennemi. On voit que l'ufage de cette arme \& de l'arc, viennent d'une même origine chez cette Nation comme chez toutes les. autres, qui garniffoient de pointes leurs maffes. 'd'armes.

Les Indiens de la partie du Nord de l'Amé rique fe fervent d'une efpèce de hache femblable à celle de cuivre dont j'ai parlé : elle a un tranchant \& une pointe; les François l'appellent cafferête; ce font eux \& les Anglois qui leur en fourniffent : elles font de fer ou d'acier; mais la forme en a été prife de celles que ces peuples. avoient anciennement, car c'eft une arme qui n'elt pas d'ufage en Europe. On en a dans les vaiffeaux, il eft vrai, mais elles font un peu différentes. On peut donc conclure que le cuivre éroic en ufage dans la partie Méridionale \& dans le Nord le plus reculé de l'Amérique; de forta 
gulón reconnoît parmi ces Nations une uniformité dans la plupart des chofes, fans que les intervalles immenfes qui les féparent, le laps de tems confidérable qui a dû s'écouler depuis qu'elles fe font féparées de leur origine, aient varié leurs rapports dans ce qu'il y a de plus effentiel.

On trouve auffi des inftrumens plats de mé$\mathrm{ral}$, de quatre à cinq pouces de long \& d'un pouce de large, ou un peu plus, fur une épaiffeur de deux lignes. Ils ont un tranchant un peu circulaire à l'une des extrémités; l'autre fe termine par une tête, de forte que l'on y voit véritablement une hachette: ces inftrumens étoient, fans doute, deftinés à couper, comme ceux des charpentiers. On trouve encore d'autres haches de même zature que les précédentes: la figure en eft circulaire, \& la grandeur la même que celle des hachoirs de nos confifeurs : elles différent feulement en ce que la poignée eft de même métal que la lame, afin de procurer plus de force aux coups que l'on donnoit.

Ces Indiens des tems reculés, connoiffoient à certain point, le mélange des métaux: on le voit par la couleur des pièces dont jai parlé. Les unes ont une teinte rouge, qui approche de celle du cuivre naturel, d'autres font jaunes comme le laiton; il y a même des nuances intermédiaires entre ces deux couleurs: quelques-mes fe rappro. chent plus du laiton que les autres; mais on ob- 


\section{D is c o t i t is}

ferve dans toutes, que fans avoir été recouvertes ou enduites d'un vernis quelconque, elles n'ont pas contracté de vert-de-gris : le mélange qu'ils en faifoient changeoit donc totalement la qualité du cuivre, fecret que l'on ignore aujourd'hui.

Mais ce qu'il y a d'étonnant, c'eft que les Indiens qui ont confervé pendant plufieurs fiècles leurs ufages \& leurs coutumes, la manière de faire ce qui étoit le plus commun parmi eux, aient entièrement oublié depuis la conquête, les inventions ingénieufes de leurs ancêtres. Cette époque n'eft cependant pas fi éloignée de nous: ainí ils ignorent abfolument la fonte \& le mélange des métaux, la manière d'imiter les vaiffeaux antiques, dont je parlerai, de travailler la pierre dure avec ces métaux fouples $\&$ de peu de réfiftance en eux-mêmes, de fabriquer les armes dont on fe fervoit alors. Cet oubli eft même porté au point, que les Indiens civilifés ne pourroient faire une flèche, $y$ ajufter une pierre, ni y pofer les plumes pour en diriger le trajet; à plus: forte raifon ne fauroient-ils faire un arc avec de juftes proportions: ainfi ce qui n'eft qu'un jeu pour les Sauvages indépendans, eft une chofe impolible pour les fucceffeurs des Indiens qui ont été les plus induftrieux; ce qu'on ne peut attribuer qu'au défaut d'ufage.

Non-feulement ils ont montré leur indufrio par ces étoiles \& ces haches , mais encore pay 


$$
\checkmark 1 \text { N G T-U N I E M IE: }
$$

les différentes couleurs qu'ils leur ont données. Les unes, comme jel'ai dit, ont une teinte rougeâtre, les autres font jaunes. Ils traitoient de même les uftenfiles \& les inftrumens avec lefquels ils travailloient, ce qui donne lieu de croire qu'ils faifoient ces compofitions pour donner plus de dureté au cuivre, autant que pour en varier les couleurs \& les rendre plus agréables à la vue.

Ils avoient aufli des tenailles de même métal que les autres inftrumens, \& fans doute de différentes grandeurs; mais celles qu'on trouve font petites, \& n'ont qu'un pouce \& demi de long $\&$ un demi pouce de large : elles font fort minces, faites d'une feuille de métal double, jufqu’à la moitié de la longueur. Le bord en eft ranchant : on y remarque certaine élafticité. Ces pinces leur fervoient à arracher les poils du vifage, quand la vieilleffe commençoit à leur en faire croître. Comme ils étoient long-tems fans avoir de barbe, ils croyoient qu'il ne convenoit pas d'en avoir avec l'âge. Nous voyons au contraire que les Orientaux, fur-tout les Mahométans, ne quittent pas la barbe, tandis qu'en Europe perfonne ne la garde, fi l'on excepte quelques peuples vers les extrémités du Nord, qui la laiffent croître comme dans les anciens tems; mais les Indiens civilifés n'en ont pas autuelle: ment, ou ne la gardent pas. 
is

$\mathrm{O}$ i s c o $\mathrm{O}$ ⿸ $\mathrm{k}$ s

On ne voit pas dans ces reftes d'antiquité, une feul inftument fait pour frapper, comme un marteau ou une maffue : peut-ĉtre les faifoientils de pierres qui fe font écrafées ou défgurées: au refte il eft remarquable qu'on n'en trouve pas dans les tombeáux. En fondant les métaux pour les inftrumens dont j'ai parlé, ils avoient aufi appris l'art d'en faire certaines figures, quoique très-petites : les unes font maffives, les autres creufes, \& auffi minces proportionnément qu'elles font petites : il paroît que c'étoit pour les porter fur eux. Ils en ont fait d'or, d'argent, de pierre \& de terre cuite : ils repréfentoient par ces figures, les Indiens qu'ils appelloient ( 1) Opas, gens monftueux \& ftupides; ne fachant rien faire de plus difforme, à ce qu'on peut préfumer.

Cette efpèce difforme eft très-nombreufe parmi eux, dans l'un \& l'autre genre. Il paroît que la aifformité eft toujours chez ces individus, accompagnée de la démence; c'êt ce que prouve l'expérience. Ils ont une figure \& une tête horribles : leur cou eft chargé de gô̂tres prefque aulli gros que leur tête. Les Indiens leur attribuent plufieurs qualités, fur-tout la vertu de deviner: ils les confultent dans le befoin, les regardant avec vénération, comme des gens qui ont quel-

(1) L'Europe a fes. Cretins: 
que chofe de particulier, dont les autres hom. mes font privés : voilà pourquoi ils en faifoient les figures, \& les portoient comme des amulettes. On voir que c'étoient-là leurs idoles, quoiqu'on ne foit pas afluré qu'ils leur rendiffent aucun culte, \& que les anciens les tinffent pour des chofes vraiment divines.

On n'apperçoit pas non plus de femblable culte idolâtre parmi les Indiens indépendans; autrement ils conferveroient ces idoles, \& leur donneroient quelques marques de vénération : il y a donc lieu de croire que les anciens Indiens civilifés par les Incas, admirent cet ufage par les loix que leur imposèrent ces Souverains, ou les premiers hommes qui pafsèrent dans ce continent, \& fe les affujettirent.

Les offrandes qu'ils faifoient au Soleil dans leurs temples, avoient pour objet d'obtenir de plus grands avantages de la chaleur bienfaifante qu'il communiquoit à la terre, \& de l'éclat de fa lumière. Uniquement attachés aux objers extérieurs, quoiqu'ils connufient Pachacamac, ou le Dieu invifible, ils fe contentoient de rendre à cet Être infini des hommages intérieurs, \& rapportoient au Soleil, en conféquence de fes effets fenfibles, ce qui appartenoit au Créateur qui les gouvernoit. On ne trouva cependant pas de figure qui repréfentât cet aftre brillant, ni même Tome II. 
d'autres que celles dont j'ai parlé, \& il eft difit cile de deviner quel but ils fe propofoient.

On reconnoît dans ces Nations un goût particulier pour ces figures laides \& bifarres : tels font les mafques de bois que font ces peuples pour fe déguifér de la manière la plus grotefque. Ils font réellement fi laids, fans cependant offrir rien de nonftuenx, que ceux de l'Eurepe ne petivent pas y être comparés, quelque ridicules qu'on ait pu en imaginer. Il n'y a rien d'abfurde \& d'extravagant qu'ils ne trouvent lorfqu'ils veulent fe mafquer : il n'ent donc pas étonnant que les Opas aient fervi de modèle chez eux pour repréfenter leurs petites figures ou amulettes; car on ne peut rien voir de fi affreux que ces gens.

Quelques perfonnes crédules veulent que ce Soit la figure du diable, que ces gens on repréfenté lorfquil leur apparoinoit pour les faire perfévérer dans lidolâtrie, leurs erreurs, leurs vices; mais il en permis de rejetter cette opinion : il eft plus naturel de croire que ces figures font une fuite de l'ignorance de ces peuples, qui ont attaché certain mérite à la repréfentation de ce qu'il y avoit de plus affreux dans l'efpèce humaine. Lorfque les Indiens ont perdu quelque chofe, ou qu'une de leurs bêtes s'eft égarée, ils vont encore actuellement confulter les Opas, pour ére infruits de l'endroit où eft ce qu'ils cher- 
V I N G T-U N I E M E:

chent: n'eft-ce pas montrer évidemment linconféquence, ou la foibleffe d'efpric la plus étrange, que d'attribuer aux hommes les plus ftupides, des qualités ou des talens que n'ont pas les gens les plus fenfés? aufi la raifon de ces peuples eftelle encore dans fa première enfance, \& y perfévère même lorfqu'ils font dans le plus grand âge. On les voir s'amufer de ces figures comme des enfans, fans y mettre d'autre intérêt que celui de l'amufement, ce qui prouve bien à quoi leur frupidité borne leur defir. Un Savant de l'Europe a dit, en parlant des Indiens occidentaux, qu'il étoit fingulièrement étonmant qu'on vît dans leurs vaftes contrées une très-grande Nation refrant toujours dans l'état de l'enfance, même à quatre-vingt ans, puifque les actions de ces Indiens étoient à tout âge les mêmes que sills n'curfent que fept ou huit ans.

On tire auffi des combeaux des vafes de terre cuite, très-reffemblans à ceux que l'on trouve parmi les antiquités Grecques \& Romaines ou Egyptiennes, \& dont les mêmes figures font repréfentées dans les Hiéroglyphes \&. les Mofäques de ces tems-là. Leur grandeur eft d'une vara $\&$ un quart, ou un peu plus : le corps du vaifreau eft plus long que gros; \& fe termine en pointe par la partie inférieure : le cou eft long \& droit, louverture large, formānt une ef́pèce d'enton- 
100

D I $S \subset O U R S$

noir : dans d'autres la bouche n'elt pas fi dilatée; quoique la forme foit la même : la terre en eft bien cuite. Ces pièces, qui font en affez grande quantité, indiquent que la forme en a été laiffée par les premiers hommes qui ont peuplé ces contrées, \& qu'ils l'avoient de la même origine que la leur propre.

Les Indiens modernes ne fuivent plus cette forme pour les vaiffeaux qu'ils font; auffi eft-il facile de les difinguer les uns des autres. Ils en faifoient aufi de petits, dont quelques-uns repréfentoient la figure d'un Llamas couché; il y a un trou au milieu. On ne peut regarder ces vafes comme des objets d'idolâtrie : cette forme n'étoit que pour varier les pièces, comme on le fait chez d'autres nations. D'autres reffemblent aux pots à boire des Catalans. La qualité des terres étoit aufli différente : on en trouve de noires; quoique les vaiffeaux les plus grands foient communément de terre blanche.

Les Indiens modernes ont l'ufage des balances, probablement des tems les plus reculés : celles dont ils fe fervent n'ont pas d'aiguilles; elles font faites de deux culs de calebaffes fufpendus par des fils aux deux bouts d'un bâton, au milieu duquel eft un autre fil pour les lever. Les poids font des pierres proportionnées à leur idée, mais qui n'ont pas de rapport avec le mare 
d'Efpagne. Ces balances leur fervent à vendre la coca, le coton, la laine, matières qu'il faut nécelfairement pefer chez eux : les autres chofes s'eftiment au coup-d'œil. On trouve parmi les antiquités de petites balances, dont les plateaux font d'argent, de même que le fléau : cés plateaux fe terminent en pointes, comme des cônes renverfés.

Il paroît par leur petiteffe que ces balances: étoient deftinées à pefer l'or \& l'argent; car elles ne pouvoient être employées pour des chofes de plus grand volume. On n'obferve pas cette invention parmi les Indiens indépendans; il femble même qu'ils n'en ont pas befoin, car ils eftimen tout à l'œil dans leurs échanges. Les Indiens du Nord, du Canada \& de la Louyfiane, font le commerce des peaux des animaux qu'ils tuent, moyennant une efpèce de tarif réglé par les $E$ uropéens, Anglois \& François. En vertu de ce rarif, ce qu'on doit leur donner en marchandifes ufuelles pour échange, eft réglé à tant par efpèce de peaux, proportionnément à leur qualité: La même chofe fe pratique avec ceux qui fon au Sud du royaume de Chili, \& avec les nations du Paraguay, voifines des. Indiens affujettis:

Il paroît donc que l'úfage des poids a été introduit par les Incas dans. les contrées qu'ils foumirent à leur empire. 
102

DIs c o U R :

On n'y trouve point de mefures; cependant ils devoient en avoir : ce font peut-être quelquesuns de ces vaiffeaux de terre cuire; car celles dont ils fe fervent à préfent pour les liquides \& les grains, font de petits pots de même terre que celle des vaifreaux dans lefquels ils préparent leur manger.

Cette variété de chofes connues des Indiens; \& femblables à celles qui étoient \& font encore en ufage chez toutes les autres nations, fait croire que les premiers qui palfèrent en Amérique n'éroient pas en petit nombre. En effer, des inventions aufli variées ne pouvoient être garanties de loubli, qu'autant qu'un peuple entier en avois connoiffance \& les pratiquoit.

Les anciens Perfes, les Grecs, \& les autres nations orientales prenoient des figures effrayantes en allant à l'armée, pour animer le courage de leurs compagnons, \& jetter la terreur parmi les. ennemis. On en voyoit fous la forme d'un ferpent, d'un lion, d'un tigre, \& d'autres animaux. féroces : ils fe couvroient de mafques, qui les défiguroient totalement. L'ufage des plumes d'oifeau pour fe parer, \& pofées en panaches, en aigrettes fur la tête, ou ceintes autour des bras, des jambes; celui du carquois, des flèches, des arcs ornés de diverfes manières, des lances, \& tout ce dont jai fait mention, prouve que les 
$V$ I N G $T-U$ N I E IF E

premières races ont eu une même origine. La coutume de fe couvrir de peaux d'animaux, enjolivées de peintures, eft encore commune à toutes. les nations : ainfi, en comparant avec foin ce qui étoit d'ufage chez les Indiens occidentaux avec ce qui l'étoit chez les peuples les plus anciens, on trouve que ces peuples fe rapprochent d'alfez près, quelle que foit la différence \& le contrafte qu'on apperçoit dans les Indiens modernes.

Quant aux tiffus dont ils fe fervoient, on découvre dans les tombeaux des mantes à leur ufage. Ces étoffes ou tifirus éroient de coton : les. plus communes font blanches, d'autres étoient. raycés de rouge \& de bleu. Ils faifoient leur teinture avecl'achote, diverfes herbes, \& une efpèce de planre fauvage qu'ils appellent chaucha. Cette plante croît dans la partie haute du Pérou, \& donne une teinture bleue : ces peuples s'en fervent encore. Ils teignoient aufli en noir les tiffus. qui fervoient de llicllas aux femmes; c'eft le nom qu'ils donnent à une efpèce de mante prefque quarrée, dont elles fe couvroient le dos, en la pafrant fur les épaules; enfuite elles l'atta-choient devant la poitrine avec un poinçon ou groffe épingle, qu'ils appellent ticpe. On trouve aufi de ces fiches dans les tombeaux: elles font d'argent. Les femmes du commun les font ordinairement de bois ou d'épines fort grandes qui

$\mathrm{G} 4$ 
IO4 DIgCOURS VINGT-UNIEME. croiffent dans les campagnes. Les habits de ces anciens Indiens femblent indiquer que les blancs étoient pour les hommes, \& les noirs pour les femmes. Au royaume de Quito les hommes les portent ordinairement noirs.

On ne trouve guère que les pièces mentionnées dans les tombeaux, \& c'eft même en petir nombre. Quant à ce qui eft d'or ou d'argent, on fond tout ce qu'on découvre, fans même excepter le cuivre ni les métaux de compofition. Les Orfèvres les emploient pour différens mélanges.

Mais il y a moins à trouver actuellement dans les tombeaux que par le paffé. Depuis la conquête on s'eft fouvent occupé de fouiller dans les lieux où lon pouvoir foupçonner qu'il y eût de l'or ou de l'argent fous une forme quelconque : $f 1$ l'on en trouve, on le fond auffi-tôt, fans avoir égard au prix que l'antiquité peut donner à la pièce. Cette cupidiré a caufé la ruine des édifices, qui, par leur folidité auroient duré plufieurs fiècles, en les abandonnant à l'action de l'air \& du tems. 


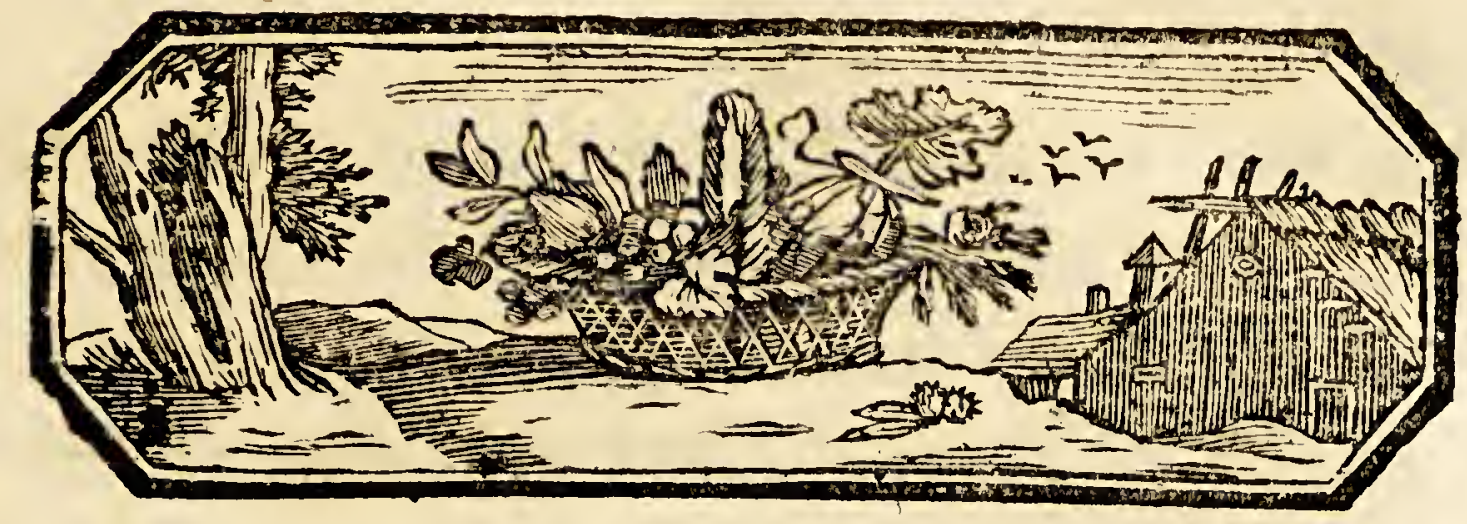

\section{DISCOURS VINGT-DEUXIEME.}

De la Langue des Indiens; du jugement qu'on peut porter de la première population de l'Amérique.

D

Es perfonnes très-verfées dans la langue Hébraïque croyent, fans héfiter, que la langue Quichua a beaucoup de rapport avec cette ancienne langue. Ces Savans en jugent par les termes que les livres facrés nous ont confervés : la prononciation \& le ton étant très-anologues, il y a un grand nombre de mots qui préfenteroient cette reffemblance. Si donc on jugeoir de ces langues par ce principe, il n'eft pas donteux que les deux langues auroient entr'elles les rapports les plus proches. Mais il refte à favoir fi la fignification des mots hébreux eft précifément la même que dans l'autre langue. Les mots qu'on a pris de la Bible pour en faire la comparaifon avec ceux qu'on croyoit les mêmes dans la Quichua, font juftement prefque tous des termes fur le fens defquels les Interprètes de l'Ecriture ne s'accor- 
dent pas, ou dont ils n'ont pu déterminer la fignification correfpondante dans l'autre langue. Mais il n'eft pas étonnant que des mots dont la forme eft la même, n'aient pas le même fens dains les deux idiomes.

Pour ponvoir prendre un pari à cer égard, il faudroit que des gens qui auroient appris la langue Quichua dès leur enfance, \& qui riendroient tonte la force de fes mots, poffédaffent aufli au même degré la langue Hébräque : alors, la comparaifon quils en feroient pourroit être jufte. Le rapport des termes de quelques idiotifmes, des dénominations des chofes, meneroit la connoiffance de l'analogie que ces deux langues auroient entr'elles, \& l'on ne feroit pas embarraffé d'expliquer par ce moyen plufieurs termes Hébreux dont le fens eft encore obfcur.

Il y a dans la langue Quichua une expreffion; ou un terme qui paroît un des premiers que prononcent les enfans, quand ils veulent commencer à parler. Ce terme, commun aux enfans. de toutes ces nations, eft inulité hors de l'Amérique : c'eft apa, racine du verbe apani, apanqui, c'eft-à-dire, porter ou apporter; l'impératif eft apanmui. Si l'on y fait bien attention quand les. enfans le prononcent, on voit qu'ils demandent qu'on approche d'eux, ou qu'on leur donne quelque chofe. On n'y fait pas d'attention, parce qu'on 
$V$ I N G T-D E U X I E M E. $\quad 107$ en ignore le rapport : mais les Indiens qui le comprennent par leur propre idiome, donnent ì l'enfant ce qu'il defire. Apachiy eft l'impératif du mot qui fignifie renvoyer ou envoyer; apariy celui du mot qui fignifie prendre ou emporter. Ainfi pour demander, envoyer, prendre, ils commencent les verbes par les deux fyllabes apa. Le mot mama; qui eft un des premiers de tous les idiomes du monde, fignifie aufi la mere chez les Indiens. Quoique les enfans de toutes les nations commencent a parler par ce mot naturel, ils le varient ou le changent par la fuite de lâge, pour en adopter un correfpondant, au lieu que les Indiens le confervent toujours dans toute fon expreflion.

On obferve auffi, à cet égard, que les Indiens ne changent pas dans le langage commun ou ufuel différens autres mots qu'ils prononcent naturollement dans l'enfance avant toute inftuction, \& que ce font les noms quils donnent aux chofes. Il réfulte de-là que fi le langage des Indiens n'eft pas celui qui fe rapproche le plus du langage primitif, c'eft au moins celui qui reffemble le plus à la prononciation des enfans.

Les mots de cette langue font très-coutrts, \& ont en même tems beaucoup de fignifications déterminées par la variété des tons ou de laccent. La variété de nombie de leurs exprefrons 


\section{8}

D I s c O U R 5

ne confifte que àans la répérition de la fyllabe précédente, \& dans l'accent final, ou dans l'addition d'une lettre à la fin, ce qui détermine le fens qu'ils y attachent. Par exemple, acacaus fignifie cela (ou $i_{i}$ ) me brûle; ce quils difent ou du foleil, ou du feu, ou des alimens trop chauds: alalau, j'ai froid : ananau, je fuis aftligé. Ces trois mots expriment ainfi chez eux les fenfations principales, favoir de la chaleur, du froid, \& de la douleur.

Mais, en changeant leur finale, ils auront une autre fignification. Alau-ni-huay, , ayez pitié de moi; anallau, que cela elt beau, doux! \& ainf de nombre d'autres. On a fait une grammaire \& un dictionnaire de cette langue; on a aufi écrir fur fon origine \& fes beautés avec toute l'étendue que demandoit le fujet.

Ce langage eft doux \& tendre; \& il eft for douteux qu'on puiffe en trouver un fi riche en expreffions de flatteries \& de careffes : on n'y voit point de longues périodes, ni de phrafes pompeufes. Quoiqu’affez bornée en général, cetre langue eft élégante, claire \& agréable, \& n’a rien pris des langues modernes, puifque cela n'a pas été poffible jufqu'ici. On penfe donc que c'eft une langue primitive, qui tient à certain point de l'Hébreu, comme j'ai dit qu'on le préfumoir. Les termes de cette langue fe trouvent dans $t_{a}$ 
$\nabla$ I N G T-D E U X I E M E: 109

Quichua dès fon origine : ainfi la première nation qui a peuplé ces contrées doit avoir été voifine des Hébreux, fi elle n'étoit pas même une branche de ceux-ci : fi elle en étoit feulement voifine, elle a pu en prendre les termes qu'elle aura confervé dans fa langue.

Cette conjecture elt appuyée par d'autres circonftances communes aux Indiens \& aux Juifs; telles font linclination à mentir \& à tromper. En effet, on ne peut s'arrêter à rien de ce que ces Indiens difent, tant ce vice eft inhérent chez eux. Ils affurent \& nient aufr facilement la même chofe: la tromperie leur eft finaturelle, qu'il faut beaucoup d'attention pour s'en garantir : ils font des plus féconds en rufes \& en détours lorfyuils font furpris en malverfation; on les voit flatter du ton le plus infidieux pour fe difculper, \& avec toutes les getticulations les plus capables d'en impofer. Tout cela eft commun aux Juifs : il femble que ce foient chez les uns \& les aurres des vices héréditaires, \& même aufi naturels que leur exiftence.

D’après ces réflexions, on peut admettre ce qui a été dit de l'antiquité de certe langite. Avant qu'on eût cultivé les fciences \& les talens naturels de l'homme, les langues qui exifoient devoient être fimples, peu riches, mais exprellives, clégantes: on fuppléoit au peu d'abondance des 


\section{0}

D I s c o v $R$ \&:

termes par les différens tons qu'on domnoit à une même fyllabe, pour en faire fentir les diverfes acceptions, \& l'on trouvoit ainfi dans une langue pauvre \& précife toute la richeffe, la douceur \& le ton affectueux des idiomes modernes.

La langue Quichua eft celle qui fe parle généralement au Pérou; mais les diverfes Nations Indiennes ont aufli chacune leur idiome, comme les autres peuples fur la furface du Globe. Néanmoins, il eft rare qu'on ne trouve pas dans une langue des mots fembiables à plufieurs d'un autre idiome. La différence apparente qu'ón y remarque, ne confifte que dans l'exprefion plus ou moins variée.

Quoique le langage des Indiens du Nord différe entièrement de la Quichua, \& foit prononcé avec plus de force \& même di gofier, on y retrouve cependant beaucoup de mots de la langue Pćruvienne. Or, il eft fingulier que, malgré de fi grandes diftances, ces peuples confervent encore ces preuves de l'identité de leur race, \& fafrent voir par-là qu'ils defcendent de la première mation qui peupla l'Amérique. Ceci démontre aufi ce que j'ai dit fur leurs ufages, leurs coucumes; \& qu'ils ont confervé les chofes telles qu'ils les avoient à leur origine; mais entr'autres chores la langue. 


$$
V \text { I } N G G \quad T-D \quad E \text { U X I E } M \text { E. I I }
$$

Les propriétés de la langue Quichua font les mêmes que celles de la langue Hébräque, qui eft forte dans fes exprefions, abondante dans le peu qui nous en refte, élégante, douce, \& concife. Si cette analogie ne prouve pas qu'elles dérivent tontes deux de la même fource, elle montre au moins que la Quichua lui reffemble beaucoup, \& qu'elle eft une de celles qui approche le plus de la langue primitive.

La Quichua eft répandue dans la partie haute du Pérou : c'eft auffi celle que les habitans parlent de préférence, \&r gui leur eft la plus familière. L'Efpagnole s'y parle auffi, mais affez mal, furtout quant à l'accent. Ce défaut vient de l'autre langue, qui eft naturelle à ces peuples. Les femmes s'expliquent plus facilement avec la Quichua, même dans toutes les claffes. Plufieurs caufes y contribuent : elles fe font fervir par des Indiens des deux fexes, \& par des métifs. Dans la partie baffe, au contraire, le fervice fe fair par des Nègres ou des Négreffes, ou par des individus de ces caftes.

La Quichua n'eft pas la même dans toutse l'érendue de la partie haute; elle diffère aufi de celle du Pérou dans le royaume de Quito \& les environs, ou elle s'écarte de l'acception des mêmes mots, \& du nom même des chofes. La vraie Quichụa eft celle du Pérou; de forte que 
par le moyen de cette langue on peut entendre les autres, au moins dans les chofes ufuelles $\&$ les plus nécêffaires. Les verbes \& la conftuction font les mêmes; il n'y a de différence que dans la prononciation.

Il a été impolfible jufqu’ici de déterminer com. ment les premiers habitans de l'Amérique y ont paffé après le déluge univerfel. On s'eft beaucoup occupé de trouver dans les climats les plus froids du Nord une continuation de terre qui communiquât de l'extrémité orientale de l'Afie avec le continent de l'Amérique feptentrionale. On penfoit que c'étoit de ce côté-là que les premiers habitans de l'Amérique avoient paffé. D'autres ont cru trouver un paffage par l'extrémité des terres du cap Boïador en Afrique, \& par les Canaries, prétendant que ces premiers habitans avoient fait un trajet de huit cens lieues pour arriver aux Inles Barlovento, par des terres écroulées depuis fous la mer qui remplit à préfent ce vaite efpace entre l'Afrique \& l'Amérique : ainfi ces premiers colons feroient, felon quelques Ecrivains, des peuples de l'Europe; felon d'autres de l'Afie, ou enfin de l'Afrique : il eft certain qu'ils font fortis de l'une de ces trois parties du Globe.

Mais de quelque manière qu'on veuille déterminer ce palfage, les difficultés fe préfentent en foule; 
$\checkmark$ I NG T-DEUXXE M E. IN foule; \& il eft fort difficile de les réfoudre, $\mathfrak{f}$ l'on ne fuppofe pas qu'ils aient fait un trajet de mer plus ou moins long : or ils y ont paffé; il faut donc auffi qu'ils n’aient pas rencontré les difficultés qui exiftent actuellement.

Nous tenons pour un fait pofitif \& avoué, que les efpèces vivantes qui fe répandirent fur la terre pour la repeupler, furent toutes fauvćes dans l'arche, par une difpofition particulière de la $D_{i}$ vinité; que cette arche flotta fur les eaux jufqu’à ce qu'elles euffent affez diminué pour laiffer appercevoir la terre; \& qu'elle s'y arrềta. Nous fa. voris auffi que quand la terre fut déja affez repeuplée, les hommes conçurent le vain projet d'élever la tour de Babel, comme un figne de ralliement \& un refuge, en cas que les eaux couvriffent encore la terre.

Mais avant de former ce projet, ils avoient ett fous les yeux l'arche dans laquelle Noé s'étoit fauvé avec fa famille : il étoit donc naturel qu'ils en fiffent de femblables, quoique moins grandes, \& pour le mềme ufage. En laiffant mềme de côté ce motif, cette arche, dont le fouvenir s'étoir perpétué dans les âges qui fuivirent le déluge, donna aux hommes la première idée de la navigation, \& des vaiffeaux capables de porter non-feulement des hommes, mais même Tome $I I$. 
des animaux de toute efpèce : au - moins effayat. on d'abord des barques capables de foutenir fur l'eau'ceux quiles conduifoient. Il eft probable qu'on tâcha d'imiter le vaiffeau de Noé, \& qu'on s'expofa ainfi fur les rivières, enfuite fur les mers, pour favoir s'il y avoit d'autres terres femblables à celles qui avoient été peuplès les premières, \& comnoitre ce qui s'y trouvoit : l'arche leur montroit comment ils devoient ajufter, lier les bois néceffaires, la forme que ces vaiffeaux devoient avoir pour flotter fur les eaux, \& la diftribution de l'intérieur.

C'eft ainfi qu'on apperçoit, fans s'écarter de l'ordre naturel, comment la population de l'Amérique a pu fe faire. Les fuccès de Noé les raffuroient ces premiers navigateurs fur l'entreprife, en éclairant leur raifon.

Il n'eft donc pas befoin de fuppofer que ces colons ont paffé par les froids climats de la zone glaciale, \& qu'il n'y a eu de mer entre les deux continens, que quand les terres fe furent affaiffées après avoir donné parrage à ces voyageurs: laiffons donc là les côtes les plus orientales \& feptentrionales de l'Afié, de même que les côtes les plus feptentrionales \& occidentales de l'Amérique : nous chercherions en vain leur embarquement \& débarquement fur ces parages. 
$\checkmark$ I N G T-D E U X I E M E II

Mais il ne répugne point que les promiers colons aient tranfporté avec eux des animaux de différentes efpèces fur leurs vaiffeaux, foir à deffein de les tranfporter pour leur ufage, foit pat hafard : ignore-t on que les Efpagnols ont tranfportéen Amérique plufieurs efpèces quin'y étoient. pas, qui s'y font très-multipliées; il n'y a donc rien d'impoffible dans tout cela.

Il eft plus naturel de croire que les hommes de ces tems-là ont confruit de grands vaiffeaux, \& ont navigé, que de prétendre quils ne lone pas fait; \& que ce ne fut quaprès plufieuts frecles quils en ont conçu l'idée. Ils avoient un monument qui leur fervoit de modèle : ils n'ignoroient pas ce que pouvoit porter un vaifeau, $\&$ que les vagues les plus fortes ne le démembroient pas. L'art de joindre plufieurs pièces de bois de manière que l'eau n'y pénétrât pas, leur étoit aufifi connue : le modèle étoit fous leurs yeux, \& bieri plus infructif qu'il ne l'eût éré plufieurs fiècles après. Quoique nous ayons-perdu toures les dates de ces tems \& de ces circonfances, il eft certain qu'on a conftruit des vaiffeaux, quon a de tout tems équippé des flottes nombreufes, \& quon a traverfé les mers, malgré la liardieffé de l'entreprife, hardieffe qui ent atteltée par les Ecrivains les plus anciens. 
L'Amérique pouvoit donc être facilement per plée par ce moyen, dès les premiers âges poltérieurs au déluge: c'êt aufi par ces expéditions maritimes que ce font peuplées les Ines nombreufes éloignées des continens, ifles qu'on ne connoît pas encore toutes, comme le prouvent les nouvelles découvertes qu'on fait tous les jours, fur-tout dans les mers du Sud.

Rien de fi facile que de fe rendre en Amérique, en partant des pays qu'elle a à l'Orient: les vents font en tout tems des plus favorables \& foutenus, de forte qu'un vaiffeau qui quitte les côtes méridionales de l'Europe ou de l'Afrique, n'a, pour-ainfi-dire, qu'à s'abandonner aux vents, \& il ira droit fur les côtes de l'Ámérique, plus ou moins éloignées de l'Equareur, entre les deux Tropiques: il ne faut pour cela ni boulfole, ni confidérer les étoiles dans le deffein de fe diriger, car les vents qu'on appelle brifes, fouflent toujours de l'Orient depuis les Canaries : d'ailleurs le continent de l'Amérique occupant toute la partie du globe qui eft comne depuis le Nord jufqu'au cinquante-cinquième degré dans l'hémifphère méridionale; il falloit néceffairement que les anciens navigateurs qui s'abandonnoient à ces vents, ou de gré ou de force, abordaffent dans l'un des parages de ce continent. 
$\checkmark$ I N G T-D E U X I E M E: II

Lorfque le globe commença à fe peupler de nouveau, les différentes familles devenues autant de peuples, ont été forcées de fe fépater pour chercher du terrein, \& de paffer ainfi d'une contrée dans une autre; elles l'ont fait tant par terre que par mer, en imitant le vaiffeau dont j'ai parlé, \& qui avoit confervé toutes les efpèces vivantes. Abandonnés aux vents \& aux courans, ces navigateurs fe trouvèrent, comme l'archie, à la merci des élémens, jufqu'à ce qu'ils apperçuffent une terre où ils pouvoient defcendre. Quoique l'arche eụt été guidée par la main de Dieu même qui l'avoit fait exécuter, les hoinmes ne s'arrétèrent pas à cette circonftance. Portés à imiter ce qu'ils voyent, cet exemple leur donnọit en lui-même affez de confiance pour qu'ils fuiviffent l'impulfion de leur curiofité, \& le defir qu'ils avoient conçu de fe rendre maîres d'un pays qu'ils alloient chercher au hafard.

Lorfqu'il fe fît écoulé certain tems depuis le départ de ces avanturięrs, \& que leüs compatriotes virent qu'ils ne revenoient pas, ne donnoient pas de nouvelles du pays oti ils étcient arrivés, ils craignirent fans donte les fuites de ces trajets, \& ne voulurent pas comir les mêmes. rifques après eux, On n'auroit de même, point fuivi la découverte de Colomb, s’il n'éroit pas.

$$
\mathrm{H} ;
$$




\title{
I 18
}

\author{
D I s c o U R s
}

revenu de fon premier voyage, pour donner connoiffance des terres qu'il avoit heureufement découvertes.

Cẹs craintes empêchèrent de s'expofer, firent ceffer la confruction des grands vaiffeaux, \& l'on ignora enfin l'art d'en faire de femblables. La navigation de long cours fe ranima par la hardiefre des Argonautes, guidés en parrie par la forme des perites barques, en partie par les craditions obfcures qui s'étoient confervées des anciens tems, On avoit alors quelque théorie fur les étoiles, fur le cours des aftres; l'aftro= nomie enfin prenoir quelque forme en Grèce. Ce fut avec ces connoiffances qu'on commença à reconftruire des vaiffeaux capables de fillonner les mers avec sûreté. Or ces connoiffances furpaffoient infiniment celles quavoient cues les premières nations pour diriger leurs courfes.

Cenx qui pafsèrent ainfi en Amérique, ne pouvoient en revenir avec le même vent qui les y avoit conduits : favorable pour aller, il s'oppofoit à leur retour. Il ent probable que ces gens ignoroient prefque totalement la manœuvre d'un yaiffeau, \& la manière de prendre le vent pour yoguer par des rhombes contraires à ceux d'où il venoit. Ils furent done forcés de refter dans le pays gu'ils rencontrèrent, \& de renoncer à toute 
$V I N G T-D E U X I E M E$.

idée de revoir un jour les parages quilis avoient quittés. Sans doute qu'en s'expofant en mer, ils n'avoient pas préfumé que la terre où le vent les pouffa éroit fi éloigné, \& qu'ils ne pourroient pas en revenir.

Arrivés dans ce pays, ils confidérèrent la longueur du trajet qu'ils avoient fait, les obftacles qui s'oppofoient au retour, \& fe décidèrent enfin à refter où ils étoient. Ces terres étoient probablement les Ines Barlovento. Infenfiblement ils pafsèrent dans le continent fur de petites barques, \& peuplèrent ces contrées dont ils étoient devenus les premiers maîtres : ils y apportèrent avec eux leurs ufages, leurs coutumes, leur induftrie nationale; les uns étoient des hommes encore groffiers, farouches; les autres plus dociles, plus fociables. Les premicrs fe fixèrent probablement dans les pays de montagnes, couverts de bois, oì fe retirèrent les bêtes féroces \& les autres animaux nuifibles. Les feconds fe fixèrent dans les pays plus découverts, où il n'y a que peu ou point d'arbres, comme dans la partie baffe du Pérou, qu'on appelle Vallées, \& dans la haute, où il n'y a pas non plus de forêts; \& par conféquent point de bêtes féroces.

Etablis en Amérique, ils ne purent avoir aucune communication ultérieure avec l'Europe ni

$\mathrm{H}_{4}$ 
120

D I s c o u is

avec l'Afrique, en partant des côtes orientales dư Nouveall-monde; ils ne favoient pas naviguer par différens rhombes: l'ufage de la bouffole étoit inconnu : its étoient mêmes incapables de fuppléer à ces moyens par la connoiffance des étoiles, par la manière de difpofer les voiles dans un fens où elles peuvent faire marcher le vaiffeau fous un vent contraire. Or, le vent n’étant pas favorable entre les Tropiques, \& ces Colons ne fachant prendre une autre route où le vent ne fût pas conftamment contraire, il fallut renoncer à tout autre pays : mais, en même tems, celui où ils éroient arrivés refta ignoré, comme auparavant, de ceux qui habitoient les autres parties. du Globe.

Les mêmes difficultés fe font préfentées à ceux qui ont été jettés dans les Iffes Philippines, $\&$ dans celles dés Larrons, entre la partie orienzale de l'Afie, \& l'occidentale de l'Amérique; car on eft obligé de gagner certaine hauteur pour rencontrer des vents moins contraires. Ainfi tous ces Colons furent contraints de refter où le fort les avoit conduits, \& ils oublièrent mệme qu'il y eut d'autres terres que celles qu'ils habitoient.

Les veints qui viennent de l'Equateur \& des paragẹs qui font un pẹtu plus au Nord, jufque vers 
$\checkmark I N G T-D E U X I E M E$ Y TH les côtes où l'A mérique méridionale s'étend, dans la mer du Sud, ces vents, dis-je, foufflent conftamment \& en toux tems, du Sud au Nord, à la diftance de quatre-vingt à cent lieues des côtes. Depuis Mai jufqu'en Novembre, ils fuivent le même cours entre l'Equateur \& les côtes dẹ Panama; depuis Décembre jufqu'en Mai, ils foufflent du Nord au Sud dans ce dernier efpace, \& recommencent ainfi ordinairement à fouffler jufqu'au troifième degré de latitude Sud : c'elt ce qu'on appelle Brifes. La même chofe arrive fur les autres côtes qui font une inflexion pour former l'Amérique feptentrionale. Ici ils fuivent tels cours, là tel autre, mais toujours conftamment: c'eft pourquoi, lorfqu'il s'agit de faire de longues. traverfées, il faut de toute néceffité aller plufieurs. fois contre le vent, pour rencontrer les vents les moins contraires à la route qu'on fait vers telle ou telle contrée; mais toutes ces opérations demandent des connoiffances nautiques \& celle des mers, ce que n'avoient pas les premiers hommes qui ont été jettés fur les côtes de l'Amérique. Quand ils l'auroient tenté, jamais ils ne feroient revenus aux côtes d'où ils étoient partis, à moins que, par un effet miraculeux de la Providence, le cours régulier des vents n'eût éțé changé. 


\section{DIS.O. URS}

Comme il eft naturel qu'un vaiffeau qui s'éloigne un peu des 'côtes méridionales \& occidentales de l'Europe, ou des côtes occidentales de l'Afrique, marche directement vers les Inles Barlovento, il feroir contre nature que ceux qui feroient dans les parages de ces Inles, \& qui s'abandonneroient au vent, arrivaffent en Afrique ou en Europe.

Cette circonftance nous donne lieu d'admirer les voies de la Providence, qui ayant pu arrêter l'arche, après le déluge, fur les hautes cimes des Cordillères de l'Amérique, ne le permit pas, quoiquie ces montagnes euffent été les premières découvertes, puifque ce font les plus hautes. Mais il falloit alors que Dieu fit un fecond miracle, en donnant un cours contraire aux vents, qui fcufflent en général d'Orient en Occident dans toute l'étendue de la Zone torride, \& dans les grandes mers, mais en des fens différens \& variablement, felon les faifons, dans les autres parties du Globe. Or, donner aux venis une direction contraire, c'ent-à-dire d'Occident en Orient, cétoit renverfer l'ordre de la Nature, \& changer diamétralement la première impulfion que le globe avoit reçue de la main de Dieu même. Dieu voulut donc oue cette arche defcendît dans un lieu du vante continent qui comprend trois 


$$
\text { VI N G T-DE U X Y E M E: I2 }
$$

des quatre parties du Globe, C'étoit de-là que les hommes \& les animaux devoient paffẹ un jour avec eux dans le continent qui étoit féparé des trois autres parties, \& tout pouvoit fe faire dans un ordre naturel.

Chriftophe Colomb entreprit la découverte de l'Amérique, d'après les notices \& les journaux (ou routiers) qu'il eut d'un Pilote qu'il logea chez lui dans l'inle de Madère; il avoit fụ par ces inftructions qu'il y avoit des terres de ce cồté-là : ce pilote y avoit été jetté par les vents. Quoiqu'on ignore comment ce pilote fit la route; il eft vraifemblable que, paffant alors des Açores aux côtes de Portugal \& d'Efpagne, les vents de Nord le prirent dans une de ces traverfées; \& le portèrent à une petite latitude où les vents d'Oueft foufflent conftamment, \& qu'étant alors dans leur cours, ils le forcèrent; fans qu'il pût regagner la côte d'où il étoit parti : ainfi il arriva malgré lui aux terres qu'il apperçut.

L'exemple de ce Navigareur \& de Colomb qui le fuivit, tous deux vivans dans les tems modernes, nous montrent aflez clairement qu'un hafard qui atriva dans un tenis où l'on connoiffoit la navigation, put arriver encore plus facilement à des gens qui n'y entendoient rien. Cẹux 
qui pafsèrent en Amérique dans les âges les plut reculés, avoient probablement de petits vaiffeaux tels que ceux de ces deux Navigateurs, peutêtre mềme de phis grands, quoiquilis ignoraffent l'art de les conduire, \& de prendre des routes détournées \& plus longues pour arriver dans une contréé.

Ce furent en partie des hafards, les courans; une légère connoiffance de l'aftronomie, \& les règles de la navigation, qui apprirent à ces deux Navigareurs à chercher la route qui devoit les ramener en Europe; car, pour revenir, ils navigèrent par le canal ou détroit que font les Inles Barlovento, \& fe foutinrent alors à une hauteur convenable pour chercher d'autres vents que ceux qui les y avoient amenés. Ils favoient déjà que depuis le vingt-huitième degré jufqu'au trentième, latitude Nord, il règne d'autres vents que depuis cetre latitude jufquà l'Equateur. Ils ne pouvoient pas l'ignorer, puifqu'ils alloient ordinairement à Madère, aux Ifles Tércères, qui fort entre le trente-deuxième \& le quarantième degrè, \& où ils favoient que les vents qui foufHoient en certain tems du Nord, Nord-Oue \& de l'Oueft, venoient, dans d'autres, de parages oppofés, fans néanmoins être conftans \& invariables, comme ils le font près du Tropique 


$$
\text { VI N G T-OD E U X I E M E. I }
$$

dans la Zone tempérée. Ils favoient, en outre, prendre les hauteurs par les étoiles, \& toutes les règles qu'il falloit fuivre pour diriger un vaiffeau, \& le conduire où ils vouloient.

Il ne leur étoit donc pas fi difficile de trouver la route qu'ils devoient fuivre pour leur retour, en fe tenant aux hauteurs où l'expérience leur avoit appris quils trouveroient les vents qui les rameneroient aux Açores ou en Europe. Si le Pilote qui fut jetté fur des terress inconnues ne fut pas revenu, Colomb n'en auroit eu aucune, connoiffance, \& n'auroir pas entrepris fon voyage. Si Colomb étoit refté avec fon équipage, on aur roit été confirmé dans lidée qu'on avoit de l'impoffibilité de cette découverte, comme on le foutenoit d'abord; ces prétendues terres auroient été regardées comme une pure fable, \& l'on auroit foutenu que les téméraires avoient péri en mer. Il eft probable qu'on a penfé de même de ceux quii les premiers ont pafré dans ce continent où le hafard les jetta; \& que c'eft ainf que toute l'Amérique, une grande partie des Ines éparfes dans la mer, ont été peuplées. Si lon a découvert des Ines inhabirées, c'eft que le hafard n'y a pas jetté cenx qui ont abordé dans celles qui le font.

La navigation eft fr ancienne qu'on ne peut en lécouvrir l'origine, fi lon ne remonte pas direc- 
126

\section{I s c o t R s}

tement à l'arche de Noé. L'hiftoire nous fait mention de vaiffeaux \& de navigateurs, dans tous les âges \& dans tous les tems. On fe fervoit de bateaux ou de barques fur les grandes \& perites rivières, foit pour paffer d'une rive à l'autre, foit pour remonter les rivières ou fuivre leur cours, foit pour naviguer fur les lacs qui étoient au milieu des terres \& y pêcher, foit pour aller en mer, même affez loin des côtes. C'êt ainfi que chaque peuple a eu fa manière de franchir les eaux, felon fon local \& fon induftrie.

On obferve que les Indiens occidentaux ont prefque par-tout préféré un local le long des Heuves, deslacs, \& de la mer, pour pouvoir $y$ pêcher avec plus de commodité, parceque la pêche faifoit néceffairement la plus grande partie des reffources qu'ils avoient pour vivre. Ils ont eu des barques de formes \& de grandeurs différentes: ils s'abandonnent même à l'élément aqueux avec tant de confiance, qu'on les croiroit des amphibies. On les voit traverfer les mers dans des petits canots, où tout autre qu'eux n'oferoit jamais s'expofer : dés leur enfance ils font grands nageurs, \& auff agiles dans l'eau que les poiffons.

Ils font leurs barques de branches d'arbres de différente grolfeur, d'ćcorce d'arbre, de feuilles, 


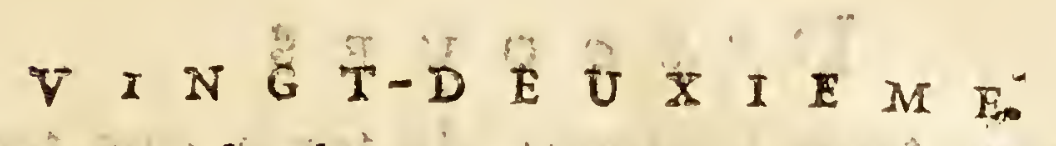

\& de peaux de loups marins, \& d'autres matières. C'eft fur ces vaiffeaux fragiles quils s'expofent hardiment en mer, \& vont anfil loin qu'ils vétlent fans être arrêtés par les flots. Ils vont auffi à la pêche fur un ímple morceau de bois rond, \& gardent l'équilibre fi adroitement, que le bois quil femble pirouetter, nè les fait pas tomber; on diroit même qu'ils ne remuent point. Ils font auffi actifs à la pêche, que difpofés à fe métre en mer. Si leur barque fe renverfe, ils ne perdent pas la tête; ils nagent \& la remettent fur l'eau pour y rentrer auffitot. On a obfervé que les peuples Sauvages font d'autant plus hardis nageurs \& accoutumés à l'eau, qu’ils font plus barbares.

On rencontre dans les mers du Sud les Ifles de Jean Fernandèz, à cent lieues de la côte de Valparayfo, qui eft la plus proche. La mer eft trèsorageufe $\&$ toujours agitée dans cet efpace, parce que les vents du Sud y foufflent avec violence \& fans ceffe : voila pourquoi le trajet ent fort difficile à faire. En 1 738 ou 1739 , il s'y trouvoit un navigateur de ces mers, nommé Pierre le $\mathrm{Gu}$ : il s'y étoit rendu pour la pêche, parce qu'elle y eft très-abondañte. Il avoir diftribué rous les gens de fon equipage dans des canots quil avoit apportés fut fón vaifeau. Chaque ca- 


\section{D I 5 C $\quad \mathrm{U}^{2} \mathrm{R}$}

not portoit trois Indiens; de forte que tous ce gens pouvoient fe rendre le foir dans l'Ille avec la pêche qu'ils avoient faite fur les côtes pendant le jour, \& faler le poiffon. On s'apperçut un jour qu'il manquoit un canot: le Gu penfa qu'il étoir allé à l'Ifle de Fuera; éloignée de vingt lieues des côtes à l'Oueft. Ne le voyant pas revenir au bout de quelques jours, il ne l'attendit plus, \& le crut perdu. Lorfqu’il eût fini fa pêche; il fit voile vers Valparayfo, \& fut extrêmement étonné d'y trouver le canọt \& les Indiens. Ces. gens à qui il ne reftoit aucun parti avantageux à piendre dans le chagrin où ils étoient de fe voir fur cette Inle déferte, s'étoient enfin déterminés à gagner les côtes du Chili avec leurs rames feules, \& fans autres provifions d'eau \& de vivres que ce qu'il leur en reftoit pour un jour. Mais il leur falloit encore éviter la merorageufe, qu'ils favoient ne pas pouvoir traverfer. C'étoit donc une plus longue courfe quils avoient à faire, \& de nouveaux dangers à braver.

On pourroit citer nombre d'autres exemples de ce genre, pour prouver combien les Indiens $\&$ toutes les nations non cultivées, s'expofent aifément à des entreprifes aufli hardies.

11 eft donc très-vraifemblable que c'eft ainfi que les trajets de mer, plus ou moins longs, 
$\checkmark$ I N G TZD E U X I E M E. I29 ont été faits, lorfque l'Amérique fut peuplée la première fois. Les Indiens \& les autres nations barbares ont paffé d'un lieu à un autre avec la même hardieffe : d'ailleurs, il eft moins difficile \& moins dangereux de paffer des Ifles Canaries aux Inles Barlovento, que de Jean-Fernandez d̀ Valparayfo.

L'Ifle de Fer, l'une des Canaries, n'elt éloignée de la Martinique que de huit cens lieues : or, c'eft un trajet qu'on peut faire en treize jours, en comptant une demi-lieue par heure : fi même les brifes font un peu plus fortes qued'ordinaire il eft poffible de franchir cet efpace en moins de tems. La navigation y eft très-facile, vu la tranquillité de la mer; on n'y éprouve point de tempête; les vaiffeaux voguent rapidement, \& fans paroitre remuer : mais il en eft tout autrement pour paffer de Jean-Fernandez à Valparayfo. On pouvoit donc faire le paffage des Canaries à la Martinique fur des canots, avec bien moins de rifques que ce dernier trajet. La tranquillité de la mer qui fépare l'Amérique de l'Ille de Fer, lui a fait donner le nom de Golfe des Damies.

Mais la tranquillité de cette mer ne prévient pas encore toute objection. On demandera comment ont pu vivre ceux qui ont fait les premiers Tome $1 I$. 


\section{D I s c o U R $\mathbf{s}$}

ce trajet; car ne s'attendant pas à le faire, n'en ayant pas même l'idée, ils n'avoient fans doute pas affez de vivres pour cette longue courfe. Il faut donc favoir que les peuples fauvages, qui n'ont aucune règle dans leur vie, paffent quelquefois deux ou trois jours fans manger, \& font accoutumés à fupporter la faim, de forte qu'ils ne fouffrent point de dérangement lorfqu'ils font obligés de jet̂ner; ce qui leur arrive fouvent dans leurs propres contrées. On peut alfurer avec vraifemblablance qu'un jetune de dix à onze jours ne doit être pour ces gens que ce qu'eft un jeune de quatre ou cinq jours pour des peuples accoutúmés à vivre régulièrement : or, on a afrez d'exemples de longs jeûnes fur mer après des naufrages.

Cependant les premiers Colons qui ont paffé en Amérique n'ont peut-être pas été réduits à jeûner : s'ils ont entrepris ce voyage dans le deffein de chercher de nouvelles terres \& de s'en rendre les maîrres, ils ont dû faire quelques provifions pour quelques jours au moins. Ces provilions n'étorent fans doute pas confidérables, parce que les gens qui travaillent peu, confomment moins que les peuples civilifés, à qui il faut plus de nourriture pour foutenir leurs travaux. Si au contraire on penfe quills ont été jettés 
$V$ I N G I-D E U X I E M E. I3I dans ces parages éloignés, par le hafard \& malgré eux, ils l'ont probablement été loríqu'ils s'occupoient de la pêche, qui éroit pour eux, comme pour les peuples fauvages, le feul morif de s'expofer en mer. Le peu de poiffon quils avoient pris leur fuffifoir pour quelques jours; dailleurs on voit dans ces mers beaucoup de poiffons volans, qui s'élèvent en troupes hors des eaux pour éviter les Dorades \& les Taburons qui les pourfuivent : il en tombe toujours un certain nombre dans les vaiffeaux qui paffent. Il y a encore différentes efpèces de poilfons dont ils pouvoient prendre certaine quantité, \& s'alimenter pendant quelque tems, jufqu'à ce qu'ils trouvalfent des terres. De quelque manière qu'on envifage ce trajet, on voit donc qu'il ent très-poffible que ces gens arrivalfent aux Inles, fans trop avoir fouferc du jeûne.

Les Indiens civilifés mangent encore tout crud le poifon qu'ils apportent fur le rivage, \& nême en le prenant; ils tiennent certe coutume des anciens tems : cela prouve qu'ils peuvent mieux fe tirer de tous les inconvéuiens, que les peuples qui font habitués à manger leurs alimens après les avoir fait cuire. Le poiffon mangé crud eft plis nourriffant, \& caufe moins de foif que quand il eft affaifonné avec du fel, du bemre 
ou des graiffes, \& d'autres ingrédiens qu'on $y$ ajoute pour animer l'appétic.

Si l'on objecte que les hommes de ces âges anciens ne mangeoient rien de ce qui eût vie, $\&$ ne fe nourriffoient que de plantes, de fruits, il eft naturel de penfer que les Colons qui ont periplé l'Amérique, ont entrepris leur voyage dans le deffein de découvrir de nouvelles terres; car ils n'auroient pu avoir d'autre motif pour s'expofer en mer: mais, dans ce cas-ci, rien ne les empêchoir de faire certaines provifions, \& de les embarquer avec eux. Le long trajet qu'ils furent obligés de faire, fans s'y attendre, leur ayant peut-être fait confommer leurs provilions, il ne leur refoir d'autres reflonires que de prendre du poifon pour vivre, \& ce fut alors que l'urage s'en introduifit.

Mais il y a encore une raifon qui donne lieu de préfumer que les premiers Colons de l'Amérique y ont paffé par mer, \& non par terre : la voici. Les Ifles du Cap-Verd, qui font à cent lieues de l'Europe, \& les Açores qui en font à trois cens lienes, n'ont pu être peuplées que par des navigateurs; car il eft impolfible d'y paffer fans vaiffeaux. Or, ceci prouve évidemment que l'on entreprenoit anciennement des voyages d'affez longs cours, qui fe terminoient plus ou moins 


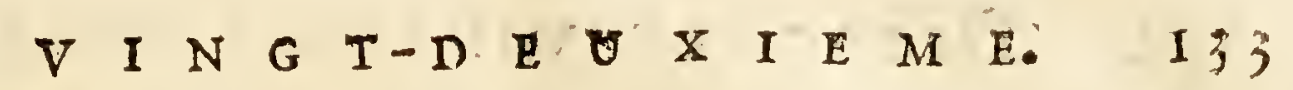
heureufement, felon la proximité des terres que l'on découvroit.

Les deux parties de l'Amérique, prifes enfemble, forment, autant qu'on les connoit, une Ine proprement dite : mais, fi l'on fuppole que cela ne foit pas, \& qu'elle tienne à l'Europe par le Nord, ou à l'Afie, ce doit être dans des parages très-éloignés, où la rigueur des cimats, les neiges, les glaces, ne permettent à aucune créature de vivre, \& où tout pallage eft impraticable.

Toutes ces raifons prifes enfemble, perfuadent donc que les premiers habitans de l'Amérique y ont pafré par eau, \& ceci parô̂t d'autant plus naturel, fi l'on veut fuivre l'ordre des évènemens \& l'analogie. Dieu ayant choifi l'arche de Noé comme l'infrument particulier avec lequel il voulut conferver toutes les efpèces de créatures vivantes, \& repeupler les terres qui devoient perdre leurs habitans dans le déluge, il eft vraifemblable que ce fut par un moyen fembiable qu'il répandic les nouveaux habitans fur la furface du Globe dans les contrées féparées par de valtes mers. 11 fuggèra à l'homme l'idée d'imiter ce grand vaiffeau, \& de fe rendre où les vues de fa fageffe le demandoient. La confervation des créatures eff fans doute un miracle aufí ćtommant que la 


\title{
I 34 DYSCOURS VINGT-DEUXIEME. création, \& une preuve qu'il donna à l'univers de fa fageffe infinie \& de fes deffeins impéné- trables, réparant par fa miféricorde ce que le bras de fa vengeance avoit détruit.
}

\author{
Fin d'Ulloa.
}

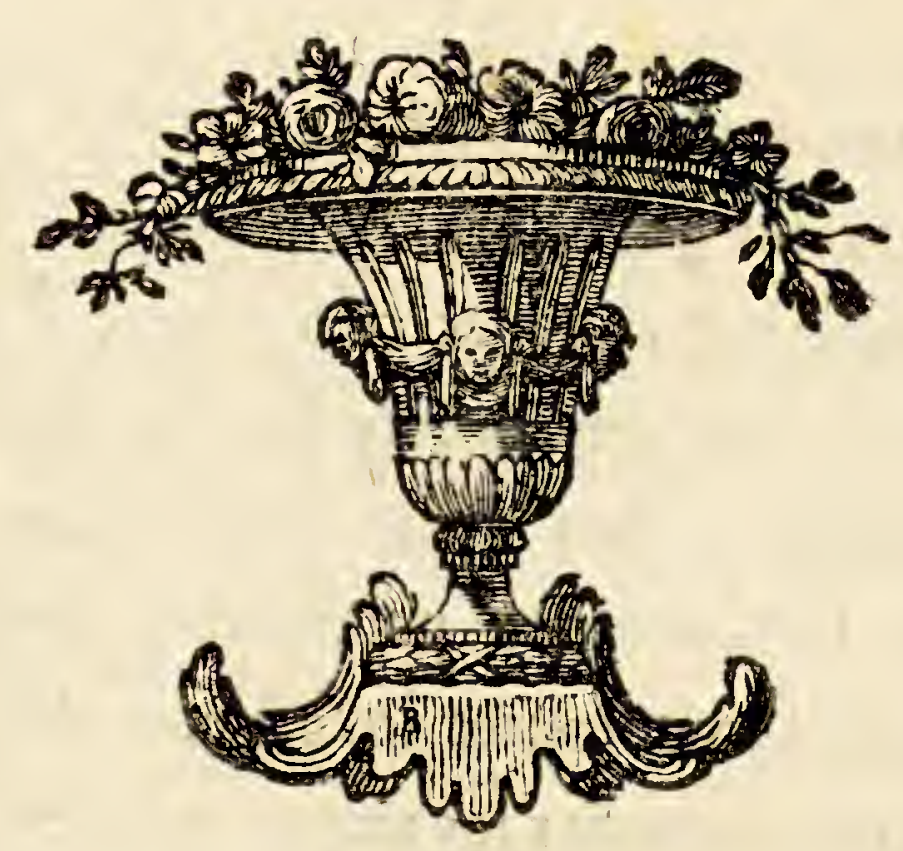


O B SERVATIONS

E T

A D D I T I O N S. 


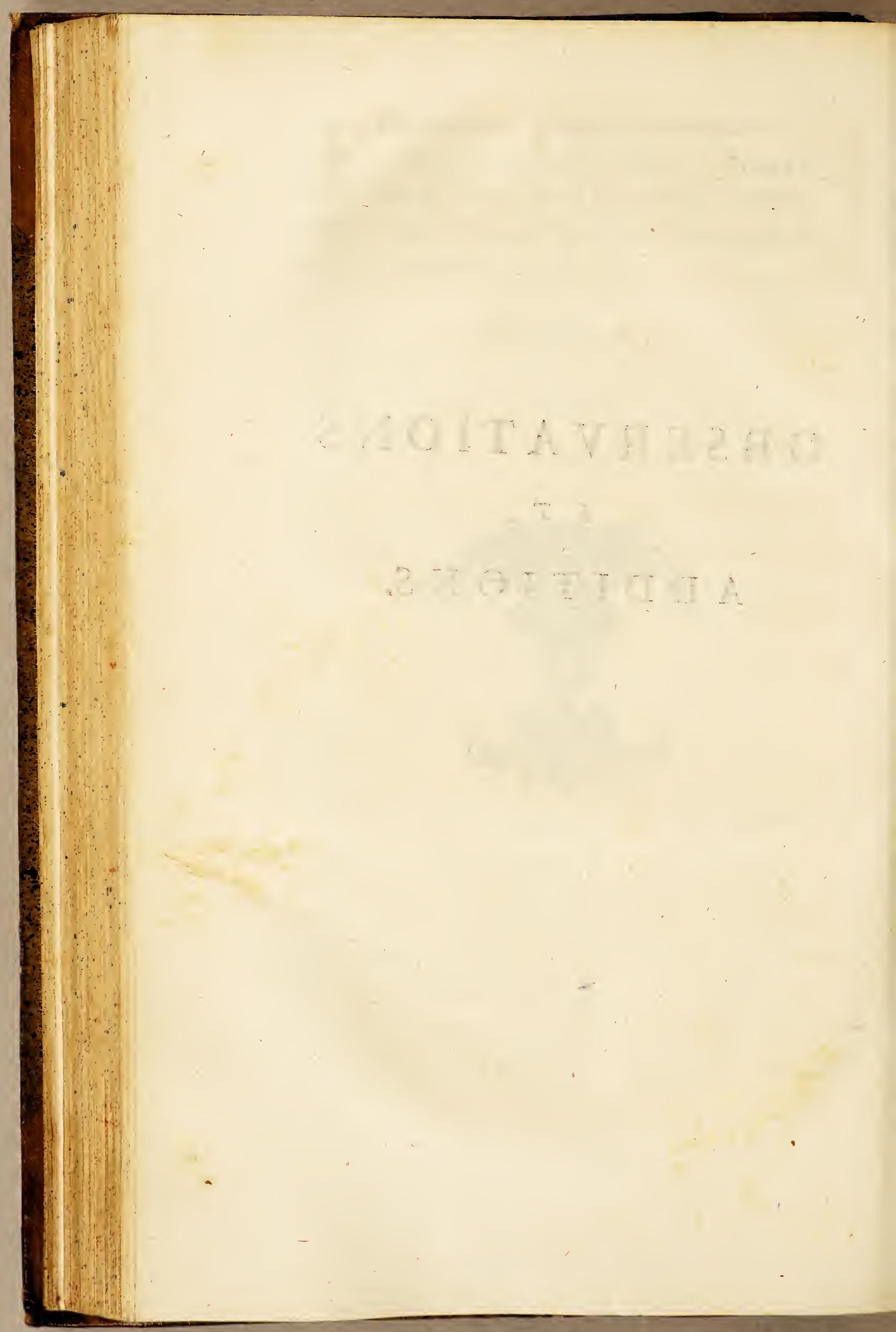




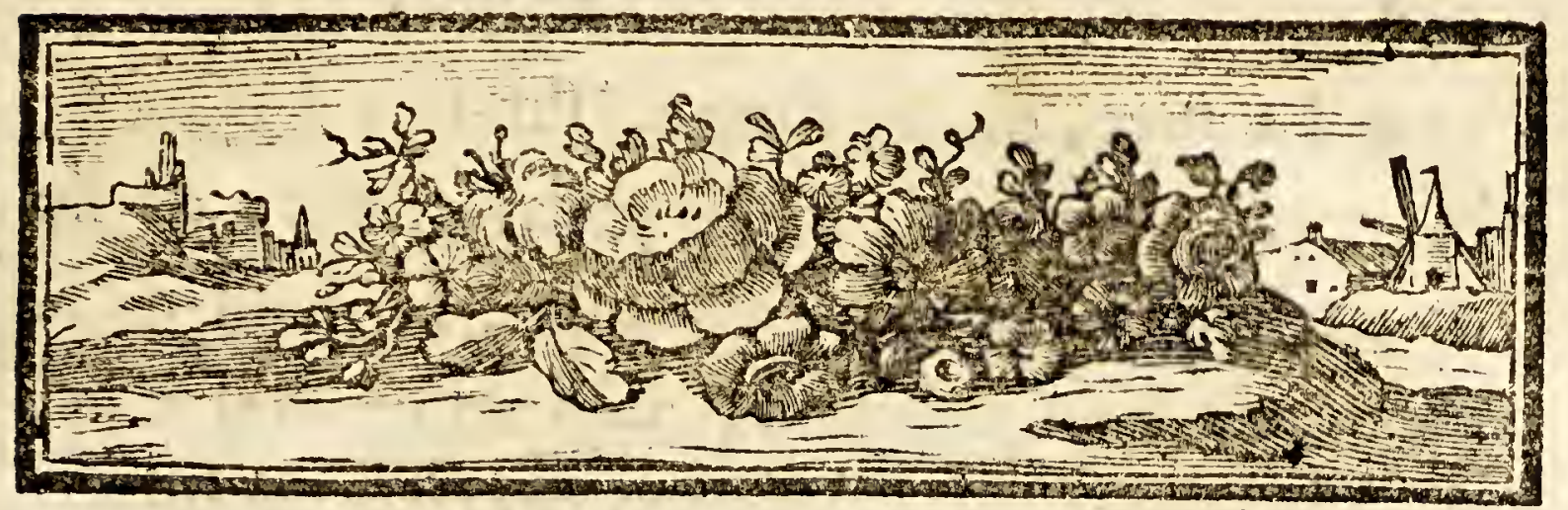

\section{OBSERVATIONS ET ADDITIONS}

$D E$

M. J. G. SCHNEIDER.

\section{GÉOGRAPHIE-PHYSIQUE.}

OBSERVATIONS fur le Difcours 11 . d'Ulloa.

$P$ marqué dans prefque tous les parages que la profondeur des mers étoir le long des côtes, dans le rapport du plan plus ou moins oblique de ces mêmes côtes; c'eft-à-dire, quê fi elles étoient très. efcarpées, la mer qui. les baignoit étoit très profonde. C'eft une remarque dont ils ont fouvent profité lorfqu'il s'agiffoit de jetter l'ancre. On trouve la même obfervation dans le Voyage de Dampier, P. II. pag. 476 . Elle n'a pas échappé non plus aux Habitans des côtes de la Norwège, comme noús l'apprend Pontoppidan, dans fon Hiftoire zaturallë de Nonwège, I. pag 


\section{Obfervations \& additions.}

123. La mer, dit-il, forme, fur-tout à l'Oueft, beaucoup de grands \& de petits golfes, de fix \& de huir à dix mille d'étendue. Le fond de la mer y eft bien différent; mais en général il eft dans le rapport de l'élévation des terres voifines: ainfi, pour eftimer la profondeur de l'eau, il fuffit de jetter les yeux fur le mont le plus proche, \&c. - Je ne m’arrêterai pas à examiner les exceptions dont cette règle eft quelquefois fufceptible. Pontoppidan effaie cependant de rendre raifon de la profondeur extrême de plufieurs de ces golfes, en difant qu'eile eft dûe à l'écoulement des eaux qui fe font précipitées des hauts promontoires à l'époque du déluge univerfel; du refte, c'eft à l'expérience à décider fi. le fond de la mer fe rapporte par-tout de même avec la fuperficie des continens. On peut confulter auffi ce qu'a dit le célèbre Bergman, dans fa Defcription phyfique du Globe. Part. I. pag: 539 .

OBSERVATIONS relatives aux Difcours $I I I$, IV \& V. d'Ulloa.

DAGEII \& fuiv. Ce que l'Auteur rapporte des propriétés de l'air des hautes montagnes du Péron, \& de leurs effets fur le corps de l'homme \& 
Obfervations Es addicions.

des animaux, s'accorde parfaitement avec les Obfervations d'Acolta, \& peut recevoir un nouveau jour de ce qu'il dit à ce fujer, liv. $I I$, chap. IX, pag. 143 de l'Édition de Maidrid. Après avoir parlé du vomiffement qu'on éprouve en mer, \& dont il croit que la caufe eft l'air même de la mer, il continue ainfi: "J'ai parlé de ce vomiffement, pour expliquer un fingulier efret que l'air ou le vent dominant produit dans certaines contrées des Indes Occidentales. On y éprouve donc le même effet que fur mer, mais à un degré beaucoup plus fenfible. Quelques perfonnes regardent cela comme une fable, d'antres n'y voyent que de l'exagération; mais je vais rapporter ce que jai éprouvé moi niême. Il y a au Pérou une très-haute chaîne de montagnes, qu'on nomme Sierra Pariacaca: j'avois ouii parièr des effers qu'elle produifoit fur le corps humain : je m'y étois donc préparé le mieux qu'il m'étoit pollible, d'après les détails des gens les plus expérimentés de ces contrées, \& qu'on y appelle Vaquianos. Malgré cela, je fus à peine fur la cime de ces monts, que j’ćprouvai une anxiété prefque mortelle, \&ije crus que jallois tomber en bas de ma mule. Nous marchions en allez grand nombre; mais chacun s'empreffoit de paffer cet endroit dangereux auffi promptement qu'il lui étoit poffible, fans s'oc- 


\section{Obfervations \& additions.}

cuper de fes compagnons de voyage : voilà pourquoi je me trouvai bientôt feul avec un Indien, que je priai de m'aider à defcendre de ma mule. A l'inftant je vomis, d'abord le manger que j'avois pris, enfuite des glaires, une bile jaune \& verte; enfin du fang, \& même avec un fí grand mal d'eftomac, que je crus que j’allois mourir.

Ce dérangement ne dura que trois à quatre heures. Nous arrivâmes alors dans un pays plìs bas, \& dans un climat plus avantageux. J'y retrouvai mes compagnons, au nombre de treize ou quatorze, mais fi abattus, que plufieurs demandoient à fe confeffer, croyant qu'ils n'avoient plus long-tems à vivre. Quelques-uns avoient mis pied à terre, épuifés de vomir; d'autres étoient morts au paffage. Un d'eux s'étoit jetté à terre, \& pouffoit les cris les plus amers, ne tenant pas à la douleur que lui avoit occafionnée la montagne de Pariacaca.

On n'y éprouve ordinairement aucun autre mal confidérable que ce vomiffement \& cette anxiéré, qui durent le tems qu'on met à paffer. On ęlt expofé à ces inconvéniens non-feulement fur 7acioute de Pariacaca, mais encore fur prefque toutes les cimes de cette Cordillière, qui fe prolonge jufqu'à cinquante lienes : cependant ce n'eft pas par-tout au même degré; c'eft fur-tour 
Obferyations \& additions.

en venant des côtes fur ces cimes: on $\backslash n$ 'a pas remarqué qu'on y' foit fujet en defcendant des montagnes dans la plaine. J'ai auffi voyagé dans plufieurs autres endroits de ces monts, par les Lucanas, les Soras, les Collaguas, enfin de différens côtés, \& j’ai par-tout reffenti dans ces contrées de femblables dérangemens, mais jamais au même degré que quand je traverfai le Pariacaca. Nombre d'autres perfonnes y ont éprouvé la même chofe.

Il paroît hors de doute que ce mal étrange eft dî à l'air ou au vent dominant de ces contrées. En effet le feul moyen qu'on connoiffe pour en être moins affecté, \& qui eft bien effentiel, c'eft de fe couvrir la bouche, le nez \& les oreilles, mais fur-tout l'eftomac, avec fes habits; car l'air y eft fi fubtil, qu’il pénètre tout le corps. Les animaux y font également expofés aux mêmes dérangemens : on les voit quelquefois $f i$ abattus, qu'il n'y a ni coups ni éperởns qui puiffent les faire avancer d'un feul pas.

Je regarde ces cimes comme un des endroits les plus élevés du Globe : la hauteur en eft immenfurable. Les Puertos-Nevados d'Efpagne, les Pyrénées, les Alpes mêmes, me paroiffent auprès de ces cimes conme des maifons ordinaires à côté de hautes tours. C'elt ce qui me fair croire que l'air y étant fi délié, fi fubtil, n’eft 


\section{I42 Objervations \& additions.}

plus propre ( $\mathrm{s}$ ) à la refpiration, comme le devienr un air plus épais, ou une région moins élevée de l'atmofphère. C'eft aufi, je penfe, la caufe des vives douleurs qu'on y fent à l'eftomac, \& celle de tout le bouleverfement que le corps éprouve. Il eft vrai qu'on reffent fur les plus hautes montagnes de l'Europe, où j'ai paffé, un froid fort pénible, qui oblige de fe bien couvrir; mais ce froid n'ôte point l'appétir, il l'augmente même plurôt : on n'y éprouve pas ces naufées, ces vomifremens; on fent feulement quelques douleurs aux pieds, aux mains: en un mot ce n'elt qu'une affection externe. Les montagnes de l'Amérique ne font, au contraire, éprouver aucune incommodité ni

(1) Des faits bien examinés ont prouvé aux Chymifes de nos jours, que l'air propre à la vie des animaux devoit être imprégné d'une cercaine quantité de méphitifme; cependant on peut affurer que les phénomènes dont il s'agit ici, viennent principalement de ce que l'air qui circule dans toutes les humeurs, ou qui réfide dans tous les folides de l'animal, n'étant plus en équilibre avec l'air ambiant dont la rarité eft extrême, il fe dilate, cherche à s"échapper par toutes les ifiues qu'il trouve, \& caufe ce trouble général, cette foibleffe éronnante dont il eit queltion. Mais la Nature a fait ici fes exceptions en faveur de certaines efpèces de volatils, tels que le Condor, '\& autres animaux qui planent on s'élèvent fur ces hautes cimes, fans y éprouver le moindre dérangewent: clle les a organifés pour cot effet. 
Obfervations $\&$ additions.

aux pieds, ni aux mains, ni à aucune autre partie du corps; ce font les parties internes feules, les entrailles, fur lefquelles l'air porte fon activité.

Mais ce qui étonne davantage, c'ent que le foleil eft même chaud à certain degré; \& c'eit ce qui me perfuade que le mal vient de l'air même qu'on refpire, \&r qui eft fingulièrement raréfié. Le froid peut auffi y contribuer; car il y $\in$ ft plus pénétrant que fenfible.

Cette Cordillière eft ordinairement déferte; on n'y voit aucune habitation, \& prefque jamais perfonne : à peine un voyageur y trouve-t-il une place où il puiffe fe retirer la nuit; aucun animal, ni utile, ni nuifible, ne s'y rencontre, fi l'on excepte les Vigognes. L'herbe y paroît comme brûlée par l'air, \& entièrement noire. Cette chaine déferte a trente lieues de large fur cinquante de longueur, comme je l'ai dit.

On voit encore dans le Pérou d'autres cimes abandonnées, ou des Paramos, qu'on y appelle $P$ unas : l'air y eft extrêmement nuifible au corps, \& tue même fubitement, fans qu'on ait éprouvó aucun dérangement antérieur. Less Efpagnols paffoient autrefois du Pérou au Chili par la chaîne des montagnes; ils s'y rendent à préfent par eau, \& quelquefois en fuivant la côte. Cette route eft fort pénible, \& même dangereure, mais non autant que celle de ces hautes cimes, oul l'on 


\section{I44 Obfervacions \& additions.}

voit des plaines dans lefquelles nombre de perfunnes ont perdu la vie; d'autres y ont échappé à la mort, mais en revenant eftropiées ou réellement mutilées. Il y règne un air qui, fans affecter fortement, eft fi pénétrant, qu'il tue fans qu'on ait rien fenti; ou les doigts des mains $\&$ des pieds fe détachent comme fi on les avoit coupés, \& fans la moindre fenfibilité. On prendra fans donte ceci pour un conte; cependant il n'y a rien de plus vrai.

J'ai particulièrement connu le Général Jérôme Caftillo : il lui manquoit aux pieds trois ou quatre doigts, qu'il avoit perdus en allant au Chili par ce chemin défert : l'air les avoit totalement pénétrés : en les regardant il s'apperçut qu'ils ćioient morts, \& il les vit tomber fans la moindre fenfation, comme tomberoit d'un arbre une pomme mûre. Ce Guerrier rapportoit qu'une grande partie d'une armée affez nombreufe qui étoit paffée au Chili, étoit morre fur certe route, $\&$ qu'il en avoit rencontré les cadavres jonchés çà \& là, fans le moindre indice de corruption \& de puanteur. Il ajouta à ces détails un fingulier évènement : un jeune homme fe préfente bien vivant à lui fur le chemin; il lui demande comment il s'eft maintenu là. J'ai, répondit le jeune homme, trouvé une hutte pour me cacher; jen fors de tems en tems pour couper avec 
Obfervations \& additions.

mon couteau de la chair d'une mule, \& c'eft ainfi que j’ai vécu depuis long-tems : plufieurs de mes compagnons de voyages fe font ainfi maintenus pendant quelque tems, mais peut-àpeu ils font morts; \& voilà comme je veux mourir: je ne me fens aucune envie d'aller ailleurs, ni le moindre defir d'aucune autre jouiffance.

Les mêmes rapports m'ont auffi été faits par un de mes confrères, qui avoit fait cette route comme Curé; \& par d’antres perfonnes. Un illuftre Prélat Dominicain, qui avoit vu ces déferts, me les a confirmés; il ajouta mềme qu'ayant été obligé d'y paffer la nuit, il n'avoit trouvé d'autre moyen de fe préferver de l'impreffion mortelle de l'air, qu'en amoncelant certain nombre de cadavres dont il s'étoit fait comme un rempart, \& à la faveur duquel il avoit dormi au milieu des corps morts.

L'air eft fans doute fi pénétrant dans cette contrée, quiil étouffe toute chaleur dans le corps, \& fupprime l'action qu'elle peut avoir pour maintenir la vie : mais cet air eft en même-tems fi fec, qu'il s'oppofe à la pourriture des corps, pourriture qui eft la conféquence de la chaleur \& de l'humidité combinées.

Zarate nous décrit, L. 3. C. 2, les difficultés que $\mathrm{D}$. Diègue d'Almagro eût à vaincre pour fe rendre au Chili par cette chainne de montagnes:

Tome 11 .

X. 


\section{$146 \quad$ Obfervations \& additions:}

ces détails font encore plus effrayans. Le grand froid fut fur-tout ce qui lui devint préjudiciable, à lui \& à fon armée; le Capitaine Ruydias, qui accompagnoit $\mathrm{D}$. Diègue, vit plufieurs de fes foldats tués par ce froid, \& refter roides fur le chemin, nonobftant leurs habits. Les chevaux n'y furent pas moins maltraités. D. Diègue retournant à Cufco cinq mois après, vit en plufieurs endroirs des cadavres de foldats gelés avec leurs chevaux, fur lefquels ils étoient encore, \& appuyés contre les roches près defquelles ils s'étoient retirés; ils tenoient même la bride. $\mathrm{Ce}$ froid exceflif les avoit préfervés de la moindre atteinte de putréfaction, \& l'on en trouva les chairs aufli fraîches que s'ils venoient de mourir; c'eft pourquoi l'on ne fe fit pas de fcrupule d'en manger à ce retour. "

C'eft fans doute d'après de femblables détails; que Halès a avancé dans la defcription de fon Ventilateur, $\$$. 130 , que l'air eft fi froid fur certaines cimes du Pérou, qu'il peut cuaguler le fang $f_{1}$ l'on fait une feule infpiration forte.

Le rapport de Bouguer confirme, à plufieurs égards, les détails d'Acofta \& d'Ulloa, quoiqu'il diffère beaucotp dans la manière dont il détermine les caufes de ces étranges accidens : mais Bouguer n'a fait fes remarques que fur le Pichinca, dans le Royaume de Quito, \& n'a point 
Obfervations \& additions.

vifité les provinces dont parle Acofta; ainfi it n'a pu être témoin des accidens funeftes dont celui-ci \& Ulloa nous font le récit. L'extrême raréfaction de l'air, felon Bouguer, lui devint très-pénible, à lui \& à fes compagnons : ceux qui avoient la poitrine délicate, fentirent encore plus la différence de l'air, \& faignèrent fouvent du nez. Il attribue, avec raifon, ces accidens à la plus grande légéreté de l'Atmofphère, qui ne pefe plus affez pour maintenir le fang dans les vaiffeaux. Quant à lui, il ne remarqua point que cette incommodité lui devînt plus pénible en montant encore plus haut : peut - être, dit-il, eft-ce parce que je m'étois déjà accoutumé à ce pays, ou parce que le froid empêchoir que la (I) raréfaction de l'air ne fût aufii confidérable qu'elle auroit dû l'être fans cela. Plufieurs tombèrent en foibleffe en montant, \& vomirent fouvent : mais ces accidens lui parurent plutôt l'effet de la fatigue, que la difficulté de refpirer. Or, ceci lui fembla démontré, en ce que l'on n'étoir point expofé à ces inconvéniens, fi l'on marchoit à cheval, ou lorfqu'on étoit arrivé à une cime

( I L L'expérience a prouvé cette affertion en Sibérie; le froid y condenfe l'air au point, que la fumée du feu qu'on fait dans les appartemens, peut à peine s'élever au-deffus de la cheminée. 


\section{Objervations \& additions:}

où l'air étoit encore plus raréfié. Il ne nie cependant pas que la grande raréfaction de l'air ne contribue à cette fatigue pénible, \& à l'abattement qu'on y éprouve, puifque la refpiration, qui devient très-difficile pour peu qu'on s'agite, ne l'eft plus fil l'on refte en repos. C'eft, dit-il, ce dont j'ai été plufieurs fois témoin, \& je l'aurois été encore plus fouvent, fi plufieurs d'entre nous n'avoient été décidés, par ce qu'ils éprouvoient, à ne plus s'expofer à un auffi grand abattement. Après ces détails, concernans ce qui leur arriva fur la montagne de Quito, il nous apprend ce qu'ils éprouvèrent fur le Pichinca. Le froid y étoit fi intenfe, que plufieurs eurent des fymptômes fcorbutiques. Les Indiens, \& les autres perfonnes du pays, qu'ils avoient pris à leur fervice, fentirent de violentes douleurs internes; ils vomirent du fang, \& quelques-uns furent contraints de defcendre. Cette incommodité fe manifeftoir toujours lorfqu'on s'arrêtoit pour quelque tems fur la cime du rocher; mais, felon Bouguer, elle n'étoit dîe qu’à ce froid extrême, auquel ils n'étoient pas accoutumés; la raréfaction de l'air ne lui parut en être ni la caufe immédiate, ni même la caufe prochaine : c'eft ce qu'il croit pouvoir affurer d'après l'examen qu'il en fit fur les lieux, \& perfuadé que la plupart des voyageurs 's'etoient trompés à cet égard, ne 
Objervations \& additions:

fachant pas affez différencier ces divers effets.

Bouguer nous parle enfin du paffage de Guanacas, par lequel on traverfe les Cordillères de l'Eft, \& par où il lui fallut revenir au fleuve de la Magdeleine. C'eft une route que l'on ne fait qu'avec crainte \& danger, fur-tout lorfqu'on vient du dehors. Les mulets y font encore plus expofés que les hommes; car outre le froid exceffif quils doivent éprouver comme eux, ils ont encore la fatigue à effuyer, \& ils y perdent toutes leurs forces. La ronte, qui s'érend à deux lieues de longueur, eft fir remplie d'offemens de mulets qui y font morts, qu'on peut à peine pofer le pied fans en toucher. Mais Bouguer fe reffentit peu de la fatigue de cette route, parce qu'il prit par le milieu des Cordillères; car il eft bien diffétent de paffer des bas pays \& d'un climat modéré, fur ces hautes cimes où le froid eft excelfif \& l'air extrêmement raréfié, ou de quitter ces monts \& dé defcendre de ces climats rigoureux, comme Acofta l'a remarqué.

Quant à la caufe de ces anxiétés \& des vomiffemens, Acolta penfe devoir l'attribuer au froid, \& en même téms à la légéreté extrême de l'air. Bouguer au contraire ne l'atrribue qu'à la ( I) fatigue : la preuve qu'il en donne eft

(I) Suivant Bouguer nieme, fon raifonnement elt $\mathrm{K}$; 
prefque entièrement oppofée aux faits que cite Acofta, dont les compagnons de voyage, ou périrent, ou fe trouvèrent fi mal. Mais ces faits ne peuvent affurément pas être attribués à la fatigue; d'ailleurs il paroîr par les détails même d'Ulloa, que Bouguer ne s'eft pas trouvé fur les lieux où il auroir pu remarquer ces accidens au degré dont ils font fufceptibles : ainfi je laiffe à d'autres à décider ici de quel côté peut être la vérité.

Des fymptômes qui fe mānifeftent fur-tout en montant, \& difparoiffent en defcendant, paroilfent dûs à l'effet fubit d'un air très-raréfié; la moindre preffion que fait l'air fur les fibres tendues \& les mufcles d'un corps qui monte, peut bien occaitionner de la foibleffe dans leur mouvement, \& donner ainfi lieu de préfumer à ceux qui s'élèvent fur ces cimes, qu'ils ont, en conféquence, une refpiration plus gênée. D'un autre côté, le furcroît de péfanteur que l'air exerce fur la poitrine \& les poumons, peut pareillement produire pendant quelque tems une affection convulfive dans l'eftomac, \& conféquemment des naufées, des vomiffemens; ou,

faux ; car Acofta étoir fur une mule : cependant il éprouva cous les accidcns que Bouguer n’attribue qu’à la fatigue réfultante de la marche à pied. 
dans d'autres fujets, dés faignemens de nez. Or, ces effets cefferont auffi-tôt que le froid d'un air très-raréfié remettra les chofes en équilibre. Mais il fe préfente aufî quelques fymptômes qui peuvent avoir pour caule, \& le froid, \& l'air extrêmement fec ou très-raréfié. L'excès du froid caufe le fcorbut avec des fymptômes très-fâcheux, met les matières animales dans un état gangréneux, mortifie les chairs des membres \& des gencives, au point qu'il faut en féparer ces parties mortifiées. C'eft ce qu'ont éprouvé les Européens qui ont paffé l'hiver dans le Groenland, $\&$ dans d'autres pays très-froids : cette température leur fit fentir des douleurs infoutenables à différentes parties du corps; elle en arrêtoir le mouvement, \& occafionnoit des taches jaunes \& des puftules ulcéreufes fur la peaul. Le fang intercepté dans fon cours, \& la refpiration trèsgênée donnèrent lieu à des vertiges, des affoupiffemens, des douleurs d'entrailles, des cours de ventre, des flix de fang, fans cependant jamais ôter l'envie de manger.

Mais, d'un autre côté, la chaleur exceffive altère les fubftances animales comme le froid, y produit la gangrène, avec cette différence néanmoins, que le froid qui produit des mortifications fur les corps vivans, préferve de la putréfaction celux qui font morts; car un corps

$$
\text { K } 4
$$




\section{IS2 Obfervations \& additions:}

ne peut pourrir s'il n'y a pas en même tems de Ia chaleur \& du mouvement dans les fucs ou fluides animaux. Tels font en général les effets que le froid \& la raréfaction produifent fur le corps humain. On peut confulter à cet égard le Traité d'Arbuthnor, concernant les effets de l'air fur nos corps.

$J$ 'ajouterai encore ici, pour jetter quelque jour fur ces phénomènes, les obfervations qui ont été faites fur les plus hautes montagnes de l'Europe, concernant les qualités de l'air \& les effets qu'ellés $y$ font fur le corps humain, autant que cela m’eft connu. Ulloa, qui les compare avec ceux qu'on éprouve fur les Cordillères de l'Amérique, ne trouve qu'un rapport très-éloigné dans les accidens qui en réfultent.

Quant aux effets que l'air froid, raréfié \& fec produit fur le corps, lorfqu'on eft parvenu au plus haut degré d’élévation où l'on puife arriver fur les monts glacés de l'Europe, on les trouve infiniment moindres que ceux dont nous parlent D. Uiloa \& Bouguer. Dans le derinet voyage que $M$. de Luc fit au mont de Sixte, il remarqua que la peau fe ridoit \& devenoit pâle; de forte qu'elle reffembloit affez, tant à l'œil qu'au tact, à une veffie ridée. On n'éprouvoit cependant là aucune autre incommodité que le froid \& le vent; la poitrine \& tout le refte du corps 
faifoient librement leurs fonctions. Il remarqua, comme un effet de la pureté \& de la féchereffe de l'air, que dans un autre endroit l'anneau de fer de fon bâton tomba de lui-même, quoiqu'il y eut été mis avec force, \& que ce bâton fût d'un bois très fec.

Il reconnut auffi la pureté de l'air à la faveur de l'eau de pluie \& de glace fondue, la trouvant beaucoup plus agréable qu'elle ne l'eft ordinairement dans la région inférieure \& plus denfe de l'atmofphère : du refte il ne s'apperçut pas que la différente denfité de l'air eût aucune influence particulière (I) fur le corps, ou y produisît quelque altération fenfible. Nous fûmes étonnés, dit-il, de n’obferver en rien la différente denfité de l'air, à l'exception de nos inftrumens : en effer, aucune gêne, aucune fenfation défagréable ne nous fit fentir que l'air que

( I) Deux perfonnes qui ont paffé le Mont-Cenis, m'ont dit que cette traverfée n'étoit pas fans danger; que les Conducteurs les avoient prévenues de faire bien attention à la moindre gêne qu'elles éprouveroient dans la ref́piration, \& de fe jetter auffi-tôt par terre, la bouche appliquée contre le fol, pour reprendre haleine, fans quoi elles courroient le rifque d'être fuffoquées : c'eft ce que ees Conducteurs appellent être effouflé. Si ces accidens fort réels, on doit fans doute les rapporter à la fatigue pour première caufe. 


\section{IS4 ObJervations \& additions.}

nous refpirions étoit prefque d'un quart moins pefant que dans la plaine, \& qu'il exerçoit fur nos corps une preffion à-peu-près moindre de cent quintaux; l'équilibre s'y maintint de même dans l'intérieur. Quelle machine étonnante que le corps humain, qui peut foutenir un changement auffi confidérable, \& dans les caufes mêmes de fes premiers mouvemens, fans en reffentir le moindre trouble!

Cet habile Obfervateur cite, en outre, l'exemple des gens qui chaffent aux Chamois, \& celui des femmes du Village prochain du mont de Sixte, qui tous les jours vont des vallées profondes au plus haut point des cimes, fans en reffentir la moindre incommodité.

M. d'Arcet nous a communiqué des obfervations analogues, dans fon Difcours fur l'état actuel des Pyrénées. L.Auteur fut étonné du froid fenfible qu'il y éprouva, nonobftant le haut point où étoit le thermomètre. L'alkali végétal ne de. venoit pas humide fur la cime de la montagne, l'efprit de nitre fumant ne jettoir que peu de vapeurs; l'électricité y avoit la même force que dans la plaine; il en étoit de même de la vertu attractive de l'aimant; la refpiration s'y faifoit avec la plus grande liberté, \& la poitrine n'y éprouvoit aucune gêne. Les expériences magnétiques qu'y fit M. d'Arcet, ont été fuivies d'effets 
qui fe rapportent totalement avec celles de Bouguer; mais Volkmar a trouvé fur le mont des Géans, en Siléfie, que la matière électrique y avoit beaucoup plus de force que dans la région épaiffe \& inférieure de l'atmofphère. On peut confulter fon Voyage, pag. 140. Il confirme aufli, page i 8 ; ce que $M$. de Luc a remarqué concernant l'excellente faveur de l'eau. On n'a encore fait, je penfe, aucune expérience fur les Cordillères, pour conftater la force avec laquelle y agit la matière électrique. Enfin, M. de Sauffure nie formellement qu'on fente fur les Alpes la moindre gêne dans la refpiration; mais il convient qu'on y éprouve un abattement extraordinaire, une envie de dormir, \& que la peau y pele.

Voilà, à-peu-près, à quoi fe réduifent les obfervations que l'on a faites concernant les fenfarions dont on elt affecté fur les plus hautes montagnes de l'Europe; on voit qu'elles ne nous préfentent qu'une très-foible partie de ce qui arrive fur les Cordillères de l'Amérique; mais ces montagnes, fuivant M. de Buffon, (Supplément, Tom. IX, pag. 434.) font d'un quart plus hautes que les cimes les plus élevées de l'Europe. 
ObSERVATIONS Jurles Garvas E. les Paramos.

D'Auteur employant plufieurs fois ce terme pour défigner une des circonfances du climat du Pérou, je crois devoir placer ici quelques obfervations relatives à ce fujet; elles éclairciront ou confirmeront ce que dit Ulloa, Difc. $V$, page Ios; Difc. VIII, page I 9o, \& ailleurs. Voici ce qu'en dit Acofta, Parice III de fon Ouvrage.

Le Pérou, cette partie du Nouveau-Monde, qui commence au Royaume de Quito \& fe termine au Chili, renferme un efpace de feize cens lienes, \& mérite une attention particulière", vu le grand nombre de chofes quilui font particulières, \& qui font une exception aux régles générales.

Premièrement, il règne fur toute la côte un feul vent, \& non le vent ordinaire dans la Zone tempérée, mais le vent oppofé du Sud \& du Sud-Ouent. Secondement, fi ce vent eft ailleurs le plus violent \& le plus mal fain, il eft. au contraire ici fingulièrement doux, agréable \& fain; c'eft même ce vent feul qui rend la côte habitable, autrement il feroit impolfible de 
Obfervations \& additions.

s'y fixer, à caufe de la chaleur étouffante dus climat. Troifièmement, on n'entend pas parler de tonnerre, de grêle, de neige ou de pluie fur certe côte, tandis qu’à peu de diftance de la côte il neige beaucoup, \& il tonne horriblement:" Des deux chaines de montagnes quil fe continuent paralèllement à la mêtme hauteur du Pole, l'une eft couverte en grande partie de grandes forêts; il y pleut prefque toute l'année, \& il y fait fort chaud; l'autre eft au contraire toute nue, très-froide, \& l'année y eft divifée en été $\&$ en hiver par les pluies \& les jours fereins. Pour mietix entendre ceci, il faut fe repréfenter le Pérou comme partagé en trois bandes, qui font les Plats-pays, les Cordillères, (Sierras) \& les Andes.

Les Plats-pays ein forment en partie les côtes, les Sierras font l'autre partie des côtes avec quelques vallées, les Andes font des montagnes rapprochées les unes des autres.

Les Plats-pays ont enviton dix lienes de large; tantôt plus, tantôt moins; la Sierra en a vingt, \& les Andes antant à-petl-près. Les Andes fe prolongent du Nord au Sud; leur largeur eft de l'Eft à l'Oueft. On voit avec étonnement que dans un aufi court intervalle qu'eft celui de cinquante lieues, \& à la même diftance du Pole. 


\section{is 8 Obfervations \& additions.}

\& de la Ligne, il y ait une fi grande différence dans l'état de l'Atmofphère, qu'il pleuve prefque continuellement dans une contrée, très-rarement dans l'autre, \& que dans la troifième le foleil \& la pluie partagent le cours de l'année.

Il ne pleut jamais fur les côtes, quoique de tems à autre il y tombe une efpèce de pluie fi fine, qu'on la prendroit pour une rofée : on l'appelle dans le pays, Garuas, \& Mollina en Caftillan. Quelquefois elle fe condenfe en partie, $\&$ forme quelques gouttes d'eau qu'on fent tomber. Malgré cela, les maifons n'ont pas de toît proprement dit; elles ne font fermées par le haut qu'avec des nattes recouvertes d'un peu de terre: on n'y a pas befoin d'autre chofe.

La pluie eft prefque continuelle dans les Andes; cependant il eft des intervalles dans lefquels le tems paroît plus clair que dans d'autres. La Sierra, qui eft entre les deux autres contrées externes, a fes pluies dans la même faifon que l'Efpagne; c'eft-à-dire depuis Septembre jufqu'en Avril : le refte de l'année eft clair \& ferein, même lorfque le foleil eft le plus éloigné.

Ce que l'on appelle Andes \& Sierra font deux chaînes de hautes (Cordillères) montagnes qui fe prolongent paralèllement jufqu'à mille lieues. On trouve dans la Sierra de nombrenx troupeaux 
Obfervations \&' additions:

'de Vigognes, de Guanacos, de Pacos, qui font les moutons \& en même tems les bêtes de fomme de ces contrées-là. Il y a dans les Andes beaucoup de beaux Singes \& de Perroquets. La Coca, fi eftimé des Indiens, \& dónt on fait un commerce lucratif, y eft un végétal indigène: La Sierra préfente, dans les lieux où elle s'ouvre, des vallées qui font la plus agréable réfidence du Pérou : telles font celles de Xaura, d'Andaguayalos, de Yucay; il vient dans ces vallées du mais, du bled, des fruits plus ou moins abondamment.

Les deux chaînes de montagnes s'éloignent plus l'une de l'autre aut-deffus de la ville de Cuzco, \& laiffent entr'elles une grande plaine, qui fait la province de Callao. On voit dans cette vafte plaine nombre de fleuves, le grand lac de Titicaca, beaucoup de terreins fertiles, $\&$ des faules. Quoique ce foit un plat pays, il a la même hauteur \& l'âpre température de la Sierra; on y rencontre auffi peu de forêts ou de bois. Les habitans plantent des papas, ou pommes-de-terre, qu'ils font fécher pour en préparer leur chugno, qui leur tient lieu de pain : ils font encore ufage d'autres racines. Le pays eft forc fain, \& en général affez cultivé : l'abondance $\dot{y}$ règne; car on y voit nombre de troupeaux de Moutons d'Europe, des Chèvres, des Vaches \& 
d'autres animaux domeftiques indigènes; comme les Guanacos, les Pacos, (Alpaques) \& beaucoup de Perdrix. Au-delà de Callao ef fituée la province de Charcas, où il y a nombre de vallées fertiles, \& de côteaux riches en minérais, tels qu'on n'en voit pas dans les autres parties de la terre.

Mais, pour revenir aux Garvas, l'Auteur nous en donne dans fon voyage des détails qui peulvent fe trouver avantageufement ici. En parlant du froid qu'on éprouve à Lima, il nous dit que la terre eft couverte pendant tout l'hiver d'un brouillard fi épais, qu'il intercepte totalement les rayons du foleil. Les vents foufflent fous ces brouillards, \& entretiennent le froid qu'ils apportent du lieu d'où ils foufllent. Ces brouillards paroiffent auffi épais dans les vallées qui font au Nord : ils ne font pas bornés à la terre; on les voit aufi couvrir une partie de la mer. C'eft régulièrement pendant toute la matinée qu'ils couvrent la terre, \& ils font fi épais qu'ils obfcurciffent tous les objets. Vers dix à onze heures avant midi, ou un peu plutôt ou plus tard, ils s'élèvent, fe partagent; mais non en totalité; les nuages ne dérobent plus la vue des objets, cependant ils cachent encore le foleil pendant le jour, \& les étoiles pendant la nuit.

On voit donc que le ciel eft continuellement caché 
Obfervations \& additions:

caché; la feule différence eft que le brouillard eft tantôt plus, tantôt moins près de la terre : de tems à autre ces yapeurs fe divifent, laifent appercevoir le difque du foleil; mais fes rayons ne font fentir aucune chaleur. Il eft à propos de remarquer qu'à deux ou trois lienes de la ville, ces vapeurs fe partagent beaucoup plus que dans la ville même; on y voit entièrement le foleil, \& il y modère le froid par fon influence. Voilà pourquoi l'hiver eft plus doux, \& le tems plus ferein dans le port de Callao, qui n’eft qu'à deux lieues \& demi de Lima.

"Cependant il arrive, comme on l'a déjà dit, que ces brouillards fe convertiffent en bruines qui humectent la terre; alors les montagnes \& les vallées, qui dans les autres faifons paroiffent arides \& \& thériles, fe couvrent de toutes fortes de plantes. Ces bruines ne font jamais affez épaiffes poụr empêcher de fe metrre en route; elles font fi fines, que les habits même les plus ligers n'en font pénérrés qu'au bout d'un tems affez long; mais, comme elles durent tout l'hiver, fans que le foleil puife percer à travers, elles pénèrrent \& humectent affez le fol pour le ferti. lifer, \& faire produire des végétaux fur les fuperfícies les plus fèches \& les moins propres à la végétation.

Tome II. 


\section{Des Paramos.}

M. Schneider ne jettant aucun jour for ce que l'Auteur dit des Paramos, Difc. $V, p .121$, \& fur la caufe de l'affection qu'on y éprouve, page 117 , je crois devoir prendre quelques éclairciffemens dans un Aureur Efpagnol. Le mot Paramo a une fignification affez vague, \& fe prend en général pour des terreins déferts \& inhabitables. L'Auteur dis qu'il répond à ce qu'on appelle Puna au Pérou; mais le P. Jofeph Gumilla, Supérieur des Mifíns de l'Orenoque, s'explique ainli dans fon Voyage, Tom. I, Chap. IV. "Je défignerai par le nom de Paramos ces montagnes qui, quoique généralement froides, ne font cependant pas toutes couvertes de neiges.

"Ces Paramos, dont la hauteur s'élève dans les nues, ont été formées par l'Etre fuprême, afin que les pays qui font fous l'Equateur fuffent habitables, quoique ces Paramos foient euxmêmes inhabités, \& fouvent funeftes aux Voy?geurs qui n'ont pas la précaution de fe garantir du froid mortel qui y règne. Ce froid eft bien différent de celui qu'on éprouve dans les contrées les plus reculées du Nord; il n'eft pas fort feníble à l'extérieur, fi on le compare à celui qu'on éprouve intérieurement, \& qui pénètre jufqu’à 


\section{Obfervations E additions.}

la moëlle des os. Les Oifeaux de proie \& les autres bêtes féroces n'ofent même approcher diu lieu où font reftés morts ceux que ce froid a fubitement pénétré, quioiqu’à peu de difftance de ces lieux on apperçoive des Ours \& d'autres animaux encore plus gros que dans les climats tempérés.

" Cenx qui font morts de ce froid confervent après la mort un air riant; ils ont les lèvres retirées, les dents découvertes, vu la rigueur du froid qui contracte les mufcles de ces parries.

"J'autribue le froid qui règne fur ces Paramos à leur hauteur extraordinaire, car ils font beaucoup plus élevés que notre A tmofphère; ainfi leur fommet \& les nuées étant frappées de ce vent fubril \& froid, il y tombe une quantité prodigieufe de neige qui ne fond jamais; c'elt pourquoi les pays voifuns éprouvent un froid exceffif pendant toute l'année : on les appelle Terres froides. Ceux qui font un peu plus éloignés \& moins expofés à ce vent, font appellés tempérés. On appelle pays chands ceux qui font affez éloignés pour ne pas fentir les atteintes de ce vent, ou qui ne le fentent que quand le foleil lui a fait perdre toute fon activité.

On voit donc que, pendant toute l'année; les pays qui font fous l'Equateur éprouvent à la fois les quatre faifoxs qui la partagent, felca

$$
\text { L. } 2
$$


$\mathrm{IJ}_{3}^{2} 4$

Objervations \& additions.

Ir pofition où ils fe trouvent. Ceux qui font au pied des Paramos, ont toute l'année un hiver pareil à celui qu'on éprouve dans le mois de Février au Port de Guadarrama dans la Nouvelle-Caftille; c'eft pourquoi on n'y a aucun des fruits qu'on trouve dans les climats chauds. A une diftance proportionnée, les pays font tempérés toute l’année, \& les arbres fruitiers couverts de fleurs \& de fruits, les uns verds, les autres mûrs, de forte qu'on y jouit en mêmetems de l'été \& de l'automne. Ceux qui font plus éloignés des Paramos ont un été continuel, ix éprouvent une chaleur plus grande que celle de Séville, aux mois de Juiller \& Août, quelque fort que foit le vent d'Ent, \&rc. Dans les églifes de Norre-Dame de Mont-Serrat \& de Guadeloupe, lefquelles font bâties aul-deffus de la Ville fur deux rochers dominés par le Paramo, l'on fent un froid continuel \& rrès-vif dans la Ville qui eit au pied de la montagne; il règne une frấcheur qui s'étend jufqu'à l'extrémité occidentale de la belle campagne de Bogota, \&c. Mais je puis affirer à ceux qui aiment la vérité, que, fous la ligne, on ne remarque aucun changement de tems, \& qu'on éprouve une chaleur exceffive \& continuelle toute l'année, dans les contrées oì il n'y a point de Paramos, ni aux environs. II en eft de même des deux premiers climats, 
foit am Nord, foit au Sud. Si l'on fent du froid ou de la frâicheur, c'eft une preuve infaillible qu'il y a près de ces endroits quelque Paramo qui caufe ces changemens. Ainfi, quand quelques Ecrivains ont affuré qu'on avoit deux fois fous la ligne le printems \& l'hiver, cela ne peut être vrai que dans la fpéculation, \& eu égard au cours du foleil dans l'écliprique.

"Je conclus de ce que je viens de dire, qu'il n'y a point d'hiver pour ceux qui habitent entre l'Equateur \& les Tropiques. Il en faut excepter cenx qui, étant entourés de Paramos, en reçoivent plus ou moins la fraîcheur, à proportion quils en font plus ou moins éloignés.

Le même Gumilla confirme la diftinction qu'on fait au Pérou, felon D. Ulloa, entre l'hiver \& l'été. Ibid. On faura que dans la Terre-ferme il eft d'ufage de donner le nom d'hiver aux tems pluvieux, \& celui d'été aux tems fecs; c'eft pourquoi, s'il pleut le matin, le peuple ne manque pas de dire: voilà un terrible hiver! \& lorfque le foleil paroît le foir : nous avons-là un bel été. Je puis citer pour 'garant de ce rapport, le Père Pierre Simon, dans fon Hifoire de la conquête du nouveau-Royaume, \& Pedrahitá, qui n’allèguent pour eux que l'expérience, qui, felon moi, l'emporte fur tous les raifonnemens. On peut auff confulter le Père André Pérez 
de Roxas dans fon Hitoire de Cinaloa, où il parle des montagnes de Topia, qui ne font que des Paramos extrêmement froids.

OBSEVATIONS fur le Difcours $X$, concernant les Lacs \& les Fleuves.

E vais réunir ici ce que $D$. Ulloa nous dit du Miffiflipi en plufieurs endroits, comme Difcours $I I$, pag. 43 \& Suiv.; Difc. X, pag. 2 I E Juiv. j'y joindrai quelques remarques qui éclairciront $\&$ confirmeront en partie fes affertions.

Les Indigènes de la Louyfiane appellent ce fleuve Meachtchalfpy, c'ett-à-dire, le Pere des fleuves. C'eft de ce nom qu'on a formé celui qu'il a parmi les Européens. On ne connoiffoit autrefois ce fleuve que jufqu'à la rivière de SaintPierre, au-deffous même de la cafcade de SaintAntoine. Le Père Hennepin le remonta jufqu'au Aeuve Saint-François. L'Anglois Carver le fir aufî après lui. Ils avancèrent l'un \& l'autre jufqu'à feize milles d'Angleterre au-delà de la Cafcade. Ce Aleuve, felon Carver, fe joint au Miffiflipi, en-deçà du quarante-cinquième degré, latitude Nord, \& au quatre-vinge-quinzième degré de latitude Oueft. Tout ce qu'on fait de la partie Septentrionale ultérieure de ce grand 
fleuve, fe réduit aux récits des Indiens. Carver a raffemblé leurs détails, \& les a marqués fur fa Carte le mieux qu’il lui a été pofible. Au Sud-Oueft fe trouve le Lac rouge, à peu de diftance du Lac blanc, qui eft à-peu-près auffi grand que le rouge. Carver compte celui ci parmi les eaux du Nord, d'où fort le Miffiflipi, \& il penfe qu'on peut fans erreur le regarder comme la fource la plus éloignée. Il l'a placé au quarante-feptième degré de latitucie Nord, $\&$ atl quatre-vingt-dix-feptième degré de latitude Oueft. Selon le calcul de Carver, le Miffifipi parcourt un efpace de 3000 milles d'Angleterre, en' y comprenant toutes les finofités, \& arrive alors au Golfe du Mexique; c'eft en ligne droite, environ 20 degré ou 1400 milles d'Angleterre. Les vaiffeaux de certaine grandeur ne peuvent le remonter que jufqu'à l'embouchure de l'Ohio; ce n'eft même qu'avec beaucoup de peine qu'ils arrivent jufques-là, vî̀ les fréquentes finuofités \& la rapidité de fon cours.

D. Ulloa dit quion ne comnoît pas encore le cours de ce Aluve jufqu'au quarante-troifième degré; cependant Carver l'a fuivi \& décrit jufqu'au quarante - quatric̀me degré laticude Nord. L'eau en eft très-claire jufqu'au confuent du Miffouri qui s'y jette, \& la trouble alors parle limon qu'il y répand: néammoins l'eau en eft

$\mathrm{L}_{4}$ 
toujours falubre, \& c'eft, dir le Page du Praz, une propriété commune à toutes les eaux limonevíes.

Le Miffipi déborde ordinairement en certains tems. Du Praz nous apprend que c'eft au commencement de Mai, lorfque les neiges abondantes du Nord fondent, \& en groffiffent confrdérablement les eaux : alors ce Heuve fe jette de tous côtés jufqu'à vingt \& trente lieues dans les terres, ce qui dure jufqu'à la fin de Juiller. Les bords du Aeuve étant beaucoup plus élevés que les terres adjacentes ou éloignées de fon cours, les eaux ne peuvent y rentrer. Une partie de l'inondation s'écoule vers l'uit, par le Manhac, qui eft un canal maturel communiquant avec le lac Maurepas; de ce lac elle gagne celui de Pontchartrain, \& de-là elle fe rend à la mer. L'autre partie des eaux s'écoule à l'Onet, dans le golfe de l'Afcenfion : ce qui en refte dans les terreins les plus bas, forme des lagunes, des marais, des lacs \& des efpèces de courans d'eaux corrompus, que l'on appelle Bayoucs dans le pays; ce qui fe voir fićquemment tout le long du cours de ce fleuve.

Les rives en font bordées de bois, au moins en général : cependant il coule çà \& là entre de hauts monts efcarpés quil ne peut inonder: fes débordemens jettent beeucoup de limon dans 
Obfervations \& additions:

les terres, \& entrainnent quantité d'arbres déracinés dans ces circonftances, ourre ceux que les eaux détachent journellement de fes bords, \& qui tombent dans fon lit. Ces arbres s'arrêtent près des bancs de fable qu'ils font angmenter, ou qu'ils renouvellent continuellement. Si ces arbres s'arrêtent en certaine quantité fans être roulés à la mer, ils forment bientôt de nouvelles Ines, qui s'aggrandiffent avec le tems, changent le cours du fleuve, \& le dérobent à ceux qui ne le voient pas habituellement. Le Page du Praz affure pareillement que le limon \& la vafe élèvent fenfiblement les terreins \& les bords fur lefquels il les dépofe.

Le plat pays de la Louyfiane eft, felon ce Voyageur, à-pen-près tel que le rond d'une eau ftagiante, \& femble n'avoir été formé que du fable \& de tout ce que la mer rejette, \& en outre de la vafe, des bois que le Aeuve entraine pendant une inondation de trois mois, \&r qu'il y dépofe; fans compter les feuilles des arbres, les rofeaux qui y croiffent en grande quantité, y tombent pendant l'hiver, ni les même arbres \& les rofeaux qui menrent, \& y êtretiennent une putréfaction continuelle. En creufant un jour audeffus de la Nouvelle-Orléans pour faire un puits, on trouva à vinge pieds de profondeur un Cyprès, dont le corps avoit trois pieds de dia- 


\section{I70 Obfervations \& additions.}

mètre; ce bois eft incorruptible. Le fol s'étoit donc élevé là de vingt pieds, depuis que cet arbre avoit été abattu : or, ce bois étant trèsléger, \& furnageant toujours, il n'eft pas à préfumer qu'il fe foit enfoncé de lui-même dans le fol amolli de cette contrée.

Au refte, les rives qui fe trouvent plus élevées que les tcrres intérieures du pays, prouvent qu'elles ont reçu cet accroiffement de la boue \& du limon quie l'eau charrie, \& dont elle laife toujours une moindre quantité dans les terres, à proportion qu'elle s'éloigne du lit du fleuve. On trouve même à cent lieues de la mer, des monticules qui ne font formées que par des amas de coquilles d'Huîtres : en outre, les habitans de ces contrées alfurent, avoir ouï dire à leurs ancêrres que la mer s'étoit étendue jufqu'à ces endroits-là. Si donc on s'en rapporte au dire de ce peuple, \& que d'ailleurs on pèfe mûrement ce aue j'ai dit, on fera obligé de confidérer la Louyfrane comme une contrée arrachée à la mer, \& dont le fol fondamental elt un fable cryftallin, très-blanc, \&z auffi fin que de la farine. Telle eft réellement toute la côte, tant à l'Oueft qu'à l'Eft de l'embonchure du Mifilipi. Elle fe trouve inhabitable : l'éclat du fable y eft fi vif, lorfque le foleil y donne, quil ćblouit \& expofe au danger de perdre la vue, lorfquon 
y marche fans avoir quelque chofe devant les yeux.

- Ce que D. Ulloa nous dit du prétendu foufre ou de la peau jaunâtre qu'on apperçoit en certain tems fur l'eau des marais \& de pluie près du Mififipi, ne m’a pas paru bien placé ici. Si on le jugeoit par ce feul endroit, on préfumeroit qu'il eft peu fait pour obferver avec exactitude la nature \& fes produits. Il dit clairement que l'atmofphère y eft chargée de patticules fulfureufes, \& il apporte pour preuve les coups de tonnerre horribles qu'on y entend. Cette remarque feroit de quelque poids, s'il étoit clairement prouvé combien une contrée chargée de foufre pelit avoir d'infuence fur la force des coups de tomnerre \& fur les orages; mais les idćes de l'Auteur tiennent ici à une théorie furannée concernant la caufe du tomerre; d'ailleurs l'Auteur ne nomme là aucun lieu où le foufre fe rencontre en fi grande quantité.

Il fuppofe enfuite que les émiffions de nombre d'arbres réfineux du pays fe mêlent avec des particules fulfureufes très-délićes; \& enfin il convient que cette prétendue pluie de foufre ne contient autre chofe que la partie (I) huileufe la plus fubtile du foufre.

(I) M. Schno devoit obferver qu'il n'y a pas un atône 


\section{I72 Obfervations \& additions.}

La feconde circonftance dont l'Autenr fait mention, favoir ce grand nombre d'arbres réfineux, mérite plus d'attention, \& fait appercevoir la caufe de cette pellicule fulfureufe en apparence; elle n'eft fans doute formée que de la pouffière prolifique que le vent emporte de ces arbres au tems de la fleuraifon. Pareil phénomène fe voit affez fouvent è Europe, \& en a auffi impofé à des gens peu attentifs. On peut voir Borgman dans fa Defcription phyfique de la terre, Part. II. page 37. Mais, pour pouvoir décider cette queltion, il faudroit foumettre à l'analyfe chymique cette peau qui fe forme fur les eaux de pluie, déterminer le tems dasss lequel paroît ce phénomène, \& favoir en quel mois les Pins \& autres arbres analogues, fone chargés de cette pouffière prolifique.

d'huile dans le foufre, \& qu'il ne peut même s'y en trouver. blaife Vigènere, ce favant Chymife \& Littérateur François, avoit découvert long-tems avant Stahl, que le foufre éroit un compofé de phlogiftique \& d'acide vitriolique. Les proportions en ont été différemment affignées par les Chymiftes modernes. Voyez la Chymie de Lemery, avec les Notes Allemandes de Zimmermann, \& les élémens de Chymie de Spielmann, le Dicion. de Macqucr, erc. Mais il n'y a rien de fi oppofé au foufre que Thuile, confidérée comme telle. 
OBSERVATIONS E additions fur le Règne Végétal.

$\angle$ Guacates. Ulloa appelle auffi ce fruit Paltas \& Poltas. De la Vega dit, L. 8, c. I I, que Paltas eft le nom Indien, \& que les Efpagnols le nommèrent d'abord fimplement Poires. Selon lui, ce fruit eft deux ou trois fois plus gros que les Poires d'Efpagne. Frezier en parle ainfi : "On voit dans la vallée d'llo de certe efpèce de fruits qu'on appelle Paltas au Pérou, \& Avocats dans les Antilles. Ils font faits comme une groffe poire, qui contient un noyau rond, un peu en pointe, de la confintance \& de la groffeur d'une châtaigne, mais qui ne fert $a$ rien que pour la teinture en murc. La fubftance qui l'enveloppe eft verdâtre, \& prefque molle comme du beurre, dont elle a un peu le goût, mêlé de celui de la noîfette, en la mangeant avec du fel. La meilleure maniere de la manger, eft de la battre avec du jus de citron. Ce fruit eft fort fain \& bienfaifant. "Bayer écrit Polta, \& dit : " La tige de l'arbre s'élève très-haut; il reffemble à nos grands poiriers : le fruic eft gros comme une moyenne poire, mais fans coque, n'ayant qu'une peau verte, femblable à un 
$174 \quad$ Obfervations \& additions.

cuir mol \& verdâtre. La pulpe renferme à fon centre un noyau affez gros, dur, \& en forme de cour. Labat, dans fon Voyage aux llles de l'Amérique, décrit un fruit \& un arbre fous le nom de l'Avocat, de manière à reconnoitre dans l'arbre le Laurus perfea de Linné, que Jacquin a décrit, Obervat 37.

Le nom que les Indiens donnent à l'Avocat, ou Avorat felon l'antre, eft une corruption du mot Indien Ahuacahuitl. Laët a donné une dercription très-circonftanciée de ce fruit, dont on peut voir la figure au Tome XXII de l'Hift. Génér. des Voyag. pag. G04.

Algarrobos. Fruit du Caroubier, arbre trèsconnu. Il s'agit peut-être ici du fruit du Guama, dont a parlé Oviedo, comme production de l'Ifle Efpagnole. Le Caroubier eft un arbre dont les efpèces font fort variées. La gomme des Algarobos, dont parle Gumilla, \& qui prend feu d'elle-même, eft un des plus curieux phénomènes qui mérite bien l'attention des Naturaliftes. Voyez Gumilla Tom. II, page 23. Ce fait devroit être vérifié.

Algodon ou Coton. Plufieurs Lecteurs verront fans doute ici avec plaifir la defcription que Frezier nous a donné du Cotonnier dont il s'agit: "Le Cotonnier, que les Botaniftes appellent Gofipium ou Xilon arboreum, eft un arbrifleau 
Objervations \& additions.

qui ne s'élève guère plus de dix à douze pieds; fes grandes feuilles ont cinq pointes, \& reffemblent affez bien à celles du grand Erable ou du Ricin; mais les petites, celles qui font les plus proche du fruit, n'en ont que trois: les unes \& les autres font un peu charnues \& d'un verd foncé.

Ses fleurs feroient femblables à celles de la Mauve, qu'on appelle Paferofe, fi elles étoient de même couleur \& plus évafées; elles, font foutenues par un calice verd, \& compofé de trois feuilles triangulaires dentelées, qui ne les enveloppent que très-imparfaitement; elles font jaunes par le haut, \& rayées de rouge dans le fond.

A la fleur fuccède un bouton de rofe, qui, dans fa parfaite maturité, devient gros comme un petit œuf, \& fe divife en trois ou quatre loges remplies chacune de huit à dix femences prefque auifi groffes que des pois, enveloppées dans une fubftance filamenteufe connue fous le nom de coton, qui part de toute leur furface, \& qui devient blanche : elle fait ouvrir les loges à mefure qu'elle mûrit, de forte qu'à la fin les flocons fe détachent \& tombent d'enx:mêmes: les graines font alors tout-à-fait noires, \& pleines d'une fubftance huileufe d'affez bon goût, que l'on dit être très-bonne contre le flux-de-fang. 
Ce Cotonnier eft fort différent de celui qu'on cultive à Malthe \& dans tout le Levant, où ce n'eft qu'une plante annuelle; d'ailleurs les feuilles font arrondies \& échancrées, \& à-peu-près de la grandeur de celles des Mauves.

On dit que ces Cotonniers font de la petite efpèce, parce quilil y en a dans ce continent de plus gros \& de plus grands que nos Chênes; ils portent le cuton de foie, qui eft très-court, mais c'eft une efpèce de houatte. "V. Ceibo.

Le Cotonnier, arbre ou arbufte, varie dans fes formes caractériftiques, felon les différens climats.

Arbre de cire, ou Cirier. C'eft une efpèce de Mirthe, ou plutôt il y a deux efpèces de cet arbrifleau. L'un né s'élève qu'à deux ou trois pieds; l'autre monte jufqu'à douze, \& a les feuilles moins larges que le premier. On le trouve dans la Nouvelle-France, \& en général le long des côtes de l'Amérique Septentrionale, depuis la Louyfrane jufqu'à l'Arcadie. La tige en elt for tortue, les feuilles longues, érroites, pointues, \& la plupart dentelées; au mois de Mai les petites branches pourent des touffes oblongues, de très-perites fieurs, fembilables aux chatons des Coudriers: elles font fuivies de perites grappes de baies bleues \& fort ferrées, dont les pepins font renfermés dans un noyau dur, oblong, couvert d'une fubitance ononerfe $s$ farineufe: 
Obfervations E additions:

ceft de-là qu'on tire une forte de cire verte. On fait bouillir ces baies en Novembre \& Décembre dans de l'eau bien pure; l'huile furnage bientôt, \& on l'enlève avec une cuillière à mefure qu'elle paroît; on la fait bouillir plufieurs fois pour la rendre moins verre; elle eft trèsfriable. Les uns difent qu'elle donne une belle lumiere, les autres difent obfcure; nous n'en avons pas vu l'ufage. Voyez aufli Catesby, $V o r$. p. 69, \& Kalm. II, p. 334. Linné, Myrica. Adanfon, Gale.

Barba EJpaniola. Cette plante appartient anx plantes parafites, que les Efpagnols appellent Bejuques, \& les François Lianes, au fujet defquelles on peut confulter Adanfon, au mot Iiaron, \& les articles qui le fuivent; Plumier, Lonvillers de Poinci, l'Hiftoire Naturelle de la Louyfiane, le Magafin de Hambourg, T. XIV. page 601, \& le Dict. de Irévoux. Liare.

Barbafco. Les Efpagnols ont donné ce nom. à la Jacquinia Armillaris de Loefling, page 237, \& que Jacquin a décrite : il vient de Verbafcum, $\&$ l'on a ainfi appellé la plante à caufe de fa verut enivrante. Le Pifcidia Erythrina, porte aufi le nom de Barbafco chez les Efpagnols. $V$. Loefling; p. 354: mais c'eft un grand arbre. Bankrofe parle fans doute de la plante, page 64; mais en même-tems il reproche mal à propos à Ulloa Tome 11. 
à avoir dit que les Indiens mâchoient cette herbe avant de la jetter dans l'eau pour prendre du poiffon. Ulloa ne parle pas de mâcher : mais on peut fe convaincre ailleurs qu'ils mâchent cette herbe avant de l'incorporer ovec leurs amorces; le jus en eft fi foporifique, qu'il endort le poiffon qui en avale, \& c'eft dans cet état qu'on le prend; les plus petits poiffons meurent même alors de leur ivreffe: le poiffon n'en contracte aucune mauvaife qualité.

Certe manièrê de pêcher avec le Verbafcum ou Phlomos, étoit comme chez les Grecs; Ariftote, H!l. anim. p. \&, c. 20 , \& Elien, L. I. c. $5^{3}, H_{i j}$ anim. ciré même par Suidas, en font mention. On verra dans Bod à Stapel fur Théophrafe, p. 3, I, quelle efpèce de Phlomos on employoir. Conférez Forskol, Flora Egypticarabica, XXXI. Adanion, Famill XXVI, \& au mot Pifcidia; Riedfel, Voyage au Levant, page II 2 .

Bejuques. On en a déjà parlé au mot Barba ESpaniola. On diftingue deux fortes de Bejuques, l'une qui eft le produit ou la ramification d'une épèce de faule; l'autre une plante, ou corde naturelle, qui s'élève de terre à la faveur des aubres qu'elle rencontre \& qu'elle embraffe. L'autre efpèce en fait autant: mais ces végétaux font très-variés dans les forêts d'Amérique, or les 
Obfervations $\mathcal{E}$ additions.

embarraffent au point de les rendre impénétrables. C'eft ainfi que l'Entada du Sénégal parvient a lier enfemble tous les arbies d'une forêt. Le nor Bejuque eft un nom qui parôit générique; \& n'être pris que des effets de ces plantes, fans en marquer, aucunement les caractères. Cux qui ont été en Amérique, favent l'ufage qu'on en fait pour jecter des ponts d'une roche à une autre, dans des endroits on les rivières font impraticables. V. Hift. gén. des Vuyag. T. XIII, 606. On en verra là l'ufage \& la forme fans parler des Tarabites. Ibid.

Calaguala. Utloa nous a décrit cette plante en Voyageur, mais non en Botanifte. Les détails que nous en donne Pernetty dans fon Voyage aux Malouines, s'accordent avec cenx d'Ulloa; mais on n'en peut déduire aucun caractère affez diftinct pour ranger cette plante dans une clate quelconque; on la dit admirable pour les apoftumes, bonillie \& prife à la dofe de trois ou quatre morceaux dans de l'eau, on infufée dans dı vin, \& à trois ou quatre intervalles dans un jour; elle eft très-échauffante. On en trouve auffi fur les paramos ou cimes défertes des Cordillères; mais elle a moins de vertu: Pernerty la vante auffi comme antivénérienne.

Camoces. On a donné ce nom à des productions différentes. Frézier dit qu'à Pifco les Ca- 
180

Objervations E additions.

motes ou Patates font moins bonnes; il ajoute qu'il y en a de rouges, de jaunes, de blanches. Ulloa les appelle une efpèce de Patates ou de Convolvulus. Dans fon voyage il les compare avec les Patates de Malaga; dains un autre endroit, c'ent une efpèce de Carotte fucrée, \& il appelle les Patates connues en Europe, Papas. On appelle Camotès aux Philippines, une groffe rave d'un goût exquis, \& d'une odeur des plus agréables. Les Camotès font dans les environs de Quito des racines, qui, avec d'autres telles quie les Papas, les Ocas; les Yucas, fuppléent aux légumes verts. Il paroît que Frézier \& Ulloa ont été abufés au fujet de la double dénomination des Camotès; ce fruit eff analogue pour le goût aux Patates de Malaga, mais ne leur reffemble aucunement par la figure.

Caobo, \& dans l'lle Efpagnole Caobar. C'eft l'Acajou, un des plus beaux bois qu'on puife voir.

Capiler, ou Culantrillo, que Lofling nomme Adianthum d'Amérique. On peut voir dans le Voyage de Kalm l'ufage de celui du Nord de ce continent, II, p. 334. Le capillaire du Canada eft trop renommé pour nous y arrêter; il eft infiniment flipérienr à tous les autres par fes qualités, fon oćeur fuave de violette, quelque tems après avoir été cueilli. 


\section{Observations \& additions.}

Ceibo; d'autres écrivent toujours Ceiba; d’aultres Leibo. Frézier indiquoir cet arbre fans le nommer, dans le paffage que nous en avons ciré. $V$. Coton \& Adanfon, Fumill. I. C'ef, après le Baubab, le pliss gros \& le plus haut arbre de la nature. Adanfon a donné des détails trèsintéreffans fur la longue vie de ces deux végétaux, T. I, p. çcxv \& fuiv. Les Anglois appellent le Ceiba, cotonnier a Soie. V. Bankroft. Nous l'avons nomméfromager, de l'odeur de fes fieurs, comme le remarque Jacquin, p. I 2 2. Linné l'a défigné fous le nom de Bombax floribus polyandris, foliis quinatis.

Cet arbre extrêmement toufîtu, s'élève droit; les feuilles en font rondes \& de grandeur médiocre : il pouffe entre fes feuilles une perite fleur, dans laquelle fe forme une efpèce de cocon d'un pouce ou deux de long, fur un pouce à-peuprès de diamètre : c'eft-là qu'eft renfermé ce coton-foie. Lorfque le cocon eft mûr, il s'ouvre, \& laiffe appercevoir un flocon de perits fils, de couleur rougeâtre, \& beaucoup plus fin, plus doux que le coton. Les habitans de ces contrées n'ont encore pu parvenir à le filer, vî fa fineffe; mais on ne peut en accufer que leur peu d'adreffe: comme l'aigledon il fe gonfe à la chaleur, au point de tendre les matelats comme un tambour. On croit quil eft mal fain, wî̀ fa nature extrề- 
182

Obfervations \& additions.

mement froide; mais l'expérience a prouvé qu'on pouvoit coucher fans inconvénient fur les matelats qui en éroient faits.

Ch ncalagua, ou Cancinalagua, \& felon les Inuigènes Cachinlagua. Selon Frézier, c'eft la petite centaurée; elle eft d'une faveur fort amère, purifie trè -bien le fang. Pernetty la décrit un peu autrement qu'Ulloa, qui ne lui donne point de fevilles fur les Paramos. On la dit excellente contre les fièvres tierces, \& autres accidens analogues. On fe gargarife aulli avec la décoction froide; elle eft trop ćchauffante $f i$ on en ufe chaude, mais elle déterge fupérieurement les humeurs. Les Indigẹnes s'en fervent beaucoup; les vertus de cette plante ne font pas inconnues à l'Europe: Frézier les attribue particulièrement au fel dont elle abonde.

Chica. Boiffon particulière aux Indiens d'Amérique. Prefque tous les Ecrivains Voyageurs ont parlé de cette bciffon, avec laquelle les Indiens fuppléent journellement à nos vins, bières, cidres; ils emploient différens végétaux pour la préparer. Frézier a détaillé comment ces gens la font, \& quelles matières ils mettent en ufage, p. 117 , \& comment ils la prennent, p. II 3 ; les excès auxquels ils fe livrent quand elle leur a échauffé la tête, $p$. i i $q$. Bayer donne un autre procédé que celui de Erćzier, \& indique d’autres 
Obfervations \& additions.

plantes. On verra des détails plus circonftanciés dans l'Hift. génér. des Voyages, T. XIV, $p .146$. Quelques-uns emploient aufli des baies de différens arbres, ou fuppléent à cette boiffon avec une efpèce de cidre. Toutes les nations anciennes ont connu les moyens de fuppléer au vin par des boiffons fpiritueufes préparées avec des végétaux. La bière faite avec de l'orge étoit la boiffon des pauvres en Egypte; les Perfes, peuple Tartare, les Celtes, la connoiffoie ntauffi : il paroît même que les premiers peuples de Rome ne l'ignoroient pas.

Chirimoyas. C'elt le fruit d'un arbre qui appartient à la famille des Anones; Miller, dans fon Diction. du Jardinage, le nomme Annona. Cherimoya. V. Adanfon, Famill. XLVI. Bayer en a donné la defcription dans fon voyage au Pérou : mais on trouvera des détails fuffifans dans l'Hift. génér des Voyag. Au refte c'efr, dit-on, un fruit délicieux.

Coca, ou, felon les Indiens, Cuca. Au rapport de Garc. de la Vega, l. 8, c. Is, cette plante eft du plus grand ufage chez les Indiens d'Amé. rique; mais cet Ecrivain ne dit rien des ingrédiens que ces peuples y mêlent felon d'autres Voyageurs \& notre Azuteur. Bayer, Frézier fe taifent aufi fur la Toccra, Llipta, Macubi. Selon Frézier, la Coca eft une feuille plus unie \& moins 
184

Obfervations \& additions.

nerveufe que celle du poirier, du refte elle hii reffemble beaucoup; d'autres la comparent à celle de l'arboifier, mais beancoup plus mince. L'arbriffeau qui la porte ne s'élève que de quatre à cinq pieds; elle fait peler la langue à ceux qui n'y font pas accoutumés; elle augmente, dit-on, beaucoup la force des Indiens; d'autres affurent qu'ils en font des fortilèges. Lorfque, par exemple, la veine de la minière eft trop dure, ils jettent deffus une poignée de cette herbe mâchée, \&z aufît-tôt ils tirent, dit-on, le minérai avec facilité, \& en plus grande quantité. Les pêcheurs mettent auffi de cette herbe mâchée à leur hameçon, lorfqu'ils ne prennent pas de poiffon, \& l'on dit qu'ils en prennent aufi-tôt beaucoup Enfin, ils l'emploient à tant de différens ufages, la plupart mauvais, que les Efpagnols croyoient communément qu'elle n'avoit ces effers qu'en vertu d'un pacte que les Indiens ont avec le Diable. Du tems de Frézier, l'ufage en étoit défendu dans la partie du Nord du Pérou; on ne l'accordoit qu’a ceux du Sud, qui travailloient aux mines. L'Inquifition eft même intervenue pour ces fortes de fortilèges, autorifés par la crédulité, fille de l'ignorance : les Efpagnols ne croient plus rien de cette prétendue vertu magique.

Ulloa dit que cette plante eft abfolument la même que le Betel des Indes Orientales. Conférez Hiflo des Voygg. T. XIV, p. I38. 
Obfervations \& additions.

Culen. Frézier a donné la figure d'une plante de ce nom, '\& lappelle en latin Citifus arboreus floribus fprcatis, dilucè coruleis, vulgò Culen. "L'Alvaquilla, dit-il, \& en Indien Culen, eft un arbriffeau dont la feuille a un peu l'odeur du bafilic; elle contient un baume d'un grand ufage pour les plaies; ce done nous avons vu un effer furprenant à l'Yrequin, fur un Indien qui avoir le col entamé bien avant. Je l'ai aufí expérimenté fur moi-même : fa fleur eft longue, difpofée en épi, de couleur blanche, tirant fur le violet. Fatkner décrit, p. 66, un arbrifiean du Chili, fous le nom Indien $C_{u}$ lem, que les habitans appellent Aloanhacca del campo ou bafilique fauvage: mais il n'a pas de reffemblance avec celui de Frézier, car il porte une graine ronde fans gouffe, des fleurs jaunes, mais non en épi. Adanfon range le Culen ou Pforalea parmi les genets. V. Famill. XLIII, p. 315, 322.

Efparto, ou Sparte. Végétal très - connu en Europe, \& dont on fait des cordes d'un ufage très-avantageux; les Grecs \& les Romains l'employoient pour les mêmes vues. $V$. Linné au mot Stipa, \& Adanfon al mot Spartion.

Frutilla, ou fraife du Pérou. Ulloa la décrit dans fon Voyage, \& la dit plus groffe, plus jutenfe que celle de l'Europe, mais d'une faveur moins agréable, \& même que celle du Chili. 
Frézier nous a donné une très-belle figure de celle-ci. Selon lui, les fraifes du Chili font ordinairement groffes comme une noix, \& quelquefois comme un cuf de poule : la couleur en cit d'un rouge blanchâtre, mais la faveur eft un peu moins délicate que rus fraifes de bois; on y voir auffí la même efpèce que celles de l'Europe. Selon Acofta, la fraife du Chili eft un manger fort agréable, \& a un petit goût de cerife, quoique très-différent de ce fruit-ci. Quand Ulloa nous dit que la fraife du Chili ne fe trouve ni dans les contrées élevées \& froides, ni même dans les climats tempérés du Pérou, il faut l'entendre de la fraife fauvage: en effet, il convient ailleurs qu'on en voit aux environs de Quito, \& même de plus groffes qu'en d'autres parties du Pérou. On cultive dans quelques parties de l'Europe ce fruit, connu fous le nom de fraife du Chili. Voyę Miller \& Duhamel.

Ginfeng. D'après ce qu'on lit dans les Lettres ćdifiantes, $T . X$, il n'elt pas poffible de douter que cette plante fe trouve en Canada; c'eft le P. Laffiteau qui l'a fait connoître aux Européens fous le nom d'Aureliana Canadenfis. On lui attribue les mêmes vertus qu'au Ginfeng de la Chine. La rivière près de laquelle on la trouve eft ì la même hauteur que la Corée, d'où l'on tire le Genfeng pour l'Empereur de la Chine. 


\section{Objervations \& additions.}

Les Iroquois qui la montrèrent à Laffiteau, la nommoient Orent-onguen, mot dont la première partie fignifie cuiffe ou jambe, \& la feconde féparation, oul chofe féparée. On croit reconnoitre dans le fens de ce mot la fignification que les Chinois attachent au Ginfeng, qui, dit-on, défigne les cuiffes humaines. Cette plante, à laquelle on prête tant de vertus qu'elle s'eft vendue plus que fon poids d'or, \& fe paie encore à la Chine cing fois fon poids d'argent, paroît réellement être la mandragore ou le dudaïm des Hébreux. Linné l'a défignée fous le nom de Panax quinque folium. V. Adanfon, Famill. XV. Quoique le préjuigé entre pour beancoup de chofes dans les vertus du Ginfeng, foit du Canada, foit de la Corée, on eft obligé de convenir, d'après des expériences, que c'efl un végétal très-fortifiant, \& capable de bien fourenir un homme qui vent jouir fouvent dans les bras d'une femme qu'il aime. Burnabay rapporte que les Anglois font entrer en contrebande à la Chine beaucoup de Ginfeng de l'Amérique Septentrionale. Voy. aufii Carver dans fon Voyage.

Granadilla. C'eft le fruit d'une plante qui grimpe comme le lierre, \& qui couvre enfin de fes feuilles l'arbre fur lequel elle 's'ent élevée. La fleur de cette plante reffemble à celle qu'on a nommé feur de la pahion; elle répand une 


\section{Is 8 Objervations \& additions.}

odeur fort douce. Le fruit a la forme d'un œuf, mais plus gros que celui de poule; l'écorce en eft fort liffe, luifante en-dehors, \& de couleur incarnate. Dans la Nouvelle-Efpagne on la dit jaune \& verte en-dehors; en-dedans la grenadille eft blanche, molle, \& contient des pepins affez femblables à ceux du raifin, enveloppés d'une fubftance vifqueufe \& liquide. Ces grains font moins durs que ceux des grenades ordinaires; la faveur de ce fruit eft d'une douceur aigrelette, fort rafraîchiffante, cordiale; mais il faut le garder quelques jours cueilli avant de le manger, fi l'on veut le trouver bon, autrement il n'auroit pas fon degré de matuité. Feuillé appelle la plante Pafiflora tilikfolia. $V$. Adanfon, Famill. LI, \& Frézier, p. 406.

Guabos, ou Pacaës. De la Vega conferve le nom Indien Pacay, de même que Frézier. On voit par la defcription de celui-ci que l'arbre eft une efpèce de Gleditfra, dont les François appellent le fruit pois fucrins. Pacaës eft le nom d'ufage au Pérou, \& Guabos celui de la province de Quito. Ulloa obferve dans fon Voyage, que ces fortes de féves ne mûriffent point dans leurs filiques au Royaume de Quito, \& qu'il faut les y garder un peu, comme tous les autres fruits, après lesavoir cueillies, pour atiendre leur degré de maturité. Frézier, qui a repréfenté l'ar- 
bre, l'appelle Inga peruviana, filiquá quadrangulâ. On peut voir dans fes détails en quoi il diffère de l'Inga de Pifon \& de Plumier; celui de Frézier eft dans Linné mimofa fagifolia, \& celui de Plumier, Inga flore albo fimbriato, fructu dulci. Ces fèves font chacune dans une loge: en ouvrant la filique on les trouve enveloppées d'une moëlle fpongieufe, légère, blanche, filamenteufe, \& que l'on prendroit pour du coton; elle eft extrêmement rafraîchiffante; c'eft une véritable huile cryttallifée.

Guao. Jacquin, dans fes plantes d'Amérique, l'appelle Comocladia dentata. Le fuc vifqueux \& laiteux de cet arbre noircit totalement à l'air, \& teint même en noir les linges \& les mains. L'odeur en eft dégoûtante, analogue à celle des excrémens humains; pour peu qu'on piquel'arbre, il répand cette puanteur. Les habitans de Cuba croyent que fon ombre a été mortelle pour plifieurs perfonnes qui s'y étoient repofées; mais Jacquin dit qu'il n'a aucune expérience fur ce fait.

Guayabos. V. Adanfon, Famill. XIV. Cer arbre, fauvage dans le continent de l'Amérique, eft devenu un objet de culture dans l'Ifle Efpagnole, \& il y vient beaucoup plus beau: il eft de la taille d'un oranger; les branches en font plus éparfes; la feuille reffemble à celle du lan- 
rier, mais elle eft plus épaiffe, \& a les fibres plus marquées. Il produit des efpèces de pommes, les unes rondes, les autres oblongues, mais plus larges à leur tête; elles font d'abord vertes, \& jauniffent en mûrifrant; la pulpe en eft blanche ou vermeille. Elles font divifées en quatre parties, maflives, pleines de perits grains fort durs, mais qui digèrent aifément; on les dit même très-utiles pour les. flux de ventre. La fleur du Guayabo reflemble à celle de l'Oranger, \& n'eft pas fi épaiffe; on fent une odeur de jafmin dans quelques-unes. Cet arbre, vieux au bout de cinq ans, ne donne qu'un bois peu propre aux ouvrages. Les Indes Orientales ont aufif leur Goiavier, quon y nomme Pereyra.

Hedionda. C'eft ainfi que l'on a nommé. Ia plante que Feuillée défigne fous la dénomination de Parqui. Linné, Spet. Planc. \& Adanfon l'ap. pellent ceftrum, ou hedionda jafmini fore, herbe fétide à fleur de jafmin. V. Adanf. Famill. XXVII!.

Loiling parle de même dans fes plantes d'Amérique; cependant il femble qu'Ulloa indique ici le chenopodium anthelmenticum, dont Kalm fait mention dans fon voyage. Adanfon obferve même que la plupart des efpèces de Chenopodium ont une odeur fétide, $T . I I, p .260$. $Y$. auffi Cleyton, Flor. Virgin.

1cho. L'Auteur parle plufieurs fois de ce végétal. 


\section{Obfervations \& additions.}

$C^{\prime} \in$ ft une herbe qui reffemble affez à notre petir jonc, mais un per plus mince; elle eft terminée par une pointe piquante. On ne trouve prefque que de l'Icho fur toutes les montagnes de la Puna. Comme dans la plus grande partie du Pérou il n'y a ni bois à brûler, ni charbon, c'eft avec l'Icho qu'on y fupplée pour chauffer les pignes par le moyen d'un four, dit Frézier. Le Pajon, dont parle l'Auteur, eft une herbe analogue. Nous obferverons feulement ici que ce mot icho a une fingulière reffemblance avec le mot acho ou achou, qui en Hébreu fignifie un jonc, \& un lien ou corde. $V$. le Lexique Hébreu de Simon.

Lucumos. Selon de la Véga, les Indiens de fon tems appelloient Rucma ce fruit que les Efpagnols ont d'abord nommé Lucma; la dercription qu'il en fait revient à celle de Frézier. On commence, dit celui-ci, à voir dans le climat de Coquimbo, un arbre qui ne croît pas dans tout le refte du Chili, \& qui eft particulier au Pérou : on l'appelle Lucumo; fa feuille reffemble à celle de l'Oranger \& du Floripondio; fon fruit eft auffi fort femblable à la poire qui enferme la graine de ce dernier : quand il eft mûr, l'écorce eft un peu jaunâtre, \& la chair fort jaune; il a à-peu-près le goût \& la confifrance du fromage fraîchement fait; au milieu eft 
un noyau tout-à-fait femblable à une châtaigne pour la conleur, la pelure \& la confiftance; mais il ef amer \& ne fert à rien.

Quant au Floripondio, Frézier en parle ainfr: "On cultive dans les jardins un arbre qui donne une fleur blanche faite en clochetre, appellée Floripondio. L'odeur en eft très-fuave, particulièrement la nuit; elle eft longue de huir à dix pouces, \& en a quarre de diamètre par le bas; la fecille eft velue, \& un peu plus pointue que celle du noyer : c'êt un puifrant réfolutif pour certaines tumeurs. Obfervons que la fleur eft à-peu-près de la forme du lis, \& a auli de fort grandes étamines. Cer arbre fleurit toute l'année. M. de la Condamine dit que les Omagues ufent de la fleur d'une plante nommée floripondio par les Efpagnols, \& de la forme d'une cloche renverfée, pour s'enivrer, \& fe procurer d'érranges vifions. Leur délire dure vingt-quatre heurés environ."

Mandragore. $V$. Ginfeng, \& conférez les. détails que Kalm donne dans fon Voyage, III. p. 407-4II.

Manzanillo, Mancenilier. Jacquin a mieux. décrit que perfonne cet arbre \& fon fruit cians fes plantes d'Amérique. Il mérite d'être lu pour certaines particularités fur lefquelles les Ecrivains ne s'accordent pas. On fait combien il eft dan- 
Obfervations \& additions.

gereux de s'arrêter à la proximiré de cet arbre, \& que le remède des plaies faites avec des flèches trempées dans le fuc de fon fruit, eft le fel. On a aufí préconifé l'huile d'olive comme un très-bon antidote. Au refte les émanations de cet arbre font des plus à craindre. Un François s'affied fous un Mancénilier après une petite pluie; il lui tombe quelques goutres d'eau des branches fur la tête \& fur l'eftomac, bientôt il lui vint des puftules dont il penfa périr; on eut bien de la peine à le fauver : il fut marqué comme de cicatrices de petite vérole aux endroits où les gouttes d'eau étoient tombées. $V$. Adanfon, famille XLV.

Marie. Arbre-Marie, un des plus grands \&r des plus gros de la contrée de Carchagène, où il eft fort commun, mais dont on n'a pas encore déterminé le genre ni l'efpèce. Il en découle un fluide qu'on a nommé Huile-Marie. Uiloa parie avec avantage du bois \& de. l'huile, dans fon voyage au Pérou. Bonguer dit qu'on y voit des arbres très-grands, remarquables par leur écorce blanche. On n'y peut employer que ces arbres pour la mâture des vaiffeaux : ils font fort flexibles, \& n'ont point cette pefanteur commune à tous les autres bois. On trouve dans le magafin de Gottingue, I vol. 1. cayer, p. 85, cet arbre comparé avec le Morus-papyrifera de Taïri. Il Tone $I$. 


\section{Obfervations \& additions.}

feroir à fouhaiter que l'analogie en eût éré détermince par Forner.

Maté : herbe du Paraguai. On nous a donné dans nombre d'Ouvrages les détails les plus circonftanciés fur l'ufage de cette plante, fur le grand commerce qu'on en fait. On nous a dit que Maté n'étoit pas le nom de l'herbe, mais du vafe dans lequel on en faifoit l'infufion; mais perfonne ne nous marque les formes caractéritiques de la plante: il eft à préfumer que c'eft le Prinos-glaber de Linné. L'Hiftorien du Paraguni dit que c'ent la feuille d'un arbre de la grandeur d'un moyen pommier; quelie reffemble un peu à la feuille de l'oranger, que fon vrai nom eft Caa chez les Indiens, qui en diftinguent trois efpèces, favoir le Caa-mini, le Caa-cuys, le Caraguzu. Le premier fe dit du bouton qui commence à s'ouvrir, le fecond de la feuille totalement développée, le troifième de la feuille à laquelle on a laiffé les côtes.

L'Apalachine, ou Cafline de la Louyfiane, dont les Sauvages boivent l'infufion des feuilles, après les avoir fait griller comme l'herbe du Paraguai, a fait croire que c'éroit la véritable herbe du Paraguai; mais Miller auroit bien pu fe tromper. Il eft plus que probable que ce n'eft pas la même; ainfi nous ne pouvons encore la rapporter à aucune clare: au refte on trouvera dans l'hiftoire 
du Paraguai, dans Frézier, dans l'Hill. geenér. des Vroyages, le plus grand détail fur cette herbe fi vantée en Amérique, \& qui fait pourainfi-dire, la plus tiche branche du commerce intérieur.

Moniatos. C'eft l'Y atropha-manihot de Linné. Ulloa a détaillé dans fon Voyage comment on en fait du pain, après en avoir extrait le principe âcre \& véneneux. L'Iuca, le Niames, ou Ignames, ou Nagmes, fervent aufli aux mêmes vues. On verra dans le Dictionnaire d'Agricule ture de M. l'Abbé Rozier, des détails trèsfatisfaifans fur ce pain, à l'article Caffave. $V$. auffi $T . X V$ de l'Hifl. génér. des Voyages, $p .71$. Les Anciens ont auffi fait du pain avec des racines analognes, \& peut-être les mêmes; mais nous ne devons pas entrer ici dans ces détails.

Nifperos. En général Néffier. Cependant Jacquin écrit dans fes Plantes d'Amérique, tine Achras-zapota, fous le nom de Nifperos, p. 59. Il n'eft pas moins vrai que le Néflier eft actuéllement un arbre très - commun en Amétique, mêtme dans les villages des Indiens, \& que e fruit y eft beaucoup plus délicat qu'en Europe. Pacaës. V. Guabas.

Pacanos. La Pacane eft le fruit d'un arbre rès-haut, dont le bois, l'écorce, l'odeur \& la igure des fevilles repréfentent aflez le noyer de

$\mathrm{N}_{2}$ 


\section{6 \\ Obfervations \& additions.}

l'Europe. Certe noix a la forme \& la longlieur d'un gros gland; la coque eft tantôt plus épaiffe, tantôt plus mince; l'épaiffeur eft toujours au préjudice de la groffeur du fruit, qui en général eft d'une faveur très-délicate.

Palmier. Le Palmier eft un arbre dont les efpèces font fi varićes dans l'Amérique Méridionale depuis l'inthme, qu'il faudroit un volume pour les décrire \& en dérailler les ufages. Dans Pexcellent Difcours où l'Auteur expofe les maladies de l'Amérique Efpagnole, il fait mention d'une efpèce particulière, qu'il appelle Palmaréal, \& en nomme le fruir Palmiche. C'eft à ce fruit, dit - il, qu'on atrribue la lèpre de la Havane \& de Carthagc̀ne; mais l'Auteur dit avec raifon, que ce ne peut pas en être la feule caufe. Il diftingue quatre forres de Palmiers dans fon Voyage. Gumilla fait mention d'un plus grand nombre d'efpèces, \& plus curieufes que celles dont parle norre Auteur. $V$. fon Orenoque. Le Palma-réal elt fans doure l'Areca-oleracea de Linné. Le Corazo, qui de tous les Palmiers rend le meilleur vin, eft regardé par Jacquin comme appartenant à l'efpèce de Palma-Elä̈s. On verra dans les Hiftoires des Indes Orientales \& des Illes adjacentes, plufieurs effièces de Palmiers non moins curieufes, \& auffi utiles que ceux de l'A mérique. Un arbre qui feul fournit du pain, 
du vin, des vafes, des cordes, des voiles, une barquie, \&c. eft fans doute bien précieux. On en compte plus de quarante efpèces dans les feules Philippines.

Paltas, Paltos, V. Aguacates.

Platanos. Ulloa écrit Plantanos dans fon Voyage. D'autres Ecrivains préfentent aufli cetre différente orthographe. On a traduit ces mots dans différens Ouvrages, par Platanes ou Planes, \& Plantains. On ne peut pas dire qu'Ulloa les confonde: s'il l'avoit fait, il auroit eu tort avec nombre d'autres, car les Platanes \& les Plantains ne font ni le même arbre, ni lè même fruit. Le Platane porte fes fruits en grappe : ceux du Plantain tiennent au corps même de l'arbre. Au refte le. Plantain eft un arbre fort cónnu dans l'Amérique \& dans les Indes Orientales. Les Indiens lappellent $A m u f a$, d'où l'on a fait le nom de Mufa, adopté par les Botaniftes. $V$. Jenn Bauhin, Linné, Adanfon. On trouvera plufieurs defcriptions fort intéreffantes de ces arbres dans l'Hift. génér. des Voyages, fur-tout celles du Plantain des Canaries, \& celle du Plantain Oriental donnée par Dampier.

Quinual. Cet arbre ent une des productions des Paramos, fur lefquelles Ulloa donne dans fon Voyage des détails plus étendus qu'ici. Le Quinual eft d'une taille médiocre, touffu, d'un 
198

Objervations \& additions.

bois fort \& denfe. Il a la feuille épaiffe. Ia graine appellée Quinoa, n'en eft pas le fruit, mais celui d'une plante qui fe feme tous les ans, \& s'éleve à trois ou quatre pieds; les feuilles ont quelque rapport avec celles de la mauve; mais elles fe terninent en pointe : du milieu de fa tige s'élève une fleur de cing à $f i x$ pouces, comme celle da maïs, \& dans laquelle les graines forment un épi. On la met à l'eau; elle eft bonne comme aliment; \& appliquée en cataplafme fur les abcès, ou fur les parties contufes ou froiffées, elle attire les humeurs, ou prévient tout dépôt.

Sapotes. Ce fruit fauvage paroît être l'Achras mammofa de Linné. Conférez Loefling, Plant. Améric. 61. \& Adanfon, famil. XXII.

OBSERVATIONS É additions fur le règne Animal.

$A_{\text {Betlles. Ce que l'Auteur dit des Abeilles }}$ de l'Ine de Cuba, que les Anglais avoient apportées avec eux de Saint-Augutin à Guanavacar, \& qui fe propagèrent enfuite dans les contrées voifines, n'a rien de particulier. Kalm. II. p; 427 . fait la mêtne remarque an fujet de l'A mérique Septentrionale, où les Sawages appellent les 
Obfervations \& additions.

Abeilles, Mouches Anglaifes. Les effaims fe portent toujours de plus en plus au Sud, \& jamais au Nord.

Les Abeilles fe trouvent très-répandues dans prefque toutes les contrées de la Domination Efpagnole. on en compte même jufqu’à dix ou douze efpèces différentes. On remarque comme une chofe affez fingulière, que quelques-unes n'ont pas d'aiguillon, au moins ne piquent-elles jamais. Telles font celles de l'Orenoque, de la Guadeloupe \& d'autres contrées du NouveauMonde; cependant ce font de vraies Abeilles, puifqu'elles font un miel excellent. D'autres ont réellement un aiguillon; mais leur piquure eft plutôt un léger chatouillement, foit que cetre arme foit trop foible pour percer la peau, foir qu'il n'ait pas la forme tranchante, ou de fcie, telle que l'aiguillon de celles de l'Europe, dans la gaine où il eft renfermé : ce qu'il y à de certain, c'eft qu'il n'y a rien à craindre lors même qu'elles font le plus irritées; aufil les finges en diffipent-ils le miel, foit en le prenant avec les pattes, foit en y trempant leur quene, quilils fucent enfuite : les ours font encore un autre ennemi des Abeilles,

Quelques Indiens logent ces mouches dans des creux d'arbres qu'ils leurs préparent fans beau$\mathrm{N}_{4}$ 
coup d'art, \& n'y cherchent que le miel, haiffant la cire, dont ils ne font aucun ufage; d'autres en font de petits vafes d'une confiltance affez forte; mais d'autres en tirent un grand profit. Il feroir à fouhaiter que quelque Naturalifte eît foigneufement examiné ces diverfes efpèces de mouches du Nouveau-Monde : on en auroir fans doute tiré des lumières pour perfectionner le travail de la cire \& du miel dans nos contrées. L'Abeille Américaine, qui paroît mériter le plus d'attention, eft celle qui dépofe fon miel, non dans des rayons, mais dans des efpèces de godets de cire de la grofeur d'un cuf de pigeon : ce miel eft extrêmement délicat. Quelques perfonnes font parvenues à les apprivoifer, \& en ont tiré beaucoup de profit.

L'Abeille prife généralement, démontre plus qu'aucun être du règne animal, combien la nature varie les efpèces d'un même genre dans les différens climats. En $\in$ fifet, fi l'on compare entre elles les Abeilles de l'Europe, de l'Amérique $\&$ des Indes Orientales, en y comprenant celles des Intes refpectives, on eft étonné de l'extrême différence qu'il y a entre les unes \& les autres. Dans nos climats même, elles différent $f_{i}$ fort entre elles, qu'il femble gue certaines efpèces font autant de genres particulicts de motr* 


\section{Obfervations \& additions.}

ches, qui n'ont de commun que la fonction de la cire \& du miel, mais avec un art qui ne reffemble en rien à celui des autres.

Alpaques. Pacos. Alpaca. Les defcriptions que divers Ecrivains nous one données de cet animal, préfentent des contradictions qu'il n'eft prefque pas pofible d'éclaircir ici. Frézier nous dit qu'il y a une efpèce d'animal noir, femblable au Llamas, appellé Alpaque, dont la laine eft trèsfine; mais il a les jambes plus. courtes \& le mufle ramaffé, de manière qu'il a quelque rapport alt vifage humain. Les Indiens fe fervent de ces animaux à différens ufages : ils les chargent d'environ cent livres. Leur laine fert à faire des étoffes, des cordes \& des facs; leurs os fervent à faire des inftrumens de tilferans : enfin leur fiente fert à faire du felı."

D'après cette defcription faite par un homme qui a été fur les lieux, on demandera fans doute avec raifon, quel eft l'animal que Linné a voulu décrire, lorfqu'en parlant de l'Alpaque, il dit: totus fanguineus, fubtus albus-nec oneribus portandis par. Boyer dit aufi que l'Alpaque ne porte rien; mais ce n'elt pas le feul animal dans la defcription duquel Limné, ce célebre Naturalifte, fe foit trompé.

Ulloa dit que l'Alpaque \& le Guanaco, font les deux efpèces les plus grolfes des trois; favoir 


\section{Objervations \& additions.}

que le Llama, que l'Alpaque fert auffi à porter des fardeaux, \& que proportionnèment à fa taille, il porte plus que le Llama; c'eft donc à dire que l'Alpaque eft plus petit : autre contradiction.

Frézier dit que l'Alpaque a la laine noire, Ulloa, qu'il l'a femblable à celle de la vigogne; mais celle-ci, felon Boyer, a la laine d'un brun clair; l'Alpaque l'a donc aufl d'un brun pareil, autre contradiction : ainfi voilà trois couleurs; $1^{\circ}$. d'un rouge de fang; $2^{\circ}$. noire, \& $3^{\circ}$. d'un brun clair.

Mais Boyer dit en outre, qu'il y a des Aipaques de couleur grife, d'autres noirs comme le charbon, d'autres d'm brun obfur, d'autrcs blancs comme neige, \& que c'elt la laine la plis eftimée des Indiens, parce que c'eft celle qui peut prendre les plus belles conleurs. Il a raifon, il s'en voit même de bigarrés, que les Indiens appellent Moromori; mais Boyer attribue aux Alpaques cette faculté particulière de cracher fur ceux qui les moleftent, une falive puante; ce dont aucun autre Ecrivain ne fait mention : il femble qu'il veut parler de ce que Frézier dit des Llamas : "Leur lèvre fupérieure, comme celle du lièvre, ent fendue au milieu : par-là ils crachent à dix pas loin, contre ceux qui les inquiètent, \& fi le crachat tombe fur le vifage, il y fait une tache roulfâtre, où fe forme fouvent 


\section{Obferyations \& additions.}

une gale. Quant aux charges que ces animaux porrent, il eit prouvé contre Limné \& Boyer, que ces animaux, comme le Llama, fervent à cetre fonction : on en voit mệme des troupes de fix à fepr cens, toutes chargées; \& quelquefois de cent cinquante livres chacun, fi la route quils ont à faire n'elt pas longue.

Mais voici encore d'autres difficultés. Boyer reconnoît deux efpèces de moutons au Pérou: la première eff celledes Llamas, la feconde des Alpaques. Selon le récit de tous les Voyageurs, ces deux efpèces on ure laine longue. Mais Acolta, qui admet aum denx elpèces de moutons, le Llama \& le Pacos, diningue cette feconde efpèce en deux autres, l'une portant laine longue, \& l'autre à poil (ou laine) ras. Celle-ci, diț-il, a une belle figure, s'arrête têtc levée, fixe hardiment l'homme, fans faire paroître le moindre figne de crainte ou de fatisfaction; cependant l'animal s'effraie quelquefois an point de fe rauver rapidement avec fa charge, fur des roches efcarpées, où il n'eft polible de l'avoir qu'en le tuant d'un coup de fufil, fi l'on ne veut pas perdre les barres d'argent dont il eft chargé.

Voilà donc bien des circonftances qui nous perfuadent que cer animal n'a pas encore été affez bien connu, ni afiez exadement décrit, pour être claffé où il doit lêtre. 


\section{Obfervations \& additions.}

Acolta ajoute que les Pacos qui fe font une fois couchés, fatigués par leur charge, ne fe relevent plus, de quelque maniere qu'on s'y premne pour les remettre en marche; que cette opiniâtreté de l'animal a domné lieu au Pérou à l'expreffion empacada, lorfqu'on veut marquer l'obntination d'une perfonne qui ne veut céder à aucun avis; mais c'eft au Llama que D. Ulloa atribue cette opiniâtreté. Nous ne fuivrons pas Acofta dans tous fes détails, car ils ne ferviroient qu'à répandre une nouvelle obfcurité fur ces efpèces d'animaux, quoique ce foit peut-ĉtre celui qui en ait parlé plus pertinemment: les Naturaliftes le confulteront. M. Schneider eft lui-même fi confus dans les remarques qu'il fait ici, que nous avons pris le parti de ne pas le fuivre: c'eft ce qui nous arrive encore en plufieurs articles, comme dans le fuivant.

Anta. Les Naturaliftes nous ont donné des defcriptions fi différentes de cet animal, que nous avons peine à croire que quelques-uns d'eux en aient parlé d'après ce qu'ils en ont vu. M. de la Condamine l'appelle Elan ; mais il s'explique, \& dit qu'il parle de l'animal que les Brafiliens appellent Tapura, \& les Portugais Danta. Les Indiens Péruviens le nomment Uagra, les Galibis Maypouri. C'eft fous ce dernier nom qu'en parle. Bajon dans fon Hitoire 
de Cayenne, T. 2.; il en donne même le détail anatomique. Ulloa, dans fon Voyagé, s'accorde avec la Condanine. Charlevoix nous apprend dans fon Hiftoire du Paraguai, pourquoi on a donné.le nom d'élan à cer animal amphibie. Falkner dit que l'Anta eft une efpèce de cerf. $V$. fon Hift. des Patagons. Erxleben le nomme Hydrocharus tapyr, \& Linné Hyppotamus terrefiris.

Une des marques auxquelles on voit combien les Ecrivains ont été peu attentifs dans la defcription de cet animal, eft leur contradiction fur les ongles des pieds. Les uns lui domnent le pied fourchu en deux fur le devant, \& en trois fur le derrière; d'autres lui donnent trois ongles a chaque pied. Mais un homme plus croyable que tous les autres, Gumilla, puifqu'il a vu, manié cet animal, \& qu'il en a mangé, nous dit : “ fes pieds font fort courts, \& terminés par quatre ongles qui font extrêmement recherchés. Il n'eft pas douteux que l'animal dont il parle ne foit celui que la Condamine appelle Elan, \& que d'autres comparent à l'Orignal du Canada. Comm ment Linné a-t-il pu nommer Hyppotame un animal qui a la tête faite à-peu-près comme celle d'un Cochon, \&r qui a fur la tête un os terrible avec lequel il renverfe tont ce qu'il rencontre, \& qui intimide même le Tigre? Voici les détails 
206

Obfervations s. addicions.

de Gumilla, puifquion ne les a pas placés dans l'Hiftoire générale des Voyages au $T . X I V$, p. I 52 \& I 53. On y ajoutera donc: “Les Achagues, Nation Indienne, fe cachent dans l'herbe, \& imitent la voix de l'Ante, à laquelle lAnte (ou grande lête) répond bientôr, \& le mâle ne tarde pas à approcher avec fa femelle; à l'inftant I'Indien décoche à chaque une fièche empoifonnée avec le Curaré, qui les fait tomber roides morts fur le champ. La viande a le même goûr que le Veau. La figure de cet animal eft des plus fingulières qu'on puiffe voir; il eft de la groffeur d'un Minlet ou d'un Cheval d'un an, fes pieds font fort coutts \& peu proportionnés à fa taille, \& terminés par quatre ongles, qui. font extrêmement recherchés. On a plufieurs fois éprouvé leur vertu contre l'épileplie; on les prend en poudre, \& l'on en pend au col du malade. Nous omettons ici comment le Tigre tue cet animal ou en eft tué, avec quelle promptitude il écorche le Chien qui ofe l'attaquer, \&c. V. Gumilla, Tom. II, pag. I 6 \& Juiv.

D'autres lui donnent la groffeur d'un Ane, \& à-peu-près la même figure; les oreilles fort courtes, une trompe quil allonge \& retire à fon gré. Mais $r$. l'Hift. générale des Voyages. Tout ce qu'on peut conclure de ces différentes defcriptions, c'eft que les Voyageurs l'ont la 
Obfervations E्G additions.

phupart décrit fur des rapports, \& non d'après l'infpection même, comme Gumilla l'a fair. Linné eft celui de tous les Naturalintes dont on doir le plus fe défier dans la defcripticn des a nimanx. Confultez auffi le Diction. des Animaux, T. $I$.

Bagre. Ulloa parle de ce poiffon dans fon Voyage, mais il ne le décrit pas d'une manière plus étendue qu'ici : il nous dit que c'eft le plus gros poifon du Guayaquil, \& qu'il a quelquefois une vara \& demi de long. Selon lui, ce poiffon ne fe mange que falé, à caufe de la vifcofité qui donne à fa chair une faveur défagréable, \& même un fuc mal fain. Il parôit par la defcription qu'en fait Falkner, que ce poiffon apparrient au genre du Silutus de Linné; mais ce genre eft-il vraiment commun aux poiffons que les Efpagnols ont nommés Bagres. La pêche ọi fe fait de ce poiffon avec le Barbafco, eft conmue dans la plupart des contrées de l'Amérique. M. Schneider pouvoit ajouter que les Indiens prennent quelquefois des Bagres qui pèfent jufqu'à cinquante \& foixante livres, \& qu'ourre le Barbafco, plante, dit Gumilla, qui a la forme $\&$ la couleur de la vigne en treille, les Indiens en emploient encore une autre qu'ils appellent Cuna, femblable au fainfoin. Cetre dernière a des émanations fin fortes, que les poiffons l'évi- 
208

\section{Obfervations \& additions.}

tent autant qu'il leur eft poffible lorfqu'on en a jetté dans une rivière. Mais les Indiennes favent tromper le poiffon; elles jettent d'abord des boulettes de mais cuit; le poilfon les fainit avidement : mais bientôt elles en jettent d'autres, où elles ont pêtri de la Cuna écrafée; le poiffon les failit, refte enivré fur l'eau, \& les enfans qui font dans la rivière le premnent fans difficulté. Quant au gros poiffon qui fuit l'odeur, il faute pardeffus une claie dont l'eau eft barrée, mais il tombe dans un autre piège, où une femblable claie l'arrête. $V$. au mor Barbafco: \& le Dictionnaire des Animanx au mot Bagre, pour les détails particuliers qui concernent la forme de fix ou fept efpèces de ce poiffon.

Baleine. Ce que dir Uiloa de l'haleine fétide \& des jeux de la Baleine, eft confirmé par le Voyage de M. Forfter. En parlant de la Baleine Boops, de la mer du Sud, il dit:"Les Baleines alloient généralement enfemble, ce qui prurut indiquer le tems de leur accouplement. Toures les fois qu'elles fe trouvoient du côté d'où le vent nous venoit, nous avions à fouffrir pendant trois ou quatre minutes, une puanteur infecte \& mal faine. Si elles fe mettoient fur le dos, elles battoient l'eau fi fort avec les nageoires antérieures, qu'on auroit cru entendre la décharge d'un canon de demi-livre de balle." 
Objervations \& additions

On trouve les Baleines en très-grand nombre fur les côtes de l'Amérique Méridionale jufqu'à l'Ifle de Falkland, \& à la Georgie Méridionale. M. Forfter rapporte que les Portugais ont établi depuis quelques années dans les premiers parages, une pêche de Baleine affez confidérable. Lemaire dit qu'on trouve dans la mer du Sud cent Baleines contre une dans celle du Nord, \& prefque tous les anciens Voyageurs s'accordent à dire que ces poiffons font bien plus gros vers le Sud que dans le Nord.

Ulloa ne peut pas avoir eu intention de parler de la Baleine Boops; c'eft M. Otho Fabricius qui nous en a donné depuis peu une defcription très-détaillée dans fa Fauna Groenlaudica, p. 38 ; en nous apprenant aufficomment elle attire à foi fa proie, \& la faifit. Son ennemi juré eft le Phyfeter microps, ou Soufleur à petits yeux de Linné. Au refte, les détails d'Ulloa méritent d'être comparés avec les penfées du Préfident Labroffe fur le Commerce chez les Patagons, lefquels fe trouvent $p .606$ de l'Hiftoire des Voyages dans la mer du Sud.

Quant aux coquillages que notre Auteur dit s'amaffer, particulièrement fur la tête de la $\mathrm{Ba}$ leine, où même ils fe propagent, Cranz dit la même chofe dans fon Hiftoire de Groenland, $I, p . i 46$, au fujet du poiffon que les Pêcheurs

Tome 1 . 


\section{\$10 Obfervations \& additions.}

Efpagnols appellent ordinairement Gubartar ou Gibbar; c'eft à ce poiffon que s'attachent les glands de mer \& en grande quantité. Otho $\mathrm{Fa}$ bricius contirme ce rapport comme témoin oculaire, \& décrit la coquille ou le lepas balanaris, dont je ne marquerai ici qu'une feule circonftance, c'eft que ce coquillage s'attache dans les rides du ventre de la Baleine Boops, ou dans les âllerons de fa poitrine : leur couleur blanche eft la marque qui fert à diriger le coup des pêcheurs lorfqu'ils veulent percer une Baleine.

Outre l'Efpadon, la Scie, la Baleine a encore an ennemi redoutable dans le Batteur, poiffon affez mince, mais qui porte jufqu’à quinze ou feize pieds.

Bejuquillos. L'Autenr ne nous apprend rien de particulier à cesferpens, qui s'attachent aux Bejuques; les Naturaliftes n'en ont pas non plus décrit l'efpèce.

Bête puante. Carver affure dans fon Voyage "d'Amérique que la puanteur qu'elle exhale ou lâche contre l'ennemi qui la pourfuir, ne vient pas de fon urine. Il ouvrit plufieurs de ces animaux qu'il avoit tués, \& trouva, près de la veffie urinaire, un petic réduit aquenx qui en étoit totalement féparé, \& duquel il fut perfuadé que venoir cette odeur fi rebutante : dit refte lexhalaifon n'én étoir pas cadavereufe, mais 


\section{Objervacions \& äddizions:}

flutuốt analogue à une forte vapeur de mufc, $8 \dot{z}$ lui parut plus choquer par fon extrêtme vivacité que par quelque chofe de dégontrant. Ce petie animal, gros comme un moyen lapin, a l'oil très-vif, l'oreille \& la patte d'une fouris : le mâle a le poil noir; celui de la femelle eft noir, avec quelque bigarrure de blanc. On voit aufi dans quelques contrées des Indes Orientales, des animaux qu'on pett appeller Bêtes puantes : celle duCapde Bome-Efpérance reffemble d l'écurecuil ì mais eft beaucoup plus groffe que celle dont parle notre Auteur. On pent voit dans Kolbe des détails ultérieurs fur cette bête ou blaireau puant du Cap: les pets ou vefles qu'il lache quand il eft pourfuivi, font d'une odeur fi infecte, qu'on en eft pour-áinfi-dire étouffé. L'animal qui le pourfuit fe fauve fur le champ hors de la fphère de l'exhalaifon, pour refpiré en fe frottant le nez fur l'herbe ou contre un arbre : pendant ce tems-là cette bête fe fauve; telle eft larme que la Nature lui a donnée. $V$. le mot Zorillo.

Bêtes rouges. Petits infectes qui fe rencontrent fréquernment dans les favanes, ou prairies; ils ont la groffeur d'une tête d'épingle. C'eft l'Acarus fanguifugus de Linné; mais l'herbe pourrie nit rien de commun avec leur production. Ils fo tiennent probablement en Amérique fur le haut des joncs, rofeaux ou autres herbes, les partes dig

O 2 


\section{Obfervations \& additions?}

devant tendues, pour fe jetter \& s'accrocher aut premier qui paffe, foit homme, foit animal, \& fe nicher dans la peau. Pallas en a parlé dans fon

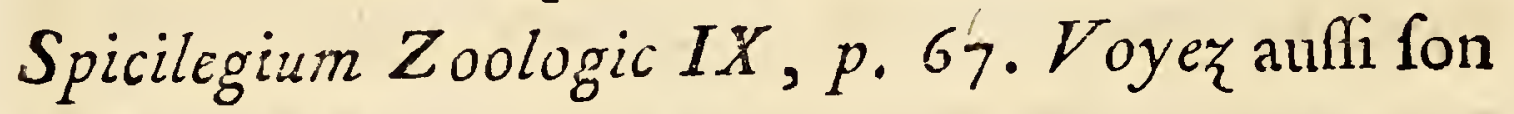
Voyage III, p. 504, Frézier \& autres.

Bezerras. Efpèce de cerf du Mexique. Ils font de la taille d'un mulet, très forts, ont la queue velue, \& plufieurs même auffi longue qu'un mulet. Les efpèces de cerf font affez variées en Amérique : on confultera les Naturaliftes fur cet article, qui nous feroit fortir de notre plan fi nous nous $\mathrm{y}$ arrêtions.

Bobas. Efpèce de ferpent commun à l'Amérique \& atux Philippines; ils font d'une grandeur dont on n'a prefque pas d'idée : on fe figure en effet avec peine qu'on puife rencontrer dans ces différentes régions, des reptiles de trente pieds de long, \& même davantage.

Boga. Poiffon du lac Titicaca, fort petit, muni a'écailles, \& d'une affez mauvaife faveur. Les Efpagnols l'ont fans doute nommé Boga, de la reffemblance qu'il a avec le Bogue, connu fur les côtes d'Efpagne, de Gềnes \& du Languedoc. Il y a au Bréfil un autre poiffon nommé Bogue, qui reffemble an Thon d'Efpagne, \& de la même grandeur.

Buyo ou Buio. Serpent d'une énorme groffeur, que les Indiens Jiraras appellent Aviofa, \& 
d'autres Yacumama, c'eft-à-dire, mère de l'eau. Carréri nous parle d'un ferpent des Philippines, nommé Ibitin, à qui il attribue la même propriété qu'on donne au Buio, favoir, d'attirer par fon haleine redoutable, les hommes, les animaux les plus gros, même les Tigres, les Caimans, $\&$ de les avaler en les fuçant peu-à-peu. On a beaucoup parlé de cette vertu attractive du Buio; qu'on a auffi traitée de fable. Ulloa, qui copie prefque mot pour mot dans Gumilla la forme de ce monftrueux Serpent, \& non de la Conda mine, femble ne pas difconvenir de cette attraction fatale, \& l'explique affez bien : mais les détails de Gumilla, les faits étonnans qu'il produit, font encore plus convainquans. $V$. fou $T . I I_{*}$ p. 32 \& fuiv. Edit. franc.

Cahuitahu. V. Criard ${ }_{2}$ Canelon.

Canelon. Ulloa a décrit cet oifeatu dans fon Voyage; il a la tête, la groffeur de l'Oie, le cou long, épais, le bec droir \& gros, les pieds \& les jambes proportionnés au corps, le plumage fupérieur des aîles gris, \& l'inférieur blanc. Le mâle \& la femelle font toujours enfemble; ils fe fixent dans les vallons, allant tantôt dans l'un, tantôt dans l'autre. On regarde auffi comme le même oifeau une efpèce, qui en diffère cependant par une petite corne calleufe \& molle fü le front, \& une touffe de plumes fur lạ tête ?

$\mathrm{O}_{3}$ 


\section{Int Obfervations \& additions:}

cette efpèce fe tient dans les parties les moins froides des montagnes. Le Canelon a le haut des âlles armé d'un ergor très-aigu, femblable à une épine de fix lignes de long : le Cahuitahu en a une femblable; cet oifeau-ci eft de la taille d'une Oie.

Curache. Maladie qui eft une efpèce de galle très-épaifre, à laquelle les Alpaques font fujets, \& qui les fait périr.

Cardinal. Une des trois efpèces d'oifeaux done PAnteur fait mention au commencement de fon Difuurrs VIII : c'eft le Loxia cardinalis de Linné, mais que Scopoli nomme plus juftement Loxia rubra dans la defcription qu'il en donne. Cet oifeau a un plumage d'un très-beau ronge, \& un perit capuchon derrière la tête, qui a fourni l'idée d'un camail; il eft gros comme un Merle, moins long; ta voix eft perçante, \& très-agréable de loin dans les bois : il fait un magafin de grain pour l'hiver, \& avec beancoup d'art; dans cette faifon froide il ne chante pas.

Caineros de la Tierra. Moutons du pays. Ce font les Llamas \& les Alpaques, Voyez ces arsicles.

Carya ou Llamas. Foyer cer article. Cafcabel.S erpent a fonnettes, très-redoutable, mias dont le bruit fait de loin fuir le danger, fion l'entend. Tous lẹs Naturaliftes en ont parlé, 
il the mord cependant que quand il eft irrité. On a remarqué, qu'étant au pied d'un arbre; s'il fixe un écureuil, ce petit animal en eft tout effrayé, \& après avoir fair de vains efforrs pour fe fauver, il tombe au pied de l'arbre, où le Serpent le dévore auffi-tôt. On voit auffi en Afrique un Serpent d'une efpèce analogue, ayant au bout de la quene une petite tumeur, qui fait un bruit affez forr pour avertir de la préfence du redoutable reptile. La fonnette du Serpent d'Amérique eft formée de plufieurs écailles qu'il a au bout de la queue; rous les ans elle augmente d'une nouvelle écaille. Gumilla dit que cette fonnette ou ce grelot, reffemble à l'écoffe d'un pois de gravance, féchée fur la plante; qu'elle eft divifée de même, \& contient cinq ou fix offelets ronds comme des pois; que l'on recherche dans le pays ce grelot avec beaucoup de foin, pour en compofer un antidote \& un remède pour plafieurs maladies. Confultez les Naturalifies pour une plus ample defcription. Ce Serpent rampe fur les roches avec une viteffe incroyable, \& va beaucoup plus lentement fur terre. Sa morfure engendre dans la plaie une pourriture qui eft fuivie de la mort en vingt-quatre heures. Gumilla propofe des remèdes qu'il ne faut pas négliger. Voyez Tom. III de fon Orenoque.

Catanillos.'Voyez Guacamayos. 


\section{Obfervations \& additions:}

Caiman. Ce que l'Auteur nous dit de la ma nière de prendre le Caiman a été mal conçu par le Traducteur Allemand, dit M. Schneider; il ne s'agit pas-là d'un croc ou hameçon quelconque, mais d'un pieu : il devoit ajouter que D. Ulloa copioir ici Gumilla, qui raconte la même chofe, \& dans les mêmes termes; mais aver d'autres circonftances extrêmement curieufes \& dignes d'être lues. Gumilla appelle Tolete un piège que l'on tend an Caiman pour le prendre; il confinte, dit-il, en un bout de bois pointu par les deux extrémités, quanon enveloppe d'un poriffon ou d'un morceau de viande : cela eft attaché à une forte controie qu'on fixe à terre; le Caiman happe avec avidité le bâton qu'on jette, mais il s'engorge tellement, que les pointes du bois lui entrent dans les deux mâchoires; il ne peut ni ouvrir davantage ni fermer la gueule : le pêcheur attend un peu, \& le tire à terre avec le fecours de fes camarades, quelqu'effort que l'animal fatfe pour réfifter. Un Indien ofe aller attaquer à terre un Caiman qui fe chauffe au foleil Ia gueuele ouverte de plus d'une vara; l'animal le prévient même, mais l'Indien prompr \& fort adiroir faute de côté, \& réitère ce manège plufienrs fois; alors il prend la Tolete, \& attend le Caiman fans bouger de place : celui-ci fe jette fur in avec fureur pour le dévorer; alors l'Indien 
Obfervations \& additions.

lui porte le bâton droit entre les deux mâchoires: le Caiman le faifit, \& fe perce ainfi, fans pouvoir ni ouvrir ni fermèr la gueule : dans cet état il devient furieux, fe jette fur les affiftans, qui l'agacent comme un Taureau, \& fe divertiffent à le voir fe lancer fur l'un \& l'autre fans qu'il puiffe leur faire de mal que de les renverfer, lorfqu'on n'eft pas affez agile pour l'éviter. Les habitans de Campêche fe procurent auffi ce divertiffement, où l'on voit paroître plus d'adreffe \& d'agilité que dans les amphithéâtres de l'an. cienne Rome. Acofta dit que le Crocodile ne fe trouve en Amérique que dans les pays chauds, \& qu’on n'en voit pas fur toute la côte du Pérou jufqu'à Paita, mais feulement, depuis cer endroit, dans tous les fleuves. Voyez auffi le Voyage d'Ulloa \& Bayer.

Centopiès ou Centipèdes. Infecte d'une forme analogue à celle des Cloportes; il y en a qui ont même près d'une vara de long fur cinq à $f_{i x}$ pouces de large; ils font garnis en-deffus \& latéralement d'écailles affez dures, d'un brun rougeâtre, qui femblent articulées de manière à laiffer tous les mouvemens libres à l'infecte. Il eft ainfi difficile à tuer, à moins qu'on ne le frappe fur la tête: il a un mouvent fort rapide, \& fa piqûure efi évidemment mortelle fi l'on n'y apporte tun prompt remède; mais fon venin fe porte fi 


\section{Is Objervations E additions?}

promptement dans la maffe des humeurs, qu'on fe reffent long-tems de fon effet, en fuppofant qu'on en guériffe.

Chullua. Nom que les Indiens du Pérou donnent généralement à tous les poiffons. Ce mot a bien de la reffemblance avec le mot Hébreu qu'on a interprêté de différentes manières fans pouvoir rien déterminer, dans un paffage de la Bible on il s'agit de prétendues Cailles qui tombèrent dans le camp des Ifraélites. J'obferverai ici en pafrant que la Langue de cés Indiens préfente une foule de mots qui fe retrouvent à la lettre, \&x dans les mêmes fignifications en Hébreu ou én Arabe. Mais nous ne pouvons entrer ici dans aucm détail à ce fujet.

Chiens. L'Autenr a donné dans fon Voyage des détails moins circonftanciés fur la maladie de ces animatix. Doit on croire que l'humidité de l'atmof phère en Amérique eft caufe que les Chiens n'y deviennent jamais enragés, comme l'a avancé M. de Paw dans fes Recherches fur les Américains? Qu'a-t il enfuite voulu dire par ce paradoxe: "Les Chiens du Pćrou, qui font de la première race tranfplantée, éprouvent encore alljourd'hui des accès du mal vénérien. "Sans doute que cet Ecrivain battoit ici la campagne, comme daras prefque tout fon Ouvrage; pent-on employer fon tems à n'écrire que des abfurdités! 
cet homme étoit, je penfe, à rêver comment il feroit un tiffu d'abfurdités.

Chillehuque. Nom que les habitans du Chili donnent au Llamas, Voyez ce mot-ci.

Chuca, Voyez Rat.

Ciboro. L'Auteur de l'Hiftoire de la Louyfrane décrit fous ce nom le Bouf fauvage, ou le Bifon de l'Amérique; il a, au lieu de poil, une longue laine frifée \& fine, d'une couleur brune chargée, \& une groffe protubérance aut deffus des épaules.

Colibris, Voyez l'article fuivant.

Condor. C'eft le Vultur gryphus de Linné. Frézier l'a décrit affez exactement, \& prouve que cet oifeau n'eft pas à l'épreuve d'une balle de fufil, comme l'avance Ulloa. On avoit rappotré que cet oifeau, le plus grand de toute l'Amérique, fe nourriffoit feulement des vers qu'il trouvoit fur les plaines arides des hautes cimes de ces contrées; mais on fait qu'il eft fort avide de viande, \& qu'il caufe de fréquentes allarmes aux Bergers, en fe jettant fur les beftiaux pour enlever la bête qu'il peut faifir proportionnément à fes forces; il eft même fort dangereux de l'attaquer feul, car il tueroit un homme d'un coup d'aîle. Les Anglois ont à Londres le fquelette d'un de ces oifeaux. La Condamine \& d'autres. ont fait connoître plus particulièrement le $C$ ondor 
220 Objervations \& additions.

ou Condur, qui d'abord avoit paffé pour ún être imaginaire fur les récits des premiers Voyageurs. De la Vega l'a bien décrit, Liv.VIII, c. 19. Aconta en donne des détails circonftanciés, \& le met en oppofition avec le Colibris, pour montrer les deux extrêmes des volatils de l'Amérique. Il devoit prendre l'oifeau Mouche pour l'autre extrême; car il eft conftant, par le rapport de plufieurs Voyageurs, que cet oifeau eit plus petit, \& plus heau encore que le Colibris. Quelques Ecrivains les ont confondus mal-à-propos : l'aifeau Mouche ne chante pas; le Colibris au contraire a un chant fort agréable, felon certains Voyageurs; d'autres ne lui donnent qu'un cri, qui reffemble plutôt à un grincement. On lui a donné, felon les différentes contrées, les noms de Quinde, Tomineio, ( \& non Tominro, comme écrit M. Schneider, ) Rabilargo, Lifongero, Picaftor, ou Suce-fleur, Guachichil, Guomanbuch, Guaiminibique, Guacariga, Guaricacaba, René; ce qui prouve bien qu'on a confondu des oifeaux de plufieurs efpèces. En effet les plumages des oifeaux qu'on a pris pour autant de Colibris, font bien différens felon les contrées où on les trouve. Il eft donc pollible qu'il s'en trouve quelques-uns qui chantent dans ce nombre, \& d'autres qui ne difent rien, ou nẹ farlent que grincer.

Coneios caferos, ou Lapins privés. Il s'agir 


\section{Objervations \& additions.}

probablement ici du petit animal que nous appellons ici Cochon d'Inde; Mus porcellus de Linné, ou Cavia cobaya ; \&c. Les Naturaliftes en ont marqué plufieurs efpèces, tant de l'Amérique que des anciens continens. On peut confulter Klein, Margraave, Ray, Seba, Catesby, Briffon, \& autres. Mais Voyez auffi le mot Lapin.

Coral. La Couleuvre coral, dit la Condamine, eft remarquable par la beauté \& la variété de fes couleurs; mais autant elle eft belle à voir, autant il eft dangereux d'en approcher. Sa grandeur parvient à quatre ou cinq pieds; elle eft couverte d'écailles rhomboïdes, de couleur de corail trèsavivé; mais le dos eft moucheté de taches noirâtres; le ventre a de femblables taches, mais plus petites, \& le deffous eft d'un jaune pâle: L'effet de fa morfure eft le même que celui de la Couleuvre, que les Grecs appelloient Hamorrö̈s: le fang fort de toutes les parties du corps, même des endroits où il n'avoit pas d'iffue naturelle, \& l'on meurt très-promptement. $V$. La Condamine, Bankroft, defcription de la Guiane, \& Seba, Théfaur. II de fon Hift. des Serpens.

Cotorras', Perriquitos, Guacamayos. L'Auteur défigne ici plufieurs efpèces de Perroquers, les uns plus gros, les autres plus petits, ayant aufi une queue plus ou moins longue. M. Schneider pouvoit ajouter qu'il y 3 , tant en Amérique 


\subsection{Obfervacions \& additions}

qu'aux Antilies, plus de cent efpèces différentes de Perroquets. L'Auteur défigne fans doute les Perruches par le mot Cotorras. Quant aux Guacamayos, Acofta dit que c'eft une efpèce d'oifeau qu'on doit ranger parmi les Perroquets, parce qu'il en à le plumage; mais il eft plus gros felon lui. Les Guacamayos (Prévôt écrit Guavamayas) n'apprennent jamais à parler. Les Indiens comprennent fous le nom d'Urita toutes ces efpèces d'oifeaux, \& les Catanillas, ou Caterinillas, les Loros \& autres. V. auffi G. de la Vega, liv. VIII, c. 2 I. l'Hift. gén. des Voyag. T. XII, p. 626, Les Naturaliftes né nous ont encore décrit qu'un perit nombre d'efpèces de ces oifeaux.

Criard. Ulloa parle de cet oifeau dans fon Voyage, \& le décrir de maniere à ne laiffer aucune équivoque. Pernetty produit auffi un oifeau du Bréfil, auquel les Portugais donnent le même nom. Il le donne pour une efpèce de corneille d'un beau plumage blell; mais enfuite il dit qu'il a la forme d'un corbeau, \& qu'on en mange. On ne fait donc pas s'il a voulu parler de l'oifeau Criard de notre Auteur \& de Frézier. Il faut le diftinguer aufí à plufieurs égards, d'un oifeau dont parle Ulloa dans fon Voyage, \& qu'il nomme Canelon ( $V$. ce mot.) Ce font less deux efpèces de Palemedea connues jufqu'ici, \& que la Condamine a défignées fous le nom 


\section{Objervations E adaitions.}

Braflien Cahuitahu. Quant aux cris que jette ces oifeau, la pie ou becaffe de mer de l'Europe (Hamatopus Ostralega) en fait de fembiables.

Crocodule. V. Cainan.

Cucarachas. Ce mot défigne ordinairement le cloporte; mais il s'agit probablement ici d'une efpèce d'infecte analogue à l'ef́carbot, qui crôt, dit-on, entre les marchandifes qui arrivent emballées des Indes, \& qui meurt dès qu'on ouvre les ballots. Sejournant dans fon Dictionnaire, dit qu'il n'y fait ancun tort. Il parô̂t qu'il a été mal inftruit, d'après le détail de notre Auteur. Difc. 8.

Cucuiios. V. Ver-luifant.

Culebrilla, ou Serpenteau. Barrere appelle cetre maladie le $\mathrm{Ver}$ de Guinée, parce qu'elle attaque les Nègres nouvellement arrivés. Bajon $l_{a}$ décrit fous le nom de Dragoncelley dans fon Hiftoire de Cayenne, T.I. C'eft le même nom (Dracontion) fous lequel Galien en parle; mais il dit ne connôtre ce phénomène que par des rapports étrangers. Cette maladie tétoit connue de fon tems. Bekmann a déjà produit ce paffage dans fon Traité fur l'Hiftoire Waturelle des Anciens, pour prouver contre Mead, que ce n'étoit pas Avicenne qui en avoit parlé le premier fous le nom de Vena Medinenfis. Mais Agatharcide en aroit parlé long-tems auparavans 


\section{Obfervations E additions:}

dans fon Voyage à la Mer Rouge, comme or le voit par les Sympofiaques de Plutarque, qui le cite, Queft. IX. Cet endroit mérite attention.

Après ces détails de $M$. Schneider, je crois devoir ajouter ici, pour l'utilité des Voyageurs, que l'on connoît plus cette maladie dans les pays chauds : il paroît même qu'elle leur eft comme particulière. Le Père Gumilla qui en a penfé périr, eft à cet égard plus croyable que tout autre. Si la maladie attaque le pied, elle fe manifefte d'abord par une tumeur; mais elle devient bientôt circulaire, \& l'on ne peut efpérer de guérifon qu'à la faveur du bain trèschaud du pied, \& d'une forte ligature, qui tient ce qu'on appelle la tête du ferpenteau. Ce prétendu infecte ou ver, fort, dit-on, alors la tête à travers la peau, \& il faut la faifrr, l'arrêter prudemmentavec le lien de foie, jufqu'à ce que ce qu'on prend pour animal, foit forti entièrement : il faut fouvent réitérer ce bain.

Mais voici ce que ce Miflionnaire éprouva. La maladie commença chez lui par une inflammation à la poitrine, laquelle fut fuivie de fièvre. A ce degré la tumeur qui s'étoit manifeftée, fe couvrit de groffes cloches, l'inflammation gagna tout autour du corps, la tumeur s'allongea en pointe comme une pyramide, \& l'endroit qu'elle occupoit, fe trouva le lendemain tour couvert d'amponles 


\section{Obfervations \& additions.}

đ’ampoules: le ferpenteau m’avoit déjà, dit-il, prefque entouré la moitié du corps. Un Indien expérimenté, baptifé depuis peu, me dir que j'étois perdu, fi je ne me laiffois pas brîler : j'y confentis : il fis aufít - tôt rougir un coutteau, il im'entama le ferpenteau en dix-fept endroits: le mal (l'enfure) ne fit plus de progrès, la fièvre me quitta en peu de tems."

* Après cette cure, une Vieille lui propofa uir autre remède sûr; favoir de faire chauffer un limon rempli de pondie, \& d'en frotter fouvent l'inflammation. Ce remède, dit G... n'exige pas de régime. Je m'en fuis fervi depuis avec fuccès, cette maladie étant très-fréquente en Amérique; mais un limon tiède fuffit fans doute pour la guérir, en frottant fouvent.

J'ai peine à me perfuader que cette maladie qui attaque toutes les parties du corps, la poitrine, les cuiffes, les jambes, les bras, les épaules, foit caufée par un animal vivant; cependant la maniere infaillible dont il s'étend, me le feroit croire. Ce que cet Ecrivain dit dis Bicho \& des Aradores, ne doit pas être ignoré des Voyageurs. Ils confulteront cet Auteur, T. III. \& Frézier, $p$. I g. édition $i n z+12$.

Danta. Le même animal que l'Anta. Voyež ce mot,

Demoifelles, Frappe-d'abord, Mofconès, MorTome $I I$. 
quires, Gegenes, Zancudos, \&c. Infectes trèsincommodes, \& même plus ou moins dangereux, fur lefquels on aura les détails néceffaires dans Frezier, le Voyage de notre Auteur, l'Hiftoire Génér. des Voyages, Gumilla \& d'autres. Voyez. le mot Nigua.

Dragonneau. V. Culebrilla.

Evêque. C'elt fans doute l'oifeau que Briflon décrit, T. I. Linné d'après ce Naturalifte, l'a rapporté au Tangra, fous le nom d'Epifcopus. Les Efpagnols l'appellent Azuleio.

Flamans, Flamencos, ou Perionas : oifeaux qu’on connoît bien ici par le Cabinet du Roi, \& qui font d'un plumage rouge un peu pâle. J'en ai vu deux vivans; ainfi je fupplée à ce que M. Schn. paffe fous filence. Is font hauts fur patte, ont un long cou, un, bec noir, crochu; dont la partie fupérieure leur fert à fouiller dans la vafe des marais \& des lagunes, mais ils pofent la partie fupérieure du bec en-deffous, la rempliffent de vafe, ou de la terre qui fait le fond de l'eau, cherhent dans ce limon avec leur langue ce qui peut leur convenir; ils le jettent enfuite, pour recommencer la même mancuvre. Lorfqu'ils veulent faire leur nid, ils amaffent des joncs, des pailles, \& fe mettent à danfer deffus mâle \& femelle, pour applatir \& confolider ces matériaux; cequifait un fpec- 
Objervations \& additions:

tacle fort divertiffant ; cependant ils ne produifent pas dans la vie domertique. Ils font fort doux, \& s'apprivoifent aifément : at moins, ceux que j'ai vus vivans étoient fort familiers : c'ent le Phomicopterus de Limné.

Fourmis. On trouvera dans Fermin \& Raynal des détails curieux fur ces Fourmis vagabondes, qui marchent en troupe comme autant d'armées redoutables; mais on fera fatisfait à tous égards, de ce qu'on lira dans le Dictionnaire des Animaux, tant fur celles - ci, que fur plufieurs efpèces de Fourmis, dont quelques-unes font extrêmement venimeufes. Gumilla mérite auffi d'être conféré.

Gallareta. Efpèce de ponle d'ean.

Gallinaz̧o. C'eft le Villtur aura de Linné. Ulloa a donné les détails nécelfaires fur cet oìfeau carnacier, dans fon Voyage. Cet oifeau eft celui qui dévore toutes les charognes qui infecteroient les campagnes : il attaque même les beftiaux, pour peu qu'un de ces animaux ait une plaie légère dont il fente l'odeur. Or cet oifeau a l'odorat extrêmement fubril : il détruir aufíles cufs du crocodile, dont il épie la femelle lorfqu'elle pond, \& enterre fes cuffs près des eaux. $V$. Gumilla, \& l'Hiftoire générale des Voyages, T. XIV.p.117.131. On le tronve décrir fous le nom de Corneille carnaciere, Tome XII. $\mathrm{P}_{2}$ 


\section{Objervations \& additions.}

p. 628. du même Oụvage, \& avec d'autreș circonftances.

Garrapatas. C'eft ainfi que les Efpagnols appellent les poux des gros bettiaux; mais les Garrapatas font proprement chez eux les teignes qui attaquent les habits. Quant aux poux de bois, c'elt une efpèce de fourmi blanche. Voyez Rochcfort, Hiftoire des Antilles, p. 270. On voir ici par la manière dont on fe guérit de la morfure de ces infectes, qu'Ulloa confond les noms, \& qu'il veut parler d'une efpèce de mite que Bankroft \& Frézier ont défigné par le mot $P_{\text {iques, }}$ \& que Labat, $T . V$. indique fous celui de Niguas. $V$. ce mot. Quant aux Garrapatas ou (Acari Americani de Linné) les feuillages, les herbes en font remplies, \& ils fe jettent également fur les hommes \& les animaux. Dans les contrées Anglaifes on en voyoit moins autrefois, lorfque les Sauvages mettoient le feu. aux forêts; mais ce moyen y eft aujourd'hui prohibé. Le Crotophage de Linné dégage les vaches \& autres beftiaux de ces infeckes, en venant les chercher fur ces animaux, comme quelques oifeaux de nos contrées d'Europe y nettoyent les muutons de leurs poux. Kalm a donné à ce fujet une differtation dans les Mémoires de Suède. La Condamine dit de la ville de Jaën, que ce n'eft qu'un village boueux \& hu- 
Obfervations \&, additions.

mide, uniquement connu par la quantité pro: digieufe des Garrapatas, infecte dégoûtant; dont on y eft dévoré : eft-ce le même infecte que celui dont parle notre Auteur ? c'ett ce qui eft incertain.

Gegenès. V. Demoifelle.

Gilguero, ou Xilguero, Chardonneret. C'eft probablement l'oifeau que les Indiens appellent Chayna, \& fur le chant duquel ils tâchent de former le leur. G. de la Vega en parle, liv. VIII. c. 20. Les Efpagnols, dit-il, lui donnent ce nom, parce qu'il eft noir \& jaune. Bayer dit qu'il n'eft pas plus gros qu'un ferin, ayant le corps tout noir \& les ailes jaunes. Son chant ent fort agréable \& beaucoup plus délié que celui du ferin; mais à peine eft-il en cage, qu'il meurt de chagrin. A-t-on voulu parler du même oifeau, lorfqu'on a dit, Tom. XII. de l'Hijt. génér. des Voyages, "On recherche beaucoup pour la cage le Silguero, qui eft blanc \& noir, \& de la groffeur d'un moineau. "Ce feroit une fingulière contradiction: on y fair cet oifeau blanc \& noir.

Gorianes. Il s'agit ici du Gorion, oifeau d'un beau noir, \& qui a le ramage le plus attrayant. Il eft gros comme un moineat. V. Piche。

Guana, ou Iguana, \& Guano. Efpèce de lézard connu de nos Naturaliftes. Boyer en fait mention; il a quelquefois jufqu'à cinq pieds de

$\mathrm{P}_{3}$ 


\section{Objervations \& additions.}

long, \& fe tronve dans une des Antilles, en Afrique, \&x. Nombre de Voyagenrs en ont mangé, \&, fi on les en croit, fa chair eft excellente. V. Hift. géner. des Voyages.

Guanacos. Cet animal n'a pas encore été bien décrit. Linnél'a défigné en le confondant avec le Pacos, ou Alpaque, lorfquil a dit de celui-ci : toius Sanguineus, Jubtus albus : c'eft vraiment la couleur du Guanaco; il a fur le dos une laine affez longue, couleur de rofe fèche, \& blanche fous le ventre. Quoiqu'il foit un des quatre analogues avec le Llama, l'Alpaque \& la Vigogne, il en differe par des attributs particuliers; il eft plus gros a plus haut que le Ilama \& la Vigogne, \& fe rapproche beaucoup de l'Alpaque par la taille \& la figure qui tient un peu à celle du Chameau; il porte de mềme le col très-droit, mais il he fe prête pas à porter aucun fardeau comme l'Alpaque. C'elt en quoi notre Auteur fe contredit avec ce qu'il a avancé dans fon Voyage. Le Guanaco fe tient en très-grand nombre fur les - Cordilleres, mais on le trouve audi parmi les uroupes de Vigognes, avec lefquelles il ne fe laiffe pas prendre, car il a affez d'inftinct pour fauter pardeffus l'enceinte de corde que font les Chaffeurs pour prendre celles-ci. La laine du Guanaco eft rude, dure, peu traitable en comparaifon des trois animaux analogues : cepen- 
dant les Indiens en font des ouvrages grofliers.

On vante beancoup les bezoards qu'on trouve dans leur eftomac; mais on en a iouvert plufieurs fans y rien voir de femblable. On eft anjourd'hui revenu du préjugé où l'on étoit à l'égard de tous les bezoards : certe matière globuleufe n'eft formée que des poils que l'animal s'arrache en fe léchant, \& qui réunis avec la terre par les fucs falivaires \& gaftriques, forment enfin une ou plufieurs plottes qui font périr lés animaux où elles fe font confidérablement grofies. Voilà ce que font tous les bezoards de l'Orient \& de l'Occident. Quelle vertu pouvoit-on raifonnablement fe promettre de pareilles fubftances?

Les Anglois nomment cet animal $W$ anotra: fon vrai nom chez les Indiens eft Huanuca, d'où l'on a fait Guanaco; mais l'Auteur du Diction. des Animaux eft dans une fingulière erreur, en confondant le Guanaco avec les.Vifcachas.Voyez ce mot-ci.

Guano. Efpèce d'oifeaux qui fe raffemblent jufqu'à obfcurcir quelquefois l'air par leur grand nombre, \& fe pofent fur les bords de l'ifle d'Iquique pour prendre le poiffon qui vient à fleur d'eau tous les jours, le matin à dix heures, \& le foir à fix. C'eft, felon Frézier, la fiente de ces oifeaux qui entretient la quantité immenfe de la terre nommée guana, qu'on tire de l'fle 
232 Obfervations \& additions.

pour fumer les terres du Pérou. Alonfo-Barba prétend an contraire que cette terre n'a rien de commun avec la fiente de ces oifeaux. Le Guano e? un oifean de mer d'une figure fort laide; fi on lapproche, il fifle, fans penfer à fe fauver, aufi ef -il facile de le tuer à coups de bâtons; mais c'eft un affez mauvais manger : il y en a dans plufreurs parages de l'Amérique, \& l'on Ar trouve de très-gros.

Kuguar. V. Lion.

Llomas, ou Moutons du pays. Prefque tous les Voyageurs ont parlé de ces animaux. Il feroit inurile d'ajouter quelque chofe ici aux détails de norre Auteur; Frézier a fait graver la figure des Ilamas dans fon Voyage. V. Guanaco.

Lapin du Pérou, autrement Vifcacha. On a défigné fous ce nom Indien, $I^{\circ}$. un animal qui tient un milieu entre le Lièvre \& le Lapin de nos contrées; $2^{\circ}$. un autre plus petit qui en diffère par fa quene, qui ef comme celle d'un chat : celui-ci a le poil d'un gris-blanc. Les Péruviens filoient autrefois ce poil. On dit qu'on ne prend cet animal que dans l'hiver, lorfqu'il va chercher fa pâture, \& que les Renards en détruifent beaucoup a mais il femble quion a confondu deux, ou même plufeurs efpeces d'animaux. Il y a aufli en Amérique une efpèce de Lièrre qui fe rerre camme nos Lapins. Barba parle d'an Bifacho 
du Pérou, de la groffeur d'un de nos Lièvres. Kalm parle d'un Lapin du Canada, plus petit que les Lièvres d'Europe, mais plus gros que le Lapin; il ajoute que la peau n'eft d'aucune utilité, parce qu'on ne peut les paffer fans que le poil s'en détache. Ulloa en dit autant ailleurs des $V i f c a c h e s$ du Pérou. Lequel croire? ou la même circonftance a-t-elle lieu à l'égard des Lapins des deux contrées?

$\mathrm{Ce}$ que l'on peut conclure de ces différens détails, c'eft que le $V i j$ cacha eft un petit animal qui ne doit pas être rapporté an Lapin, \& qu’on ne nous a pas encore donné une defcription exacte du vrai Lapin d'Amérique, s'il y en a rééllement dans ce vafte continent, ce qui paroît fort douteux. Erxleben, Feuillé, Cieza \& G. de la Vega, comparés enfemble par les Naturaliftes, leur éclairciront peut-être la difficulté.

Lavanco, ou Labanco. Efpèce de Canard fauvage.

Lion. Ce qu'on appelle Lion d'Amérique eft un animal qui tient à peine de la figure du Lion des anciens continens; il eft lâche, fuit à la préfence de l'homme : fa tête tient de celle du Loup $\&$ du Tigre; il eft bien plus petit, n’a pas de crinière. Les Péruviens l'appellent $P_{\text {uma }}$ c'eft le Kuguar de M. de Buffon, \& le Felis concolor de Linné. 
234 Obfervations \& additions.

Loro. Belle efpèce de Perroquet, qui a la têté \& les extrémités des âles d'un beau jaune, \& le refte du corps d'un verd très-agréable.

Mante. Ce poiffon large \& plat a été connu des anciens. Pline en fait mention dans fon $L . I X$. Les Pêcheurs, dit-il : " ferunt quamdam nubem crafceffere fuper capita animalium planorum pifcium finilem, prementem eos, arcentemque à reciprocando : \& ob id ftios preacutos lineis annexos habere fe; quia nife perfolfa ita, non recedant. "C'eft le Bos Thalafjus d'Hippocrate. Oppien en fait mention dans fes Halieutiques II, I 40. Elien en parle auffi dans fes Animaux, I, 19, comme un des ennemis les plus dangereux de ceux qui pêchent les perles \& les éponges.

On lui donne; dit Gumilla, le nom de poiffon, quoiquil en ait à peine l'apparence; il reffemble à une courte-pointe, \& eft quelquefois fi large, qu'il couvre prefque entièrement un canor, \& le fait périr avec tous ceux qui font dedans. Je fus témoin de l'effroi des Matelots \& des Paffagers qui en apperçurent un. Des perfonnes dignes de foi m'ont raconté que ceux qui pêchent les perles s'arment d'un couteau pointu \& affilé, \& que les Mantes fe retirent dès qu'elles font bleffées. Rien de plus conforme au dire de pline. M. Schneider devoit rapprocher ces deux parfages. 
Obfervations \& additions:

Maripofa. Les Efpagnols donnent ce nom à l'oifeau que nous appellons Papes. Jacquin le décrit ainfi fous le nom de Fringilla Maripofa, parmi les oifeaux de fon cabinet: "Il eft de la taille d'un Pinfon ordinaire; on voit autour de fes yeux un cercle d'un jaune doré; les grandes plimes de fes aîles font d'un gris-brun; la tête \& le cou font de couleur améthylte, le ventre eft rouge \& le dos verd. Le mot Maripofa, Efpagnol, fignifie papillon. Nous avons dit deux mots du Cardinal \& de l'Evêque. On trouvera des détails plus amples fur, le Cardinal dans l'Hiftoire générale des Voyages, $T . X I, X I I, X V$.

Mules. Ce que dit notre Auteur fur la vente \& les voyages des Mules, eff d'accord avec ce que Frézier en avoit rapporté long - tems auparavant. Frézier évaluoit de quatre-vingt à cent mille par an, les Mules qui font ces immenfes trajets pour remplacer celles qui meurent.

Nigua. Cet infecte fi fâcheux dans l'Amérique, \& que l'on y appelle aufi Pique, eft de deux er. pèces; l'une fans venin, lautre avce un venin, dont l'effet fe porte jufqu'aux ânes, où il furvient une inflammation aux glandes, accompagrace de vives douleurs, quoique l'infecte n’ait piqué que les doigts du pied. Cette efpèce ent do coulent jatme; il faut extirper le nid \& les oufs qu'il a dépofés dans la partie on il eft entrće, \& même 


\section{Obfervations \& additions:}

avec beaucoup de prudence fi l'on veut guérir; fon nid a une conleur cendrée : l'autre efpèce eft de couleur puce, \& fait un nid qui a une teinte blanche. Il eft important de déloger promptement çes deux infectes qui pullulent très-vîte, \& pénètrent bientôt jufqu'aux os, fil on veut braver la douleur qui en réfulte. On peut voir de plus amples détails dans le Voyage de notre Auteur, dans Pernetty, qui l'a copié en grande partie à ce frjet. Cet infecte, heureufement, ne peut pas fauter comme la Puce, fans quoi ce feroit un fléau des plus terribles. Rolander le range parmi les Poux, \& l'appelle Pediculus ricinoz̈des; il lui donne fix pattes. Brown en fait une efpèce de Mite, \& lui donne huit pattes. Catesby le décrit encore différemment, ce qui fait croire que chacun a parlé d'un infecte différent. On peut aufi voir les détails de Gumilla. Ulloa dit qu'if s'attache auffi au Cochon, \& à un autre animal, (le Cerdo) dont il dévore les pieds de devant \& de derrière. Juffien eft celui qui en a bien diftingué les deux efpèces, dont il a été d'abord fait mention ici.

Outre cet infecte, on a encote à effiyer le tourment que caufent les Mofquites, ou Maringonins, dont les Zancudos font la plus groffe efpèce. Les Gegènes font beaucoup plus petits. Fes Manteanx-blancs font une efpèce de Cirons 
prefque imperceptibles; les piqûures de ces infectes font fuivies de tumeurs plus ou moins groffes, \& dont la douleur dure plufieurs heures de fuite. On a remarqué que l'air eft fi pur dans la province de Quito, qu'à peine y voit-on un reptile ou un infecte fâcheux. Les Indiens ont foin d'avoir près d'eux la nuit dans leurs huttes des vers luifans, ou Cucuios, pour écarter ces Mofquites \& autres infectes.

Oifeaux. On a remarqué que nombre d'oifeaux d'Amérique changent de couleur à mefure qu'ils prennent plus d’âge, \& que la dernière couleur à laquelle fe fixe la nature, devient peil-à-peu beaucoup plus vive. Nous citerons pour exemple le Guara, que Marc Grave a décrit p. 203, \& que Linné appelle Scolopax rubra. Pernetty parle auffi de cet oifeau marin du Bréfil : fes plumes, dit-il, font d'abord toutes noires, deviennent d'un gris cendré, blanches, \& enfin peu-à-peu d'un beau rouge écarlate qu'elles confervent toujours, de forte que l'on peut prendre pour un oifeau différent, le même vu à différens âges. Frézier parle d'une efpèce de Mouette ronge, qu'il nomme Oura : cette efpèce de pêcheur, dit-il, eft toute rouge, d'une belle couleur. Oura eft fans doute une faute d'impreffion, page 4.8 , Edit. in-12. Ce Guara vole en troupe, \& fait 


\section{ObJervations \& additions:}

quelque chofe de très-beau à voir dans l'éclat d'uri beau jour. $V$. auffi Hift. gén. T.XIV, p. 302.

Bajon remarque en outre que la clafle des oifeaux cft en Amérique beaucoup plus nombreufe que celle des quadrupèdes. Tous dépofent leurs aufs dans la faifon des pluies, \&z les font éclore alors : beaucoup d'oifeaux qui font paffagers en Europe, ne le font pas en Amérique : tels font les Hirondelles, les Roffignols, les Cailles. Si les oifeaux y chängent de contrée, ce n'elt qu'en conféquence des grandes féchereffes extraordinaires, ou des pluies exceffives. La plupart des oifeaux n'y acquièrent leur véritable couleur que par le laps du teńs; nombre de Palmipèdes fe perchent-là fur les arbres comme les autres oifeaux, \& y font même leurs nids.

Ours. L'Auteur de l'Hiftoire Naturelle de la Louyfrane, parle aufli de l'ufage qu'on y fait de la graiffe de l'Ours; mais, dit M. Pallas, l'Ours de l'Amérique eft tout différent de celui de l'Europe : Spicileg. Zaologic. $X I V$, page 6. Mais Pallas afirme cela trop généralement. On voit au Mexique des Ours qui, fans êrre aufî́ gros que les nôtres, en ont toute la forme \& la férocité: à peine en rencontre-t-on jamais un de jour. L'Ours fourmillier eft un tout autre animal. Pacos. V. Alpaque, Guanacos. 


\section{Objervacions \& additions.}

Palomite. Efpèce d'infecte, ou vermiffeau.

Papes. V. Maripofa.

$P$ atos. Canards. Frézier en a fur-tout remarqué une efpèce, qu'on appelle, dit-il, Patos reales, \& qui ont une crête rouge fur le bec; mais Forfter entend cela de la peau rouge $\&$ nue, dans laquelle font les yeux de cet oifeau, que Lininé appelle Pelecanus pifcator. Mais Bouguer donne à ces Patos reales, ou Canards royaux, une huppe fur la tête. Comment accorder ces rapports?

Perdrix. Il parô̂t que l'oifeau qu'on a appellé Perdirix en Amérique eft fort varié; on en compte au Bréfil feul cinq efpèces; dont les unes font auffi groffes, dit-on, que des. Oies, \& dont les autres diminuent par gradation jufqu'à la groffeur de la Tourterelle. Bayer compre trois efpèces de Perdrix au Pérou; G. de la Vega n'en reconnoît. que deux efpèces, \& les nomme différemment. Nous ne parlerons pas des Perdrix à têre bleue de la Havane, ni des blanches du Nord de l'Amérique.

Pericoligero, ou Pierrot-coureur, autrement Farefeux. Linné l'a nommé Bradypus. Il vit particulièrement des feuilles de l'arbre appellé dans le pays Yagramo, \& que Linné appelle Cecropia peltata. V. Lofling, Plant. Améric. p. 350. Ce fingulier animal a été ainfi nommé par ironie, à caufe qu'il peut à peine fe trâner fans jetter 
$240 \quad$ Objervations \& additions:

des cris douloureux, \& il n'a que ces cris pout défenfe contre l'homme ou l'animal qui veut l'attaquer. Il reffemble à un Singe de médiocre groffeur; il grimpe cependant, quoiqu'avec beaucoup de lenteur, fur les arbres, où il voit les fruits fauvages qui lui conviennent, en abat autant qu'il peut, \& fe laiffe tomber en peloton pour n'avoir pas la peine de defcendre; alors il mange au pied de l'arbre la provifion qu'il a abattue.

Périonas. V. Flamans.

Perroquets. L'Auteur en nomme plufieurs efpèces. V. Cotorras.

Picaflor, ou Suce-fleur, ou Bec-fleur. On a donné ce nom à un oifeau extrêmement petit \& magnifique de l'Amérique, parce qu’il ne vit qu'en voltigeant fur les fleurs, dans les pétales defquelles il allonge $\mathfrak{f}_{a}$ langue pour en prendre le fuc \& s'en nourrir : ce nom convient au Colibri \& à l'Oifeau-mouche.

Piche. Oifeau plus gros que le Gorion. $V$. ce mot. Il a le plumage gris, avec des taches obfcures; le cou \& la poitrine font d'un beau rouge, qui s'étend jufqu’à la première \& la plus forte partie des â̂les; les grandes plumes des âles préfentent quelques teintes de rouge \& de jaune.

Poiffons. Notre Auteur ne préfente que les noms Efpagnols des poiffons du Pérou. G. de la. 
Obfervations $\hat{\xi}$ additions.

Vega, au contraire, les défigne par les noms Indiens : mais celui-ci obferve cu a y a peu de poiffons au Pérou ; ainfi il eft facile d'en rapprocher les dénominations, \& de reconnoître les efpèces. On attribue le petit nombre des efpèces, \&r des poifons en général, à la rapidité dés courans. Ces poiffons, dit-il, font bien différens de cent. de l'Efpagne, \& paroîtroient même ne former qu'une efpèce, car ils ont tous une tête platte, femblable à celle d'une Grenouille, \& font fans ćcailles. Les Indiens les défignent par le nom général de Challua, qui veut dire poiffon : on les mange avec la peau, \& on les trouve fingulièrement favoureux; en effer ils font fort délicats. Il y en a peu dans les rivières qui fe déchargent à la mer fur les côtes du Pérou, parce qu'il y a peu d'eau dans leurs lits; leur cours d'ailleurs eft extrêmement rapide, fur-tout lorfqu'elles font groffies par les pluies d'hiver : il eft même alors impolfible de les traverfer.

Mais on trouve beaucoup de poiffons dans le lac Titicaca, \& ils paroiffent être les mêmes que ceux dont on vient de parler. Les Indiens diftinguent ceux - ci par le nom général de Súchi; ils font fi gras, qu'il ne faut aucune graiffe pour les accommoder. On prend dans ce lac un poiffon que les Elpagnols appellent Boga; il elt très-petit, de mauvais goût, \& cotivert d'écailles. Il y en a

Tome II.

Q 


\section{Obfervations \& additions.}

d'autres efpèces qui y trouvent fuffifamment de quoi fe nourrir, par les matières qu'y portent les cinq groffes rivières qui s'y jettent. Les deux premières efpèces de ces poiffons font probablement les Bagres \& les Pregnadillas, dont parle Ulloa, \& analogues au Silurus. Le Boga feroit-il le Chiche des Indiens? Acofta décrit les deux dernières efpèces affez brièvement en parlant de ce lac, L. III, c. I 8. L'eau du lac, dit-il, n'eft ni auffi falée, ni auffi amère que l'eau de mer; mais elle eft fi lourde, qu'on ne peut en boire. On y trouve deux efpèces de poiffons en grande quantité; l'une s'appelle Sucha; c'eft un poiffon favoureux, mais glaireux \& mal fain : l'autre eft le Boga, qui eft fort petit \& plein d'arêtes, mais plus falubre. Selon la defcription de Falkner, le Boga eft de la forme d'une Carpe; il pèfe même jufqu'à trois ou quatre livres dans les rivières de la Plata \& de Prana : la grande quantité empêche qu'ils ne foient chers. Les habitans les falent ou les font fécher, \& en confervent ainfi une affez grande provifion : il faut être attentif aux arêtes lorfqu'on en.mange. Bayer compare les Suches à la Perche, \& dit qu'ils font aufi bons à manger.

L'Auteur obferve que les poiffons devenus venimeux par le fruit du Mancenilier, ont les dents jaunes. Frézier a fait la même remarque. Ces Becunes vénimeufes font une efpèce de Brochet 
des lacs; ( Efox. $V$. le Voyage de Loefling, $p$. I 48, en Efpagnol Picuda.) ils deviennent auffi à Surinam un aliment très-nuifible. On en goûte d'abord le foie; s'il eft amer, on peut compter que le poiffon eft venimeux, comme le dit Fermin, Voyage de Surinam, Liv. II, pag. 239. Waffer en dit autant de fon Paracod. L'épreuve faite par l'argent eft trop incertaine pour s'y fier, car tous les poifons n'attaquent pas ce métal.

Pregnadillas. V. l'article précédent. L'Auteur parle auffi de ces poiffons dans fon Voyage. On trouve dans leslacs de S.-Paul \& de Cuichoca beallcoup de petits poiffons de la forme d'une Ecreviffe de mer, mais fans écaille ou coquille; on les fale pour les tranfporter à Quito, où l'on en fait beaucoup de cas : car le poiffon frais manque dans cette ville, où l'on ne s'en procure qu'à grand prix.

Pumu. V. Lion.

Punaife de bois. Acarus Americanus de Linné: $V$. Garrapatas. Il en êf quelques efpècés d'un. poifon fi fubtil, qu'il eft très-dangereux de fe les écrafer fur la peau.

Rat-de-bois, autrement Mucamuca, ou Chuca: Animal fort commun dans la Louyfiane : mais on en voir dans les deux parties de l'Amérique; il a les mêmes propriétés que nos Rats d'Europe. C'eft le Delphis marfupialis \& l'OpoßJun de Linné; $\mathrm{Q}_{2}$ 


\section{Objervations \& additions.}

car ces deux noms font celui de la même efpèce. Rochefort dit que dans le Bréfil les Indiens l'appellent Carigueya. Lofling à vu près du fleuve Aragua un de ces rats à bourfe dans un creux d'arbre. Les habitans l'appelloient Mapcha; les Efpagnols, dit-il, le nommoient Robipelado; il veut fans doute dire Rabopelado, c'eft-à-dire queue chauve. Mais Lefling remarque une circonftance qui n'auroit pas dû échapper aux Naturaliftes, c'eft que cet animal a le membre génital tourné en fens contraire entre les deux cuiffes, \& nud; ce membre eft affez gros, rond \& bifurqué au bout comme la corne d'un animal à pied-fourchu : les tefticules font en avant fous le ventre, c'eftà-dire à l'endroit où doit fe terminer ordinairement le bout de la verge.

Serpens. Nous avons dit deux mots du Cafcabel, ou Serpent à fonnettes, du Coral, ainfi nommé de fa couleur rouge, du Bobas. Le nombre des Serpens eft fr grand dans le continent de l'A mérique \& dans les Ifles adjacentes, qu'il faudroit un très-gros volume pour les faire connoître tous; il en eft qui n'ont aucun venin; les plus dangereux font le Cafcabel, le Coral; le Macaurel, la couleuvre Sibucane, la Chaffeufe, \& quelques autres. On a propofé différens remèdes pour leur morfure; la béjuque de Guayaquil, le tabac mâché \& appliqué, lail, \&c.; mais l'effet du poifon 
Obfervations E additions.

de ces Serpens eft fi prompt, qu'on a à peine le tems d'y recourir. Les Sauvages font à cet égard beaucoup plus expérimentés que les Européens ou les Créoles.

Serpent à deux têtes. C'eft un être chimérique; mais eft-il vrai ou même poffible que ce Serpent coupé en deux, \& même en trois, fait rejoindre fes morceaux du côté même où ils étoient auparavant? Gumilla produit à cet égard des faits qui le perfuaderoient : on le confultera. Quant à fes deux têtes, Bankroft, $p$. I 32 , convient qu'au premier coup-d'œil les deux extrémités de ce Serpent feroient croire qu'il a réellement deux têtes; mais il nie le fait comme témoin oculaire. $V$. Gumilla, $T^{\prime} . I I I, p .85$.

Carver dit avoir vu un Serpent qui avoit deux têtes l'une à côté de l'autre fur un feul col; mais il le range parmi les montres, comme un écart affez ordinaire de la Nature dans les autres efpèces du règne animal.

Senfonte, ou Oifeau moqueur. On l'a, dit-on, ainfi nommé, parce qu'il fe plaî à contrefaire la voix de l'homme. D'autres écrivent Senfoutlé, \& difent que cet oifeau-ci joint à l'éclat du plumage un chant fi agréable, qu'on a cru le devoir défigner par ce nom, qui fignifie cinq cens voix: il eft un peu moins gros qu'une Grive, d'un 
$246 \quad$ Objervations \& additions:

cendré très-luifant, avec deux taches blanches fort régulières aux â̂les \& à la queue.

Mais le Senfonte de notre Auteur paroît être différent de celui que Bankroft défigne comme particulier à la Guiane; celui-ci eft lè Loxia dominicana de Linné. Notre oifeau moqueur eft au contraire celui que Kalm a décrit dans fon Voyage II, p. 361 , \& qui eft le Turdus polyglottus de Linné.

Spatule. Efpatula. C'eft l'Oie à cuiller de l'Amérique, \& une variété du Plantalea ajaja de Linné; \& dont le corps eft tout rouge. La Sparule de D. Ulloa paroît être au contraire femblable au Héron gris, même pour le plumage.

Taburons, ou Tiberons \& Tulurons. Gros poifon de mer, de la forme du Chien de mer, fort dangereux pour cerx qui s'occupent de la pêche des perles. Les Tintorètes ne font pas moins ì craindre pour enx.

Tomineio. Nom da Colibris, ainfinommé parce qu'il ne père avec fon nid que deux tomines d'Efpagne, on vingt-quatre grains; mais il paroît que c'eft plutôr l'Oifeau-mouche qu'on a ainfi nommé; il eft de la taille d'une grofe Abeille.

Tucan, ou l'oifeau prêcheur du Pérou. L'Auteur a parlé de cer oifeau curieux fous le nom de Tulcan, dans fon Voyage du Pérou; Pernetty, qui le copie, écrit auffi Tulcan; Feuillée en a auffi donné une 
Obfervations \& additions.

très-belle defcription', \& écrit Tocan ; d'autres Toucan. Le bec de cet animal eft fur-tout remarquable par la grandeur de fon volume \& par fa forme. On a nommé cer oifeau prêcheur, à caufe des mots quili femble articuler \& faire entendre affez loin pendant que les autres oifeaux dorment, pour les garantir des oifeaux de proie. Limné rapporte le Tucan au Ramphaftos.

Uagra. Nom de l'Anta au Pérou. V. Anta.

Ver luifant, ou Cuculio. Rocheforr dans fon Hiftoire des Antilles a parlé de ce Ver, \& de la manière de le prendre la nuit avec des charbons ardens. Les détails de notre Auteur montrent affez qu'il parle de l'Elater noctiluca de Linné, \& que Bankroft a décrit, $p .460$ : on en trouve une figure dans les Mémoires de l'Académie des Sciences, an. $1776, p .340$. Quant à ce que D. Ulloa dit d'une autre efpèce de Ver luifant, on ne peut décider par le peu qu'il en dit s'il a voulu parler de la Mouche luifante, Lampyris, ou Mufca noctiluca. Cette Monche luifante eft une efpèce d'Efcarbot, décrit dans le Tome XII de l'Hift. géner. des Voyages, p. 229 . Il eft fingulier que la matière de fa lumière brille également la nuit, fi l'on 's'en répand fur les mains \& fur le vifage. Ces infectes phofphoriques rappellent les anneaux lumineux des Anciens, auxquels les Chymiftes modernes devroient bien

\section{Q 4}




\section{Obfervations \& additions.}

faire attention, avec tout leur prétendu favoir : mais qu'ils font encore loin des connoiffances des Anciens!

Ucumari. Nom d'un animal qu'on a nommé Ours fur le Maranon; c'eft aufi le nom du vrai Ours du Mexique.

Uritu. Nom par lequel les Indiens défignent routes les efpèces de Perroquets, à caufe de leurs cris tumultieux.

Vena medinenfss. V. Culebrilla.

Vigognes. Cet animal a été décrit par tous les Voyageurs; nous ne nous y arrêtons pas, après ce qu'en a dit l'Aureur. V. Alpaques.

traches de Buenosayres. Ce que l'Auteur en dit étoit vrai par le parlé, mais le nombre de ces animaux eft confidérablement diminué, felon ce qu'en dit Falkner, $p . s 2$. Lorfque je vins la première fois dans cette contrée, dit-il, les bêtes ⿳亠丷 comes y éroient en fi grande quantité, qu'outre les troupeaux privés, ces bêtes fe répandoient par troupeaux dans les plaines qui bordent les rivières de Parana, Uragay, Plata, \& couvroient les campagnes de Buenos-ayres, Mendoza, Santa-Fé, \& de Cordoue; mais la négligence ou l'avidité aveugle des habitans a tant contribué à la diminurion de ces animaux, que la viande y auroit été extrềmement chère, fi quelques particuliers ne s'étoient encore occilpés du foin de quelques 
Objervations \& additions.

troupeaux privés. Depuis mon arrivée dans ce pays, il ne s'eft guète paffé d'années qu'on ne chargeât depuis cing jufqu'à huit vaiffeaux de cuirs à Buenos-ayres; on tuoit une quantité énorme de bêtes dont on ne prenoit que la graiffe, le fuif \& la peau; la chair étoit abandonnée dans les champs à la pourriture. Le nombre qu'on en tuoit dans les Diftricts de cette ville \& de SantaFé ne fe montoit pas à moins de cent mille bêtes par an. Ce commerce, qui ne pouvoit fe foutenir long-tems au même point, a infiniment diminué; cependant il n'eft pas entièrement tombé; les bêtes n'y font même pas proportionnément auffi chères qu'elles devroient l'être: : un jeune Bœûf n'y coûte que deux écus, mais c'eft beaulcoup en comparaifon du prix antérieur. C'eft ainfi qu'on-s'occupoit aufi des beftiaux au Chili, où l'on fa procure d'affez grands troupeaux, qu'on tire des plaines du Paraguai par le pays des Puelches : on n'y prend non plus que le fuif, la graiffe \& le cuir. Par la graife il faut entendre, felon Frézier, la fubftance qu'on tire des viandes \& des os qu'on fait bouillir, ce qui fert de beurre \& d'huile pour les fauces. Les Indiens ne connoiffent pas l'ufage du beurre \& du fromage, \& les Créoles font trop fiers pour fe rabailfer jufqu’à tirer ces deux fubftances des beftiaux. Cependant Ulloa nomme dans fon Voyage plufieurs 


\section{$250 \quad$ Obfervations \& additions.}

endroits où l'on trouve du beurre \& du fromage.

Vache marine, ou Manati. Cet animal a été décrit \& repréfenté dans plufieurs Voyages imprimés; on peut voir les détails \& la figure qui s'en trouvent dans Gumilla \& autres. Ses détails font les plus exacts que nous en ayons.

Vifcachas. V. Lapin.

Wanotra. Autre nom du Guanaco. $V$. ce mot.

$\boldsymbol{Z}$ aramagullon. Oifeau qu'Ulloa nomme amphibie, \& qui appartient certainement aux Pingouins, que M. Forfter a diftingué à propos, comme il femble, des Papageys-plongeurs, \& des autres efpèces avec lefquelles Linné \& Briffon les ont confondus fous le nom d'Aptenodyta. Frézier en parle ainfi : “ Nous prîmes dans un marais un de ces animaux qui vivent fur terre \& dans l'eau, nommés pingouins, de la groffeur d'une Oie. Au lieu de plumes il avoit un poil gris, prefque comme un Chien de mer, \& des âlerons femblables à ceux de cet animal. $V$. la figure, Planche XVI, T. I, p. 208 , lettre $\mathrm{H}$ de Frézier.

$\boldsymbol{Z}$ orillo. L'Auteur parle de cette bête en paffant, lorfqu'il fait mention de la plante Coca, \& dans le Difcours qui concerne les maladies; il dit ici que le foie de cet animal eft un remède infaillible pour la pleuréfie. G. de la Vega, Liv. VIII, c. 17, nomme une bête de l'Amé- 
rique $Z$ orilla, \& dit que les Indiens du Pérou l'appellent Annas. Elle entre pendant la nuit dansles villes, \& y répand par-tout une puanteur infoutenable. Pernetty nous décrit dans fon Voyage le Zorillo de Monte-viedo. "Il eft, dit-il, de la grandeur d'une Belette, un peu moins long, d'un poil fauve, plus clair fous le ventre, qui eft prefque gris; deux lignes blanches's s'étendent le long du dos, \& forment depuis le con jufqu’à la queue une figure prefque ovale: cette queue eft bien fournie de poil, \& l'animal la tient prefque toujouts dreffée comme fait l'Ecureuil. Lorfqu'il fe fent pourfuivi, ò qu'il s'irrite, il tâche fon urine, qui infecte l'air à plus d'une demi-lieue par une odeur de charogne prefque infupportable. Le Zorillo eft peut-être le même que la Bềé puante ou enfant du diable du Canada, dont l'trine produit à-peu-près le même effet. Le Chinche des parties méridionales de l'Amérique a aufli beaucoup de rapport avec le Zorillo.

Kalm dit dans fon Voyage, Part. II, p. 4I 9, que l'on trouve dans nombre de contrées de l'Amérique Septentrionale \& Méridionale cet animal, auquel on donne les noms de Bête puante, Polcat, Skunk, \& Enfant du diable. Catesby le décrit fous le nom de Putorius Americanus friatus, \& en donne la figure. Mais il y a en Amérique différentes efpèces de Bêtes puantes, qu’on 
$2 s^{2}$

Obfervations \& addicions.

a confondues fous plufieurs noms. Erxleben appelle le Pecan du Canada, Muftela Canadenfis. La defcription que Feuillée donne d'un animal des côtes de Magellan, nommé Chinche, eft conforme à celle qu'on vient 'de lire de Pernetty. Narboroug femble nommer le même animal Grogneur; parce qu'il grogne, \& fouille la terre avec les deux pieds de devant lorfquil apperçoit un homme. Pennant appelle Skunk le Chinche de Buffon, \& Erxleben le nomme Viverra mephitis. On voit dans Charlevoix que le Zorillo du Chaco n'elt pas différent de la Bête puante du Canada.

Mais, felon la defcription que Mutis nous donne du Viverra putorius, il paroît que $f_{a}$ puanteur ne vient pas de fon urine, mais d'une humeur quil exprime \& jette fur fa route. $V$. les Mém. de Suede, Vol. XXXII. Ullóa le nomme dans fon Voyage, Zorro, ou Renard, \& penfe; comme Feuillée, que c'eft avec fa queue qu'il répand fon urine. Je ne vois nulle part qu'on ait parlé de l'ufage du foie d'aucune de ces efpèces d'animaux, pour les vues dont notre Auteur fait mention.

Yasumama. Gros Serpent de l'Orenoque. 
OBSERVATIONS E additions concernant les Mines de l'Amérique Efpagnole.

D. Ulloa fair d'abord mention des mines de Virreyno dans fon Difcours XIV. En parlant de ce Corrégiment dans fon Voyage, il ne dit rien à ce fujet, probablement parce que l'on n'y travaille plus. Il en eft de même du Corrégiment de Vilcas-Guamen, dont il donne auffi la defcription. Quant à celui de Guanta, il dit feulement que les mines d'argent y étoient autrefois très-riches, mais que les produits en font actuellement fort diminués, \& il remarque comme en paffant, qu'on s'y occupe d'une mine de plomb.

Son Voyage ne nous apprend rien d'une mine près d'Angarraës. Barba s'exprime ainfi concernant la mine d'argent appellée Machacado, ou Plata blanca, (argent blanc) L. 1. chap. 22. On trouve quelquefois dans les veines des minieres, l'argent en filets blanc \& fin, \& formant comme un entrelacement dans la gangue; c'eft ce que les Efpagnols appellent Machacado, ou argent natif. Ils donnent aufli ce nom à la mine de cuivre, lorfque ce métal fe rencontre natif out tout formé, fous l'apparence de filets tors, comme 
254 Obfervations \& additions.

Barba le remarque, chap. 29. Le mot Macnacado vientdu verbe machacar, qui, en Efpagnol, fignifie écrafer, bocarder, comme l'obferve Frézier dans fon Voyage au Pérou, \$. T. I. p. 277 . Il vit auffi des minerais blancs \& gris, mêlés de taches rouffes ou bleuâtres; c'eft proprement ce que les Efpagnols appellent Plata blanca. Les minerais de Lipes font la plupart de cette qualité. Pour l'ordinaire on y diftingue à l'œil quelques grains d'argent, fouvent même de petites palmes couchées dans le lir de la pierre.

L'Auteur parle des Lucanes dans fon Voyage: il dit qu'on y rencontre dans les campagnes beaucoup de mines d'argent; elles font toujours fi riches, qu'elles font une grande partie des tréfors du Pérou.

Il dit à l'égard de Chucuito, qu'on trouve dans toutes les montagnes de cette Province; des veines d'argent qui , après avoir été trèsriches autrefois, font actuellement déchues prefqu'en totalité.

Les mines de Huantajoya, dans le Corrégiment de Caranguas, ont fans doute été comprifes dans la defcription générale qu'il nous a donnée de cette Province dans fon Voyage.

Il y dit, qu'on rencontre dans les campagnes beaucoup de veines d'argent où l'on travaille continuellement. La plus renommée eft celle de 
Turce; qui contient un minerais qu'on appelle mine blanche d'or, nom que les mineurs donnent au minerai où les veines font à découvert dans la gangue, \&z forment un tiffu par l'entrelaffement des tamifications : ce minerai eft ordinairement très-riche. Il y a d'autres mines qui, à la vérité, ne font pas fi riches, quoique fort importantes, \& qu'on rencontre dans les déferts fablonneux vers les côtes de la mer du Sud. Lorfqu'on fouille dans le fable, on y trouve des morceaux d'argent ifolés, \& fans aucune autre veine ni gangue fuivie que celle qui eft adhérente ou mêlée avec ces morceaux d'argent : on y appelle ces morceaux Papas, parce qu'on les découvre à-peu-près comme ces racines qu'on tire çà \& là en fouillant. (Dans le paffage fuivant, l'Auteur attribue leur origine aux émiffrons des feux fouterrains.)

Ces Papas d'argent font réellement femblables à de l'argent fondu. On voit des molécules de terres adhérentes à leurs furfaces, \& qui n’y forment que peu ou point de mélange : c'eft de ce phénomène que $\mathrm{D}$. Ulloa conclut que leur formation eft due à des émiffions ignées. Ces morceaux ou échantillons d'argent natif fondu, fe trouvent en différens endroits d'un même canton; mais généralement en petit nombre dans le même lieu. Barba nous apprend L. I. c. 29. qu'il y a 


\section{Obfervations \& additions:}

dans le diftriet de Caranguas, près de la mine d'argent, quelques montagnes remplies de cuivre que l'on appelle Turco. Le mor Macizo dont fe fert l'Auteur, fignifie dur, ma/fif.

Larecaxa. D. Ulloa fe contente dans fon Voyage, de parler des veines de mines d'or qui y font; mais il ne fait pas mention de Saraca. Quant aux mines de Caylloma; il dit qu'elles ont été découvertes il y a long-tems, \& 'qu'on commença à y travailler aufli-tôt qu'elles le furent : que du refte elles ont toujours procuré affez de bénéfice. Il y a dans le cheflieu de ce diftrict; une caiffe royale, \& deux officiers pour recevoir le droit de quint, \& pour veiller à la diftribution du mercure.

Oruro. L'Auteur dit dans fon Voyage, qu'il $s$ y trouve beaucoup de mines d'or \& d'argent. Les premieres étoient déjà conntes du tems des Incas; mais on s'en eft peu occupé. Quant à celles d'argent, elles font encore aulfi fameufes quautrefois : ce qui donne encore autant de renom à ce pays quili en avoit eu, à caufe de fes tréfors; cependant ces grandes richeffes ont bien diminué, parce que, malgré les travaux les plus affidus des mineurs, les eaux ont gagné en beaucoup d'endroits, \& ont obligé d'abandonner des fouilles que l'on bénéficioir avec le plus grand avantage. Les mines qui rendent actuellement 
Obfervations \& additions.

le plus, font celles qui fe trouvent fur le $P_{O P O}$, montagne qui eft à douze milles environ de la ville. Barba nous apprend, L. 1. c. 28. que les trois grandes montagnes de Saint-Chriftophe, Pie-de-Gallo, \& la Flammenca, dans le diftrict de Panna, font enfemble ce que les Efpagnols appellent les mines d'Oruro:

On a fait nombre de tentatives inutiles pour découvrir des mines dans le Tucuman, comme nous le dit auffi Falkner, p. s4.

Manto. Ce mot eft une expreffion de mineurs Efpagnols, que Barba explique ainfi, L. I. c. 2.5. Quoique le mor veta (veine) foit l'expreffion dont on fe fert pour défigner tous les endroits qui contiennent du métal, les mineurs ne donnent cependant cenom qu'aux veines qui tendent à une direction verticale \& profonde, ou, ce qui eft plus général, à celles qui s'écartent de la ligne horizontale. Quant aux mines qui courent directement, fans baiffer par une déclinaifon quelconque de l'horizon, ils les appellent Mantos (Manteaux). On rencontre ordinairement les unes \& les autres; mais généralement, ce font les mines profondes \& inclinées qu’on bénéficie. Les veines qu’on rencontre le plus rarement, font celles que nos mineurs Efpagnols appellent' Sombreros, c'eft-à-dire Chapeaux. Ces Sombreros ont lieu lerfque les métaux fe trouvent enfemble fur une maffe ou Tome 11 . 


\section{Obfervations \& additions:}

motte, en quelque quantité \& quelque étendue qu'ils y foient, lorfqu'il en part en même-tems des veines foit profondes, foit latérales. Les Mantos de D. Ulloa font donc de perites mines accumulées, qui s'étendent à la fuperficie du fol. Au contraire les mines qui, felon l'original, courent entre caxas formales, font fans doute. celles qui s'étendent \& fe prolongent entre des couches de pierres qui en forment la gangue.

Barba explique ce quion doit entendre par caxas, L. I. c. 22. Les pierres, dit-il, qui occupent les interftices des métaux, \& que l'on appelle caxas, ou receptacles, fervent comme de conduits, qui donnent un libre paffage aux émiffions ignées fouterraines \& à leur rencontre mutuelle. - Ce qui fe trouve réuni entre ces receptacles, eft ce que nous appellons veine ou filon métallique. Barba nomme encore, dans le Chap. XIII, parmi la pierre ou la roche que l'on coupe avec le métal, les caxas, ce que l'on' doit entendre des pierres pures.

Acofta nomme Tejos ou Barutas, c'eft-à-dire petites barres d'or, ce que notre Auteur écrit Texos. Le mot Texo Efpagnol, défigne ordinairement l'arbre que nous appellons If, ou un animal, le Blaireau.

Ces Texos, de même que les Pignes ( $P$ inas) n'entrent pas dans le commerce, à moins quion 
Obfervations \& additions.

en ait payé le quint, \& qu'ils n'ayent été fondus aux caiffes royales pour être dégagés de tout le mercure qui peut y être refté, afin d'avoir ainfi le poids \& l'alloi requis. Les Texos \& les $P_{i-}$ gnes font donc ainí marqués du poinçon royal qui en défigne \& le poids \& la qualité. Le poids avec lequel fe pefe l'or, fe nomme Caftillan, comme le dit Frézier. Un Cafilllar eft la centième partie de la livre Efpagnole. Le Caftillan fe divife en huit tomines, de forte que fix caftillans \& deux tomines font une once. Il faut obferver que le poid's d'Efpagne eft de $6 \cdot \frac{x}{3}$ par cent plus léger que le poids de marc de France.

La bonté ou l'alloi de l'or s'eftime par quilates, ou karats. Le plus fin eft de 24 karats, \& jamais au-delà. Frézier a donné à cet égard les détails les plus clairs.

La Pigne eft une chofe qui n'a point cours hors des mines, \& l'on doit indifpenfablement la porter à la Caiffe royale ou à la Monnoje, pour en payer le quint : c'eft-là qu'on fond l'argent en maffe, pour y imprimer enfuite les armes de la Couronne, le lieu où elle a été fondue, le poids qu'elle a, \& l'alloi de l'argent: on eft toujours sûr que ce métal eft légitime avec cette marque; au lieu qu'on a généralément lieu de foupçonner les Pignes : car ceux

$\mathrm{R}_{2}$ 
qui les font, mettent fouvent au milieu du fer du fable ou autres matières hétérogènes, pour leur donner plus de poids.

Les mines d'or font privilégiées, \& l'on ne peut exercer de faifies par corps fur tous ceux qui y travaillent. On ne paie au Roi que le vingtième denier de l'or, c'eft ce qu'on appelle le Cobo. Ce mot vient du nom d'un particulier qui offrit cetre rétribution gratuite au Roi d'Efpagne. On n'étoit pas moins obligé auparavant de payer, comme à préfent, te quint de l'argent au Roi. Le dixième de l'argent avoit commencé à fe payer en 1737. Depuis 1761 , on a obtenu l'exemption du quint du mercure, comme notre Auteur le dir : en conféquence de cette remife du quint, \& de quelque diminution dans le prix de la vente du mercure, ce demi-métal qui fe vendoit auparavant 80 pefos le quintal, fe livre à préfént pour 60. V. Camipomanes Educat. Popul. II. 132.

Cet Ecrivain-ci eftime le produit des mines de l'Amérique Efpagnole, à trente millions de $P$ efos, ce que Robertfon évalue à 7,425,000 liv. fterling, dont le quint attribué au Roi, monteroit à $1,485,000$ livres fterling, s'il étoit exactement payé ; mais il faut d'abord déduire de cette fomme moitié pour les frais de dépenfes \& de régie, afin de fixer ce qui vient net 
an Roi. Mais outre les circonftances favorables dont, felon notre Auteur, on fait profiter pour faire paffer fecrétement les lingots d'argent, Frézier nous apprend encore que les particuliers s'entendent avec les Corrégidors, \& font ainfi paffer ces Pignes de contrebande jufqu'au port d'Arica.

D. Ulloa parle des Aviadores dans fon Voyage. Ces Aviadores font des Marchands qui paffent à Potofi avec de l'argent monnoyé, \& en fourniffent à ceux qui exploitent les mines pour les dépenfes qu'exigent leurs befoins journaliers, \& prennent en échange des pignes d'argent. Il va auffi d'autres Marchands dans les endroits où ces travaux font en vigueur, \& qui donnent des matchandifes pour ces pignes. On appelle ces gens Refcatadores; mais il y a beaucoup de mauvaife foi $\&$ de tromperie dans ces trafics: voilà ce qui oblige à ufer de tant de précautions \& de vigilance. Pour découvrir la rufe, il faut foumettre ces pignes à l'action d'un feu vif: fi elles font falfifiées, le feu lés fait noircir ou jaunir, ou plutốt couler. Cette épreuve fert auffi à diffiper l'humidité dont on les a impregnées dans l'endroit où elles ont été mifes à deffein d'en augmenter le poids. Frézier affure qu'on peut en porter l'augmentation à un tiers,

$\mathrm{R}_{3}$ 


\section{2}

Objervations \& additions:

en les éteignant très-chauds dans de l'eau. Nous parlerons plus bas du lavage.

Les corvées qu'on exige dès Indiens, \& que l'on appelle Mitas, font d'un an, felon Frézier. Selon les Ordonnances du Roi, les Paroiffes des ęnvirons de Potofi doivent y envoyer tous les ans un certain nombre d'Indiens pour les travaux des mines. Les Corrégidors les font partir à la Fêre-Dieu. La plupart de ces gens prennent avec eux leurs femmes \& leurs enfans, qui n'y vont qu'à regret, \& non fans verfer des pleurs : nalgré cela, il y en a auffi parmi eux plufieurs qui, après avoir fạit leur tems, oublient leur lieu natal, \& fe fixent à Potofi.

Selon Bayer, les Caciques de la Province de Chucuito doivent fe rendre au mois de Juillet avec leurs Indiens, fur la place de cette ville, pour fe rendre à leur tour à Potoli, \& y travailler aux mines : ils paffent alors en revue en préfence du Gouverneur, \& chaque bande pare avec fon Capitaine.

Selon les Ordonnances du Roi que cite Ro. bertfon, le nombre des Indiens qui doivent fe rendre touss les ans à Potofi, eft fixé (pour le Pérou) ąu feptième des habitans de chaque département. Les Indiens étant en plus grand nombre dans la Nouvelle-Efpagne, on y prend quatre hommes: 
par cent pour ces corvées, que l'on y appelle Tandas.

Chaque Mita, ou Bande n'eft tenue à travailler que fix mois : on leur paie le falaire que notre Auteur a dit, \& que Robertfon évalue à deux fchellings fterlings; mais tout Indien, qui demeure à plus de trente milles d'Angleterre audelà d'une mine, ne peut être contraint à venir y travailler. On n'oblige pas non plus les Indiens des plaines à paffer de ces pays chatids dans les froids climats des montagnes pour travailler aux mines, ce qui les expoferoit à une mort inévitable. Mais dans la Nouvelle-Efpagne on ne peut forcer les Indiens aux corvées que dans l'efpace de quatorze milles de diftance de leur habitation: on ne voit pas la raifon de cette différence, ni pourquoi les Perruviens font plus furchargés que les autres, à moins, comme nous l'avons dit cidevant, qu'elle ne vienne du nombre des habitans plus grands dans un Royaume que dans l'autre.

Mais les ordonnances qui prefcrivent ces tra-: vaux avec ces reftrictions font la plupart du tems. mal exécutées, ou plutôt on n'en tient prefque aucun compte dans ces contrées éloignées du Souverain; car fouvent on force à ces mitas ou corvées, des Indiens qui font à cent cinquante \& même deux cens lieues de la mine. Les Rois

$\mathrm{R}_{4}$ 
d'Efpagne voulant mettre à profit des mines trèséloignées dans des contrées défertes, ont euxmêmes donné plus d'extenfion aux termes de leurs crdonnances, \& ont permis à leurs Vice-rois de contraindre' les Indiens à venir les exploiter, quoiqu’à des diftances confidérables. V. E falona Gazophylac. Peruv. I, c. 16. Le Gouvernement Efpagnol a cependant cherché à diminuer le poids de cette fervitude, en ordonnant aux Vice-rois d'engager les Indiens à venir fe fixer dans les environs des mines qu'on pouvoir bénéficier.

Notre Auteur prétend que les travaux des mines ne nuifent pas à la fanté des Indiens; mais on voit par fes propres paroles à l'article des maladies, que les mines produifent des effers bien contraires à fes autres affertions; d'ailleurs, Roberton produit le témoignage de deux Ecrivains Efpagnols, qui affurent que le nombre des Indiens diminue, par-tout où ils travaillent atx mines, tandis que dans les provinces où il n'y a pas de mine, leur nombre eft augmenté de plus d'un tiers depuis la conquête. Juan Gonzales de Alzevedo alfuroit en 1609 , que le nombre de ces indigènes étoit diminué de moitié dans les environs des mines du Pérou, \& d'un tiers, en d'antres endroits, depuis i $s \delta$.

Une autre obfervation de Frézier confrme une / partie du récit de notre Auteur. Il ne faut pas 
Objervations ş additions.

s'étonner, dit-il, que les Indiens gardent un fi grand fecret à l'égard des mines d'or \& d'argent qui leur font connues, puifque ce font enx qui ont la peine de tirer ce métal fans en profiter. Mais ces Indiens font plus propres à ces travaux que les Nègres, qui y périffent tous; ils ont un corps robufte, \& font, fans contredit, plus capables de foutenir ces fatigues que les Efpagnols: d'ailleurs ceux ci s'imaginent que le travail des mains eft un déshonneur pour un Blanc. Avoir le vifage blanc, c'eft un honneur qui difpenfe un Européen du travail.

Mais, d'un autre côté, l'Épagnol 'eft-il plus blâmable de tenir ces pays conquis dans cette fervitude, lorfqu'on voit tous les Européens vendre \& acheter les Nègres comme des bêtes fur la place? Ils font même, à l'égard des Nègres, plus humains que les autres Européens; car fi un Nègre, maltraité par fon maître, trouve un Européen qui veuille payer à ce maître inhumain le prix qu'il lui a coûté, il peut le quitter moyennant ce rembourfement. En outre, fi un Nègre peut amalfer de quoi fe racheter, il eft fur le champ libre, en payant $f a$ rançon à fon maître. Cette lis, pleine d'humanité, devroit fervir d'exemple à toute l'Europe, \& prouve que le Gouvernement Efpagnol n'eft pas aufi dur à l'égard de fes ferfs, que bien des Ecrivains ont voulu le dire. On 
verra, fi l'on veut, dans Herrera \& d'antres Hiftoriens Efpagnols, plufieurs ordonnances des Rois d'Efpagne, en vertu defquelles il eft défendu à aucun parriculier Européen d'exiger le moindre fervice d'un Indien, ni aucune chofe quelconque, fans lui payer ou fon fervice, ou ce qu'on reçoit de lui. Mais ces Souverains, fi éloignés de leurs poffeffions Américaines, ne peuvent que s'en rapporter à leurs Officiers; s'ils font trompés, pourquoi en accufer le Gouvernement qui a eu d'autres intentions, qui a rendu des ordonnances toutes contraires à la conduite que l'on tient en violant toutes fes loix? Nous faifons icices réflexions, pour montrer que les vexations qu'on exerce contre ces Indiens, \& que notre Auteur n'a même pas diffimulées, ne font pas dans l'efprit dú Gouvernement, \& que s'il a quelquefois pris des voies contraires à fes intentions antérieures, il a encore moins été dur à l'égard des Indiens, que le refte de l'Europe ne l'eft à l'égard des Nègres. On reproche à un Efpagnol de forcer un Indien au travail des mines, \& l'on approuve un François qui fait écorcher un Nègre à un poteau par cent cinquante coups, d'un fouet énorme, qu'on lui donne : je demande lequel eft le plus barbare, \& quelle différence il y a entre le Nègre \& l'Indien qui eft encore moins maltraité? Mais laiffons - li ces riftes objets, qui font tant de déshonneur à l'hu- 
Obfervations \& additions:

manité, \& convenons que l'homme ne connoît que fon intérêt pour mefure de la juftice. Il n'y a pas de Gouvernement en Europe qui n'ait eu fes écarts, \& contre lequel on ne pût faire autant de déclamations que contre l'Efpagne. Le foleil a fes taches; c'eft le partage de l'humaniré d'avoir fes momens obfcurs.

Pour bien fentir la raifon des plaintes que fait notre Auteur au fujet des manipulations maladroites avec lefquelles on fait ufage du mercure dans le traitement des minérais, il faut confidérer attentivement les procédés comme ils feront expofés dans ce qui fuit. Alonzo Barba avoit déjà fuffifamment expofé les fautes incroyables que l'on faifoit de fon tems dans les mines de l'Amérique; mais il eft probable que les chofes reftèrent long-tems dans le même état, quoique par la fuite on ait voulu çà \& là améliorer quelques procédés felon les vues qu'il avoit ouvertes. On a repris l'ancienne méthode fous la direction de nouveaux entrepreneurs, fans avoir égard à ce qu'il avoir confeillé pour éviter la perte confidérable que l'on faifoit du mercure. Bowles avance même que les Efpagnols pourront fe trouver dans le cas de manquer de mercure pour exploiter leurs mines au Pérou. En effet la mine d'Almaden, qui ne fourniffoit de mercure que les mines du Mexique, eft obligée d'en envoyer une grande 
quantité au Pérou, parce que la mine mercurielle de Guancavelica n'eft plus fuffifante. $V$. Bowles, Introduct. à l'Hift. Nat. de l'Efpagne, p. 48.

Je vais reprendre ce qui concerne les mines d'argent de Potoli, \& y joindre ce qui conceme les procédés que l'on tient dans les fouilles; procédés qui ont fervi de modèles aux autres mineurs, \& que d'autres Ecrivains ont plus ou moins exactment détaillés.

Je m'arrête d'abord à la defcription que nous en fait Acofta dans fon Liv. IV, c. 6 : plufieurs Ecrivains l'ont copiée, \& la plupart l'ont tronquée ou défigurée. Telle eft celle que nous produit Bruckmann dans fes Magnalia, T. II, p. 1097, d'après Hugues de Linfchotten, quoique tout $y$ foit pris d'Acofta.

La fameufe montagne de Potofi, dans la province de Charcas au royaume du Pérou, eft à $21 \frac{2}{3}$ degrés de la ligne équinoxiale, latitude $S u d$, de forte qu'elle fe trouve en-deçà du Tropiquie vers les extrémités de la Zone Torride; malgré cela, il y fait plus froid qu'en Flandres \& que dans la vielle Caftille; cependant il devroit y faire chaud, vu la pofition du lieu. Le froid qu'on y fent vient de la grande élévation du local, \& des vents froids qui y fouflent de tous côtés, furtout du froid \& violent vent Tomahavi qui y règne pendant les mois de Mai, Juin, Juillet 
Objervations \& additions.

\& Aount : le pays eft fec, froid, défagréable \& entièrement ftérile, ne produit ni plantes, ni fruits; \& eft ainfin naturellement inhábitable; mais l'attrait de l'argent, \& le defir que les hommes ont de s'en procurer, y ont attiré tant de monde, qu'il n'y a pas un endroit plus peuplé dans tout ce Royaume. On y trouve en abondance tous les befoins \& toutes les commodités de la vie, parce qu'on y apporte de tous côtés des marchandifes de toutes efpèces. La montagne a une couleur rouge, obfcure, \& un afpect affez agréable; on diroit voir une efpèce de pavillon, ou un cone femblable à un pain de fucre : fa cime domine fur toures les montagnes des environs.

Le chemin par lequel on y monte eft fort difficile, cependant on peut le faire en totalité fur un cheval. Le mont fe termine en une pointe ronde, qui a, au bas où commence la pointe, une lieue de circuit : depuis cette pointe jufqu'au pied du mont, on compte environ feize cens vingtquatre varas, qui font le quart d'une lieue Efpagnole. On voit fur le flanc du mont une éminence où il y avoit autrefois quelques fouilles d'où l'on tiroit quelques minérais tendres, \& comme enfermés dans des bourfes, \& non par veines régulières : ces minérais étoient fort riches, quoiqu'on n'en rencontrât qu'en petit nombre. Cette éminence s'appelle, felon les Indiens, Huaynat: 


\section{Obfervations \& additions.}

potofi, ou Potofi le jeune. ( Le grand mot eft pour eux Hatunpotofi, ou Potofi le pere, comme le dir G. de la Vega, qui a pris les Chap. 24 \& 2 g de fon Liv. \& prefque mot pour mor d'Acofta.)

C'eft près de cette éminence que commencent les habitations des Efpagnols \& des Indiens qui s'y font établis, pour avoir part au gain ou à la perte des métaux que l'on tire du Potofi; toute la Bourgade peut avoir environ deux lieues de circuir: c'eft-lì le centre du commerce de tout le Pérou.

Les Incas ne faifoient point travailler à ces mines, mais à celles de Porco, qui font à fix lieues de Potofi : ils ne les connoiffoient probablement pas, car les autres caufes qu'on en allégue, font une pure fable.

Voici comment on découvrit ces mines douze ans après l'arrivée des Efpagnols dans cette contrée. Un Indien nommé Hualpa, natif de Chumbibilca, dans la Province de $C_{u} \int c o$, pourfuivoit quelques chamois, qui fe fauvoient droit à cette montagne : elle étoit alors couverte de l'arbre appellé Quinua, \& de plufieurs arbriffeaux: I'Indien continue fa pourfuite, arrive à un chemin un peu rude \& efcarpé, qui menoit à la montagne, il faifit une branche, \& par fon poids il caffe l'arbre, dont la racine couroit fur la veine métallique, qui fut enfuite appellée la riche. Cet homme qui entendoit le 
travail des mines, ayant apperçu à la racine \&c au trou qu'elle laiffoit, un minérai fort riche; examina le local, \& trouva dans la terre quelques morceaux de ce minérai, qui s'étoient détachés de la veine, mais que le foleil \& les eaux avoien rendu entièrement méconnoiffables; il les emporta à Porco pour en faire l'effai au feu, \& ne tarda pas à en reconnoître la bonté : il réitéra fes recherches, fouillant fecrétement, fans fe laiffer appercevoir de perfonne.

Ceci dura jufqu'à ce qu'un autre Indien nommé Huanca, de la vallée de Xauria, s'apperçut que le métal que Hualpa fondoit, étoir différent de celui de Porco; que d'ailleurs Huanca en formoit de plus gros lingots, \& fe trouvoit beaucoup plus à fon aife qu'auparavant. Il le pria; le follicita fi vivement, qu'à la fin Hualpa, deux mois après avoir joui feul, le prit avec lui, \& le mena au tréfor, \& lui montra une autre mine qu'il avoir découverte, \& qu'il lui abandonnoir. Cette veine giffoit près de la Riche, \& c'eft celle qui fut appellée la veine de Diego Centeno. Elle étoit aufli riche que l'autre, avec cetre feule différence, que le minérai étoit plus dur à bénéficier. Après s'être ainfi accordés, ils revinrent chez eux.

Mais Hkanca trouvoit toujours beaucoup de difficultés à traiter fon minérai, vu $\mathrm{fa}_{2}$ duroté. 
272 Obfervations \& additions.

Hualpa ne vouloit lui donner aucune part au fien : la divifion fe mit donc entre eux, \& Huanca découvrit toute l'affaire à fon maître Villaroel, qui demeuroit à Porco. (Zarate, Découverte du Pérou, nomme cet endroit Plata. On lit auffi chez lui les chofes avec quelques différences qui ne font rien au fonds.) Ce Villaroel fe rendir fur le lieu pour s'affurer d'abord de la vérité des rapports, \& fir enfuite porrer Huanca fur le regítre, \& marqua avec lui l'efpace de terrein accordé par les loix à ceux qui découvrent les mines: c'eft ce qu'on appelle en Efpagnol fe paliffader, ou Eftacarfe. Ils devinrent alors poffeffeurs du terrein marqué dans lequel eft la mine, après en avoir donné connoiffance au Magittrat, \& en payant au Roi le quint du bénéfice. Ce fut donc ainfi qu'on découvrit la mine de Potofi, dans le diftrict des mines de Porto, \& qu'on la fit enregiftrer. Ceci arriva le 2 I Avril i 545. Quelques jours après on découvrit d'autres veines, fort riches à la vérité, mais dont le minérais étoit extraordinairement dur. On appelle en Efpagnol ce minérai dur, Mine de l'Etain. Le 3 I Août de la même année, on découvrit la mine appellée Mendieta, qui fut aufi enregiftrée : telles font les quatre principales veines de Potofi.

On dit que la Riche formoit une pierre qui fortoit 


\section{Obfervations \& additions}

fortoit hors de terre comme une roche, à la hauteur d'une vara, fe prolongeant à la diftance de trois cens pieds, fur I 3 de large. Le minérai étoir fi riche, qu'il rendoit moitié de fon poids d'argent. Cette richeffe fe foutint à la même quantité, jufquà ce qu'on eût fonillé à go ou 60 toifes de profondeur, alors le bénéfice diminúa. On dit que ces plateaux ont été découverts par les eaux du déluge, \& qu'ils ont réfifé par leur dureté, à la violence énorme des flots de cette inondation générale. Tel eft le contenu du Chapitre 16 d'Acofta, que notre Auteur a fait entrer tout entier dans fon Voyage. La différence qu'il obferve à l'égard du nom de Gualpa, autrement Hualpa, ne vient que de l'orthographe \& de la prononciation. La langue générale du Péroù ne connoît pas l'articulation dont $G$ eft le figne : la lettre $\mathrm{H}$ y fupplée en conféquence d'une articulation différente; mais le mot Gualca pour Gualpa, eft fans doute une erreur intro= duite par une faute d'impreffion. D. Ulloa nous apprend en outre, que la mine découverte la première, fut nommée Defcubridora, ou celle qui fit découvrir les autres.

Acofta s'exprime ainfi dans le feptième Chapitre du même Livre." On voit par les Livres de Comptes des Caiffes royales, ce que plufieurs Ecrivains atteftent auffi : favoir que penTome 11 . 
dant que Polo étoit Gouverneur, on paya tons les Dimanches au foir le quint de s go mille ou 200 mille livres, ce qui montoit à 30 ou 40 mille livres de quint, \& faifoit au bout de l'année, un million \& demi, ou peu moins." «Il faut encore remarquer que ce calcul ne comprend que l'argent dont on payoit le quint, \& qui étoit contrôlé; mais on fait que depuis long-tems il a été d'ufage au Péron de ne pas payer le quint de l'argent qu'on y appelle de cours, \& qui n'eft pas contrôlé. Or ceux qui connoiffent ces mines, affurent qu'une grande partie de l'argent qu'on tiroit de Potofi, n'étoit pas quinté, fur-tout l'argent qui étoit de cours parmi les Indiens \& les Efpagnols, comme cela fe pratiquoit encore de mon tems. On peut donc croire que le tiers, \& peut-être même la moitié de l'argent de Potoli, n'étoit pas exhibé aux Caiffes royales, \& ne payoit pas la taxe ordonnée par le Roi." "

“La mine de Potofi n’a jamais été expofée aux inondations fouterraines, quoique les fouilles aient été portées au-delà de 200 toifes de profondeur; au lieu que ces inconvéniens ont fait abandonner prefque totalement les rravaux à Porco. Sa Majefté Catholique n'a de notre tems, années prifes l'une dans l'autre, qu'un million de quint des mines de Potoli, fans cependant y comprendre 
le profit qu'elle tire du mercure, \& d'autres droits royaux. Quelques perfonnes verfées dans ces affaires, ont fait le compte de ce qui fe paie de quint à la Caiffe de Potofi, quoique les premiers regîtres n'aient pas été tenus dans l'ordre où ils font actuellement, \& lorfqu'on fe fervoir de la romaine pour évaluer le poids; mais on a trouvé, felon les comptes faits par le Vice-Roi D. François de Tolece, que les droits de quint montoient à 76 millions depuis i 564 jufqu'à l'année mentionnée; \& l'on peut démontrer par les regîtres royaux, que depuis $156_{4}$ jufqu'à I 85 inclufivement, ils ont monté à 35 millions; de forte que l'argent du produit du quint faifoit depuis fon établiffement jufqu'en is 85 , la fomme de cent onze millions de pefos en fayados, le pefo valant treize réaux \& un quartello, ou un quart de réal.

Mais on ne comprend pas dans cette fomme l'argent qui n'a pas payé le quint, ni ce qui a été payé aux autres Caiffes pour le quint des mines de leur reffort, ni tout ce quauroit dût produire de quint l'argent immenfe qui étoit appellé de cours, \& qui ne payoit rien : ce compre fut envoyé de mon tems au Vice-Roi du Pérou, de la part de la Caiffe de Potofi. Depuis ce tems-là les richeffes que l'Efpagne a tiré du Pérou par les Gottes, ont confidérablement augmenté. En effet, 
$276 \quad$ Objervations \& additions:

les deux flottes qui venoient du Pérou \& du Mexique en I 85 , apportoient onze millions, dont prefque la moitié appartenoit au Roi, \& dont les' deux tiers venoient du Pérou feul.

Acofta nous dit dans fon huitième Chapitre, qu'il y a quatre veines principales dans le Potofi, ce que nous avons déjà vu plus haut. Ces veines fe trouvent, felon lui, à l'Orient, vers le point même où le foleil fe leve; \& qu'il n'y en a pas au Couchant. Les veines fe portent du Nord au Sud, \& ont fouvent fix pieds d'épais : les plus minces ont une palme; mais il ajoute qu'il fe détache des groffes veines plufieurs petites, comme autant de ramifications du minérai.

Ulloa nous apprend auffi dans fon Voyage, que les quatre mines principales fufdites fe portent du Nord au Sud, en tournant un peu vers l'Oueft. Selón le fentiment des gens verfés dans les travaux des mines de ce Royaume-là, les plus riches, ou celles dans lefquelles on trouve la plus grande quantiré d'argent, font celles qui fuivent cette direction : mais Ulloa fuit ici Alonfo Barba. Celui-ci nous dit, Liv. I, Chap. $25^{\circ}$ : S'il ett permis dans ce Nouveau-Monde, \& dans un climat tout oppofé, de déduire des règles d'après l'expérience à l'égard des riches mines du Potofi, je regarderois comme les plus riches celles qui fe portent du Nord au Midi fur le côté méridional de la 
montagne, en tournant un peu vers le Couchant, direction que tiennent les quatre principales mines de ce mont, qui font la Centeno, appellée autrefois la Defcubridora, la Riche, la mine de Cinabre, \& la Mendieta. Je mettrois au fecond rang celles qui fe portent au Nord \& au Midi, fur le côté méridional du mont. Or, ce point eft parallèle avec la direction que fuivent le veines les plus riches des mines d'Oruro.

Chaque veine a des fouilles différentes, ou des champs qui appartiennent aux particuliers qui en font les maîrres, \& portent le nom de ces propriétaires. La fouille la plus grande a quatre-vingt varas, \& les loix défendent de leur donner plus d'étendue : les plus petites en ont quatre; elles font prefque toutes fort profondes. On compte foixante-dix-huit fouilles à la Riche; en quelques endroits elles vont à cent quatre-vingt, \& dans d'autres à deux cens toifes de profondeur. La veine Centeno a vingt-quatre fouilles, dont quelquesunes ont foixante ou quatre-vingt pieds de profondeur. Il en eft ainfi proportionnément des autres.

On a percé, pour le befoin de ces fouilles; différentes galeries qui vont depuis un des flancs du mont jufqu'aux veines; mais il faut favoir que les veines, en fe portant du Nord au Sud, s'abaiffent auffi du fommet au pied du mont, ce 
qui, felon quelques perfonnes, fait un efpace de douze cens toifes: on compte encore une diftance fix fois auffi grande jufqu'au fond, qui devroir ère le plus riche, puifqu'il eft regardé comme le tronc ou la fource de toutes les veines : mais l'expérience a toujours prouvé le contraire jufqu'ici; en effet, plus les veines paffent certaine profondeur, plus le minérai fe trouve pauvre.

Mais, pour revenir aux galeries, on en a pratiqué, afin d'exploiter les mines avec moins de peine, de dépenfes \& de danger, \& l'on a tâché de procurer par ce moyen les entrées \& les forties les plus commodes que permertoir le local. Ces galeries ont huit pieds de large, fur une braffe de haut, \& font munies de portes par lefquelles on exporte le minérai; ces portes peuvent fe fermer \& s'ouvrir à volonté. Les propriétaires des galeries perçoivent le quint de tout le minérai que l'on tire : il y a déjà neuf galeries de pratiquées, $\&$ l'on en fair de nouvelles. On a employé prefque vingt-neuf années pour pratiquer \& confolider la galerie del venino, laquelle fe rend à la veine Riche: elle a été commencée en i $55^{6}$, onze ans après la découverte de la mine, \& n’a été achevée qu'au premier Avril i s\$s. Cette galerie arrivoit à la veine Riche à une profondeur de trentecinq toifes, mais il y avoit encore cent trentecing toifes de-là au fond de la fouille. Telle étoir 
la profondeur à laquelle il falloir defcendre pour rravailler dans la fouille. La galerie a depuis fon entrée jufqu'à la rencontre de la veine, que l'on appelle le Carrefour, deux cens cinquante varas, efpace auquel on a travaillé pendant les vingtneuf années.

C'eft à la lumière qu'on travaille dans les fouilles, \& ceux qui ont travaillé de jour vont repofer la nuit. La pierre, ou gangue, eft fort dure, il faut la brifer avec le maillet \& le fer pour l'enlever. Lorfque le minérai eft réduit en petites parties, on le monte, moyennant des échelles faites d'une triple corde de cuir de Bouf, tourné comme un cable; les échelons y font tous deux à deux, de manière qu'un homme peut defcendre \& l'autre monter: ces ćchelles ont chacune dix toifes de long, \& font folidement enlacées les unes dans les autres à chaque extrémité, où l'on a comme un point de repos en allant $\&$ revenant, fur une efpèce de faillie de bois faite exprès, car on fent bien que le nombre de ces échelles doit être confidérable. Chaque homme porte une charge du poids de deux arrobes, ou cinquante livres, dans une groffe toile (manta) placée fur les épaules, \& attachée devant la poitrine : ils montent toujours trois en même tems, fe tenant par les mains à chaque échelon : le premier a toujours une lumière fixée fur le pouce. 
La veine mérallique paffe ordinairement entre deux efpèces de pierres que l'on appelle la Caiffe, (Caxa) \& dont l'une eft auffi dure qu'un caillou, l'autre tendre \& facile à brifer : le minérai fe rrouve au centre, \& n'eft jamais de même qualité par-tout : tantôt on l'a plus précieux, tantôt plus pauvre: le plus riche elt celui qu'on appelle $\mathrm{Ca}$ cilla, ou Tacana. Le riche minérai a dans cette montagne une couleur d'ambre, un autre paroît plus noirâtre, un autre rouge, ou cendré, ou enfin de plufieurs autres couleurs. Les mineurs favent juger de fa richeffe à l'inftant, par les taches, les petites veines, les ftries, \& autres fignes qui leur font familiers : tout le minérai qu'on a tiré fe porte au moulin. Les moutons du pays, Llamas, Alpaques, qu'on appelle autrement Moutons-Chameaux, fervent à ces tranfports.

Le bon minérai fe bénéficie fimplement par la voie de la fonte, dans des fourneaux que l'on appelle Guayras; il tient ordinairement plus de plomb que celui d'une qualité inférieure, \& c'eft ce qui en facilite la fufron; c'eft pour cette raifon que les Indiens ajoutent même à la fonte une partie de minérai Soroche, parce qu'il tient beaucoup de plomb. Les fcories gagnent le fond fur le feu, le plomb fond avec l'argent qui vient au-deffus, \& qu'on purifie plufieurs fois.

Un quintal de minérai rend à la fonte trente; 
quarante, jufqu'à cinquante pefos d'argent. On m’a montré du minérai qui rendoit deux cens \& même deux cens cinquante pefos par quintal; mais c'elt une chofe fort rare. Le minérai pauvre ne rend que deux, trois, cinq, lix pefos, ou peu davantage; ce minérai eft ordinairement fec, \& mélangé de plomb: voilà pourquoi on ne peut le bénéficier au feu.

Cette difficulté avoit fait jetter à Potofi de gros tas de ce métal pauvre, qu'on regardoit comme le rebut du minérai riche, \& dont on ne fit par conféquent aucun cas, jufqu'au moment où l'on introduifit l'ufage du mercure pour bénéficier ces mines : on tira pour lors des richeffes immenfes de ces rebuts abandonnés parmi les déblais. L'amalgame convient même à ces minérais pauvres \& fecs : ils confomment aufli moins de mercure que le riche. On bénéficie actuellement par le mercure prefque tous les minérais d'argent $\grave{a}$ Potofi, Cacatecas, \& dans toutes les mines de la Nouvelle-Efpagne.

On voyoit autrefois fur la cime \& la croupe du Potofi, fur les côteaux, plus de fix mille fourneaux ou Guayras, qui, lorfqu'ils étoient allumés, faifoient de loin pendant la nuit le plus beau fpectacle qu'on pût voir : on en voit actuellement deux mille tout au plus, parce que l'on bénéficie prefque tout par l'amalgame. 
Notre Auteur (D. Ulloa) nous donne dans fon vingt-quatrième Chapitre, $\$$ I s. un détail trèsimparfait de la meilleure manière dont les Indiens fondoient les métaux. D'abord il nomme les fourneaux Guayras, \& en fecond lieu Cayana; $\&$ il obferve que les fourneaux dans lefquels on pouffe l'argent au fin, confervent encore le même nom. La différence de ces dénominations vient probablement, de ce que l'une eft Efpagnole, \& l'autre Indienne. Laët tient le mot Guayras pour Efpagnol dans fes Origines des Nations Américaines, p. 33. Zarate dit au contraire que les Indiens nomment ces fourneaux Guayras, comme qui diroit Le vent. Ce mot eft done Indien felon lui.

G. de la Vega s'explique d'une maniere plus circonftanciée fur ces travaux. Les Indiens, dit-il, prenoient leurs minérais d'argent au grand Potofi; mais d'abord ils ne furent pas le bénéficier. L'argent, au lieu de fondre au feu, s'y diffipoit: ils imaginèrent enfuite d'y mêler du plomb pour le fondre, ce qui leur étoit facile, puifqu'ils avoient découvert une mine de plomb dans le petit Potofi. L'effai leur réuffit, \& ils nommèrent le plomb Guruchec, c'ent-à-dire le fondant : l'expérience leur montra en quelle proportion ils. devoient l'y metrre. Le minérai étant donc préparé, ils le fondirent dans des fourneaux por- 
Obfervations \& additions.

catifs, mais fans foufflet, car ils avoient remarqué qu'en employant ce moyen, le métal refufoit de fondre : pour cet effet, ils fe rendoient de nuit fur la montagne \& le monticule, \& fe plaçoient du côté où le vent leur paroiffoit le plus propre à leurs vues; tournant, comme le dit Zarate, l'ouverture de leur fourneau du côté du Midi, pour qu'il fût expofé à toute la force du vent du Sud, qui y fouffle impétueufement : cétoit-là qu'ils exécutoient leur premier travail. Après cette fonte, ils revenoient chez eux, \& réitéroient les fontes jufqu'à ce que le métal fût parfaitement purifié ; mais ils employoient pour cet effet des tuyaux de cuivre pour fouffler.

Les Indiens furent d'abord les feuls qui travaillèrent aux fouilles, \& qui fondoient aufi les métaux ; mais les Efpagnols s'occupèrent enfuite feuls de la fonte : ils imaginèrent de nouveaux moyens pour la faciliter, firent de grands foufflets pour entretenir continuellement le plus grand feu dans les fourneaux. Cet expédient ne leur ayant pas réuffi, ils imaginèrent des machines à voiles, analogues à des moulins à vent, \& que des chevaux faifoient aller : ils n'eurent pas plus de fuccès, \& reprirent les anciens procédés des Indiens, qu'ils fuivirent jufqu'à ce que l'on introduisît l'amalgame.

Acofta nous parle encore de la fonte des 
$284 \quad$ Objervations \& additions:

Indiens de manière à jetter du jour fur leurs procédés, L. IV. c. 5. Les mines d'argent, dit-il, fe trouvent la plupart fur des éminences \& des monts efcarpés \& déferts, quoi qu'on en découvre quelquefois dansles plats pays. Le minérai d'argent eft ou par place, épars \& fans continuité, ou il forme des veines fuivies, \& des filons réguliers. Nous appellons filons \& veines, le minerai qui fe prolonge en s'enfonçant comme autant de ramifications d'un arbre. En général, on rencontre plufieurs ramifications femblables à peu de diftances l'une de l'autre.

Les Indiens favoient fuivre ces minérais, \& les bénéficier par la fonte : ils les foumettoient à l'action du feu, qui en fépare les fcories, \& débarraffe l'argent du plomb, de l'étain, du cuivre \& des autres matières qui s'y trouvent mêlées : pour cet effet, ils employoient de petits fours qu'on appelle Guayras au Pérou : ils les chauffoient avec du bois, du charbon, les expofoient fimplement au fouffle du vent.

Il y a des minérais que l'on ne peut traiter par la fonte, mais pour lefquels l'amalgame eft néceffaire; ce font ordinairement les minérais pauvres : or ces minérais font en plus grande quantité que les autres; mais il eft fingulier que certains minérais ne foient pas traitables par la fonte, en y employant le vent d'un fouflet, 
Objervations \& addicions.

\& demandant nécelfairement un cours de vent naturel, ou autrement, d'être abandonnés au fouffle de l'air, tandis que d'autres fondent en employant un foufflet. C'eft ainfi que le minérai qu'on tire des fouilles de Porco fe traite facilement avec le foufllet, tandis que celui des mines du Potofi ne cède qu'à un feu animé par un courant d'air. Il eft difficile fans doute de rendre raifon de la différence de ces effers; mais ils n'en font pas moins conftarés par l'expérience.

C'eft de ces fortes de minières que les Indiens tiroient leur argent, dit Frézier, T.II, p.227, parce que n'ayant pas l'ufage du mercure comme les Européens, ils ne travailloient qué celles dont le minérai pouvoit fe fondre : comme ils avoient peu de bois, ils chauffoient leurs fourneaux avec de l'Icho, efpèce d'herbe ou de jonc dont nous: avons parlé, \& de la crote des Llamas ou autres animaux, \& ils les expofoient fur les montagnes, pour que le vent entretint le feu dans $f_{a}$ force. Voilà tout le fecret dont les Hiforiens du Pérou parlent comme d'une chofe merveilleufe.

Eclairciffons à préfent les dénominations dont fe fervent Acofta \& Ulloa. Le minérai qu'ils appellent $P$ aco eft d'un rouge jaunâtre, dit Frézier; p. 278 ; il eft forc mou \& brifé en morceaux; mais il eft rarement riche, $\&$ l'on n'en travaille les minières qu'à caufe de la facilité qu'il y a do 
le tirer. Barba s'explique à-peu-près de 'mênre. Pacos, dit-il, felon l'expreffion vulgaire du pays, fignifie une couleur rougeâtre, \& c'eft plus ou moins de cette couleur que font les pierres que l'on appelle Métal paco; quoiqu'on donne auffi le nom de Paco dans Berenguela de Pacagès au minérai verd de cuivre : on le donne même dans ce pays-là aux minérais de couleur quelconque, pour les diftinguer de ceux qui brillent comme l'acier ou le verre, \& de celui qu'on appelle Negrillo. Le Negrillo, dit Frézier, eft un minérai noir comme du mâche-fer, où l'argent ne paroît point; s'il eft noir, mêlé de plomb, on l'appelle plombo ronco; l'argent y paroît en le grtatant avec quelque chofe de rude : c'eft ordinairement le plus riche, \& celui qui revient à moins de frais, parce qu'au lieu de le faire pêtrir avec le mercure, on le fait fondre dans des fourneaux où le plomb s'évapore à force de feu, \& laiffe l'argent pur \& net.

Le Tacana, dit Barba, eft un minérai tiche $\&$ ordinairement noir; il s'en trouve auffi de verd \& de cendré, que l'on appelle Llipta, \& qui appartient au Paco. Ils appellent Suco le minérai d'argent qui fe trouve le plus fouvent noir, gris, cendré, verd, blanc, \& d’un brun jaunâtre; ils appellent auffi ce minérai plomb. On en trouva lannée dernière dans le Potofi d'une couleur ca- 
Obfervacions \& additions.

nelle, vive $\&$ brillante, \& de couleur du vermillon le plus fin, ce qu'on n'avoir jamais apperçu dans les autres mines.

Le Soroche pourroit paffer pour une quatrième efpèce de minérai; mais je penfe qu'il eft de l'efpèce du Negrillo, de même que le Rofícler, le plus riche minérai que la Nature ait produit fous la forme d'une pierre. Le Soroche eft brillant, facile à rompre : lorfqu'on en mêle la poudre bien fine avec quelque chofe de bien broyé, il a une couleur de fang pur, ou celle d'un vrai cinabre. Mais, felon le même Barba, le Soroche eft noir ou cendré fans éclat, \& tient ordinairement un peu d'argent. On l'appelle minérai de plomb mort, Soroches muertos, Liv. I, chap. $3 \mathrm{I}$. Suivant le même, le Soroche eft un minérai qui tient du foufre \& du plomb.

Mais voici ce que dit Frézier à l'égard de ces deux derniers minérais. Il y a du minérai qui brille comme du Talc : celui-ci eft ordinairement mauvais, \& donne peu d'argent. On en voit une autre efpèce où l'argent ne paroît nullement; au contraire, en le mouillant \& le frottant contre du $\mathrm{fer}$, il devient rouge, c'eft pourquoi on l'appelle Rofficler : celui-ci eft fort riche, \& donne l'argent du plus haut allo:

Il $\mathrm{y}$ en a de verd, qui n'elt guere plus dur que le Paco: on le nomme Cobriffo : il eft très: 
rare; néanmoins, quoique l'argent y paroiffe ordinairement, \& qu'il foit prefque friable, c'ent le plus difficile à bénéficier : il faut quelquefois, après qu'il eft moulu, le torrefier, \& employer plufieurs moyens pour le féparer; fans doute parce qu'il eft mêlé de cuivre. On a auffi trouvé au Potofi un autre genre de minérais fort rare, dans la feule mine de Catamito : ce font des fils d'argent pur, entortillés comme du galon brûlé, en peloton fi fin, qu'on les nomme aragna, ou araignée, à caufe de la reffemblance qu'ils ont avec la toile de cet infecte.

Le Cochico elt de même nature que le $R o / f_{\text {- }}$ cler, très-riche, mais non auffi friable, ni auffi poreux: il tient plus de plomb, \& ne fe réduit pas en poudre avec la même facilité : la couleur n'eft pas non plus d'un rouge auffi beau. Le Tacana elt, dit le même Barba, un minérai d'argent denfe, épais, noirâtre, \& fans brillant. La Polverina eft un Tacana qui n'eft ni coagulé, ni pierre, mais riche, \& qui fe trouve dans le Paco, mais non dans le Negrillo, à caufe du mélange du cuivre. Le Rofficler \& le Cochico fe différencient par le brillant qui dérobe leur couleur naturelle \& particulière. Les Negrillos qui ont le brillant de l'acier ou d'une glace de miroir, \& qui pour cette raifon, fe nommeut Acerado, ou Espeiado, font d'autant plus riches, 
Objervations \& additions.

qu'ils approchent plus du Rofficter \& du Cochic. Le Pacos qui ne brille point, fe traite particulièrement avec le mercure. Le Tacana peut auffi s'incorporer avec le mercure; mais comme c'eft un minérai fi riche, qu'on ne peut l'extraire totalement pur \& net, en ce quil en refte toujours une partie dans les fcories, ou le traite par la fonte avec du plomb. Le minérai appellé Mire de plomb, étant fort groffier, ne fe laifre pas broyer comme il faut, \& ne fe lie pas de manière à faire corps avec le mercure; c'eft pourquoi il vaut mieux le fondre avec du Tacana. Le Machacado fe broye très - bien avec le marteau; le Soroches a befoin de feu ; le Rofficler \& le Cochico doivent fe fondre comme le Tacana; le Negrillo demande \& le feu \& le mercure. Selon le même Barba, le feu augmente tellement le vitriol dans le grillage du Negrillo, qu'on eft obligé d'y ajouter quelques matières pour le griller.

Mais on confultera, fil l'on veut, Frézier, Barba; Bouwles, Boyer, pour les éclairciffemens ultérieurs qu'on pourroit defirer fur les dénominations de ces minérais, \& de plufieurs autres efpèces, tant fimples que mixtes, \& plus ou moins traitables.

D. Ulloa nous donne au fujet des richeffes immenfes qu'on a tirées de Potofi, un état pris Tome II. 


\section{Obfervations \& additions:}

de D. Gaspar de Efcalona. Selon celui-ci, on en tira trois cens quatre-vingt-quinze millions fix cens dix - neuf mille Péfos jufqu'en I $_{3} 8$. Or depuis l'époque de la découverte jufqu'à cette année-là, il y a 93 ans : ainfi c'eft par an quatre millions deux cens cinquante-trois mille quarante-trois Pefos. On n'en tire pas actuellement le même produit, dit $\mathrm{D}$. Ulloa, quioique le bénéfice en foit encore affez confidérable.

Il nous donne enfuite le rapport di mercure confommé , à l'argent tiré d'après Barba, qui écrivit fon Otivrage en 1637. Celui-ci nous apprend que depuis 1574 , époque à laquelle on commença à traiter les minérais avec le mercure, jufqu'à l'année dans laquelle il écrivit, on porta à la Caiffe royale de Potofi, deux cens quatre mille fept cens quintaux de mercure, \& mếme quelques quintatix de plus, fans compter la grande quantité qui fat introduite clandeftinement. Or il fe trouve foixante-trois ans entre ces deux époques : c'eft donc par an trois mille deux cens quarante-neuf quintaux.

Mais la chofe eft préfentée avec des dates bien différentes dans la traduction Allemande de Barba, imprimée à Francfort en 1726. Il y eft dit : On commença à marquer pour la première fois, en 1574 , le merctire qui venoit $\mathrm{du}$ Potofi pour le compte du Roi, \& depuis ce 
Obfervations \& additions:

rems-là jufqu'en $164^{\circ}$, on en reçut plus de deux cens quatre mille fix cens quintaux, outre la grande quantité qui y fut portée fur d'autres états. "

De cetre grande différence il réfulte que ce paffage ne peur fervir i. fixer l'année de lintroduction de l'amalgame, époque fur laquelle on n'eft pas d'accord; mais on ne peut non plus en dérerminer le rapport du mercure employé avec l'argent tiré. En effer, la quantité de mercure néceffaire, dépendir d'abord autant de la richeffe plus ou moins grande da minérai, que des procédés plus ou moins directs, ou mal combinés avec lefquels on trairoit les mines. Ulloa dit lui-même: "Peu de tems avant qu'on ê̂t amélioré les procédés de la fonte de l'argent, \& qu'on n'employât plus tant de mercure, il falloit un marc de mercure par marc d'argent, \& fouvent plus, lorfque les ouvriers n'étoient pas affez expérimentés dans l'art de traiter ces mines "; mais D. Ulloa ne nous apprend pas en quoi a confifté l'amélioration qu'on a faite aux procédés, quoique ce foir un point fur lequel tout lecteur voudroit fans dcute être inftruit.

Avant de paffer aux procédés de l'amalgame, je vais joindre ici en faveur de plufieurs lecteurs peu inftruits de tous les travaux des mines, ce

$T_{2}$ 


\subsection{Objervations \& additions:}

que nous dit Acolta fur la manière de bocarder ou broyer le minérai. Notre Auteur a palfé un peu légèrement fur cé fujet, qui eft affez curieux, pour mériter d'être connu plus généralement.

Le minérai, dit Acofta, eft d'abord moulu ou broyé, afin qu'il puiffe s'incorporer avec le mercure. Or ceci s'exécute dans des moulins, avec des procédés différens. Quelques-uns de ces moulins font mis en mouvemint avec des chevaux, d'autres avec des courans d'eall, \& l'on voit là un grand nombre des uns $\&$ des autres. Comme il n'y a ordinairement au Potofi que l'eau de la pluie qui tombe en Décembre, Janvier \&' Février, on n'y moud non plus le minérai que pendant trois mois. On a donc fait de valtes réfervoirs, qui ont jufqu’à 1700 varas de tour, \& trois toifes de profondeur. Il y en a fept pareils, que l'on ouvre avec des vanes, \& que l'on ferme les jours de repos. Si les eaux de pluie font abondantes, \& groffiffent confidérablement les réfervoirs, on peut quelquefois moudre du minérai pendant fix ou fept mois; c'eft pourquoi les gens du pays demandent de l'eau, non pour avoir du pain, comme il arrive ailleurs, mais pour avoir de l'argent. On voit de pareils moulins à Tarapaia, vallée diftante de deux ou trois lieues de Potofi, dans laquelle il paffe une 
riviere : on en voir auffi en plufieurs autres endroits : la feule différence qui s'y trouve, eft que les uns ont fix, les autres douze, \& même quatorze bocards. Le minérai eft broyé dans des mortiers, où l'on en jette jour \& nuit, retirant ce qui eft écrafé, pour le paffer. On voit fur le bord de la riviere de Potofi, quarante-huit moulins de huit, dix \& douze bocards : il y en a encore quatre autres de l'autre côté de l'eau, \& vingt-deux dans la vallée de Tarapaia. Outre ces moulins à eau, il fe trouve à Potofi trente autres moulins à chevatix , fans compter plufieurs autres plus éloignés.

On-trouvera fans doute ces détails fort infuffirans; mais les détails de Frézier, quoique connus de gens inftuits, donneront des notions plus claires à ceux qui ne le font pas. Voyez fon Ouvrage, Tom. I. pag. 186. \& p. 269. fuiv. édit. in-1 2.

Paffons à l'amalgame telle qu'Acofta nous la décrit de fon tems, \& comparons-là enfuite avec le même procédé dans des tems plus modernes. On confomme, dit-il, année commune, au Potofi, fix à fept mille quintaux de mercure pour préparer le minérai, fans y comprendre la fomme de ce que l'on tire des bones qui font reftées du premier lavage. Ce fédiment que l'on appelle Lamas, eft grillé \& préparé dans un 
194 Obfervations \& additions:

fourneau, pour en tirer le reftant du mercure: Il y a aufi dans le territoire de Potofi \& de Tarapaia, cinquante fournaux pareils.

La quanticé du minérai qu'on prépare tous les ans, monte, felon des gens expérimentés, à rois cens mille quintaux, des boues defquels on tire encore plus de deux mille quintaux de mercure.

Il faut obferver que les minérais n'ont pas tous la même propriété: l'un tient peu d'argent, \& confomme beaucoup de mercure, l'autre rend beaucoup, \& n'en confomme que fort peu. C'eft de la qualité du minérai que dépend le gain ou la perte dans les travaux des mines: généralement, celui qui rend beaucoup, confomme aufi beatucoup de mercure, E vice yersâ.

Le minérai eft auparavant broyé dans des machines appellées Ingenios, où l'on fait agir des pilons. Quand il eft bien écrafé, on le paffe par des efpèces de tamis de fer ou de cuivre, qui, lorfqu'ils fone bien faits \& bien difpofés, rendent en vingt-quatre heures trente quintaux de poudre de minérai très-fine. On tranfporte ce minérai dans une aire ou parquet partagé en un certain nombre de planches, ou de mafres parallelogames : dans chacune on étend cinquante guintaux de minérai pulvérifé, fur lefquels on 
Obfervations \& additions.

jette cinq quintaux de fel, pour attaquer cette poudre, \& la féparer des impuretés qui y adhèrent, de forte que le vif-argent puiffe mieux faifir l'argent, \& s'y incorporer : après cela on met du mercure dans une toile de cannevas, pour le faire tomber en le preffant, comme une pluie fine : pendant ce tems-là on remue fans celfe le minérai, afin qu'il foit bien arrofé, \& pénétré par-tout de ce mercure, qui s’incorpore ainfi peu à peu.

Avant qu'on eût imaginé les Buytrons à feu, on pêtriffoit plufieurs fois le minérai avec le mercure dans des auges, \& l'on en faifoit enfuite de grandes maffes rondes, qu'on laiffoit repofer pendant quelques jours. On recommençoir à pétrir ces maffes, jufqu'à ce qu'on vît que le mercure fût incorporé avec l'argent, ce qui duroit quelquefois vingt jours \& plus, \& au moins neuf; mais on remarqua que le feu abrégeoit beaucoup le travail, \& que le mercure s'uniffoit plus vite avec l'argent.

On conftruifit donc pour cet effet des Buytrons, dans lefquels on met de grands Caxons, où l'on jette le minérai avec le fel \& le mercnre : on fait alors deffous un feu modéré dans les foyers voûtés qui y font adaptés, \& en cinq ou fix jours tout le mercure s'eft incorporé.

Dès qu'on s'apperçoir que le mercure a pro$\mathrm{T}_{4}$ 
$296 \quad$ Obfervations \& additions.

duit fon effet, que l'argent s'y eft entièrement uni, \& que la maffe a abforbé toute l'eau comme une éponge, de forte que l'argent fe trouve dégagé de la terre, du plomb, du cuivre, avec lequel il étoit mêlé, on ouvre les caxons pour en ôter la maffe, \& l'on procède à en extraire le mercure.

On jette pour lors la maffe dans une auge où l'on fait couler de l'eau : la boue y étant continuellement remuée par de petirs moulins, ou par des roues que l'eau fait tourner, elle s'écoule avec le courant d'eau, tandis que le mercure tombe par fon propre poids, au fond de l'auge, \& y refte. Le fédiment a l'apparence d'un fable: on l'en tire pour le laver une feconde fois dans des baffins, en l'agitant: ce lavage fait néceffairement paffer avec l'eau quelques particules d'argent \& de mercure; mais on fait les raffembler, \& on les bénéficie fous le nom de relaves.

Lorfque l'argent uni au mercure a été ainf́n purifié, de manière à paroîre un peu brillant, on prend toute la maffe pour la jetter dans une pièce de gros drap de laine, dans laquelle on la preffe très-fortement : le mercure qui ne s'étoit pas incorporé avec l'argent, en découle; il refte alors une mafre qu'on appelle Pella: certe malfe, après avoir été bien preffée, contient cing parties 


\section{Obfervations \& additions.}

de mercure, \& un fixième d'argent. Si la Pella pefe foixante livres, il $s^{\prime} y$ trouve par conféquent cinquante livres de mercure; \& dix livres d'argent.

C'eft avec la Pella qu'on fait alors les Pignes en forme de pains de fucre: elles font creufes en-dedans: ordinairement elles pefent cent livres. Pour en extraire le mercure, on les foumer à l'action d'un feu vif, en les couvrant d'un vaiffeau de terre de forme d'un bonnet dont la pointe eft tronquée, \& fur lequel on allume du charbon. Le mercure eft donc forcé d'en fortir en vapeur; mais comme il renconrre les parois du vaiffeau de terre, il fe condenfe de nouveau, \& tombe par un tilyau qui y eft adapté comme à un alambic; de forte qu'on l'extrait tout, \& l'argent devient abfolument pur.

L'argent conferve fon volume \& $\mathrm{fa}_{\mathrm{f}}$ forme; mais il eft comme poreux ou fpongieux, \&s perd cinq parties de fon poids fous ce volume. On fiit avec deux pareilles pignes, une barre d'argent du poids de foixante-cing à foixante-fix marcs; on la livre auffi-tôt à la Caiffe royale pour être effayće, \& l'on en paie le quint: elle eft alors marquéee à cette Caiffe du poinçon du Roi, \& l'on y indique auffi par une empreinte, le poids qu'elle a, \& fon alloi. L'argent purifié de certe manière, eft fi fin, quil n'a jamais auw 
298 Obfervations \& additions. deffous de 2380 (I) d'alloi. Sa bonté oblige même les Orfèvres d'y mettre de l'alliage, lorfqu'ils veulent en faire quelque ouvrage : il en elt de même lorfqu'on veut en faire de la monnoie.

Telle eft la defcription qu'Acofta nous donne des procédés qu'on tient pour traiter les minérais d'argent par l'amalgame. Un lecteurattentif s'apperçoit aifément que l'Auteur fuppofe vers la fin de fes détails, des chofes qu'il auroit dû dire d'abord, mais dont il n'a pas parlé : il paroît même qu'à certains égards il a été mal inftruit, c'elt pourquoi nous ne pouvons nous difpenfer de rapporter ici ce que Frézier nous a dit des mêmes procédés, non qu'il foit fuffifant feul, car il a auffi omis plufieurs chofes; mais ces deux Ecrivains comparés \& rapprochés l'un de l'autre, leveront tous les doutes; d'ailleurs nous ajouterons d'autres dé tails.

"A près avoir concaffé la pierre qu'on tire de la mine métallique, on la moud dans des moulins à meule verticale, comme celles avec lefquelles on écrafe les pommes pour faire du cidre, ou avec des Ingenios reales, qui font des pilons qui fe levent comme dans les moulins à tan ot a plâtre. Ces machines confiftent ordinairement

(I) L'Autcur entend fans doute parler ici de maravédis. 
Obfervations \& additions.

en une roue de vingt-cinq à trente pieds de diamètre, dont l'effieu prolongé, eft garni de triangles mouffes, lefquels tournant, accrochent les bras des pilons de fer d'où ils échappent tour d'un coup à chaque révolution; \& comme ils pèfent ordinairement environ deux cens livres chacun, ils retombent fi rudement, qu'ils écrafent \& réduifent en poudre la pierre la plus dure, par leur fimple pefanteur: on tamife enfuite cette poudre par des cribles de fer ou de cuivre, pour tirer celle qui eft la plus fine, \& remettre la groffe au moulin. Lorfque ce minérai fe trouve mêlé de certains métaux qui l'empêchent de fe pulvérifer, on le met au fourneau, $\&$ on le repile enfuite."

"Dans les petits minérais où l'on ne fe fert que de moulins à meule, on moud le plus fouvent le minérai avec de l'eau, qui en fait une boue liquide, qu'on fait couler dans un réfervoir; au lieu que quand on le moud à fec, il faut enfuite le détremper, \& le bien pêtrir avec les pieds pendant long-tems. ”

"Pour cet effet, dans une cour faite exprès, appellée Buyteron, on range cette boue par tables d'environ un pied d'épais, qui contiennént chacun un demi caxon, ou vingt-cinq quintaux de minérai, ce qu'on appelle $C_{u}$ erpo, ou le corps. 
300

Obfervations \& additions.

On jette fur chacun environ deux cens livres de fel commun, plus ou moins, felon la qualité du minérai que l'on pêtrit, \& qu'on fair incorporer avec la terre pendant deux ou trois jours : enfuite on y jette une certaine quantité de vif-argent, en preffant de la main une bourfe de peau, dans laquelle on l'a mis, pour en faire fortir quelques gouttes, dont on arrofe le corps également, fuivant la qualité \& la richeffe du minérai : on en met à chacun ro, is ou 20 liv; car plus il eft riche, plus il faut de mercure pour ramaffer l'argent qu'il contient : ainfi l'on n'en connoît la dofe que par une longue expérience."

"On charge un Indien du foin de pêtrir une de ces tables huit fois par jour, afin que le mercure puiffe s'incorporer avec l'argent. Pour cer effet, on y mêle fouvent de la chaux, quand le minérai eft gras; en quoi il faut ufer de précaution : car on dit qu'il s'échauffe quelquefois tellement, qu'on n'y trouve plus ni mercure ni argent, ce qui paroît incroyable: quelquefois aufli on y fond du minérai de plomb ou d'étain, pour faciliter l'opération du mercure, qui fe fait plus lentement dans les grands froids que dans les tenis modérés : de - là vient qu'au Potofr \& à Lipes, on eft fouvent obligé de pêtrir le minérai 
Obfervations \& additions.

pendant un mois ou un mois \& demi; mais dans des pays plus tempérés, il s'amalgame en huit ou dix jours. "

"Pour faciliter l'opération du mercure, on fait en quelques endroits, comme à Puno \& ailleurs, des Buyterons voûtés, fous lefquels on fait du feu pour échauffer la poudre du minérai pendanr vingt-quatre heures, fur un pavé de briques.

"Lorfqu'on croit que le mercure a ramalré tout l'argent, l'Enfayador, ou l'Enayeur, prend de chaque Cuerpo un peu de terre à part, qu'il lave dans une affiette de terre, ou un baffin de bois, \& l'on connoît par la couleur du mercure qu'on trouve au fond du balfin, s'il a eu fon effet; car lorfqu'il eft noirâtre, le mercure ent rrop échauffé : on y remet du fel ou autre drogue. Ils difent alors que le vif-argent difpara, ou s'enfuit. Si le vif-argent eft blanc, on en prend une goutte fous le pouce, \& en l'appliquant vite deffus, ce qu'il y a d'argent parmi refte attaché au doigt, \& le mercure s'échappe en petites gouttes : enfin lorfqu'on reconnoît que rout l'argent eft ramaffé, on tranfporte la terre dans un baffin où tombe un ruifrean pour la laver. Au lieu de crochet dont on fe fert pour l'or, il fuffit ici qu'un Indien la remue avec les pieds 
pour la faire délayer (2); d'un premier baffin'; elle tombe dans un fecond, où eft un autre Indien qui la remue encore pour la bien délayer $\&$ en détacher l'argent : de ce fecond elle paffe dans un troifième, où l'on en fait autant, afin que ce qui ne fera pas tombé au fond du premier ou du fecond, n'échappe pas du troifième. "

3) Après que l'on a tout lavé, \& que l'eau eft claire, on retrouve au fond des baffins qui font garnis de cuir, le mercure incorporé avec l'argent; c'eft ce qu'on appelle la Pella. On la met dans une chaulfe de laine de Vigogne fufpendue, pour faire couler une partie du vif-argent : on la lie, on la bat, \& on la preffe autant qu'on peut, en pefant deffus avec des morceaux de bois. Quand on en a tiré ce qu'on a pu, on met cette pâte dans un moule de planches de bois, lefquelles étant liées ènfemble, forment ordinairement la figure d'une pyramide octogone tronquée, dont le fond eft une plaque de cuivre percée de plufieurs petits trous : là-dedans on la foule pour l'affermir, \& lorfqu'on peut faire plufieurs pignes de différens poids, on les divife

(I) Frézier a fait graver les figures des meules, des ingenios, \& des baffius. 


\section{Obfervations \& additions:}

par petits lits de terre qui empêchent la continuité. Pour cela il faut pefer la Peilie ou Pella, $\&$ abandonner les deux tiers pour ce qu'elle contient de mercure, \& l'on fait, à peu de chofe près, ce qu'il y aura d'argent net."

"On leve enfuite le moule, \& l'on met la pigne avec $\mathrm{fa}$ bafe de cuivre fur un chandelier ou trépied, pofé fur un grand vafe de terre plein d'eau, \& on l'enferme fous un chapiteau de terre, qu'on couvre de charbons, dont on entretient le feu pendant quelques heures : par ce moyen la pigne s'échauffe vivement, le mercure qu'elle contient en fort en fumée; mais comme cette fumée n'a point d'effor, elle circule dans le vuide qui eft entre la pigne \& le chapiteau : venant alors à rencontrer l'eau qui eft atl-deffous, elle fe condenfe, \& tombe a fond, transformée de nouveau en mercure. On en perd donc peu, \& le même ferr à plufieurs fois; mais il faut en augmenter la dofe, parce qu'il s'affoiblit. "

"Quand le merclire eft évaporé, il ne refte plus qu'une marque de grains d'argent contigus, fort légère, \& prefque friable, qu'on appelle Pigna. C'eft une marchandife de contrebande fortant des mines, parce qu'on efr obligé par les loix du Royaume, à la porter aux Caiffes royales ou à la Monnoie, pour en payer le quint au 
$304 \quad$ Objervations \& additions:

Roi. Là on les fond, pour metre cet argenten barres ou lingots, fur lefquels on imprime les armes de la Couronne, celles du lieu où ils font faits, leur poids, leut qualité, avec l'alloi de l'argent, pour en faire la mefure de toutes chofes, fuivant l'expreffion d'un ancien Philofophe."

"On eft toujours sûr que les lingots quintés font fans fourberie; mais il n'en eft pas de même des pignes. Ceux qui les font, mettent fouvent au milieu du fer, du fable \& autres chofes, pour en augmenter le poids, de forte qu'il eft toujours de la prudence de les faire ouvrir \& rougir au feu, pour s'en affurer; car, comme nous l'avons déjì dit, fi elles font falfifiées, le feu les fait noircir, ou jaunir, ou fondre plus facilement."

Ce détail de Frézier s'accorde avec celui que Laër avoit eu d'un Flamand qui s'arrêta au Potoli en 1600 : il diffère cependant en une circonftance; car felon ce récit, on ajoute du fer \& du cuivre, \& l'on bocarde ainfi : il ne parle pas de l'addicion du fel. Quant à ce que de Lac̈t nous rapporte, il peut fort bien l'avoir pris en grande parcie d'Acofta, qu'il cite un peu auparavant.

Bayer fait mention de plufieurs circonftances dont les détails précédens ne nous apprennent rien, 
rien, \& nous expofe plus clairement quelques procédés; j’ajouterai donc ici la defcription qu'il nous préfente, $p_{0} 176$. "Ce fable d'argent, ou cette poudre réfultante du minérai écrafé dans les moulins, fe grille enfuite dans un four ordinaire avec des broffailles, après quoi on le tranfporte avec les cendres dans une cour pavce de pierres, où on le réduit en boue en y jettant de l'eau; \& on le divife en différens petits lits: quelques jours après on y jette du fel, quíon y mêle en quantité fuffifante: on le réduit encore en boue, \& un Indien le foule \& le pêtrit avec les pieds tous les jours, pendant plufieurs jours confécutifs。 Lorfqu'on préfume que le fel a bien mordu dans l'argent, on répand fur chaque lit autant de mercure qu'on le juge néceffaire, \& on pêtrit encore le tout enfemble comme auparavant : cela fait, on laiffe repofer les lits d'argent avec le mercure pendant plufieurs jours, \& autant qu'on le juge néceffaire, pour que le mercure s'empare de tout l'argent. Ce tems expiré, on porte les maffes dans une auge de pierre, où on les agite \& les lave avec de l'eau qu'on fait couler fur des peaux inclinées, \& qui ont une petite profondeur ats milietr. L'eau qui tombe d'une goutière fur ces peaux qui forment une efpèce de canal, entraîne avec elle toutes les impuretés : le mercure chargé de l'argent étant plus pefant, tombe dans le fond Tome $I I$ 。 


\section{Obfervations \& additions.}

des peaux, \& y refte tandis que l'eau en emporte ces matières hétérogènes. Après cetre opération le mercure eft retiré du fond de ces peaux, \& mis dans des bourfes de ctir terminées en pointe: on les fufpend fur un vaiffeau où le mercure tombe à mefure qu'il paffe aut travers de la peau; l'argent refte comme en pain dans la bourfe. Cet argent eft enfuite mis dans des formes où on le fait entrer de force avec un pilon pour le faire durcir. Lorfque ces pains ( $l^{\prime}$ Auteur dit fromages) d'argent font bien durs, on ôte les formes, \& on expofe la pigna à un feu vif de charbon, où on la laiffe rougir, afin que le peu de mercure qui refte encore dans l'argent fe diffipe au feu, s'évapore à l'air, \& que l'argent refte parfaitement pur. On appelle alors le réfidu argentvierge, parce qu'il eft fans aucun mélange de matières étrangères. "

Il faut favoir qu'il y a dans ces trois defcriptions des omiffions qu'un mineur defireroit bien connoître: malgré cela il eft poffible, d'après ces détails, de fe former une idée des travaux des mines de l'Amérique Efpagnole, \& des procédés qu'on tient pour l'amalgame. On pourra aufì fe repréfenter quel eft l'ordre \& la police qui règne dans toutes les opérations requifes pour l'exploitation, \& les fautes confidérables qui s'y commettent quelquefois, fi l'on compare ces détails 
Obfervations $\&$ additions.

avec l'avertiffement que Barba donne dans $f a f e-$ conde Letrre; mais pour faire cette comparaifon, il faut néceffairement recourir à l'original, car les traductions que nous en avons font prefque inintelligibles en nombre d'endroits, outre qu'on y a paffé plus de la moitié des obfervations prátiques.

Mais, pour ne rien omettre de ce qui peut donner une idée précife des procédés Efpagnols; je vais rappeller ici ce que nous dit Acofta dans fon Chapitre XIII fur la manière de foumettre les lingots à l'action du feu pour les tirer au fin.

"Lorfque les lingots (ou barres) font faits, on les porte à l'effayeur prépofé par le Roi, pour affigner à chaque pièce la valeur qu'elle a, \& il y marque le nombre felon l'ordre où elles ont écé foumifes à l'effai. Il coupe un morceau de chacune, le pèfe exactement, le porte fur un teft, \& le place par ordre dans le fourneau, où il donne un coup de feu très-vif. Le métal fond entièrement, le plomb qui peut s'y trouver fe diffipe en fumée, le cuivre ou l'étain fe confument, \& l'argent refte pur, de couleur de feu. Il eft furprenant que l'argent étant ainfi en fufion pour fe purifier, ne coule pas de différens côtés; il ne fe répand même pas quand on renverferoit le teft. L'effayeur connoît à la couleur \& à d'autres fignes quand le métal eft devenu très-pur; il retire alors 
$308 \quad$ Obfervations \& additions.

le telt du fourneau, pèfe chaque morceau avec la plus fcrupuleufe attention, \& obferve combien chacun a perdu de fon poids; celui qui étoit plus fin avant l'effai perd moins, Ė vice verfâ. Après ces opérations, il marque fur chaque barre la qualité, le poids qu'elles ont. Les poids d'effai font fi petits, qu'on ne peut les prendre gu'avec des pinces; on ne pèfe même ces pièces qu'à la lumière d'une chandelle, \& non au jour, afin que le mouvement de l'air n'agite pas la balance: car la connoiffance de l'alloi \& le poids, dépend de la plus rigoureufe exactitude.

On trouvera dans Gemelli Carreri, les procédés que l'on tient au Mexique pour bénéficier les mines d'argent. Cet Ecrivain remarque comme une amélioration des anciens procédés de l'amalgame, l'idée qu'eut un Dominicain d'ajouter des fcories de cuivre, outre le fel ; ce qui donne lieu au minérai broyé, de s'échauffer promptement. Le Traducteur Allemand rend par pyrites fulfureufes (2), l'expreffion de fcorie de cuivre.

(I) Les détails que nous avons vus jufqu'ici laiffant quelque chofe à defirer fur les procédés qui fe tiennent lorfque quelqu'un découvre une mine, fur les fouilles \& la manière d'y defcendre, fur l'exploitation, la réduction des minérais, la féparation de l'or d'avec l'argent, ce done les.Auteurs cités n'ont rien dit, on va placer ici quelques. 
Le fel eft, après le mercure, le plus néceffaire des ingrédiens; mais toutes les mines ne peu-

détails de Carreri, pour donner des notions plus étenducs à ceux qui ne connoiffent pas ces travaux.

« Celui qui découvre une mine d'or ou d'argent, peut y faire travailler en payant au Roi le cinquième du produit; mais s'il l'abandonne, elle tombe trois mois après au Domaine. Le Roi accorde quatre cens pieds de terrein vers les quatre vents principaux depuis l'ouverture de la mine, ou d'un feul côté, au choix du propriétaire : enfuite un autre a la liberté d'en ouvrir une nouvelle à dix-huit pieds de la première, \& quoique cet efpace foit comme un mur de féparation, il peut entrer dans le terrein du premier, en creufant fous terre, du moins jufqu'à ce qu'il rencontre fes ouvriers; alors il doit fe retirer dans le fien, ou pouffer fon travail au-deffous de l'autre: mais fi la mine qu'il ouvre au-deffous eft inondée par quelques fources d'eau, celui qui travaille att-deffus doit lui donner la fixième partie de ce qu'il tire, \& fi l'eau venoit de la mine fupérieure, le propriétaire de cette mine eft obligé de la faire vuider, 》

“ Dans l'empreffement où j'étois de voir les mines, je me fis conduire le même jour, par un chemin fort efcarpé, à deux des plus proches : la preinière eft celle de Santa-Cruz, l'autre celle de Navarro. On tiroit le minérai de la première avec des malacates, oú efpèces de roues foutenues fur un long effieu, autour duquel on cmploie pour corde une groffe chaine, dont un bout monte avec le minérai, \& l'autre defcend pour en prendic d'autre ; quatre mules attachées à l'effieu par un bois qui le traverfe, font agir cette machine. Une autre malacate, montée 


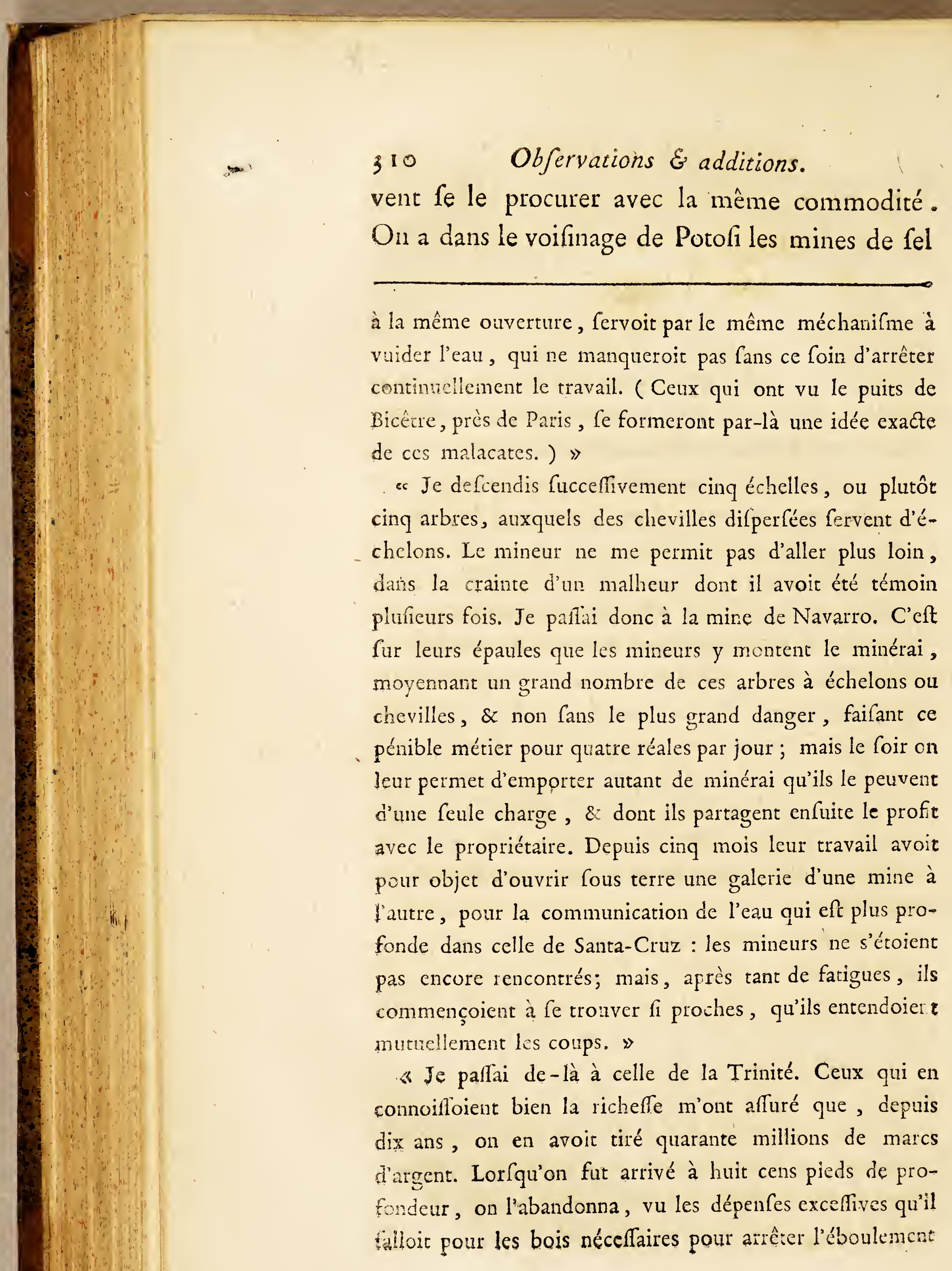


de Yocalla, qui, felon Barba, fourniffent une prodigieufe quantité de fel. On en emploie tous

des terres, \& on en ferma les principales ouvertures.

« J'eus la hardieffe de defcendre dans celle de SaintMatthieu, malgré les plus grands rifques, fouvent embarraffé pour mettre le pied fur les chevilles, ou dans l'entaille, \& quelquefois pour' embraffer l'arbre. J'arrivai enin dans le lieu où les mineurs faifoient fauter avec leurs inftrumens de fer des pierres métalliques d'une extrême dureté ; quelques-unes étoient moins dures, \& d'autres diverfement colorées: $j$ 'en pris quelques morceaux; mais confidérant le danger auquel je m'étois expofé, \& commençant à me reffentir des vapeurs peftilentielles que la terre exhaloit dans ce gouffre obfcur, je remontai avec autant de difficultés que de crainte, après y avoir paffé deux heures, \& jarrivai fort fatigué à la lumière du jour. Tout ce que j'avois vu d'affreux fe retraçant alors à mon irragination, je reconnus que de toute ma vie je n'avois fair aucune action fi folle. 》

" La profondeur de ces mines vient de la méthode du travail qui fe fait toujours perpendiculairement, jufqu’à ce qu'on ait rencontré quelque bonne veine; alors on la fuit horifontalement, \& lorfqu'clle finit, on recommence à creufer plus bas, fur la première ligne.

\section{Procédés pour l'extraction du métal.}

«On brife à coups de marteaux la picrre qui fort de la mine. Ceux qui font chargés de cette opération connoiffent, par une longue expérience, les morceaux qui lont pour le feu, \& ceux qui renferment le vif-argent, on les 


\section{Obfervations \& additions.}

les jours 1800 quintaux au moins, Quant aux mines de fel des carrières de Chilea, D. Ulloa

met dans dẹs facs féparés, Les pierres de métal font brocardées par des machines dans des mortièrs de fer. Pour les fondre on y mêle certaine quantité de plomb brûlé , gui reffẹmble à de l'écume de fer; on les met, avec une égale quantité de charbon, dans un fourneau de douze palmes de hauteur, \& plus large en-haut qu'en-bas: deux grands fouflets, qui doivent leur mouvement à deux unules, fouffent dans le fourneau, \& pendant fix heures on y met de nouveau minérai, à mẹture que le premier fond. Lorfque l'argent \& le plomb font fondus, on enlève avec un croc de fer l'ẹcume brûlée, tandis que, parr une ouverure du fourneau, on laiffe couler l'argent dans une forme, où il ne tarde pas à fe durcir. On le retire alors, \&: bouchant louverture du fourneau, on continue d'y jettẹ du minérai, du plomb, du charbon, pour en faire se que les ouvriers nomment d'autres plaques. Ces plaques font mifes dans un autre fourneau, femblable à nos fours, ąrec une fofle au milieu, remplie de cendres mouillées \& battues, afin de recevoir l'argent pur, On l'échauffe d'abord avec un feu de bois d'un troifième fourneau voifin, qui fe nomme le fourneau d'affinage. Aufr-tôt gue les plaques font prètes à fondre, on applique au foumealt deux grands fouffets pour pouffer le fell; l'argent coule alors dans la foffe, \& l'on tire avec un croc de fer le plomb ou la terre qui, venant à refroidir, n'ont plus qu'une apparencé d'écume ou de pierre-ponce. On garde f'écume de la première \& de la feconde fonte pour en faire le mệme ufạge dans'le foụncau où l'on fond les. pierrẹs ẹn poudre. 
Obfervations \&' additions.

n'en parle dans fon Voyage, que pour nous dire qu'on tire de cette contrée du falpêtre dont on

« Les plaques d'argent pur font de quatrc-vingt ou cent mares; on les porte à l'effayeur : fi elles n'ont pas le degré de perfection, on les refond. Lorfqu'elles font au titre, on les marque avec le nombre de grains d'or qu'il y a dans chaques marcs; s'il s'en trouve plus de quarante, on les porte au rafineur pour les léparer.

c Pour faire cette féparation, l'on fond l'argent en petites balles qu'on fait diffoudre avec de l'eau forte; l'or qu'elle ne peut attaquer tombe au fond. Le titre que l'or doit avoir eft de vingt-deux karáts, \& celui de l'argent de deux mille deux cens dix maravédis; alors on le marque, comme il a été dit dans les détails que nous avons vus.

*On affure qu'il entre tous les ans dans Mexico deux millions de marcs d'argent, outre ce qui paffe par des voies indirectes, \& qu'on en frappe aufin tous les ans fept ceps mille marcs en piattés. Les propriétaires paient non-fenlement les frais de la fabrique, mais ils joignent au cinquième, qui eft le droit de la première déclaration, une réale, qu'on nomme le vafielage. Quoique chaque particulier puiffe faire fabriquer de la monnoie, on travaille prefque uniquement pour le compte des Marchands; ils achetent tout le métal qu'on veut leur vendre, en retenant deux réales par marc, l'une pour le Roi, \& l'autre pour la Fabrique. 2

Ancien procédé de l'Amalgame.

* L'extraction de l'argent par l'intermède du mercure - par l'amalgame n’a lieu que quand le minérai ne 


\section{Obfervations \& additions.}

fait de la poudre à canon à Lima. Quant aux mines de fel des montagnes du Pérou, \& à la

contient pas beaucoup d'argent. Quand il eft bien réduit en poudre, on le paffe, pour le mettre enfuite dans de bons moules de bois, avec de l'eau, du fel, \& de l'écume de cuivre; on y ajoute le mercure, \& l'on remue toute la maffe pendant vingt-quatre heures avec les pieds, jufqu'à ce qu'il foit répandu dans toutes fes parties; on en fait alors un monceau, qu'on met fous un toît couvert de tous côtés, avec une marque qui apprend quel jour on I'a mis dans cette fituation. Le principal ouvrier vifite chaque jour les monceaux : en lavant un peu la pâte, il connoît par l'argent qui refte dans le vaiffeau, \& par la chaleur extérieure de toute la maffe, la quantité de mercure \& d'écume qu'il faut ajouter ou retrancher. Un excès de chaleur la rend noire, \& demande qu'elle foit refroidie avec la bourbe des rivières voifines; lorfqu'elle eft trop froide, on y ajoute de l'écume de cuivre. Le mercure n'é. tant pas capable de fermentation, ne donne \& ne reçoit aucune qualité ; mais l'expérierce fait voir que fi la pâte eft de couleur de fon, il faut ajouter du mercure, qu'elle eft en bon état lorfqu'elle eft couleur de perle, \& qu'étant couleur de cendre, elle ne peut acquérir plus de perfection. Cette opération demande vingt ou trente jours, fuivant la qualité du méral. 》

c On lave enfuite ces maffes dans un lavoir, avec des roues de bois qu'on fait mouvoir de la main. La terre lavée paffe par trois tuyaux dans trois vaiffeaux, l'un audeffous de l'autre. L'argent qui coule du premier s'arrête dans le fecond ou dans le troifième, duquel l'eau fort par un tuyau, \& fe rend dans nn réfervoir où les femmes 
qualité du fel qu'on en tire, je ne trouve aucun paffage qui puiffe éclaircir ce que $\mathrm{D}$. Ulloa nous en dit. On trouvera dans Barba quelques détails fur ces falines.

\section{De la Mine de mercure de Guancavelica.}

Ce que D. Ulloa nous dit de l'origine du nom de Guancavelica \& de fa fignification, ne s'accorde

trouvent toujours quelques particules d'argent. On met celui qui refte au fond des vafes dans une chauffe de toile, qu'on preffe pour en faire fortir le mercure. $\mathrm{Ce}_{-}$ pendant, comme il n'en fort pas plus de la cinquième partie, on met ordinairement plufieurs balles de cette pâte molle, chacune d'environ trois livres, dans une cloche de fonte ou de terre, avec de petites barres fur l'ouverture, pour empêcher que l'argent ne tombe lorfqu'il commence à durcir. On enterre une de ces cloches remplie d'eau jufqu'au tiers, \& l'on y applique l'autre, afin que rien ne puiffe s'évaporer: on fait enfuite un grand feu de charbon fur la cloche fupérieure, jufqu'à la faire rougir, ce qui marque que le mercure eft féparé, \& que l’argent s'eft réuni en un feul corps. On le retire alors, pour le porter aux Officiers, afin qu'il foir effayé, marqué, \& qu'on en paie les droits. »

« On ne fe fervit d'abord pour cette extraction que de mercure \& de fel; mais cette opération demandoit une année entière : un Dominicain la rendit plus facile, en confeillant d'y ajouter de l'écume de cuivre, qui échanffe fur le champ la maffe. 
316 Obfervations \& additions.

pas avec le détail de G. de la Vega. Celui-ci nous dit, Liv. VIII. c. 25. que Huanca-villca (car c'eft ainfi quiil écric) eft formé de deux mots, dont le premier (Huanca) eft le nom de la Province où eft cette mine, \& que villca fignifie hauteur, éminence (I), grandeur. Il penfe qu'on a donné ce nom à la mine, à caufe du grand profit qu'on en tiroit. Ulloa prétend au contraire, que les deux mots qui forment le compofé, font les noms de deux Nations Indiennes: en effet de la Vega nomme le Peuple Huancavillcas', L. III. c. 3., fans dire où il habitoit. Il nous décrit, L. VI. c. Io, les Nations de la Province d'Huanca; il remarque que les Efpagnols la nomment mal-à-propos Huan cavillca, puifque la Province de ce nom eft près de Tumpiz, fur les côtes de la mer; au lieu que Huanca s'en trouve à près de trois milles audelà, au milieu des terres, du côté de Humanca, aujourd'hui Guamanga. On rencontre au Pérou plufieurs lieux \& peuples qui ont le nom de Villca; tel eft, par exemple, celui de Villcas. Guamon, \& Villcas, palais ruiné des Incas, dans la même Province où eft la mine de mercure: d'où l'on peut conclure que D. Ulloa a plutôs

(I) Ce mot fe retrouve dans les langues du Nord, oth sulck fignifie une groffe mafe. 
Objervations \& additions:

taifon que G. de la Vega. On peut même croire par le récit d'Acofta, que ces mines ont eu d'abord le nom de Palcas, jufqu'à ce que le Bourg de Guancavelica fe fût formé auprès. "C'eft ainfi, dit-il, que les mines de Palcas ayant été découvertes dans les environs de Huamanga, plufieurs particuliers s'occupèrent de les exploiter, \& le Bourg appellé Guancavelica, fe forma près du giffement des mines.

Mais Acofta nous donne fur la découverte \& les autres particularités hiftoriques de cette mine, des détails qui méritent d'être placés ici. Il dit donc, L. 4. c. I I. Les Incas du Pérou \& les Indiens ont long-tems joui de cette mine de mercure, fans en connoître la nature. Ils n'y cherchoient que de la couleur rouge, ou le cinnabre, qu'ils appellent Llimpi, dont ils faifoient beaucoup de cas : c'étoit avec cela qu'ils fe peignoient le corps en rouge, \& frottoient aufil la face de leurs ( $I$ ) idoles, comme on le faifoit en Ethiopie, \& comme felon Pline, on rougiffoit à Rome

(1) Cet ufage de la couleur rouge étoit commun à prefque toutes les anciennes Nations, dont quelques-unes marquoient même leurs beftiaux de couleur rouge : c'étoit, dit l'Hiftoire, en mémoire de l'embrafement général qui ayoit brûlé toute la terre. On voit par-là que la théorie de M. de Buffon n'eft pas nouvelle. Cet incendie paffois pour une chore conftarte chez les Scythes, 
la face \& la Itatue de Jupiter; ils s'en peignoien le corps, fur-tout quand ils alloient à la guerre, $\&$ ils le font encore dans leurs fêtes \& leurs danfes: c'eft ce qu'ils appellent $\int e$ farder, embixarfe.

C'eft pour cette raifon qu'ils ont fait des fouilles très-profondes dans les côteaux de Guancavelica, fouilles qui étonnent même aujourd'hui; car les perfonnes qui defcendent dans les anciennes galeries des Indiens, courent rifque de fe perdre, \& de n'en jamais revenir.

Les Efpagnols connurent d'abord aufi peu que les Indiens, le mercure caché dans les mines. Ce fut en i 66 ou i s 67 , qu'on le découvrit comme il fuit, lorfque Caftro étoit Gouverneur dı Pérou. Un homme intelligent, Portugais de nation, nommé Henri Garcès, obtint par hazard un morceau de minérai rouge, que les Indiens appellent Llimpi, \& dont ils fe fervent pour fe farder. Il reconnut bientôt que ce minérai étoit ce qu'on nommoit cinabre en Caftille, \& d'où l'on tire le mercure. Il préfuma donc qu'on devoit trouver du mercure dans cette mine. Il s'y rendit, en effaya, \& vit que cela étoit vrai. Les mines de Palcas ayant été ainfi découvertes fur les confins de Guamanga, il s'y rendit beaucoup de monde pour en tirer du mercure, qu'on tranfporta à Me- 
Objervations \& additions.

sico; où l'on s'en fervoit pour bénéficier les mines d'argent. Ces travaux \& ce commerce enrichirent beaucoup de monde.

Il y a là plufieurs fouilles qui rendent beaucoup; mais la plus riche eft celle qui porte le nom d'Amador de Cabrera, \& qui s'appelle aufi celle des Saints. Cette mine confifte en un rocher extrêmement dur, qui eft pénétré de mercure dans toute fa capacité. Elle a quatrevingt varas de long fur quarante de large. On a fouillé dans cette mine jufqu’à foixante-dix toifes de profondeur; la fouille eft fi fpacieufe, que trois cens hommes peuvent y travailler en même tems.

Certe mine fut découverte par un Indien nommé Navincopa, d'Acoria, qni appartenoit à Amador de Cabrera. Amador fit enregiftrer cette mine fous fon nom, \& eut enfuite un procès avec le fifc; mais il le gagna, \& le profit de la mine qu'il avoit découverte, lui fut alloné : il la vendit enfuite pour deux cens cinquante mille ducats. Bientôt après il crut avoir ćté trompé dans cette vente, \& intenta un procès à fon acquéreur. Quelques perfonnes croyoient que cette mine valoit bien un million.

Dans le tems que François de Tolede étoit Gouverneur du Pérou, il fe préfenta à Potoíi un particulier nommé Pierre Fernandez de Velaíco, 
qui avoit vu à Mexico la manièré de traiter largent par l'amalgame, \& qui propofa de bénéficier l'argent à Potofi de la même manière. L'effai ayant réuffi, on commença les procédés en grand à Potofi en 1577, \& l'on y employa le mercure de Guancavelica. C'eft par ce puiffant moyen qu'on exploite à préfent les mines de Potofi, \& l'on tira d'abord nne prodigieufe quantité d'argent des minérais qui avoient été enterrés fous les déblais des fouilles. L'amalgame a l'avantage confidérable d'extraire, des minérais fecs \& pauvres, lepeu de métal qui s'y trouve; ce qu'on ne peut obtenir par la fonte.

Le Roi tire de ces mines de mercure, fans frais \& fans rifques, environ quatre cens mille Pefos de minas par an. ( Ce font probablement des Pefosenfayados qu'indique ici l'Auteirr), lefquels font chacun quatorze réaux, ou un peu moins, outre ce qu'il a de profit fur l'argent qui fe tire du Potofi. Années communes on tire des mines de Guancavelica, huit mille quintaux de mercure, \& même d'avantage.

La pierre dans laquelle git le mercure, eft moulue, \& mife enfuite au feu dans des pots fermés. Le mercure fe fépare de la gangue par la chaleur, s'élève en vapeur avec la fumée, $s^{3}$ atrache aux corps folides qu'il rencontre, \& y prend fa forme nétallique; ou s'il n'en ren- 
contre aucun, il voltige jufqu'à ce qu'il fe refroidiffe, \& tombe fous fa forme concrète. Lorfqu'on a brûlé ainfi le minérai, on ouvre les pors pour en retirer la terre épuifée, mais après les avoir lailfé refroidir; autrement on rifqueroit d'être frappé du refte de la vapeur qui s'échapperoit peut-être encore; \& la perclufion des membres, ou tout autre accident, là mort même, pourroient en être la conféquence. Comme ce feu exige beaucoup de combultibles, un mineur nommé Rodrigue de Torrès, imagina d'employer une herbe des montagnes du Pérou, où elle vient en abondance; c'eft une ef́pèce de jonc femblable au fparte de l'Efpagne : on l'appelle $J$ cho. On dépofe le mercure dans des outres de cuir, pour être tranfporté au Magazin royal : de-là on le rend par mer à Arica, où on le charge fur des Moutoris-chameaux du pays (Llamas, Alpaques) qui vont par bandes à Potofi, fous la conduite des Indiens. (Ces bandes s'appellent Recuas, ou felon Frézier, Requas.)

G. de la Vega a répété, Liv. VIII.c. 25.ce que dit Acofta. De Laët a fait de même. D. Ulloa qui les a imités, a mal produit en partie, les détails d'Acofta \& de de Laët, lorfqu'il dit que ce fut Navincopa qui découvrit la mine de mercure de Guancavelica, mais que Pierre Tome 11 : 


\section{Obfervations \& additions.}

Contre ras \& Henri Garces en découvrirent une autre en 1564, à Pataż. Au refte, qu'il en foit ce qu'il voudra, il eft certain que la mine de Gunncavelica eft la feule où l'on a conftamment travaillé. Ulloa a probablement pris dans Efcalona, ce qu'il cite d'Acofta \& de de Laët.

La température de Guancavelica eft fi dure, qu'il n’y crô̂t ni grains ni fruits. Il y a dans le Bourg une fontaine dont les eaux ont une vertu très-pétrifiante: c'elt pourquoi les habitans s'en fervent pour bâtir leurs maifons \& autres outvrages. La mine eft la feule qui ait long-tems fourni le mercure au Pérou, pour le traitement des mines d'argent. L'Auteur dit même dans fon Voyage que, malgré la grande quantité qu'on en a tiré, on n'y remarque alicune diminution. Depuis fa découverte, les Rois d'Efpagne s'en font toujours confervé la propriété. Un des Auditeurs de l'audience de Lima en avoit l'infpection, fous le titre de Surintendant: ces Auditeurs changeoient tous' les cinq ans; mais, depuis 1735 , le Roi Philippe V. jugea à propos d'y envoyer un Officier qui en̂t l'infpection de la' mine fous le même nom de Surintendant. Cet Officier étoit un homme fort inftruit de la manière dont on devoit procéder dans l'exploitation de cette mine, $\&$ y étoit venu d'Efpagne. On penfe que fi l'on avoit fuivi fes vues \& fes réformes, cette mine 
Obfervations solditions.

suroir duré bien plus de tems, \& auroir beallcoup moins exigé de dépenfes. Le mercure s'envoie à toutes les Caiffes Royales, \& eft vendu aux mineurs qui fe propofent d'exploiter quelque mine. Cette répartition dut mercure faite en différens endroits, leur donne lieu de s'en 'foumir plus commodément, même à des diftances éloignées.

Les dérails que Feuillée ncus a donté dans fon journal d'Obfervations n'ont rien d'importane à ce fujet, que ce qu'il dit de la fource pétrifiante. Selon lui , la montagne où gît la mine de mercure avoit menacé de s'écrouler en r yon; la charpente qui la foutient intérieurement en nombre d'endroits s'étoit pourrie : or la dépenfe qu'on avoit faite pour ces étais \& fupports, jufqu’aus moment où il écrivoit, montoit à trois millions deux cens livres.

On voit dans cette mine des places, des rues, des chapelles où l'on dit la meffe les jours de fête; tout eft éclairé par un nombre infini de lumières; mais les émanations mercurielles qui voltigent fans ceffe, rendent ce féjour fort dangereux.

G. de la Vega obferve, au fujet du récit d'Acofta, que le Llimpi dont celui-ci parle, étoit tine terre de couleur pourpre, plus groflière que le cinnabre, \& que l'on prenoit dans une autre 


\section{Ob ervations \& additions.}

fouille; que c'étoit au contraire le cinnabre le plus fin dont les Indiens fe fervoient pour fe peindre.

Mais les détails de Frézier ne feront pas inuriles ici. " Guancavelica eft ( en I 7 I 4 ) une petite Ville ou Bourgade d'environ cent familles, éloignée de foixante lienes de Pifco; elle eft riche \& fameufe par la grande quantité d'argent 'qu’on tire d'une minière qui a quarante varas de front, \& qui feule fournit de mercure tous les moulins d'or $\&$ d'argent du Royaume. Les particuliers y travaillent à leurs frais, \& font obligés de remettre aut Roi tout ce qu'ils en tirent, fous peine, aux contrevenans, de confifcation de tous leurs biens, d'exil \& d'efclavage perpétuel à Baldive. Sa Majefté le paie à un certain prix fixé, qui eft à préfent foixante piaftre le quintal fur les lieux, \& le vend quatre-vingr ( $\mathrm{I}$ ) dans les mines écar-

(I) Carréri fait à ce fujet une obfervation qui peut trouver place ici. «On paic quatre-vingt piaftres du quintal, qui ne fert à féparer que mille marcs d'argent, \& quelquefois jufqu’à trente piaftres, non que le Roi les vende fi cher, mais les Officiers royaux cherchent à tirer parti du befoin qu'on en a, \& cette difette de vif-argent caufe beaucoup de préjudice à Mexico; aufi le Roi ne prend-il dans la Nouvelle-Efpagne que dix pour cent, au lieu qu'au Pérou il prend vingt à la rigueur, parce que le vif-argent y eft à meilleur marché. T. XI, Hijt. génér. des Voyages.» 


\section{Obfervations \& additions.}

zées. Lorfqu'on en a tiré une quantité fuffifante, le Roi fait fermer l'entrée de la mine, \& perfonne n'en peut avoir que de celui de fes dépôts.

La terre qui contient le vif-argent eft d'un rouge blanchâtre, comme de la brique mal cuite; on la concaffe, \& on la met dans un fourneau de terre, dont le chapiteau eft une voûte en cul de four, un peu fphéroïde : on l'étend fur une grille de fer recouverte de terre, fous laquelle on entretient un petit feu avec de l'herbe Icho, qui eft plus propre à cela que toute autre matière combutible; c'eft pourquoi il eft défendu de la couper à vingt lienes à la ronde. La chaleur fe communique à travers cette terre, \& échauffe tellement le minérai concafré, que le vif-argent en fort volatilifé en fumée; mais comme le chapireau eft exactement bouché, elle ne trouve d'iflue que par un petit trou qui communique ̀̀ une fuite de cucurbites de terre, rondes \& emboîtées par le col les unes dans les autres; là cette fumée circule \& fe condenfe par le moyen d'un peu d'eau qu'il y a au fond de chaque cucurbite où le vif-argent tombe condenfé, \& en liqueur bien formée : dans les premières cucurbites il s'en forme moins que dans les dernières, \& comme elles s'échauffent fi fort qu'elles cafferoient, on a foin de les rafraîchir par-dehors avec de l'eau. " 
On voit par ce détail, qu'on avoit déjà fait à cette époque un grand changement dans les procédés requis pour exiraire le mercure du minérai broyé. Du tems d'Acolta, on le diftilloit dans des pots de terre per defcenfurn, comme on le faifoit aufli autrefois à Idria. Mais on voit aufli par l'expofé de Frézier qu'on n'extrayoit pas le mercure du minérai dans des retortes de terre ou de fer placées dans un fourneau, comme il eft d'ufage dans la plupart des mines de mercure en Allemagne. ( car nous remarquons ici que D. Ulloa étoit mal infruit fur le nombre des mines de mercure connues.) Cette manière de difiller le mercure, \& de le revivifier au moyen d’une fuite de cucurbites, paroît analogue à ce grand nombre d'aludels qu'on emploie dans les mines d'Almaden. Ces cucurbites, dont le fond contient certaine quantité d'eau, tiennent lieu, \& avec plus d'avantage, de cette chambre vaporatoire oì le mercure fe précipitoit après avoir circulé long-tems, \& devoit néceffairement fe perdre en partie. On a fans doute introduit, depuis I735 en Amérique, les procédés quion fuit à Almaden.

Autant quion peur le prélumer des détails dUlloa, la gangue où gî́ le mercure eft une épèce de roche feuillerée; mais nous ne favons pas encore de quelle nature eft l'extérieur de la 
Obfervations \& additions.

montagne. Autrefois on rencontroit dans les fouilles, \& en nombre d'endroits, la gangue pénétrée de mercure natif \& de cinabre; elle en paroilfoir même comme abforbée. C'eft fans doute ce giu'il vent dire par ce paffage : "autrefois la capacité de cette grande maffe fe trouvoit en grande partie maffive. "C'eft auni dans ce fens que nous entendons ce que dit Acofta du lit des Saints, qui, felon fon expreffion, confiftoit en une roche totalement pénétrée de vif-argent. (es un pegnafco de piedra durifima empapada toda en azogue.) D. Ulloa ne nous donne pas plus de lumière fur la nature du minérai; mais Bowles dit dans fon Introduction à l'Hintoire Naturelle d'Efpagne, pag. 6o, qu'on trouve généralement le cinnabre d'Almaden dans un grais, un quariz, du Spath, de la roche cornée, femblables aux échantillons de minérai de Guancavelica qu'il a eu de Jofeph de Carvaial.

Les effers \& les dangers des émanations que D. Ulloa appelle Umpe, font aufi confidérables dans les mines d'Idria. On pent confulter la defcription de Ferber, $p .67$. Ces vapeurs minérales peuvent fort bien produire les effets que D. Ulloa attribue aux émanations mercurielles, \& qui minéralifent de nouveau les déblais des fouilles.

Quant aux maladies des ouvriers, Ferber les borne aux endroits où l'on trouve le metcure $X_{4}$ 


\section{\$8 Objervations \& additions:}

vierge, $p .12$. Ces gells en font $f i$ affectés, quils ne peavent y tenir que quelques jours, à caufe de la falivation \& des cremblemens dont ils font pris. Bowles, p. 42 , regarde auffi comme peu de chofe le danger où font expofés les travailleurs dans les mines d'Almaden.

\section{Origine de l'Amalgame.}

Je reprends ici l'hiftoire de l'amalgame pour parler de fon origine, \& communiquer au Lecteur quelques éclairciffemens que M. Bekmann nous a donnés à ce fujer dans fes Mémoires, pour fervir à l'Hiftoire des des découvertes, $I^{\text {er }}$ cayer, p. 47. Henri Garcès, dont nous avons parié, étoit de Porto, \& au fervice de l'Efpagne. Il fut enfuite Chanoine de la Cathédrale de Mexico: it donna lieu à la prohibition de l'argent non monnoyé dans le commerce; ( peut-être doit-on entendre ces termes d'Acolta, des pignes, qui, comme nous l'avons vu, ont long-tems eu cours dans l'Amérique Efpagnole.) mais ce qui lui firle plus d'honneur, fut la découverte de l'amalgame. M. Bekmann part de cette époque pour déterminer l'introduction de l'amalgame en Améririque, \& en conclud fort fenfément qu'elle a ćté en ufage au Mexique avant I 577. Mais à quelle date fixe? c'elt fur quoi il n'a pu produire rien de farisfaifant. 
Robertfon II, $p .5^{8} 3$, fixe la découverte de la mine de Guancavelica à l'année $156_{3}$, \& l'introduction de l'amalgame à i 574 . Le palfage que j'ai cité plus haut de Barba, femble confirmer cette opinion : mais ce paffage eft fort douteux. Raynal dit que le commerce du mercure a été libre depuis la découverte de la mine jufqu'en I 571 , \& que ce fut alors qu'il fut mis au nombre des droits royaux. L'ufage nouveau qu'on fit à cette époque de ce demi-métal, fait appercevoir la raifon de ce changement.

Gobet femble reprocher à Barba, dans les anciens Minéralogiftes de France, d'avoir voulu s'attribuer l'invention de l'amalgame; mais $M$. Bekmann le juftifie de cette inculpation, \& donne en même-tems un expofé très-utile de l'ouvrage métallurgique de cet habile Efpagnol. Barba dir feulement, que cette manière de tirer l'argent du minérai pulvérifé, eft une invention qui eft de peine venue dans l'efprit des anciens, Es qu'ils ont très-peu mis en ufage; mais on regarde cette invention comme appartenante aux Efpagnols, \&c qui date du milieu du quinzième fiècle. Bowles eft auffi de ce fentiment, \& la fixe à l'an 1566 : ce que, fans doute, on peut entendre de l'ufage qu'on fir de l'amalgame au Mexique. La chofe eft affez importante pour produire ici le paffage de Bowles, contre lequel Bekmanns'eft élevé avec 
raifon. Il feroit d'ailleurs à fouhaiter que Bowles eût pu donner les preuves néceffaires pour confirmer l'époque qu'il fixe.

“ On exploite plufieurs mines de la Nouvelle"Efpagne par la fonte; mais dans les endroits " où le bois eft rare, \& dans ceux où les mines " font pauvres, on les exploite en les amalga"mant avec le vif-argent. C'eft aux Efpagnols 2 que l'on doit cette découverte de 1566 ; fi " d'autres peuples en avoient été les inventeurs, ע ils s'en glorifieroient beaucoup. Quoiqu'il foir » vrai qu'avant cette époque on exploitoit les " mines d'or de Hongrie en les amalgamant avec " le mercure, l'ufage des Hongrois 'n'a rien de " commun avec la découverte des Efpagnols, "puifque dans leurs mines d'or le métal fe " manifefte à la vue, ou tout au moins il eft " facile de l'appercevoir avec une loupe. Or, " comme tout le monde favoit que le vif-argent " s'emparoit de l'or \& fe mêloir avec lui, il " étoit facile d'imaginer qu'en appliquant le "mercure à l'or que l'on voyoit, il feroit aifé "de l'extraire par ce moyen; mais perfonne, " avant les Efpagnols, n'avoit eu l'idée de mêler " le vif-argent avec une pierre qui contint de " l'argent invifible, diffous avec le foufre \& l'ar"Sénic, \& mêlé fouvent avec le plomb, le cuiэv vre \& le fer. 
Obfervations \& additions.

"Les Efpagnols imaginèrent donc l'ingénieufe " méthode de moudre la matière du minéral

" pauvre, de la réduire en poudre extrêmement s ine, d'en former une maffe d'environ vingt"cinq quintaux, \& de la mêler enfuite avec du " Fel ou de la couperofe verte, avec de la chaux " ou des cendres, le tout également réduit en "poudre très-fine : quoique ces matières foient " de naturre oppofée, elles refteroient dans une " éternelle inaction fans le fecours d'un diffol"vant; auffi, après les avoir fufinfamment mouil"lées, les Efpagnols y jettent-ils ( $\mathbf{r}$ ) trente livres " de mercure en diffétentes fois, en remuant le "tout à pluneurs reprifes, pendant deux mois. "L'alkali fixe des cendres \& de la chaux s'unit

(I) Il fembleroit par ces expreffons que ce diffolvant fût le mercure; mais Carreri obferve très-fencément que le mercure ne donnant ni ne recevant aticune qualité dans ces mélanges, ne peut faire fermenter la mafre. Le premier mouvement qui s'excite dans ces mafies vient du dégagement de l'acide vitriolique de l'alun, de la couperofe \& de l'acide fulfureux contenu dans le foufre du minérai. C'eft d'après ce premier branle que les autres fubltances s'attaquent felon les degrés de leur afinité : de ce mouvement réfulte l'effervefcence \& la chaleur, non que la chaleur foit une conféquence de la feule effervefcenfe, qui, dans d'autres cas, produit un très-grand froid; mais nous ne pouvons en dire davaritage ici : il cft cependant faux que le plomb, le fer, le cuivre fe trouvent détruits. 


\section{Obfervations \& additions.}

"à l'acide du fel \& de la couperofe, \& cette 2) action intérieure caufe une effervefcence vio" lente \& une chaleur à l'aide defquelles le " foufre \& l'arfénic détruifent abfolument le 2) cuivre, le fer \& le plomb : alors les atômes „ imperceptibles de l'argent fe détachent de leur " prifon ou de leur couche, \& dans le même " inftant le vif-argent les reçoit \& s'amalgame " avec eux, en formant cette pâte qu'on appelle ?. pigna au Mexique.

"Voilà la Méthode par laquelle on parvient " à tirer une once \& demie ou deux onces " par quintal d'un minéral, qui, fuivant le pro" cédé ufité en Europe, ne produiroit pas pour "Les frais. Je ne puis affurer politivement la quan" tité de vif-argent qui fe perd dans cette opéra"tion, parce que les mineurs ne font pas d'ac" cord fur ce point : ce qu'il y a de plus pro» bable, c'eft qu'on perd autant d'onces de mer" cure, qu'on tire d'onces d'argent; \& que " rendu au Mexique, une livre de mercure 32 coûte prefque autant qu'une once d'argent." J'obferverai encore pour M. Schneider, qu'il y a bien du faux dans tous ces raifonnemens. On peut dire d'abord que nous n'avons pas d'ouvrage métallurgique complet des anciens; ainf $B$... a tort d'en arguer l'invention en faveur des Efpagnols. Combien d'ouvrages faits 
Obfervations \& additions

n'avons-nous pas perdus fur d'autres fujets importans, \& qui nous détromperoient à bien des égards! Qu'on ouvre feulement Diogène de Laërce, \& l'on verra quelle foule de Livres les Anciens avoient écrits fur des matières que nous n'avons même pas touchées depuis eux, malgré leur importance. Quel eft enfuite ce raifonnement, l'ufage des Hongrois n'a rien de commun avec la découverte des Efpagnols? Il falloit dire avec l'application que les ESpagnols on faite de la découyerte de l'amagame connue des Anciens : car peuton appeller découverte l'application d'une connoiffance qui avoit été mife en ufage chez les Anciens, \& pour dorer \& pour argenter. D'ailleurs, M. B...a-t-il pris garde à ce qu'il dit lui-même, que "tout le monde favoit que le vifargent s'emparoir de l'or, \& fe mêloit avec lui, \& qu'il étoit facile d'imaginer qu'en appliquant le mercure à l'or, il feroit facile de l'extraire par ce moyen." Mais fi les Anciens par conféquent (car l'Auteur dit tout le monde) connoiffoient ce moyen, sils favoient que les minérais d'or \& d'argent avoient quelquefois befoin d'être broyés dans des machines (in pilis, dit Pline, ) femblables aux Ingee. nios dont nous avons parlé, s'ils ont fu mêler de la pierre de ponce pulvérifée, \& de l'a. lun avec le mercure anquel its vouloient faire 
adhérer l'or pour dorer l'airain, s'ils l'amalga: moient avec l'argent pour argenter, qu'eft-ce que l'invention des Efpagnols a donc de merveilleux? S'ils favoient enfuite extraire le mercure du cinabre (ou vomica de Pline) per defcenfum, comme les Efpagnols l'ont appris fans doute de cet Ecrivain, qu'ont donc fait les Efpagnols de fi merveilleux? Je m'arrête à ces circonftances de Pline, auxquelles MM. Bekman \& Schneider n'ont pas fait affez d'attention.

Les.Efpagnols ont d'abord exploité les mines par la fonte, comme les Anciens : ils ont employé l'amalgame pour en extraire les métaux précieux, \& comme dit Bowles, en mêlant le mercure avec une pierre qui contint de l'argent invifible; mais qu'eft-ce que faifoient les Anciens quand ils vouloient dorer? ils mêloient le mercure à une pierre (la ponce) volcanique réduite en poudre, non pour en extraire l'or, mais pour y joindre de l'or, \& le faire adhérer par ce moyen plus facilement au mercure, en ajoutant l'acide vitriolique contenu dans l'alun, \& uni à une autre terre qui fait la bafe de ce fel. Les Efpagnols ont pris l'acide vitriolique uni à une bafe ou rerre ferrugineufe. La terre de minérai, dit M. Bowles, étoit foivent mêlée avec le plomb, le fer, \&c. mais Pline avoit fait voir que le plomb, loin de nuiré dans cette opération, y 
Obfervations \& additions.

devenoir même utile. Quant au fer, l'acide vitriolique s'en emparant, favorife encore l'amalgame, \& les Anciens le favo ient, puifqu'ils l'em. ployoient. Je pourrois fuivre cette comparaifon plus loin, \& faire voir que Bowles eft un pauvre Chymifte, \& n'a, comme bien d'autres, connu aucun des procédés des Anciens.

Mais on peut ajouter à tout ceci, que les procédés des Efpagnols n'ont été faits qu'en tâtonnant \& au hazard, fur les premiers apperçus ou de Pline, ou des procédés dont la tradition fubfiftoit encore d'après ce qu'avoient pratiqué les Anciens. Pline ne devoit pas non plus nous donner de plus grands détails que ceux que nous lifons chez lui : il feroit forti de fon plan. M. Bekmann, qui a difputé aux Efpagnols l'invention de l'amalgame, avoit raifon; mais il s'eft contenté d'un paffage de Pline, où cet habile homme parle de la ferme adhérence du mercure avec l'or dans la dorure, de la vertu qu'il a de bien purifer l'or, \& de l'ufage qu'on en peut faire pour obtenir lor des cendres des galons ou étoffes d'or, qu'on a réduites en cendres dans des vaiffeaux de terre. M. Schneider obferve très-bien que Pline a pris ce paffage dans Vitruve; mais l'habile Naturalifte Latin ne doit pas à Vitruve les autres détails que j'en ai 
$336 \quad$ Objervations \& additions.

cirés, \& auxquels ni M. Bekmann, ni M. Schneider n'ont fait attention.

M. Bekmann remarque encore que long-tems avant la découverte des mines de l'Amérique, on la pratiquoit en Allemagne fur les bords du Rhin, pour extraire l'or que ce lleuve roule dans fes fables. Cette comnoiffance y a peut-être éré répandue par les Colonies, ou les Troupes Romaines, qui ont été fur les bords de ce fleuve. La Hongrie l'a auffi probablement conférvé de la même origine. L'amalgame étoit certainement connue d'ancienne date en Efpagne, puifqu'lfidor de Séville dit, que fans ce moyen, il eft impoffible de dorer ni d'argenter: fine hoc neque argentum, neque as inaurari poteft. Or ce paffage nous montre clairement que l'on connoiffoit l'adhérence du mercure avec l'argent, puifque ce n'étoit que par fon moyen qu'on y faifoir adhérer l'or, de même que fur le cuivre. Il faut néanmoins convenir qu'il ne nous refte pas d'Ouvrage dans lequel on voie que les anciens fe ferviffent du mercure pour exploiter les mines d'argent; mais on peut conclure par ce qu'on vient de voir, que non-feulement la chofe, mais même les matériaux accelfoires étoient affez clairement indiqués, pour commencer, au hafard de fe corriger, comme ont fait les Efpagnols 


\section{Obfervacions \& additions.}

après leurs premières tentatives, car leurs Hiftoriens conviennent des défauts extrênes de leurs premiers procédés, \& de la perte confidérable qu'ils faifoient du mercure.

Les anciens s'expliquent plus clairement à l'ćgard du minérai dans lequel on préfumoit qu’il $y$ avoit de l'or. Pline ne permer pas de douter de la réalité de l'amalgame avec le minérai écrafé. On le paffoit enfuire dans des facs de peaux, \& c’eft fans doute ce qua voulu dire Pollux, en parlant de ces facs parmi les inftrumens des mineurs; an lieu que les fots Editeurs Grammairiens qui l'ont commenté, n'y ont vu que des facs pour mettre du pain. Quelle ignotance! Platon, qui parle de la génération de l'or \& de la manière de le purifier, he dit rien du mercure; mais il eft aifé de voir la raifon de fon filence; il ne parle de cet purification que comme terme d'une comparaifon qu'il fait. Enfin je finis fur ce fujet, en difant que fi nous avions l'Ouvrage d'Agatharcide, nous en faurions davantage; mais nous ne le connoifons que par la citation de Photius. Ariftote ne parle non plus du metcure que pour en faire une comparaifon avec la mobilité du monde.

Nous ne voyons pas, dit M. Schn. que les anciens aient fait des miroirs de verre comme les nôtres, par le moyen du mercure; au moins

Tome 11 . 


\section{8}

Objervations \& additions.

aucun des anciens qui nous reftent n'en fait men:tion. Mais ne peut-on pas répondre qu'on a cependant lieu de le foupçonner, lorfque Sénèque \& Pline nous difent qu'ils ornoient les murs de leurs appartemens avec des glaces, invention nouvelle, à la vérité, dit Pline. Le même dit encore qu'ils faifoient des miroirs de glace avec une feuille d'or : or peut-on faire un miroir d'un verre en y appliquant feulement cette feuille d'or fans amalgame? Mais cela ne nous apprend rien. On peut confulter, au fujet de cette utile invention, les Remarques de Klugel fur l'Hiftoire de l'optique de Prieftley. Part. II, p. 470, fuivant M. Schneider. Je n'ai pas l'Ouvrage.

La contrée de Guancavelica donne lieu à un amateur d'hiftoire naturelle de faire nombre d'aurres obfervations. La nature eft dans toutes les hatutes montagnes du Pérou comme au centre d'un arfénal, où elle cache des quantités prodigieufes de minéraux de toute efpèce, \& des four. naifes immenfes d'où elle vomit fouvent des torrens de feux, en ébranlant \& troublant toute la nature, ne laiffant quelquefois pas à l'Indien effrayć un feul fentier pour fe fauver du bouleverfement de ces montagnes, \& des inondarions qui abîment tout. Telle eft la caufe des nombreufes fources d'eaux chaudes ou pétrifiantes qu'on y a remarquées. D. Ulloa nous a affez bien décrit les 


\section{Objervations \& additions.}

phénomènes remarquables de cette contrée dans fon Difcours X; je joindrai ici quelques circonftances qu'il a omifes. Frézier nous parle de la fource pérrifiante dont notre Auteur fair mention: mais il eft aifé de voir qu'il n’a pas été fur les lieux. Barba mérite plus d'attention. Liv.I, c. 12. "Qu'on prenne de cette eau, dit-il, dans un vafe de la forme qu'on voudra, \& qu'on le laiffe au foleil pendant quelques jours; on en obtiendra une pierre affez dure pour être empioyée à la conftruction d'un édifice : tout animal qui en boit, en meurt inévitablement. "

Fenillée s'étend encore davantage à ce fujet, Journ. des Obferv. I, p. 434. En parlant de la grande utilité de cette fource pour bâtir, \& autres ouvrages, il nous apprend que certe eau fort du milieu d'un baffin quarré, fort chaude, \& fe pétrifie à peu de diftance de fa fource dans la campagne où elle fe répand. Cette eau eft blanche, tirant fur le jaune : la fuperficie en eft femblable à celle d'une glace brute qui n'attend que le poli pour être tranfparente. C'elt de ces pierres qu'on s'eft fervi pour bâtir une grande partie des maifons de Guancavelica. Les ouvriers n'ont pas beaucoup de peine à la tailler; car ils n'ont quà à remplir de cette eau un vaiffeau de la forme dont ils veulent avoir leur pierre, \& quelques jours après ils trouvent cette pierre de la forme qu'ils 
la demandent, fans équierre \& fans marteau: “ Les Statuaires n'ont pas non plus befoin de grand travail pour faire les draperies \& les traits de leurs ftatues: dès que les formes dans lefquelles ils veulent les faire font bien finies, ils n'ont befoin que d'aller les remplir d'eau à la fource dont l'eau ne cefle de fe pétrifier; peu après ils en retirent les ftatues, auxquelles ils n'ont plus qu'à donner le poli pour les rendre tranfparentes. J'ai vu nombre de ftatues femblables: tous les bénitiers des églifes de Lima fon de cette matière, \& d'une telle beauté, qu'on ne pourroit croire comment ils ont été faits, fi l'on n'en jugeoit qu'au coup d'œil. "Bergman, qui cite ce paffage dans fa Defcription phyfique du Globe, a fait fes réllexions fur la nature de cette fource d'eau chaude; elles auroient fans doute été plus fatisfaifantes, s'il avoit pu examiner le dépôt de cette eau auffi fcrupuleufement que les dépôts \& les incruftations des fources chaudes de l'Inande. Voyez les Lettres de Troil fur l'Inande. Il dit done fur cette fource de Guancavelica, qu'il appelle l'unique de fon efpèce : " l'eau qui fe pétrifie doit contenir une prodigieufe quantité de matière hétérogène; ce à quoi contribuent fans doute en partie le mouvement, en partic la chaleur fouterreine qui fe trouve enfermée. Plus l'eau ent chaude, plus elle en doit tenir en dif. 
Obfervations \& additions:

folution : or la chaleur peut être portée à un degré ćtonnant dans un lieu convenablement fermé, quoiqu'à l'air libre elle ne refte pas chaude à plus de cent degrés. L'effet qu'on produit dans la machine de Papin eft tiès-connu, mais cette chaleur-ci ne peut entrer en comparaifon avec celle que la nature produit de la même manière."

Il eft donc impoffible de fe rendre à l'opinion de D. Ulloa. L'eau fe coagule, il eft vrai, \& fe pétrifie; mais il faut l'entendre des molécules terreufes ou pierreufes que l'eau avoit diffoutes, \& qu'elle ne peut plus tenir dans cet état après certain degré de refroidifement. L'éloignement où la pétrification du fédiment ou dépôt pierreux s'opère, répond certainement au degré de. chaleur avec lequel l'eau peut le tranfporter jufques-là. Il eft donc très-poffible que le baffin de la fource ne s'obftrue pas \& ne s'élève pas: mais fi cela n'arrive pas non plus à certain éloignement, comme Ulloa le dit, il faut fuppofer des circonfances dont il feroit befoin qu'on fût inftruit : en effet, ou D. Ulloa a mal vu, ou bien Acofta s'eft trompé; car celui-ci dit tont le contraire, Liv. III, c. 19. "L'eau en fe pétrifiant obftrue le paffage à celle qui va y arriver : voilà pourquoi l'on eft obligé de lui ouvrir un autre cours à mefure que la pierre s'élève. "

Quant au merveilleux des ftatues \& autres ou-: 


\section{2}

Obfervations \& additions.

vrages faits de cette pétrification, il difparoît fir le champ lorfqu'on lit ce que Ferber nous dit dans fes Lettres fur l'Italie; il nous apprend qu'on fait dans cette contrée des médailles, des bas-reliefs $\&$ des buftes avec les dépôts de différentes fources d'eaux chaudes.

(M. Schneider peut croire Ferber; car je vis l'été dernier à Vincennes, chez un Chevalier de S. Lnuis, une jolie figure \& affez grande, faite fur un champ de même matière, avec un fédiment femblable; elle eft blanche, diaphane; mais il faut laiffer le moule affez long-tems dans l'eau, pour obtenir ces pétrifications ou dépôts pierreux.)

Outre les fouilles de mercure de Guancavelica, il y en a plafieurs autres; par exemple, au Sud de la province de Quito, aflez près du village d'Azognes, dans le corrégiment de Cuenca; mais il a été défendu par ordre du Roi de les exploiter, afin d'éviter la fraude \& la fouftraction du quint qui n'eft que trop fouvent arrivée. On eft à la vérité parvenu au but qu'on defiroit; mais la défenfe qu'on a faite d'ouvrir ces mines, a confidérablement fait déchoir le travail des mines d'argent dans la province de Quito; \& c'eft le jugement même que porte Ulloa dans fon Voyage. Il parloit à cet égard fur des rapports, fans doute, qu'il contredit dans cet Ouvrage-ci: en effer il affure ici généralement que l'on a été trompé dans 
les efpérances qu'avoient fait concevoir tous les endroits qu'on ouvrit, mais inutilement, dans la crainte que donnoit la diminution de la mine de Guancavelica.

Je dirai deux mots de la Platine, pour terminer ces Remarques fur la parrie des mines : c'eft l'Anglois Wood qui la fir connoître en Europe en 1741. Bowles, à qui D. Ulloa en avoit donné, en parle ainfi dans fon Introduction à l'Hift. Nat. d'ESp. “ Le célèbre D. Ulloa, à qui j'ai demandé des inftructions fur la Platine, prétend qu'elle elt fouvent mêlée avec quielques minérais d'or, \& même unie fi ćtroitement à l'or, qu'elle lui fert comme de mère ou de matrice, \& l'on ne peut l'en féparer qu'avec beaucoup de peine : c'eft pourquoi il faut abandonner la fouille quand elle y eft mêlée en grande quantité, parce que l'exploitation en deviendroit préjudiciable, vu la peine qu'il y auroit à bocarder le minérai, \& à exécuter les autres travaux. On ne trouve la $\mathrm{Pla}$ tine que dans le Royaume de la Nouvelle - Grenade, mais fur tour dans les mines de Choco \& de Barbacoas, où il y en a beaucoup : du refte on n'en trouve pas ailleurs, ni au Chili, ni au Pérou, ni au Mexique. Ce n'eft pas non plus fous la forme de pierre, mais de poudre ou de grains de fable qu'elle fe trouve dans ces contrées-là. " Les détails qu'Ulloa nous donne dans fon $\mathrm{Y}_{4}$ 


\section{Objervations \& additions.}

Voyage ne font pas fi précis : voici ce qu'il dit; $T . I, p .606$ de l'édition originale. "On trouve quelquefois dans le territoire de Choco des mines qu'on eft obligé d'abandonner à caufe de la Platine, pierre qui fait une figtande réfifance, quil n'ert pas facile de la rompre, ni de la réduire en perites parcelles à coups redoublés de marreaux fur une enclume; on ne peut non plus la réduire par la calcination, \& l'on ne connoît pas de moyen d'extraire le métal précieux qu'elle enferme, fans des dépenfes confidérables \& le plus grand travail.

Bouguer eft encore plus court fur la Platine, \& n'en parle que comme en paffant. "Quelquefois, dit-il, on a recours à un moyen tout oppofé, favoir le mercure, comme on y eft fouvent contraint à Choco, où le minérai eft mêlé avec la Platine, efpèce de caillon particulier à ce pays."

( Il eft étonnant que M. Schneider écrivant ces dernières années-ci, ne prévienne pas fes Lecteurs que la Platine n'eft pas du tout particulière ì l'Amérique, comme on l'avoir affuré; on en trouve même en France; l'A fie en a comme l'Amériq̣ue. Il pouvoit enfuite ajouter, d'après les Gazettes favantes d'lena de 1785 , que la Platine n'eft pas infufible, même fans aucun intermède. Je fais qu'un homme s'elt flatté à Paris d'y être parvenu fans aucun intermède; mais il a abufé 
Obfervations \& additions.

la crédulité des gens pen inntruits. Je fais auffi qu'un habile homme, qui a même été en Amérique, s'eft occupé l'année dernière de la fufion de la Platine par le feu, \& de fa diffolution par les menftrues, \& qu'il avouoit de bonne foi l'avoir toujours trouvée réfractaire : cependant des gens qui s'en font long-tems occupés, difent qu'il n'y a dans la Platine qu'une mine de fer, mafquée dans un autre principe qui lui donne cette réfiftance, \& c'eft cette mine combinće qu'il s'agiroit de rendre fufible, ou de dégager, ce qui n'eft pas impollible, d'après les détails que préfentent les Journeaux que j’ai cités.)

Lofling dit que la Platine qu'il nomme Platania, \& non Platina, fe trouve auffi dans les mines d'argent de Potofi. Ce minéral, qu'il vit, confiftoit en une poudre groflic̀re inégale, ou femblable aux paillettes qui fautent du fer battu fur une enclume, \& elle avoit une couleur blanche. Selon lui, cette forme venoit de la mine d'argent qu'on avoit broycée \& lavée: mais il faut obferver que Lœfling écrivoit cela en Efpagne, fans avoir vu la mine d'argent de Potofi, \& qu'ainfi il ne pouvoit juger de la forme naturelle de la Platine. Il eft également incertain $f_{1}$ ce minéral fe rencontre là dans les mines d'argent. Voyez d'autres détails dans Sciagraphie de Bergmann, p. 184 , Edit. françoife. 
Obfervations \& additions fur les Foffles \& les Pécrifications.

A costa nie formellement, Liv. I. quil fe foir confervé quelque idée d'un déluge univerfel chez les anciens habitans du Pérou. Il rapporte uue inondation poftérieure \& particulière ; pareille à celle qui arriva dit tems de Deucalion en Grèce; ce que les Indiens difent d'un Viracocha, qui, après la perte des hommes, fortit du lac Titicaca, où le foleil étoit allé fe cacher pendant ce tems-là dans une Ine. Ce Viracocha, felon cette tradition, fe retira enfuite avec $f a$ famille à Cuzco, où il fonda le Royaume des Incas. G. de la Vega raconte de pareilles fables, qu'il eft inutile de répéter, \& qu'on verra dans fon Liv. III. c. 25. Acofta n'a pas tout - à-fait tort de rejetter ces fables, \& de les regarder comme des fonges. Ce que de Laër objecte pour les rapporter à un déluge univerfel, n'eft pas de grande importance.

Mais Acofta femble fe contredire lui-même, en difant que les Indiens du Pérou ont eu connoiffance d'un déluge univerfel, Liv. IV.c. 19. Il eft bon de connoitre fon récit. "Le titre auquel les Incas conquirent ce pays, \& s'en rendi- 
Obfervations $\}$ additions.

trent les maîrres abfolus, fut de feindre que depuis le déluge univerfel dont les Indiens avoient connoiffance, le Monde aroit été repeuplé par ces Incas, qui étoient fortis au nombre de fepr de la caverne ou grotte de Pacaritambo, \& que conféquemment tous les hommes leur devoient tribut \&ै vaffelage, comme à leurs äenx. »,

“Toutes les fables des Péruviens concernant le déluge du Soleil, \& Viracocha, ou autres femblables, confidérées fans préjugé, ne rappellent que des tems peu antérieurs aux conquêtes du premier Incas, à la population \& à la culture de ces pays, d'où il étendit fa domination, introduifant peu-à-peu la culture dans les autres parties du Pérou. Tout ce qu’on comioit de l'ancien état de ces contrées, remonte à ce déluge, comme l'état de l'ancienne Gièce, à l'époque du déluge de Deucalion; mais les conjectures qu'on peur fournir fur le tems du déluge de l'Amérique, font établies fur un fondement d'autant plus ruineux, qu'on penfe étre plus près de la vérité. "

M. Schneider reproche à Acofta, \& avec raifon, d'être peu d'accord avec lui-même; mais il ne l'eft pas plus que lui : d'ailleurs fur quel fondement peut-il préfumer que la tradition du déluge de l'Amérique ne rappelle que des tems peu antérieurs aux Incas? Il igtiore 
$34^{8} \quad$ Obfervations \& additions. donc que cette tradition peut fans erreur s'interprêter par celles de plufieurs autres Nations de ce continent, chez lefquelles le fouvenir d'un déluge univerfel, de la barque ou arche de Noé, de fes trois fils, de la colombe mênie, de la confufion des langues, s'étoit confervé. Or, qui lui a dit que la tradition du Pérou ne tient pas à celle des autres Nations de ce continent?

"Les habitans du Méchoacan difoient que leur Dieu Tusapacha avoit créé de terre un homme $\&$ une femme, qui étant allés fe baigner, avoient perdus leur forme; mais leur Dieu la leur rendit avec un mélange de certains métaux. Le Monde ou le genre-humain defcendit de ces deux perfonnes; mais les hommes étant tombés, dans loubli de leur devoir \& de leur origine, ils furent punis par un déluge univerfel, (Ovide affigne auffi la même caufe de déluge) à l'exception d'un Prêtre Indien nommé Težpi, qui fe retira avec fa femme \& fes enfans dans un grand coffre de bois, où il a voit raffembléquantité d'animaux \& ( $\mathrm{I})$ d'ex-

(1) Cette tradition des femences s'étoit confervée en Grèce, \& c'étoit avec des femences feules bouillies qu'on offroit tous les ans des facrifices ollaires pour les morts qui étoient péris dans le déluge. On peut voir Meurfius \& fur-tout Bianchini, qui prouve que ces offrandes faites pour ces morts étoient en ufage à la Chine, au Japon \& dans coute l'antiquité. 


\section{Observations \& additions:}

cellentes femences. Qu’après la retraite des eaux, il avoit lâché un oifeau nommé Aura, qui n'étoit pas revenu, \& fucceffivement plufieurs autres, qui ne reparurent pas non plus; mais que le plus petit, celui que les Indiens eftiment le plus pour la variété de fes couleurs, avoit bientôt reparu avec une branche d'arbre dans le bec." Hij. génér. des Voyages, Tom.XII. \$. 570 .

Cet oifeau, ou ces oifeaux, nous rappellent affurément la colonibe de Noé \& de Deucalion, dont Plutarque a fait mention, pour ne pas citer Lucien fur le même fujet. Mais cette colombe r'étoit pas inconnue au Mexique à l'époque d'un déluge univerfel arrivé du tems de Coxcox, qui y échappa avec fa femme \& fes enfans, lefquels cefsèrent d'être muets à l'apparition d'une colombe ( $\mathrm{I}$ ) qui vint fe percher fur un grand arbre; mais les enfans de Coxcox ne s'entendant plus, à l'exception de quinze qui reftèrent enfemble, tous les autres fe difpersèrento Ibid. p. 523 .

Mais la tradition du délugé univerfel fubfiftoit encore chez les Tlafcalans lors de la con-

( I) Cette Colombe eft celle de Dodone, qui s'envolant du fein de Thébé, (ou de l'arche appellée Thébé en Hébreu) rendit des oracles, noìs difent les, Grecs; \& voilà comme le don de la parole a été interprêté chez un autre Peuple. 
quête du Mexique. Le principal Cacique des Zapotecas, fe difoit defcenda en ligne direcke, du chef de ceux qui échappèrent au délige univerfel. Ses vaffaux, à qui cetre opinion le rendoit fort refpectable, lai faifoient même de fon vivant des facrifices comme à leurs Dieux. Ibia. $p \cdot 572$.

La rradition des trois fils de Noé, de l'arche, du déluge, n'étoir pas non plus perdue totalement ailleurs. La Nation Achagua exprimoit le Cataclyfme ou déluge, dont elle avoit le fouvenir, par Catena manoa, qui veut dire à la lettre, grand lac, ou Jubmerfon générale : cette idée s'étoit ranfmife de père en fils. Un des Indiens de Cuba apoftropha ainfí le nommé Gabriel Cabrera: "Pourquoi me grondes-tu, puifque nous fommes frères : ne defcendez-vous pas d'un des fils de celui qui conftruifit le grand vaiffeau, pour fe préferver de l'eau, \& nous de l'autre" ? Herrera, Decad. I. L. IX. c. 4. cité dans Gumilla, T.II. p. Iss. fuiv.

Je ne réunirai pas ici les parfages qui prouveroient que la plupart de ces Nations avoient une idée directe d'une première caufe qui avoir créé la grande machine, ou le fyftême du Monde; mais je crois pouvoir conclure contre M. Schneider, que le déluge dont les Péruviens avoient confervé le fouvenir, tenoit à un ćvè- 
Obfervations \& additions.

nement bien plus ancien qu'il le donne à entendre. Quant à ces contrées fubjuguées par les Incas, je vois encore moins fur quel fondement il voudroit infinuer qu'elles n'ont été habitées, \& peut-être même libres des eaux, que peu de tems avant les Incas. Je fais qu' $u$ 'un des hommes les plus célèbres de nos jours, a avancé que l'Amérique n'étoir habitée que depuis fix ou fept cens ans; mais M. Gufmann, Profeffeur de Phyfique expérimentale à Lemberg, a fuffifamment réfutécette idée dans fes Mémoires (Beytrag, \& c.) pour Servir à l'Hiftoire de l'Origine du Globe *erreftre Es à fes Habicans. 2. vol. in-8 $8^{\circ}$. Allemands. Ce précieux Ouvrage n'eft pas traduit, ou plutôt n'eft pas connu ici. M. Schneider, Allemand lui-même, ne le connoît-il done point ? Je lui confeille de le lire avec autant d'attention \& de plaifir que $j^{\prime}$ ai eu à le lire : il y verra Moyfe \& fa tradition vengés de toutes les attaques des Paw, Bailli, \& autres.

Acofta nous a dit, L. I.c. 24. d'une manière affez vague : "Pour moi, je crois qu'il n'y a pas plufieurs milliers d'années que le Nouveau Monde \& les Indes Orientales ont des habitans, \& que les premiers qui y font entrés, étoient des hommes plurôt fauvages $\&$ chaffeurs que des Nations policées, \& qui euffent un ordre civil.» $\hat{\beta}$ colta ne produit rien de plus pour appuyer $f_{2}$ 


\section{Obfervations \& additions.}

réflexion. Paw s'appuie d'un parfage d'Acofta; où cet Ecrivain Efpagnol s'eft plus clairement expliqué au fujet du déluge \& de la population de l'Amérique; mais ce paffage n'exifte que dans les termes de Paw, qui s'exprime ainfi :

"Tout cela fuppofé, il fera plus facile d'expliquer les caufes de la différence qu'on a déjà remarquée entre notre hémifphere \& celui de l'Amérique, qui avoit probablement éprouvé des cataftrophes Phyfiques, d'épouvantables tremblemens de rerre, \& des inondations confidérables plus tard que notre horizon. Acofta, dans fon excellent Ouvrage de Situ Novi Orbis, convient que les pius habiles Naturaliftes de fon tems rencontrèrent au Nouveau Monde des veftiges d'un déluge plus récent que cenx de Deucalion ar d'Ogygès, \& que le grand Catachyfme, dont la mémoire s'étoit confervée dans les livres facrés des Cohens, ou Prêtres Egyptiens, qui en avoient apparemment reçu la trádition de la poftérité de ceux qui fe refugièrent dans les montagnes de la haute Abyfinie, où la rerre eft plus exhaufée de neuf lieues que le niveau de la mer à Alexandrie."

Mais Acofta qui cite ici Paw, parle bien différemment. Il n'allègue point l'autorité des $\mathrm{Na-}$ turalifies de fon tems: il produit tout fimplement fes réflexions. „Les Indiens, dit-il, parlent bealloup 
Obfervations \& additions.

beaucoup d'un déluge; mais il eft difficile de déterminer s'ils l'entendent du déluge général dont parle le texte de la Bible, ou d'un déluge particulier de leur pays. Pour moi, je me range du parti de ceux qui penfent que les reftes \& les veftiges qu'il y a là du déluge, ne font pas de celui de Noé, mais de quelque particulier; tel que celui dont parle Platon, ou de celui dont les Poëtes ont rapporté l'époque au tems de Deucalion. »

Paw, accoutumé à ne citer, qu'en altérant tons les textes, pour prouver fes rêves \& fes chinà̀res, déraifonne encore davantage lorfqu'il prétend démontrer que le fol de l'Amérique a fubi une inondation plus récente que la nôtre a' en ce que ce fol eft encore couvert d'une quantité prodigieufe de lacs \& d'eaux marécageufes; que d'ailleurs il y a un grand nombre de volcans fur les haures montagnes du Mexique \& des Cordillères, des tremblemens de terre prefque continuels dans les Indes, des veines métalliques qui fe montrent comme à la furface du fol, une quantité infinie de productions marines dans les bas pays; que les grandés efpèces d'animaux ne $s^{\prime} y$ font pas trouvés; enfin la tradition générale de tous les habitans qui, depuis le détroit de Mageilan jufqu'au Aleuve Saint-Laurent, difens Tome II.

Z 
qu'autrefois leurs ancêtres n'habitoient que les: montagnes.

Comme M. Schneider fe contente de rapporter ces réflexions fans y rien répondre, je vais ajouter quelques mots. Les lacs \& les marécages prouvent que les terreins font plus bas que les autres, $\&$ rien de plus. Les volcans, loin de fournir une preuve de la nouvęauté du fol de l'Amérique, feroient plutôt une preuve du contraire; ou il faut convenir que l'Italie, la Sicile, l'Ihande, le Kamtchatca, les Inles de la mer du Sud, font des pays que l'eau a quittés depuis bien peu de tems. Mais les Voyageurs qui ont parcouru les mers du Sud, \& qui ont été témoins des tremblemens de terre qui font continuels dans les Ihes, ont préfumé qu'ils y détruifoient \& anéantiffoient peua-peu les terres, \& avoient probablement fait crouler dans les eaux plus de quinze cens lieues de pays. On diroit au contraire avec une certitude qui va prefque jufqu'à la démonftration, que les tremblemens de terre \& les volcans qui les caufent font plutôt en général une preuve de l'ancienneté d'un continent, que de fa nouveauté, \& je crois que tous les Phyficiens en conviendront. Les veines métalliques qui fe trouvent à la fuperficie du fol, n'ont rien de plus particulier que d'autres contrées où l'homme, enfant de la 
Obfervations \& additions:

Nature, ne mettoir prefque aucun prix à ces minéraux, par l'ignorance des arts \& la privation de tout commerce. Les premières peuplades qui pafsèrent en Amérique ayant été féparées du continent où fe font confervés les théories \& les arts de l'Ancien-monde, ont néceffairement dû s'abrutir, \& leur poftérité dégénérer au point où l'on voit prefque toutes les nations de l'Amérique. L'homme, uniquement attentif aux befoins du moment, a négligé ces métaux pour chercher ce qui pouvoit contenter fa faim : ainfi ces métaux font reftés à la fuperficie du fol comme ils y. étoient en Efpagne lorfqueles premières Colonies Carthaginoifes, qui connoiffoient les arts, les y trouvèrent en maffes, même à couper au cifeaut. Voyez Gognet. Sans la découverte de Colomb \&c. fes fuites, ces métaux feroient encore en Amérique dans les mêmes giffemens où les Efpagnols les ont trouvés, \&, felon Paw, ils auroient prouvé en y reftant dix mille ans, fi l'on veut, que le fol y étoit tout récent. Quelle abfurdité! Les productions marines, coquillages, plantes, pétrifications, \&c., loin de prouver un fol récemment découvert, font plutôt une preuive du contraire. On a trouvé en Amérique des lits de coquillages, adhérens \& non adhérens fur des montagnes trèșhautes, dans des rochès de la plis grande dureté, \& dans des lits de pierres-très-gros, très-étendus. 
Mais nous voyons la même chofe dans nos anciens continens : le rocher de Gibraltar, qui a douze cens pieds \& plus au-deffus du niveau de la mer, couvre un lit très profond de coquillages $\&$ d'offemens humains très-reconnoiffables, femblables à cette immenfe quantité d'offemens qui giffent fous terre, quoiqu'à peu de profondeur, le long de la mer Adriatique, ( $V$. Forris.) avec des pétrifications de toute efpèce : on a même découvert il y a peu de tems fur les côtes d'Afrique un certain nombre de fqueletes humains, enfermés dans un rocher nud à la furface du fol. J'ai moi-même trouvé dans les Alpes, à la fuperficie du fol \& fur un mont extrêmement élevé, un poiffon de feize pouces de long, \& fur lequel les écailles étoient encore marquées, quoiqu il fût totalement pétrifié. Certainement, fi le raifonnement de Paw prouve que l'A mérique n'elt découverte que depuis peu de tems, les phénomènes que je cite démontrent aufli que notre conrinent n'a été libre des eaux que long-tems après l'époque généralement admife; mais en bonne logique ces phénomènes font bien la preuve du contraire. Quant aux grandes efpèces d'animalix. terreftres, on ne connoît, il eft vrai, en Amétique que le Bifon; car les Taureaux \& les Vaches fąuvages qui y font, y ont été originairement tranfportés par les Efpagnols. Mais cette abfence 
Obfervations \& additions:

des gros animaux, tels que les Eléphans, Rhinoceros, Chevaux, \&rc., n'a rien de fi étonnant : des animaux d'une telle maffe ne s'expofent pas à de longs trajets d'eau; d'ailleurs, pour paffer en Amérique, ils ne pouvoient s'y rendre que par le Nord; or ils ne peuvent vivre dans ces climats froids. Les fqueletes de ceux qu'on trouve aux extrémités de la Sibérie, où ils fe font confervés prefqu'entiers, ont été pour le célèbre Pallas des preuves d'une inondation qui s'eft écoulée de ces côtés-là, \& a entraîné ces gros animaux, dont elle rouloit les cadavres dans les eaux où ils étoient péris; \& il eft probablement vrai, ou prefque démontré, que fans ceux qui ont été confervés par Noé, à quelqu'époque qu'on fixe le grand déluge, il n'en exifteroit pas plus en Afie qu'en Amérique. Le Bifon, animal qui par fa conftitition brave les climats les plus rudes, a pu paffer, comme d'autres animaux, de l'Afie en Amérique par le Nord, où ces deux continens ne font féparés quie par un court intervalle, \& probablement ne l'ont pas toujours été. Si les premiers peuples de l'A mérique ont tous habités les montagnes, ils ont et cela de commun avec les peuples des anciens concinens; mais les peuples actuels de l'Amérique ont trop peu de connoiffances \& de traditions conftantes pour préfumer, d'après leurs récits, que les habitans des montagnes ont été des hommes nou- 


\section{Obfervations \& additions.}

vellement arrivés dans le continent. Pour moi, loin de regarder l'Amérique comme une terre découverte long tems après la nôtre, \& fes habitans comme des hommes nouveanx, je crois que tout y prouve une antiquité très-reculée; mais que ces habitans féparés à une très-grande diftance de la fource des premières connoiffances, ( qui fe font confervées dans l'Afie) y font tombés néceffairement dans cet état de dégradation, de foibletfe \& de pufillanimité même, qui en fait une nation uniquement propre à l'efclavage, ou des hordes de barbares qui n'ont de réflexion que pour le befoin du moment. Toutes ces nations n’ont fans doute pas été dans cet état d'abrutiffement : car il eft difficile de croire qu'elles viennent toutes d'une même famille, ou d'une même Colonie qui fe fera tranfportée dans ce continent. Le milieu de Amérique peuplé par ceux qui y auront été jettés en partant des Inles qui font à l'Oueft des côtes de l'Afrique, a préfenté chez eux des idées, un fyrtême même d'affociation, de police \& d'arts, peu perfectionnes il eft vrai, mais fuffifans dans des contrées oì la nature étoit beaucoup plus libérale que dans les autres climats.

Paffons aux autres détails de M. Schneider. Les traditions des faits fe confervoient au Pérou moyennant des filets de nœuds ou de grains enfilés qu'on y appelloit Quipos. L'intelligence de 
tes fortes d'archives étoit réfervée à un certain nombre de perfonnes chargées d'y confacrer les faits relatifs à l'hiftoire du pays, \& fur-tout à celle des Incas. Les inftrumens répondoient parfaitement aux idées groflìres de ces peuples. Selon Acofta, Liv. VI, c. 8. ces Quipos confiftoient en des grains ou nouds de diverfes conleurs, faits ou enfilés les uns à la fuite des autres. Les différentes couleurs marquoient différens évènemens, $\&$ des chofes également différentes entr'elles. Les Interprêtes trouvoient dans les Quipos, \& avec beaucoup d'exactitude, tout ce qu'on auroit $\mathrm{pu}$ attendre de livres deftinés à confacrer les évènemens hiforiques, les cérémonies religieufes, les loix \& autres chofes femblables. Ces gens s'appelloient Quipocamayo, \& l'on ajoutuit fói aux réponfes qu'ils faifoient fur les chofes dont on leur demandoit le détail. (J'ai vu \& tenu de ces Quipos, dont parle Acofta : ććtuient des brins de ficelle de douze à feize pouces, attachés enfemble par un bout, les uns au nombre de quatre, les autres au nombre de fix, de huit ou dix. Les uns avoient leurs nœuds ou leurs grains d'une feule couleur, d'autres étoient variés, verds, rouges, bleus, gris; d'autres avoient perdu la couleur de leurs nouds ou de leurs grains dans la terre d'où on les avoient tirés.)

Il y on avoit de différentes fortes, pour la

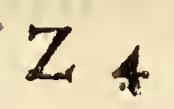




\section{0}

Obfervations \& additions.

guerre, le gouvernement, la police, les tributs, les taxes, les cérémonies \& fêtes publiques, pour la province \& pour la ville, \&c. Les grains avoient des volumes différens. Les couleurs fervoient fans doute aufli à différencier le genre, l'efpèce ou la nature des chofes \& des évènemens. C'étoit pour ces gens un alphabet avec lequel ils compofoient les fignes repréfentatifs des chofes, comme nous les formons avec nos lettres dans les mots que nous écrivons. Ils pouvoiont donc aufi les varier à l'infini, \& conferver le fouvenir d'une quantité innombrable d'objets qui auroient néceffairement éré oubliés fans cela. Máis, dira-t-on, ces combinaifons étoient-elles toujours affez sûres pour ne pas induire en erreur? On peut répondre quil eft encore plus facile d'attacher un fens direct à ces fignes qu'à des milliers de mors formés avec les vingt-trois ou vingt-quatre letrres de nos alphabers. Les peuples chez lefquels l'ufage de l'écriture ou s'eft perdu, ou n'a pas été introduit, ont eu recours aux fignes, foit arbitraires, foit pris de la nature des chofes: or ces fignes ont dù fe multiplier prefque à l'infini, \& cependant l'habitude en rendoit la fignification $\mathrm{fa}$ cile à fainr. I'ufage de Quipos n'elt pas encore oublié chez ces Nations, même chez celles qui ont été forcées d'adopter en partie la religion \& la couame des Européens. S'il fe fait, au bout de deux 
Obfervations \& additions.

ou trois ans, une recherche au fujet de la conduite d'un Officier qu'on foupçonne avoir malver$f^{\prime}$, les Indiens de fon département ne manquent pas de venir avec leur Quipos, \& de demander le prix des volailles, foins, fourrages, animaux qu'il s'eft fait donner par force, ou qu'il a enlevés lui-même, foit fans payer, foit en ne payant que telle partie défignée par les nœuds de ces cordons. Voilà ce qui leur tient lieu d'écriture \& d'Arithmétique, \& jamais ils ne fe trompent.

J'ai vu, dit Acofta, un faifceau de ces cordons fur lefquels une Indienne avoit noté tous les évènemens de $f_{a}$ vie, \& avec lefquels elle alloit à confeffe; certaines petites plumes, qui me parurent d'abord défigner quelques circonftances particulières, indiquoient, comme je l'ai fu, des particularités qu’il ne falloit pas oublier à confeffe. Il eft réellement curieux de voir un vieillard Indien apprendre le Credo, le Pater \& l'Ave Maria fur trois filets différens, dont chaque grain repréfente un mot, \& ne fe les mettre dans la tête qu'autant qu'il fe le fixe par ce moyen. Il fait, par exemple, quel nœud ou grain défigne conçu du S. Esprit, quel autre fignifie a fouffert Sous Ponce Pilate; s'il fe trompe, il regarde auffi-tôt ces nouds, qui me jetteroient dans une relle confufion, que joublierois promptement tout ce que je fais. 


\section{Obfervations \& additions?}

Ils ont encore une autre forte de Quipos faits de grains de mäis, avec lefquels ils terminent promptement les zalculs \& les répartitions les plus compliquées des taxes \& des contributions.

(Il feroit biẹn à defirer qu'Acolta nous ent an moins donné une idée de la manière quelconque dont ces Indiens arrangeoient les grains de ces Quipos numéraires; on y verroit probablement quelqu'analogie avec cet abaque Chinois que Bianchini, p. 109, a fait graver d'après le Jéfuite Martinius, J'ai tenu il y a trois mois un pareil infrument, fort ancien ici à Paris, chez un ami, Cloître Saint-Honoré. L'abaque des Romains feroit peut-être aufli plus analogue ì la manière expéditive de calculer avec ces grains de maïs. IT. le même Bianchini, $p .107$. On voit avec peine que des Hiftoriens omettent de faire attention à des circonftances qui ne paroiffent pas importantes en elles-mêmes, mais qui le deviennent infiniment par les chofes auxquelles elles tiénnent : en effet, fil ces Sauvages difpofent ces Quipos numéraires par colonnes parallèles dans lefquelles ils enfilent leurs grains, n'eft-ce pas une circonftance qui tient à ces lignes parallèles qu'on foupçonne avec raifon être des abaques numéraires dans les pyramides anciennes, ou à la manière de compter dont ufent les Chinois depuis plus de quatre mille ans. Cette circonf- 
Obfervations \& additions.

tance étoit bien précieufe; cependant Acofta n'y a fait aucune attention, non plus que nombre d'autres; tant il eft vrai que pour voir il faut être en état de voir. Je fais cette remarque que M. Schneider omet.)

Acofta dit que les Péruviens fuppléoient à l'écriture littéraire par des efpèces de figures, comme les, Mexicains, mais que leurs figures étoient beaucoup plus grofières que celles de ces derniers; cependant Zarate, Liv. I. c. S, nie que les Péruviens euffent une femblable écriture; ils avoient, dit-il, des Quipos, au moyen defquels ils confervoient la mémoire des chofes les plus importantes, les faifoient paffer à la poftérité. Il eft furprenant de voir avec quelle facilité ces gens entendent $\&$ font entendre aux autres, par ce moyen, ce qui s'eft paffé plufieurs fiècles avant eux. Zarate, dans $f_{a}$ defcription, ne parle néanmoins que des nouds qui déterminoient le nombre des chofes exprimées par les différentes conleurs.

G. de la Vega, Liv. VI. c. 8, 9 , ajoute différentes circonftances au récit d'Acofta. Il avoue franchement que ces nœuds défignoient bien le nombre des différentes chofes, mais non des mors, $\&$ qu'ils exprimoient encore moins les penfées. "On ne pouvoit pas, dit-il, exprimer par ces nocuds le contenu d'une ambaffade, les paroles 
364 Obfervations \& additions.

expreffes de la déclaration, \& tels autres évènemens hiftoriques, parce que ces chofes confiftoient dans des termes articulés de vive voix, ou par écrit, \& que les nouds marquoient bien le nombre, mais non pas les paroles. Pour fuppléer à ce défaut, ils avoient certaines marques par où ils comnoiffoient les actions mémorables, les ambaffades \& les déclarations faites, \&c. Mais auels étoient ces fignes, c'eft ce qu'il ne nous apprend pas. On trouve dans le Chap. 24 de fon Liv. II. un moyen de conferver le fouvenir des chofes, \& dont le nombre de Peuples fauvages du Nord de l'Amérique fe fervent: c'eft le $W$ ampum. Il confifte en quelques courroies de cuir, fur lefquelles ils attachent des peignes (coquilles) de différentes couleurs pour leur fervir comme de livres dans lefquels ils vont revoir tout ce qui les intéreffe. On dit auffi que quelques ( 1 ) bâtons peu différens, fourniffent abondamment à un député Indien, matière à parler dans une conférence de quatre ou cinq heures fur tous les points qu'il a à traiter dans les Affemblées générales, \& que loin de rien oublier, il détaille tout avec ordre. Selon Frézier, les Indiens du Chili fe fervent de certains nœuds

(x) Il en eft de même chez prefque tous les Indieñs du Continent de l'Amérique. 
Obfervations \& additions:

de laine pour retenir le nombre de leurs troupeaux, \& fe rappeller leurs affaires particulières: les diverfes couleurs dont ils font marqués; leur tiennent lieu de figne \& de lettres; mais l'intelligence de ces Quipos eft chez eux un fecret que le père ne révèle à fon fils que quand il eft près de mourir.”

Ce récit de Frézier, conforme à certain point à celui d'Acofta, ne s'accorde pas avec ce que nous dit G. de la Vega. Si d'un côté, quelquesuns ont regardé ces Quipos comme des efpèces de regîtres où l'on confignoit ce dont on vouloit conferver le fouvenir, ou dans lefquels on portoit les comptes publics ou particuliers; d'autres; entre lefquels font Robertfon \& Paw, ont objecté que de quelque manière que ces cordes $\&$ ces nœuds fuffent arrangés ou peints, ils ne pouvoient préfenter aucune notion abftraite, ni exprimer aucune affection de l'ame, \& n'étoient par conf́́quent, que de peu d'utilité, pour tranfmettre aux fiècles futurs les évènemens qui les précédoient ; qu'ainfi l'on doit à peine ajouter foi à ce qu'ils pouvoient défigner concernant les faits, les batailles, les victoires, les conquêtes, les qualités perfonnelles, \& le caractère des Souverains du Pérou. D'ailleurs, la plupart de ces inftrumens \& antres monumens de l'invention des Péruviens, ont péri dans le tems de la con- 

quête, c'eft pourquoi Robertfon ne recọnnoîs pour vrai dans lhintoire des Incas, au moins pour aflez croyable, que quelques faits relatifs au fyftême de la religion \& à celui de l'ordre civil, dont la mémoire n'a pu s'éteindre, à caufe de leur connexion intime \& réciproque. Mais ces faits ne furent pas cachés aux yeux des Conquérans; ils les virent : ainfi c'eft encore plus fur le témoignage de leurs yeux, que fur les Quipos, qu'on doit les croire.

Selon le récir des Indiens, la durée des règnes de leurs treize Incas, ent de 400 ans; mais Acofta, Liv. V.r. c. 19. dit que ces Princes n'ont régné qu'un peu plus de 300 ans. D. Ulloa remarque ici fort fenfément, qu'en donnant même trente ans à chaque règne, on ne trouveroit pas encore 400 ans. Il obferve encore d'après le nombre des fqueletes trouvés dans les tombeaux', qu'en excluant le treizième Incas, \& accordant à chacun des douze aurres vingt-un ans de règne, on n'aura que le nombre de 250 pour la durée de tous ces règnes. D. Ulloa trouve cependant cette durcée trop courte, en ce qu'elle ne s'accorde pas avec l'opinion générale de la durée des Monarques du Pérou. Mais les obfervations du célèbre Newton ont aujourd'hui fait adopter comme règle générale, que les règnes pris l'un dans l'autre, ne paffent pas vingt ans: 


\section{Obfervations \& additions:}

zinfl la đurée des règnes des Incas prife en fomme, ne feroit même que de $24^{\circ}$, ce qui revient on ne peut mieux, au nombre des années indiquées par les fquelètes trouvés dans les tombeaux Indiens. On peut voir aufili à ce fujet la remarque de Robertfon, Liv. II. p. 558 .

Mais qu'on faffe la durée de ces règnes ou plus courte ou plus longue, felon l'une ou l'autre de ces manières de calculer, il n'eft pas moins inconcevable que les Nations du Pérou aient pu parvenir à ce degré de culture où elles étoient arrivées, en un fi court efpace do tems.

D. Ulloa tâche delever la difficulté, en difane que les Incas venoient d'une race d'hommes plus cultivés \& plus formés que les Indiens qu’on connôt aujourd'hui ; mais il avoit autrefois fuppofé dans l'hiftoire des Incas à la fuite de la quatrième Partie de fon Voyage, qu'avant Manco-capac, lo premier de ces Princes, il y avoit ell dans les environs de Cuzco, un Peuple gouverné par fes propres Rois, moins barbare que les autres Nations de ce continent, \& qui salfujetrit fes voifins; que de cette Race royale ćtoit forti un Souverain, qui avoit étendu $\mathrm{fa}_{\mathrm{a}}$ domination plus loin que fes ancêtres, par fa: grande capacité \& fa fineffe particulière. Le fouvenir des Rois précédens fe perdit, felon le même 
Auteur, parce que Manco-capac fit accroire à la Nation qu'il étoit fils du Soleil, \& empêcha ainfi la mémoire des autres de paffer à la poltérité.

Mais cette obfervation d'Ulloa eft encore plus fufceptible de difficultés que la première. En effet, quelque puiffance qu'ait un Souverain, Manco-capac ne pouvoit pas anéantir totalement la mémoite d'un fait auffi généralement connu, qne devoit l'être l'état antérieur d'une Nation qui étoit policée, qui avoit eu fes Rois avant lui : de côté ou d'autre il s'en feroit confervé quelque fouvenir, puifque les Indiens actuels du Pérou, qui ne font plus une Nation, qui font foumis à des étrangers, n'ont pas oublié leurs anciens maîtres, \& foupirent encore après eux. Mais en accordant que D. Ulloa foit bien fondé dans cette dernière fuppofition, il feroit encore permis de demander d'où étoit venue cette Nation, moins brute aux environs de Cuzco? qui l'avoit policée, lui avoir formé un fytême politique? C'eft retomber dans de nouvelles difficultés, d'où il n'eft. pas poffible de fe tirer.

Mais paffons aux pétrifications \& aux différens états du fol. Ce que nous dit Ulloa des coquillages du Chili, eft relatif à ce qu'il avoit rapporté dans ce paffage de fon Voyage. “ Depuis Talcaguano jufquà la Conception, à un éloigne- 


\section{Obfervations \& additions:}

ment de quatre à cinq lieues de la mer, on remarque ce qui fuir, comme une chofe affez particulière. Si l'on creufe depuis une démi-vara, ou depuis les trois quarts jufqu'à deux ou trois toifes de profondeur, \& même plus avant en plufieurs endroits, on trouve de purs coquillages de diverfes efpèces, fans le moindre mélange de terre, de forte que les petits rempliffent les interftices \& les cavités des gros, \& s'y uniffent de certe manière. On y fait de la chaux avec les plus gros. Il n'y auroit rien de merveilleux, fi cela ne fe trouvoit que dans des terrains bas \& plats ; on en concluroit naturellement, que la mer a couvert ces furfaces; mais on voit avec étonnement, que ces mêmes coquillages fe trouvent fur des éminences qui font plus hautes de trois cens pieds que le niveau de la mer. Je n'ai pas examiné moi-même s'il fe rencontroir quelque chofe de femblable fur les plus hautes cimes; cependant les habitans m'ont affuré qu'on y en trouvoit auffi, \& j'en ai vu fur d'autres montagnes, qui avoient cent-vingt pieds au-deffus du niveau de la mer.

J'ai examiné ces terreins avec le plus grand foin, \& je n’y ai pas apperçu la moindre trace de feux fonterreins; car on ne voit rien de calciné ni en dehors fur le fol, ni dans les coquillages. Ces coquillages y font pareillement fans

\section{Tome 11 .}


nucun mélange de terre, \& l'on n'y rencontre ni terre, ni autre chole: en un mot, ce ne font que des coquilles, dent les unes font entières, les autres brifées, comme cela dóit arriver par leur preffion réciproque, \& par le poids des couches fupérieures.

Tous ces coquillages ont antrément été portés lì par le déluge univerfel : vouloir les amener dans ce local par une aurre caufe, c'elt recourir à une abfurdiré, contre laquelle le bon fens \& l'expérience réclament, puifqu'on ne vos que des coquillages fur ces montagnes \& plufieurs autres : \& ce qu'il y a de remarquable, c'eft que les coquillages ou'on trouve ici dans la mer, \& quion ramaffe en grande qnantité dans cette baie, ne font pas les analogues.

On a cru fur le témoignage des Académiciens François, qu'il n'y avoit pas de coquillages ni de pétrifications fur les Cordillères, \& M. de Buffon a bâti là-deffus différentes hypothères. Paw a trouvé cela fort naturel \& bien fondé : il a même avancé qu'il ćroit impóflible qu'il y en ent. Voici comment il s'explique à ce fujet. "Ceux qui fe fon imaginés que l'Amérique n’a jamais été fujette a des inondations, parce qu'on ne trouve pas de coquillages au Pérou, ignoroient apparemment quon rencontre à la Terre de feu, au Chili, anz Antilles, à la Louyfiane \& à la Caroline, 


\section{Obfervations \& additions:}

des lits, des bancs \& des collines entières des dépouilles marines. Pourquoi les fommets des Cordilières fourniroient-ils des coquillages, puifqu'on n'en trouve déjà plus fur les plus hautes pointes des Alpes, qui font cependant de plus de fix mille cinq cens pieds moins élevés que la tête du mont Chimboraco au Pérou?

D'autres font d'autant plus étonnés qu'il ne fe trouve point de coquilles, ni aucune trace de productions marines fir les Cordillères, que l'on y voit à plufieurs endroits différens marbres, \& que Guayaquil eft fitué fur un mont de craie : ils préfument de-là que les feux vomis par les volcans, les ont couvertes, ou détruites. »

Cette opinion n'a el de fondement que fur les rapports de Bouguer \& de la Condamine, que Bergmann a ciré pour témoin dans fa Defcription Phyfique du Globe; mais elle'a été fuffifamment réfutée par le témoignage de D. Ulloa. Il eit cependant douteux qu'il ait fait lui-même l'obfervation qu'il rapporte. La Condamine avoit déjà été inftruir par des lettres d'Amérique à fon retour en France, qu'on trouvoit des cornes d'ammon fur les hautes cimes du Pérou, \& qu'en I 761 on avoit auffi découvert des pectinites dans le Gotivernement de Guancavelica, à une hauteur confidérable au- 
delfus du niveau de la mer : c'eft ce que Bergmann avance d'après les Mémoires de l'Académie, années 1792 \& 1768. Mais je n'ai pu voir que cette dernière date dans ces Mémoires, où M. Monter, dit M.de la Condamine, a fait mettre dans un Journal une lettre di Pérou, dans laquelle on remarque qu'on a trouvé des cornes d'ammon fur les plus hautes montagnes de cetie contrée.

J'ajouterai à ces rapports le témoignage important d'Alonfo Barba, qui n'a fans doute été inconnu aux Savans, que par la rareté de fon Ouvrage. Il y dit, Liv. I. c. 17. que, "fur le haut chemin qui mene de Potofi à Oronefta, l'on ramaffe des pierres qui font marquées de différentes figures, \& fi au naturel, qu'il n'y a que la main du Créateur qui puiffe produire un pareil chef-d'œuvre; qu'il a pardevers lui des pierres dans lefquelles on voit des coquillages de toute efpèce, grands, moyens \& petits : les unes font placées en haut, les autres en bas, \& préfentent les traits les plus déliés propres à chaque coquille dans la plus grande perfection. Or, ajoute-t-il, cet endroit eft directement au milieu du pays, \& fur des éminences où ce feroit une folie de croire que jamais la mer fût venue couvrir les terres, \& ait laiffé là ces coquillages. Parmi ces pierres, il y en a qui ref- 
Objervations \& additions. femblent parfaitement au crapad-buccin granaleux, ou calque à verrue, à des bivalves \& autres de formes fingulières; de före que malgré les rémoignages que j'en ai eus, je n'en parle qu'en craignant d'être à peine cru de mes lecteurs. Si donc l'on avoit marqué la profondeur de tous les terreins où l'on trouve des traces de productions marines, on pourroit, en comparant leurs différens giffemens, afingner l'époque de la grande inondation de l'Amérique. Il faudroit moins s'occuper de ces recherches dans les montagnes, parce que la furface des terreins y a efftiyé divers déchiremens \& des ruines continuelles, ne fuit-ce même que par leur élćvation \& leur abaiffement.

Le paffage de Bouguer dont nous avons parlé, fait voir qu'il parle des Quebradas que notre Auteur a bien repréfentées quant ì la forme externe. Comme celui-ci n'a prefque rien dir fur la nature même des terreins, ce paffage de Bouguer fuppléera à ce qui manque ici : en voici un extrait. "L'on n'a trouyé, dit-il, dans ces profondeurs aucune trace de la grande inondarion, qui fe décèle par tant de marques dans les autres parties du globe: c'ef en vain que j'ai cherché a découvrir quelques coquillages. Les cimes du Pérou font probablement trop hautes : on y trouve par-tout un fable noir, qui attire hai-

$$
\text { A } 3 \text { 3 }
$$


394

Obfervations E addiținns.

mant, \& l'on apperçoit aifément que les couches que l'on y voit, ne viennent pas d'une alluvion ancienne, mais ont plutôt été le réfultat de matières combultibles vomies par le feu dos volcans. Tout y paroît l'ouvrage du feu. Plufieurs de ces montagnes ne fon formées que de fcories jufqu'à wue aflez grande hateur. On y apperçoit de la ponce, des morceaux de pierres brûlées de différentes grandeurs : or toit cela fe trouve quelquefois fous une couche de terre végétale qui produit des herbes, \& même des arbres. Les couches de ces matières ne font pas par-tout d'une même épaiffeur : elles deviennent d'autant plus minces, qu'on s'éloigne davantage de la montagne. Tantôt elles ont un pied d'épais, tantôt un demi-pouce, \& on re les perd pas de vue jufqu'à la difance de quatre à cinq lieues, à moins qu'on riapproche d'un autre volcan, où l'on apperçoir bientôt les mêmes phénomènes. J'ai fait toutes ces obfervations au pied du Cotapaxi, qui a la forme d'un cône tronqué, car fon fomet ent tout déchiré."

Après d'autres détails relatifs à la forme de ces monts, \& en particulier de celui du Cotapaxi, le Voyageur ajoute qu'il croiroit prefque que les couches fupérieures de ce mont, formées par des pierres calcinées, font dues à l'horrible inflammation dont tous les Hiforiens font men- 
Objervations \& additions.

tion, \& qui arriva en 1533 , après la mort d'Athahualpa, Roi de Quito, \&c. Les autres obfervations qui accompagnent ces récits, font affurément au moins aufi précieufes, pour ne pas dire plus, que celles que fait $D$. Ulloa dans fon Voyage fur les volcans de l'Amérique Méridionale.

(M. Schneider omet ici quelques réflexions, qui fe préfentoient cependant d'elles-mêmes. Les détails du Voyageur Académicien nous apprennent qu'il n'a pas découvert de coquillages fur ces monts : mais, felon ces mêmes détails, il ne devoit pas en trouver dans les endroits qu'il décrit, puifqu'il confidère ces monts comme un produit volcanique. On avoit donc eu tort de conclure de fon récit qu'il n'y avoit pas de coquillages fur les hautes cimes du Pérou, puifque l'expérience ne tarda pas à prouver le contraire, \& que d'ailleurs on avoit oublié de confulter Barba, homme en état de mieux voir que Paw. Mais Paw, qui raifonne par-tout aux dépens du bon fens \& de la vérité, a cru devoir ajouter une preuve de fa mauvaife logique, en difant qu'on ne pouvoit même pas trouver de coquillages fur ces cimes énormes. Quant à la comparaifon qu'il fait avec les hautes cimes des Alpes, fur lefquelles, dit-il, on n'en trouve pas, ent-il bien sûr du fait? A-t-on bien parcouru \& A $_{4}$ 
376 Obfervations \& additions.

examiné ces cimes? Je réponds que non. Son raifonnement eft donc faux, de quelque côté qu'on le prenne. Si l'on n'avoit parcouru en Amérique que les monts qui font le produit du feu, affurément on auroit été en droit de croire quil ne fe trouvoit pas de coquillages dans les Cordillères. Mais dans toutes les chânes de montagnes il faut diftinguer des monts de différente formation \& de différente nature. Les uns tiennent encore à l'origine même du Globe, en gratide partie ; les autres ont été formés par les bouleverfemens que ce même Globe a effuyés dans nombre de ces parties, bouleverfemens que le Poëte Manilius a mieux préfenté que perfonṇe; j’óe même dire que la plume du célèbre de Buffon n'a jamais peint avec la force de ce paffage-ci. Liv. IV.

Concutitur Tellus, validis compagibus hreens, Subducitque folum pedibus : natat orbis in ipfo, Et vomit Oceanus Pontum, fitienfque reforbet. Ne fere ipfe capit : fic quondan merferat urbes Humani Generis quum folus conftitit hæres Deucalion; fcopuloque orbem porfedit in uno.

Voilà une peinture fidèle des révolutions que le Globe a éprouvé en ce moment; \& d'accord pour les principales circonftances avec le récit de Moyfe, Les eaux du grand abîme n'ont pu fé 
Observations E् additions.

repandre fur la terre quautane que le Globe fe fera entrouvert : ì ces eaux fe font jointes celles de l'atmofphère; \&, de l'aveu de toute l'aniquité profane \& facrée, ce délige a étŕ le châtiment de la pourfuite des hommes, comme l'ont penfé quelques peuples de l'Amérique que nous avons cités.

Pana placet diverfa; Genus mortale Jub undis Perdere, \&c., dit Ovide.

C'eft dans cette terrible cataftrophe quill s'ent formé de nouvelles montagnes. Les animaux qu'on a trouvés pétrifiés à des profondeurs énormes dans des vaftes montagnes, ne permettent pas de douter de la formation de ces monts fecondaires. Il en eft une troifième efpèce que les volcans ont formée des matières quilis avoient fondues ou brûlées en partie, ou réduites en cendres. Ce font-là les. volcans dont parloit le Voyageur Académicien. Eft-il done étonnant qu'il ne s'y trouve pas de coquillages, quelque hauteur qu'on leur fuppofe? On n'en trouvera pas non plus dans les monts originaires, ou ce ne fera qu'à la furface, dans les couches plus ou moins épaiffes que les limons des eaux y ont laiffées. Mais quelles font les marques caractériftiques auxquelles on reconnoîtra les monts de première origine? M. Gufmann a trop bien prouvé que ce ne potvoit pas être lo 
378 Ob fervations \& additions.

granit, quoiqu'on l'ait regardé comme une pierre originaire, au moins comme un produit du feu, $\&$ dont les débris ont peu-à-peu donné lieu à la formation de pierres d'une autre nature, par l'action des différens principes qui s'y font combinés. Mais cet habile Phyficien, qui a fi long-tems étudié la Nature dans fes laboratoires mêmes, \& non dans fon cabinet, a vu le fchite \& le granit fe métamorphofer réciproquement, \& toutes les efpèces de pierres fe convertir de même en des efpèces toutes contraires. Nous avons même découvert dans l'Auvergne des monts entiers de granit qui giffent fur des couches calcaires, atgilleufes, fchiteufes, \&cc. C'en ainfi que le rocher de Gibraltar gît fur une couche extrêtmement profonde d'ofremens humains, que la mer Méditerranée y a fans doute raffemblés lorfqu'elle fubmergea tous les terreins qu'elle occupe, en $\mathrm{fe}$ féparant par des révolutions, dont nous n'avons pas la date, de la mer Rouge proprement dite: je dis fe fépara, car le petit efpace de terre qui la fépare n'eft formé que de coquillages, qu'on découvre fans creufer bien avant. Peur êrre même cette mer n'a-t-elle été formée que des eaux du vafte bafin qui fubfiftoit en Afre au-delà de la mer Cafpienne, \& dont les Grecs nous ont confervés la mémoire. Si le déluge de Deucalion en Grèce n'eft pas une fable, comme Bianchini 


\section{Obferyations \& additions.}

le penfe avec les Auteurs qu'il cite, on pent préfumer que c'eft lirruption de ces eaux qui on alors fubitement inondé la Theffalie, l'Attique, \& toutes les contrées voifmes : mais en même tems la tradition a confondu cette fubmerfion avec le déluge univerfel. Cette révolution partielle eft une de ces cataftrophes dont parle Sénéque dans ces beaux vers :

Omnia tempus edax depafcitur, omnia carpit; Omnia fede movet, nec finit effe ditu.

Flumina deficiunt; profugum mare litora ficcat; Subfidunt montes \& juga cella ruint, \&c.

Mais fuivons M. Schneider. Je ne dois pas omettre ici quelques mots fur ces pierres peintes, dont Bouguer a parlé; il rencontra fouvent de gros morceaux de roches, épars çà \& là fur le fol; ces pierres étoient noires en-dehors, \& paroiffoient avoir fenti l'impreflion du feu, \& l'on croiroit prefque qu'elles ont été jettées là par l'embrafement de quelque volcan. On ne peur mieux les comparer quavec de groffes maffes d'argile féchée au foleil, que la chaleur a fait fendre, \& qui fe font enfuite converties en pierre. On trouve de pareilles pieries en divers endruits, mais entr'antres au tiers de la route qui mène de la Plata à Honda, à trois lieues environ aiidefous d'un petit village qui fe nomme Backic; 


\section{Obfervations \& additions.}

celles-ci font fort remarquables, \& au nombre de deux. La furface extérieure de la plus groffe eft environ de vingt pieds en longueur, fur onze de haut : elle ne préfente aucune fente, mais une fuperficie très"unie. On y remarque divers fignes \& plufieurs figures qu'on y a gravées; on en rencontre encore d'autres femblables à des hauteurs beancoup plus éloignées dans des contrées pius près des Cordillères : elles préfentent aufi des figures gravées. Mais le Voyageur dit ne pas avoir vues celles-ci; on les appelle dains ces pays piedras pintadas. Ces fignes $\& \dot{c}$ ces figures font peut-être, dit-il, une infcription qui marque le tems \& les circonftances d'un embrafement volcanique, ou peut-être aufî tout áutre évènement, comme le débordement de la rivière; all moins ces pierres paroiffent-elles être un ouvrage fait à deffein, \& achevé avec beaucoup de patience: la gravure a au moins deux pouces \& demi de profondeur. I'action marquée que ces pierres exercent fur la bouffole, nontre qu'il y a quelques parties ferrugineufes; mais elles doivent $y$ être bien enveloppées : l'intérieur de la pierre eft de couleur blanche, \& confifte outre cela en un grais ou fable très-fin.

D. Ulloa nous parle des pyramides de la plaine de Zucara dans le Corrégiment d'Angaräs, \& les compare avec les tertres fépulcratx que lou 
trouve près de Quito. Je n'ai connoiffance d'aucun Ecrivain plus ancien qui en faffe mention; ainfi je ne puis déterminer fi c'eft un ouvrage de $\mathbf{l a}$ nature ou de l'art. L'Auteur parle dans fon Voyage, d'un monticule de terre qui a vingtcinq à trente toifes de haut, dans la Province de Latacungo, vers le Nord; il a la rondeur d'un pain de fucre, \& fe trouve fi uniforme de tous côtés, qu'on le prendroir pour un ouvrage de mains d'homme, d'autant plus qu'il fait dans tout fon contour un angle égal avec la furface du. fol. Cette forme \& celle des Guacas ou fépulcres, font pour Ulloa deux raifons qui lui feroient croire que ce mont eft un ouvrage de l'art, \& que pour le faire, on a pris de la terre dans une vallée prochaine où il paffe une rivière qui coule au Nord; mais il ne fe préfente aucune autre raifon de le croire, que cette conjecture.

On peut cependant obferver que ce monticule, connu fous le nom de Panecillo de Callo, a tenu lieu d'une ftation où l'on plaçoit une garde qui pût infpecter de-là toute la campagne cn liberté , \& veiller ainfi à la sûreté du Prince, dont le Palais n'étoit pas éloigné.

Si l'on prend les pyramides dont parle l'Autcur, pour des monumens fépulcraux des Indiens notables, comme il femble le préfumer, 


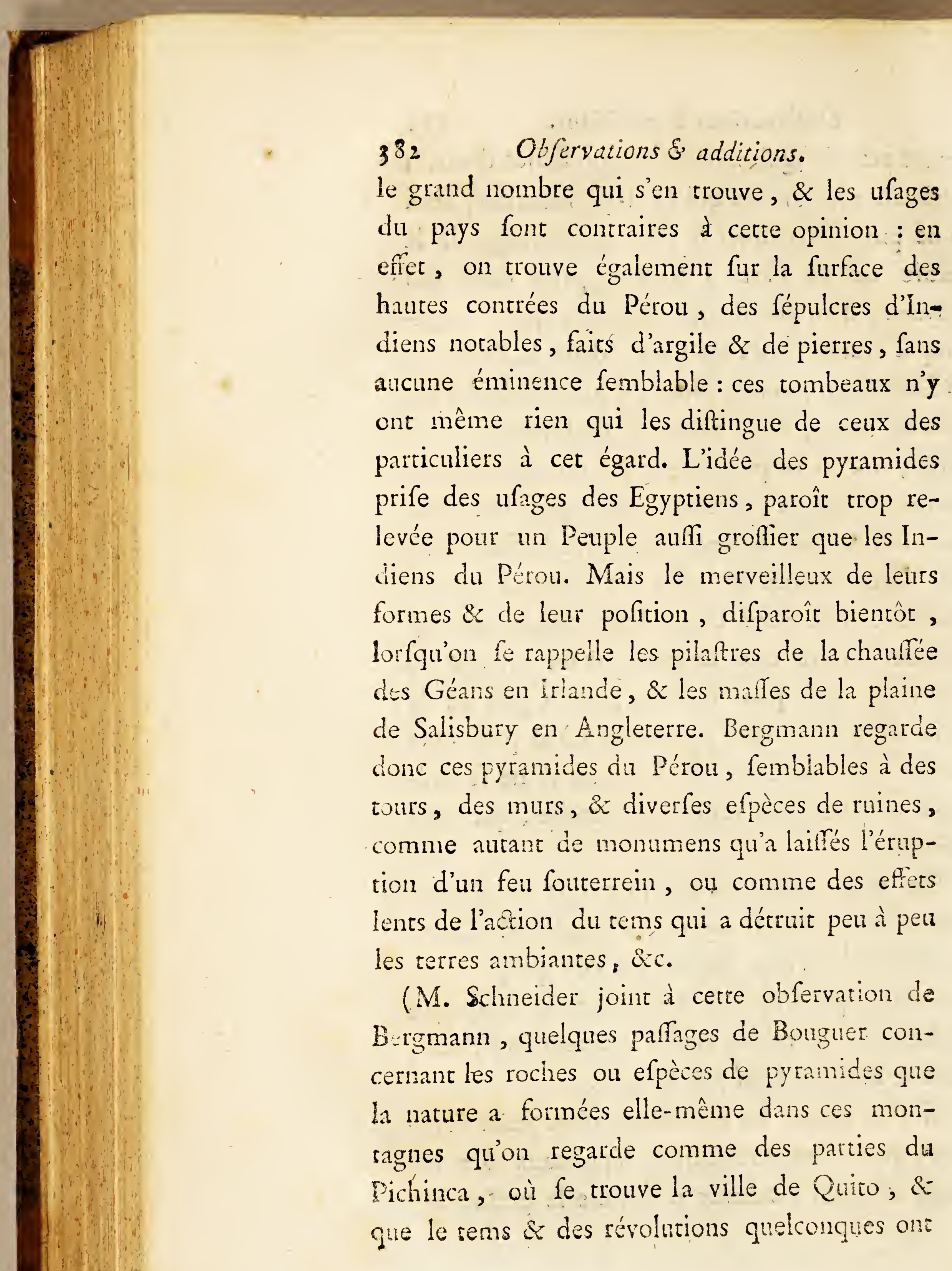




\section{Obfervations \& additions:}

dépouillées de la terre qui les environnoit. Ces citations feroient applicables à des circonftances toutes différentes de celles dont il s'agit dans cet Ouvrage-ci. On pourroít probablement expliquer d'après Bouguer, comment fe font formées ces pyranides dans les environs de $\mathrm{Me}$ xico. Telles font celles done parle Carreri, que M. Schneider devoit confulter : il auroit aufli vu qu'avant D. Ulloa, l'on avoit parlé de pyramides qui fervoient de tombeaux en Amérique : pourquoi ce qui s'eft fait à cet égard au Mexique, n'auroit-il pas eu lieu au Pérou?

Carreri dit formellement, "que ces grandes maffes de pierres renferment des tombeaux des Rois du pays, que quantité de petits monts dont elles font, environnées, paroiffent avoir été les tombeaux des Seigneurs Mexicains, que le chemin qui y conduit, s'appelloit encore de fon tems, le Chemin des Morts. Voild les monts fur lefquels $M$. Schneider devoit s'arrêter, \& non fur ces maffes énormes de pierres dont parle Bonguer. L'explication que Bergmann donne des pyramides dont il s'agit dans notre Auteur, eft en Phyrique un de ces efcamotages à la faveur defquels des gens qui venlent tout expliquer par leurs hyporhèfes, rendent rairon bien ou mal de ce quilis n'ont pas vu. La réflesion que frit $M$. Schneider au fujet de la grof- 


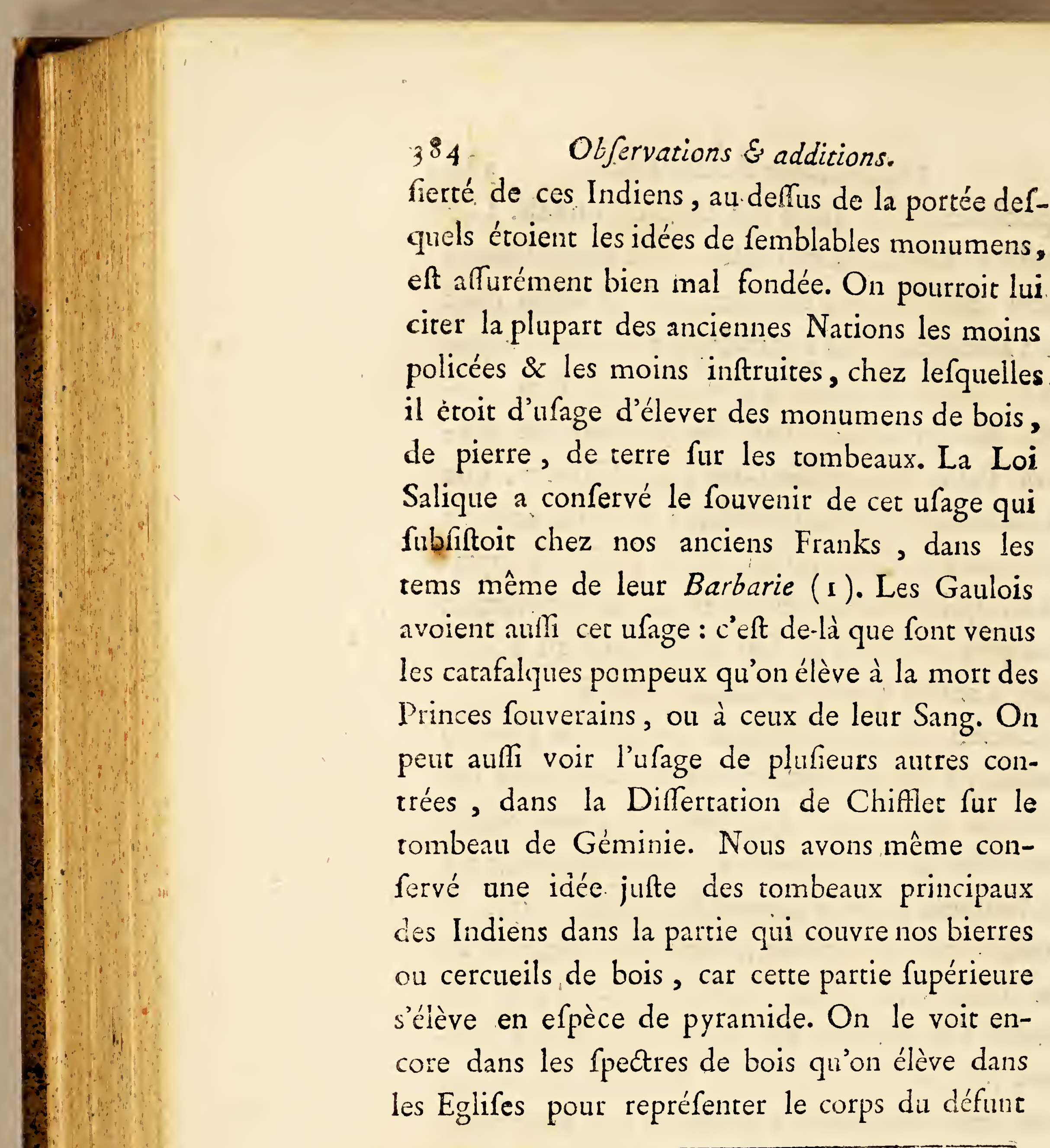

(1) Ces monumens étoient en pyramides, \& s'appelloient faples, ce qui fignifie encore un clocher dans les langues du Nord. Mais le mot ariftaton, qu'employe auffi la loi falique, expliqué en partie par Eccart, rappelle les mots arichten, ériger, \& toon, montre, théâtre. Ces crabeaux pyramidaux avoient done de la magnificence. 
Olfervations \& additions.

pour lequel on fait un Service. Mais ce grand nombre de pyramides ne paroî pas avoir été deftiné à être le fceau de la fépulture de ces Caciques, dir M. Schneider. Il devoir réfléchir que ces Peuples étant tous en très-petit nombre fous l'autorité de chaque Cacique, le nombre de ces Chetś devoit auffi être très-grand, par une règle inverfe : on en inhumoit donc fotivent. Quelle difficulté y a-t-il donc à croire que ces nombreux monumens aient fervi à décorer leurs tombeaux, puifque les tombeaux des Rois du Mexique étoient formellement dans des pyramides, \& ceux des Seigneurs dans des monticules, comme ceux des amans de Sémiramis. Quant à l'Egypte d'où l'on auroit pu avoir cet ufage, c'eft une autre circonftance qui tient au paffage des premières Colonies qui ont peuplé l'Amérique. Mais en fuppofant qu'elles y aient paffé de l'Afrique par les Ines Canaries nommées dans Prolémće, ou par celles du Cap-Verd, on n'auroit pais befoin de rétrograder dans l'Egypte même, pour trouver l'idée des pyramides. Il y en avoit un affez grand nombre en plufieurs parries de l'Afriqne, à une diftance confidérable de l'Egypte. Le refpect que toutes les anciennes Nations non dégradées avoient pour leurs morts, leur avoir fuggéré d'enterrer leurs 'parens de manière qu'on ignorât le lieı de leur fépulture, ou au moins qu'on le refTome II.

$\mathrm{B}$ b 
pectât à la faveur d'un figne qu'on y poloit. $\mathrm{C}$ e monument le plus durable étoit, fans contredit, une pierre droite fur le comble du tombeau. Les chambres des Géans du Nord en fone une autre preuve. On voulut auffi que les morts fuffent dépofés avec certain extérieur, \& alfez commodément. Molliter offa quiefcant, difoient les Latins ( 1). Si M. Schneider \& d'autres avoient des doutes fur les pyramides d'Afrique, différentes de celles de l'Egypte, ils confulteront la differtation que M. Paucton a publice fur celles de l'Egypte Or je demande aćluellement s'il faut fuppofer beaucoup d'idées dans ces Indiens, pour fuivre un urage qui tient à l'origine même de l'hommes ou moins à celle de la race gui habice aujourd'hui le globe; car jajoute on finiffant cet Arricle, que les pyramides fépulcrales étoient d'ufage en Grèce, en Afre, en Etrurie. Mais nous parlerons encore des tombeaux des Indiens ci-après.

( I) Aufi difoit-on des morts : ils dorment. Nos Franks obtinrent même, étant devenus Chréticns, la liberté d'inhumer leurs morts hors de l'enceinte des murs qu'ils habitoiene, afn d'y élever avec plus de facilité les mcnumens dont ils vouloient décorer leurs fépulcres : c’eft ce que nous apprend le Canon d'un Concile. Les Barbares dont parle Olivicr Noort, mettoient des coquilles trèsfines fous la tête de leurs morts, \& couvroient les tombcallx de grofics pierres pcintes en rouge. 


\section{Objervations \&ै additions:}

$\mathrm{Si}$ les raifons de M. Schneider avoient été bien fondées, je m’arrêterois à un pafrage de Bouguer quil cite, \& dans lequel cet habile Académicien croir, d'après la dépreffion ou l'abaiffement des terreins dont il parle, que ce que - Platon a dit de l'affaiffement de l'Atlantide, devient très-probable. Mais je dirai en paffant, que l'Atlantide de Platun étoit où períonne n'a voulu la reconnoître, quoique les dimenfions en aient été marquées fi precifément dans le Critias de ce Philofophe. On n'a pas du tout compris ce qu'il entend par Tyrrhenie, par Afie, par Colonnes d'Hcrcule, parce qu'on n'a pas fait attention au nombre des ftades quil lui dome en longueur \& en largeur, \& qui certainement ne font qu'une très-petite partie de l'érendue de l'Ine qu'on a fuppofée fin grande, \& en outre dans des contrées où il eft impoffible de reconnoître les pays voifins de l'Me dont il s'agiffoit. Mais aes pays fubfiftent encore, quoique l'I truite par un volcan qui eft éteint dans le lac qu'il a long-tems empefté de fes vapeurs; \& dont l'éruption a même une époque dans l'Hiftoire (i). Reprenons M. Schneider.

(I) Les recherches de ceux qui fe font occupés de cette Ine, ont prouvé ce que dit l'Auteur des proverbes Arabes, publiés par Erpenius : Les erreurs des favans font favantes; aịnf fachons-leur gré de leurs tentatives."

$\mathrm{B} \mathrm{b}_{2}$ 
L'Aureur nous parle de Guijos, on caillours. Il entend fans doute parler de ceux dont il a fait mention dans fon Voyage. La cointrée à Lima, dit-il, elt pierreufe \& fablomneufe, c'eftà-dire qu'elle confilté en pierres à feu, ou en une efpèce de cailloux (pedernalès ò chinos). On en rouve une fi grande quantité, qu'on ne voit prefque pas autre chofe: dans d'autres endroits, ce n'eft que du fable, un détritum de pierres, ou de la terre, ce qui rend même les chemins fort incommodes. Les endroits où ils font répandus, ont ordinairement une furface terrenfe d'un pied \& demi ou deux pieds de profondeur. Tour le deffous eft de pierre. Cetre circonfance, jointe à ce que ces pays font près de la mer, dont les bords ont auni un pareil fond, dome lieu de penfer que la mer a couvert autrefois ces endroits jufqu'à deux ou trois lienes dans les terres, 8 même plus dans quelques pa. rages. Cetre conjecture elt appuyée par ce quon remarque dans un golfe au Nord de Callao, à cinq lieues environ de-là, \& qúon appelle la Côte du Marquis. Selon toutes les apparences, la mer fe portoir encore, il y a peu d'années, à une demi-lieue plus avant qu'elle n'eft actuellement, \& une liene \& demie plus loin, le long des côtes. Mais depuis que ce golfe a ćté laillé à fec, \& rempli de pierres, la mer continue à fe re 
Obfervations \& additions:

tirer, \& le terrein fec prend plus d'étendue. Les roches qui s'avancent le plus fur les côtes, font en partie très-unies \& formées comme celles que l'ean baigne encore; c'eft fans doute une preuve que la mer a autrefois battu les autres, contre lefquelles elle eft venue fe brifer longzems, \& dont elle a rongé, \& entraîné de groffes maffes femblables à celles qu'on voit fur le fonds de terre. Il paroît donc aufili naturel de conclure la même chofe à l'égard de la contrée où eft Lima, \& que la mer l'ayant couverte autrefois, y a laiffé, en fe retirant, ces cailloux \& ces graviers femblables à ceux qu'on trouve fur le fond de la mer.

Quant à ces fortes de cailloux qu'on trouve dans les murs de cette contrée, notre Auteur avance quil y en a aufli de gros tas \& des maffes où ils font agglutinés enfemble par une matiere cornée d'un gris blanc, \& qu'il regarde aufli comme des preuves d'un déluge univerfel. (Cette affertion pourroit affurément être des plus mal fondées. M. Schneider pouvoir obferver ici que la pierrre cornée n'eft pas long-tems à fe former \& $\mathrm{a}$ le déliter pour revenir à $f_{a}$ premiere terre confiturive, lorfque l'acide qui l'a formée s'en fépare.) Il feroir à fouhaiter que l'Auteur eûr précifément déterminé le gifrement, la hauteur des monts où l'on trouve ces maffes, la nature de $\mathrm{Bb}$ z 


\section{Obfervacions \& additions.}

la pierre près de laquelle on les rencontre. Les maffes font probablement formées de différentes efpeces de pierres auxquelles D. Ulloa donne le nom général de cailloux, Guijos. Alonfo Barba donne le même nom à une efpece de pierre femblable au fable ou grais, \& qui tient de l'or, de l'argent, ou quelqu'autre mineral. L. I. c. I 3 .

L'Auteur faic en outre mention des bois pérrifiés qu'on trouve çà \& là fur les montagnes du Pérou. Il avance différentes conjectures affez fingulieres mêmes, \& qui recevront du jour des obfervations de Bouguer. D'ailleurs ce que dit celui-ci fur les diverfes efpèces de pierres de ces monts, mérite d'avoir place ici. Selon cet habile Voyageur, le marbre eft fort commun fur les rives de plufieurs des fleuves de ces contrées. On y voir aufi des roches de pierre feuilletée, \& fouvent il a ell occafion de remarquer la grande affinité qu’il y a entre ces deux efpèces de pierres. Il avoit déjà fait cetre obfervation dans les Cordillières, particulièrement aux environs d'Atapu, de Sula, \& avec fa compagnie à Senagoualap, Sachattian. Le marbre \& la pierre feuilletée s'y rencontrent fouvent enfemble. Quelques pierres font même feulletées par une extrénité, \& marbre de l'autre. Toutes les fois qu'mn nonveau fuc lapidifique, qui a de taffnité avec la pierre feuillecée, fe tronve a la 
Eencontre \& en lie les feuillets, toute la roche en devient extrêmement dure, \& il fe forme un marbre d'une pierre feuilletée. On remarque le même changement dans une pierre qui fe divife aufi par feuillet, \& que l'on appelle fchice. Outre que les feuillets fe joignent fimplement les uns aux autres, il s'unit auffi des morceaux de cette pierre par de purs hafards. S'ils viennent à-être pouffés par un Heuve fur un fable groffier ou des cailloux, \& arrondis par le frottement qui en détache les parties faillantes, ils prennent une forme cylindrique, enfin celle d'un tronc d'arbre, \& y reffemblent fi exactement, quil eft quelquefois difficile de les en diftinguer. Il a eu regret de n'avoir pu emporter un pareil morceau. C'étoit un morceau de marbre qui avoit vingt pouces de long fur dix-fept ou dix-huit de diametre. On auroit cru y reconnoître des fibres ligneufes. La furface préfentoit des nouds de différentes formes, \& toute la furface externe étoit réellement faite pour en impofer. D'un côté, il y avoit un enfoncement qui faifoit un angle rentrant, mais qui failloit de l'autre. Il ne favoit pas plus que ceux de la compagnie ce qu'il devoit en penfer, \& il lui fut impofible de rien déterminer avant d'avoir jetté les yeux fur un autre morceau de fchite qui fe trouvoit près de là, \& qui commençoit à prendre uné pareille forme, mais non

$\mathrm{B} \mathrm{b}_{4}$ 


\section{2}

Obfervations \& additions:

encore affez avancée pour en impofer à des yeux attentifs. Ce fut ce qui l'éclaira fur le morceau de marbre dont nous venons de parler.

Le gayac paroît être le bois le plus difpofé à la pétrification, felon les rapports qu'on lui a faits. On lui affura qu'au-deffus de Mompou, dans un village nommé Pueblo del Rey, il pourroit voir une croix dont la partie verticale fupérieure étoit encore de bois, tandis que le bas éroit réellement converti en véritable filex. Plufieurs perfonnes lui dirent en avoir tiré des étincelles; mais lorfqu'il fut fur les lieux, il apprit que cette croix, qui y avoit réellement été, avoit auffi, depnis fix ou fept ans, difparu dans une crue d'eau de la riviere.

Quant à ce qui regarde le marbre dont il s'agit dans Bouguer, il veut probablement parler du granir fur lequel étoit aflis de la pierre feuilletée, ou qui s'étoit totalement délité à fa furface, où il étoit devenu pierre fenilletée. Ce font les deux plus anciennes, les plus fortes, $\&$ les plus confidérables couches de pierres des principales montagnes de notre hémifphere, \& probablemelit auni de celles de l'Amérique. On peut voir à ce fujer les Lertres Minéralogiques de de Born, \& les Mémoires de Ferber, pour fervir à lHiftoire Minéralogique de la Bohême. $\mathrm{Ce}$ dernier fait mention de quelques blocs fem 


\section{Obfervations \& additions.}

blables à du bois, \& qu'on appelle dans les mines arbres du'déluge. Ces blocs font, felon quelques Ecrivains, une métamorphofe noire \& fibreufe du gris wake (ou de la roche grife.) D'autres les regardent réellement comme du bois pétrifié. On voit donc, par ces détails, qu’il faut avoir des yeux fingulièrement habitués à voir, pour déterminer précifément la nature de pareils corps. (J'ajouterai à ce que dit M. Schneider, que j'ai ćté plus fatisfait de ce que M. Gufmann dit du granit \& de fa formation journalière, que des hypothèfes $\&$ de de Born \& de Ferber. Leurs idées tiennent à des théories dénuées de fondement.)

On peut compter auffi parmi les monumens des anciennes époques, ces offemens d'une grandeur prodigieufe qu'on a tirés d'anciens tombeaux, \& fur la réalité defquels on ne peut douter, d'après les témoignages de gens dignes de foi. Selon les traditions des Indiens, ces offemens prodigieux viennent d'une race de géans qui abordèrent fur les côtes du Pérou, dans des barques ou canors de joncs, près la pointe de Sainte-Helène, \& qui fe fixèrent dans le voifinage. Ils allèguent comme des preuves de ce fait, certaines fources profondes qu'ils difent avoir été creufées dans les roches par ces géans. 
394 Obfervations \& additions:

On verra des détails circonftanciés à ce fujet dans Piedro de Ciez̧a de Leon, Acofta, Garc. de la Vega.

(M. Schneider auroit pu confirmer ces récits relatifs aux géans, par ce que rapporte Correal. Juan d'Helnofa, dit-il, Gouverneur de PortoRegio, faifant fouiller dans quelques endroits, on trouva des offemens d'hommes d'une grandeur prodigieufe. Les dents des mâchoires avoient trois doigts de large \& cinq de long. Waffer affure avoir vu à Mexico, pendant le Gouvernement du Duc d'Albuquerque, des os \& une dent d'une grandeur auffi furprenante. Mais ces geans feroient-ils venus en Amérique par les Canaries? car les Hiftoriens des conquêtes de ces Inles difent que les géans n'étoient pas rares parmi les Guanches. On trouva même chez eux féparément une tête d'homme d'une énorme groffeur, \& dont les mâchoires portoient quatre-vingt dents : le corps fut trouvé dans unne des fépultures des Rois, fi je m'en fouviens bien. Olivier Noort parle aufí du Peuple Tirimenen, quili a vu, \& dont les individus avoient dix à douze pieds de haut. Si les Colonnes qu'on fuppofe avoir écé élevées en Afrique par les Cananéens fugitifs étoient bien avérées, ne pourroit-on pas croire qu'une partie de ces Anakins, vis- 
Obfervations \& additions.

defquels les Ifraélites fe difoient des fauterelles, prit la ( $\mathrm{I}$ ) route de l'Afrique en fuyant Jofué qu'ils appelloient brigand, \&z paffa dans les Canaries, d'où quelques-uns furent jettés par un coup de vent dans les contrées du Midi de l'Amérique? Ces conjectures ne font pas dénuées de vraifemblance : ce qu'il y a de vrai, c'elt que l'ufage des barques ou canots de joncs étoient en ufage daris la plus haute antiquité fur les côtes de la Méditerranće : les Livres Hébreux l'atteftent. Je ne difimuleari cependant pas que les Auteurs cités qui atteftent avoir vu ces os énormes, n'avoient probablement pas les connoiffances anatomiques requifes pour les diftinguer d'os d'animaux, que les inondations quelconques ont $\mathrm{pu}$ engloutir \& laifer dans les lieux où on les a vus : l'erreur de Goropius a été celle de bien des gens; mais la têtê \& le corps du Géant Guanche n'admettent pas de doute fi les Auteurs du récit ont bien vu. )

On trouve encore, dit M. Schneider, dans plufieurs autres contrées de l'Amérique, des offemens qui ne peuvent venir d'aucune efpèce d'homme ou d'animal. (Il pouvoir citer particulièrement la Penfylvanie.) On peur confulter parmi les récits les plus nouveaux ceux de Falkner,

(1) D'autres ont eu cette idée avant moi, 


\section{$396 \quad$ Obfervations \& additions.}

Defcription du pays des Patagons. Robertfon 2 aufi réuni plufieurs témoignages à ce fujet dans fon Hiftoire de l'Amérique. Bergmann ne fera pas non plus inutile. Voyez fa Géographie Phyfique. Quant à $\mathrm{Paw}$, à qui il ne coûte rien d'affirmer les chofes les plus fauffes, ou de nier ce quilily a de plus avéré, il dit tout net que jamais on n'a déterré d'offemens humains de cette énorme grandeur, que cela eft même impoffible; il foutient au contraire que tous ces offemens font ceux de différentes efpèces d'animaux qui ont péri dans des inondations, ou par des révolutions extraordinaires arrivées dans ce continent. Mais il me femble qu'un homme qui penfe comme lui pourroit auffi facilement fuppofer une efpèce d'hommes femblables, que d'imaginer des efpèces d'animaux inconnus, qu'il extermine aufi-tôt par une cataftrophe quelconque. Il eft fans doure permis de douter; mais fuppofer que tant de témoins s'en font tous laiffé impofer, c'eft un orgueil qui n'eft pas le partage d'un homme vraiment inftruit. Mais fi certains offemens énormes qu'on trouve en Amérique, \& qui certainement appartiennent à des animaux inconnus, y ont été laiffés par les eaux du grand cataclyfme que Palv admet; pourquoi des offemens humains ne s'y feroient-ils pas confervés? Il y a des efpèces de terres où les fubftances animales une fois enter. 
rées, ne pourriffent jamais, à moins que la terre ne foit remuée, \& ne fe charge ainfi des agens deftructeurs dont l'air l'imprègne. Paffons aux Difcours XVII \& XVIII.

OBSERVATIONS \& Additions concernant les Indiens de l'Amérique Méridionale, leurs moeurs, leurs ufages.

Robertson compare la peinture que D. Ulloa nous a faite des traits caractériftiques des Indiens, avec celle qu'il a tirée d'un Manufcrit du Chevalier Pinto, qui s'exprime ainfi : "Ils font tous de couleur de cuivre, avec quelque différence dans les nuances : ces nuances ou ces ombres ne font pas en raifon de leur diftance de l'Equateur, mais de l'élévation plus ou moins confidérable des terreins qu'ils habitent. Ceux qui demeurent dans un pays élévé funt plus blancs que les habitans des bas terreins, \& répandus le long des côtes: ils ont la face ronde, plus différente de la forme ovale que celle d'aucun autre Peuple, le front étroit, le petit lobe de l'oreille éloigné du vifage, les lèvres épaiffes, le nez plat, les yeux noirs ou châtains, perits, mais perçans, \& la vue très-longue, les cheveux toujours épais \&: plats, fans jamais tendre à devenir crêpu; it 
n'ont aucun poil fur tout le corps, qu'à la tête:

Au premier alpect un Indien de l'Amérique Méridionale paroit d'un caraetère doux, \& non porté au mal: mais fi on l'examine mieux, on $y$ remarque quelque chofe de fauvage, de foupçonneux, de fombre \& de chagrin.

L'abfence cie la barbe \& la peau liffe du vifage de ces Indiens, dénotent un défaur de forces naturelles, qui vient fans donte d'une conftitution viciée depuis long-tems : cependant plufieurs anciens Voyageurs, \& tout récemment Carver; n'ont pas penfé de même; ils ont vu \& décrit des Nations barbares en Amérique, \& les ( I) infrumens avec lefquels ces Peuples avoient contume de s'arracher les poils de la barbe \& des autres parties du corps. C'eft pourquoi quelques Savans ont penfé que la Nature, violentée continuellement à cet égard, avoit fuivi forcément l'inclination \& le goût de ces Indiens, en formant enfin leur peau de manière à n'être plus velue où elle devroit l'être. Paw, qui n’a jamais ćtudié la Nature, s'eft élevé contré certe opinion, \& dans fes paradoxes il a foutenu que cela éroit impoffible: mais Blumembach a réfuté fes affertions, en produifant des exemples qui prouvent que la

( $:$ ) On en trouve la figure dans le T.XIII, p. 577 de l'Zintoire généraie des Voyages. 


\section{Objervations $\mathcal{E}$ additions:}

Nature, long-tems forcée, donne enfin aux corps Ia forme qu'on veut leur faire prendre. $V$. le $\mathrm{Ma}$ gafin de Gottingue, I. Vol. Vi $i^{\text {eme }}$ Cayer, p. 262.

Quant à la couleur des Indiens d'Amérique, ceux qui ont les premiers vu \& fréquenté le Nouveau-Monde, ont été étrangement furpris que les habitans de la Zone Torride n'y euffent pas la couleur noire de ceux qui font fous les mêmes parallèles dans les autres parties du Monde. On a attribué cette différence de couleur à plufieurs circonfances par lefquelles on a cru que l'effer de la chaleur étoit arrêté, \& ne pouvoit pas y produire fur la peau de cés Indiens la même noirceur que fur celle des Nègres. $M$. de Buffon produit dans fon Supplément, $T$. IV, $p .494$, une obfervation de M. Bruce, par laquelle on voit que la race des Nègres d'Afrique n'eft répandue que fur les côtes, c'eft-a-dire dans les baffes contrées de ce continent. Les Indiens qui font fous la ligne en Amérique habitent des pays où il y a beaucoup de montagnes, \& y font blancs: mais les grandes montagnes ne font pas expofées à des chaleurs exceflives; d'ailleurs il y pleut beaucoup en certaines faifons, ce qui rafrầchit l'air \& la terre, \& tempère l'ardeur du climat. M. de Buffon en conclut que la couleur des ivegrès n'elt dûe qu'à la trop grande chaleur de leur pays; il ajoute que comme on ne fent pas de fortes cha- 


\section{$400 \quad$ Objervacions E additions.}

leurs dans ces terreins, ni dans ceux qui font forc élevés au deffus du bord de la mer, il en réfulte que les habitans du Pérou \& ceux de l'intérieur de l'Afrique ne font pas noirs. M. Pallas paroît tenir pour la même opinion dans fon petit $\mathrm{Ou}-$ vrage fur les montagnes, \& les changemens du Globe terreftre. Il y dit : "dans l'Amérique, au contraire, où le continent a probablement été habité plus tard, un climat aufli chaud n'a pas encore pu produire autant d'effet que fur les Nègres, parce que les premiers hommes qui y pafsèrent, rencontrèrent une chaîne de montagnes du Midi au Nord, changèrent ainfi de climats fur ces monts, allant tantôt d'un côté, tantôt de l'autre, mêlant leurs races à plufieurs latitudes, \& furent moins affectés des effers de la Zone Torride. "Il y a du vrai \& du faux dans ce raifonnement de M. Pallas.

( Quant à la couleur des Nègres, je n'ignore pas les raifonnemens fpécieux qu’à faits Gumilla, \& qui certainement méritent attention; je fais aufi ce que le célèbre Chirurgien Lecat a écrit fur l'origine de cette couleur. Il a cru appercevoir dans le cerveau même \& dans le fluide nerveux, l'origine de ce mucus noir qui teint le peau des Nègres. Mais la caufe qu'en afligne M. de Buffon me paroît la plus viaifemblable, quoique peut-être la plus mal fondée. Ce qui fe palle 
Objervations \& additions.

paffe tous les jours fous nos yeux, femble prouver combien il a raifon d'attribuer cette couleur à l'action continuelle d'un air imprégné de molécules ignées. L'opinion de plufieurs Chymittes de nos jours, qui regardent la chaleur comme une vraie fubftance, \& non comme un mode ou manière d'être, appuieroit fon fentiment : en effet nous voyons que les corps foumis à l'action de particules ignées, en prennent une teinte plus ou moins rouge, ou brune, ou noire; mais voici ce à quoi l'on n'a pas fáit attention à ce fujer. D'où vient la couleur vermeille que prennent les fruits du côté où le foleil les frappe? Macquer auroit domné une réponfe très - fatisfaifante d'a près fes principes : c'eft que la lumière abondante dont ils font frappés fe fixe dans le tiflu de la peau jufqu'à la rendre pourprée. Dans certains fruits elle ne pénètre que la peau, dans d'autres elle en pénètre toute la fubftance, en s'y fixant, ce qui dépend dia tiffu plus ou moins propre à fubir cetre métamorphofe. Voila comment les molécules ignées, appliquées continícellement fur la peau des Nègres, ou des premiers habitans des côtes où fe trouvent les Nègres, a d'abord ćté brunie, \& enfuite totalement noircie, non promptement fans doute, mais après un tems confidérable. La Nature, ainf violentée par un effet continuel auquel rien n'apportoit de Tome II.

C c 
402 Objervations \& additions. modification, a enfin admis, dans le principe fpermatique même, ce qui dans l'origine n'étois que factice à la fuperficie, «z a développé peuà- peu à la peau de l'enfant Nègre ce principe hétérogène dont elle a cherché à fe débarraffer dans l'intérieur.

Mais voici une expérience que j’ai répété plufieurs fois fur des plantes de différente efpèce; je les ai mifes dans des endroits frais \& trèsobfcurs; leur conleur d'un verd très-foncé eft bientôr devenue ( 1 ) auffi blanche que l'albâtre: je les ai retirées; elles ont reverdi, mais avec langueur, parce que l'action de la lumière étant auffi néceffaire au développement de leurs parties organiques qu'à leurr couleur, leur tiffu n'en étant plus frappé, avoir été trop dérangé dans l'inaction où elles étoient reftées, ce qui prouve combien Hippocrate avoit raifon de regarder le feu ou le principe phofphorique, comme le grand mobile de la Nature : nous difons aujourd'hui que c'eft l'éther porté dans les corps par la vibration des rayons folaires. Mais parlons - nous plus jufte? Voilà au moins ce que je crois de plus direct pour faire fentir le vraifemblable de la réflexion de M. de Buffon. Suivons M. Schneider.

(1) Les plantes bulbeufes fur-tout font voir ce phénomène en très-peu de toms. 


\section{Obfervations $\mathcal{E}$ additions.}

Il faut encore obferver que la couleur cuivreufe des Indiens du Pérou admet différentes nuances, comme la teirite noire des Nègres de l'A frique; c'eft une obfervation que Bonguer a faite, ou plutôt qu’il répète après plufieurs autres. Il dit qu'il eft certain que cette couleur prefque cuivreufe des Indiens d'Amérique, \& qui leur eft naturelle, n’a été regardée que comme une différence accidentelle, \& non comme produites par les couleurs dont ils fe frottent; gu'il a remarqué que ceux qui habitent directement au pied des Cordillères, ou à l'Oueft, ou vers la mer du Sud, font prefque aufli blancs que nous; ceux-ci ne font pas fi expofés à une chaleur brîlante $\&$ continuelle, \& paffent leur vie dans un pays où l'atmofphère eft fil calme, que jamais on n'y fent la moindre agitation dans l'air : les monts les garantiffent des vents continuels de l'ER, qui paffent à plus d'une lieue pardeffis leur tête.

Si l'on s'éloigne plus des Cordillères pour aller vers les côtes, on n'ert plus dans le même rapport; on fent alors du vent, \& l'on retrouve des Indiens avec leur couleur de cuivre rouge. Mais quoique la cuuleur de la chair de ces Indiens blancs femble faire ceffer toute différence entre eux \& nous, on en voit cependant une effentielle, en ce qu'ils n'ont ni barbe, ni poils firr la poitrine, ni fur aucune autr e partie du corps:

$$
\mathrm{C} \mathrm{C}_{2}
$$


404 Objervations E additions:

d'ailleurs leur chevelure épaiffe, noire, eft totsjours platte \& pendante. Quand on accorderoir que la couleur des Indiens vient de la nature du climat, ou d'une forte action de l'air à l'impreffion duquel ils font toujours expofés par leur nudité, il eft cependant permis de préfumer que cela dépend aufi des antres circonftances qui font ici quelque différence.

Bayer remarque que les Chiriguans font auff blancs que les Européens, \& bien faits : leur pays touche d'un cốé à la Sierra, \& de l'autre au pays des Chiquitos. Il eft fâcheux que Bayer n'ait pas mieux déterminé les environs de leur local : on auroit pu en tirer des inductions au fujet de la difiérence de leur couleur. Le palfage de Bouguer fert auni à confirmer ce que dit notre Auteur fur la taille \& la forme extérieure \& générale de ces Indiens dans tous les climats: Robertfon a produit plufieurs témoignages qui prouvent ćgalement le fait.

Mais l'ufage de fe peindre le corps, de fe farder avec le cinabre, n'étoir pas chez les Péruviens aufi général que les Ecrivains Efpagnols le prétendent; au moins G. de la Vega les contredit-il. "Au refte, dit cet Auteur important, les hommes ne fe fervoient point de ce vermillon ni d'aucun autre fard. Je fais cette remarque contre certain Auteur, qui a avancé mal-à-propos 
Obfervations \& additions.

que les Incas \& les Indiens en général, lorfqu’ils alloient à la guterre, ou qu'ils folemnifoient leurs fêtes, fe peignoient le vifage de diverfes couleurs; il eft certain qu'il n'y avoit que quelques Nations particulières qui fe peigniffent ainfi le vifage pour paroitre plus farouches. "

Mais de la Vega ne veut peut-ĉtre pas parler ici de fe peindre par-tout le corps, \& ne l'entend que des figures qu'ils fe faifoient fur le vifage avec un art fort étudié. D. Ulloa nous dit que les Indiens du Pérou ont renoncé à l'ufage de fe peindre le corps depuis leur affujettifement; ils de faifoient donc auparavant. C'eft d'après cela qu'il faut entendre ce que dit Bouguer des Indiens en général : "Ils vont prefque tout nuds, à caufe de l'extrême chaleur; ils $\mathrm{fe}$ peignent généralement avec du rocou, \& cherchent en cela certain ornement particulier : mais au lieu de fe frotter par-tout, ils ne fe peignent que par raies, $\&$ même fur le vifage. Bouguer penfe que cet ufage eft venu de la néceffité de s'oindre ainfi le corps pour fe garantir des piqûures de certaines efpèces de mouches. ( C'eft fans doute dansice befoin que les onctions des Grecs \& des Romains ont pris leur origine. Sophocle voulant paroître nud pour danfer avec plus de liberté lorfqu'il étoit jemne, commença par fe frotter d'huile. Cette néceffiré devint donc un ufage prefque général chez toutes

$\mathrm{CC}_{3}$ 


\section{Obfervations \& additions:}

les Nations anciennes, \& enfuite on en fit un objet de luxe. Un Sauvage que l'on demandoit hors ce chez lui, répondit qu'il étoit nud, \& qu'il ne pouvoir pas paroître; fa femme ne l'avoit pas encore frotté : fon prétendu habillement étoit cette onction de graiffe. )

Mais Robertfon a allégué des raifons plus importantes \& en plus grand nombre que celle que donne Bouguer. Eft-il bién fondé? Paw a adopté l'opinion de Bouguer, \& en a fait l'ápplication aux ufages analogues des quatre parties du Monde; ce qui étoit connu fans fes commentaires.

Quelques Chirurgiens ont obfervé au Bréfil cette infenfibilité des Indiens, dont nous parle D. Ulloa : ils nous difent qu'un Indien fouffre l'amputation d'un bras oil d'une jambe fans jetter la moindre plainte. Malgré ces affertions, Robertfon penfe que cette fermeté des Indiens dans les plus cruelles douleurs ne vient pas d'une foible conftitution particulière à ces peuples, mais plutôt d'un point d'honneur ( 1 ) porté à l'excès qu'on

(I) Ces Peuples fauvages, qu'on croit fi méprifables, font, dit un Voyageur, les plus méprifans de tous les hommes; on voit même par les récits de notre Auteur qu'ils fe croyent une intelligence bien fupérieure à celle des Européens, ce qui ne vient que diun fond cxceflif d’orgueil. Mais l'infenfibilité apparente du Sauvage eft encore bien plus frappante dans les tourmens auxquels les 
Obfervations \& additions:

leur infpire dès l'enfance, comme la plus belle prérogative de l'homme, \& la plus belle qualité

prifonniers font réfervés. Pour donner une idée de ces horribles fcènes \& de la conftance incompréhenfible de ces barbares, voici un exemple qui peut fervir pour tous les cas imaginables. Un Capitaine de ces Nations ayant mieux aimé braver le péril que de fe déshonorer par une fuite honteufe, fur enfin enveloppé par le grand nombre de fes ennemis qui vouloient le prendre en vie pour aflouvir lẹur vengeance, \& en faire le plus bel ornement de leur victoire. La Bourgade où il fut conduit avoit quelques Mifionnaires, aux quels on laifia la liberté de l'entrtenir : ils le trouvèrent affez docile pour fe laifer baptifer. $P_{c u}$ de jours après il fut conduit au lieu du fupplice pour être brûlé avec fes compagnons. Sa conftance étonna les Sauvages mêmes. Comme il n'étoit pas lié, il fe crut en droit de faire à fes ennemis, malgré $f_{a}$ converfion, tout le mal dont il étoit capable. On l'avoit fait monter fur une efpèce de théâtre, où le feu lui fut appliquéà toutes les parties du corps par un fi grand nombre d'ennemis, qu'il ne put leur réfinter: mais il parut d'abord infenfible. Un de fes compagnons qu'on tourmentoit auprès de lui ayant donné quelques marques de foibleffe, il eut l'attention de l'animer à la pátience, \& fes exhortations le firent mourir en brave. Alors on retomba fur lui avec une fureur qui fembloit le mettre cn pièces. Il n'en parat pas ému, \& fes bourreaux étoient embarraffés de lui trouver quelqu'endroit fenfible, lorfqu'un d'eux s'avifa de lui cerner la peau du crâne, \& de l'arracher avec violence : la douleur le fit tomber fans connoiffance. On le crut mort, \& chacun fe retira. Un moment après il revint de cet évanouiffemzent, \&r ne voyant plus perfonae

$\mathrm{C}_{4}$ 
408 Obfervations \& additions.

d'un guerrier; quau contraire ils paroiffent dans les douleurs aufi fenfroles que les autres hommes,

autour de lui, il prit des deux mains un gros tifon de feu, rappella fes bourreaux, \& les défia d'approcher. Sa réfolution les furprit; ils poufsèrent des hurlemens, s'arnèrent, les uns de tifons ardens, "les autres de fers rongis ât feu, \& fondirent tous enfemble. Il les reçut avec me vigueur qui les fit reculer; le feu lui fervit de retranchement d'un côté, il s'en fit un autre avec les échelles dont on sétoit fervi pour monter fur l'échafaud; cantonné dans fon propre bûcher, il fut l'effroi d'une Bourgade entière : un faux pas qu'il fit pour éviter un tifon qui lui fut lancé, le fit retomber au pouvoir de l'ennemi, \& ces furieux lui firent payer bien cher la frayeur qu'il venoit de leur caufer. Après avoir épuifé leurs propres forces à le tourmenter, ils le jettèrent au milieu d'un grand brafier, \& l'y laifsèrent, dans l'opinion qu'il y. feroit bientôt étouffé. Ils furent trompés; lor qu'ils y penfoient le-moins, ils le virent defcendre de l'échafaud armé de tifons, \& courir vers le Village comme pour y mettre le feu. On fut glacé d'effroi, \& perfonne n'eut la hardieffe de fe préfenter à lui pour l'arrêter; mais, à quelques pas des premières cabanes, un bâton qu'on lui jetta de loin entre les jambes le fit tomber, \& l'on fur fur lui avane qu'il pût fe relever. On lui coupa d'abord les pieds \& les mains, on le roula fur des charbons embrafés, enfin on le wilt fous un trone darbre tout en feu : alors toute la Bourgade fit un cercle autour de lui pour le voir brûler; fon fang qui couloit de tontes parts éteignoit prefque le feu: mais on n'appréhendoir plus aucun effort du mourant. Cependant il en fit encore un dernier qui renouvella le 
dè̀s que ce motif puiffant ne fe trouve pas chez eux.

( Le reproche que leur fait notre Auteur fur leur lâche timidité eft rrop générale, \& ainfi mal fondée, au moins en grande partie. Les Conquérans du Mexique les ont vus braver le feu des armes \&r toutes nos rufes de guerre avec la plus grande intrépidité; les monceaux de corps morts ne les décourageoient pas, \& ils font revenus affez de fuis à la charge pour prouver à leurs Conquérans que s'ils avoient eu quelque taćtique, même avec

trouble; il fe traina fur les coudes \& les genoux avec une intrépidité \& un air menaçant qui écartèrent les płus proches, moins effrayés à la vérité qu’étonnés. Les Miffionnaires s'approchèrent de lui ; il écouta encore avec connoiffance leurs cxhortations, \& ne parut plus fonger à autre chofe qu'à mourir, \& bientôt on lui coupa la tête, que l'on jetta au feu.

Mais on n'en a pas moins obfervé que $f_{1}$ ces peuples bravent prefque tous avec une intrépidité incroyable les plus horribles fupplices, il eft parmi eux un affez grand nombre d'individus à qui les douleurs quelconques, pouffées à certain degré, font pouffer les cris les plus amers, lorfqu'une fois l'orgueil, la fuperftition, le défépoir, la vengeance ne font plus les motifs de leur confance. Toutes les Nations fauvages de l'Amérique fe reffemblent à cet égard : c'eft donc moins dans la durcté \& la denfité de leurs organes que dans ces caufes, qu'il faut chercher ceste infenfibilité. 
leurs foibles armes, jamais les Efpagnols n'auroient apporté en Europe la nouvelle de leurs conquêtes. Malgré la valeur plus qu'humaine de Cortez, il n'eut même pas ofé attaquer Mexico fi les Tlafcalans, ennemis jurés des Mexicains, n'éroient entrés dans fes vues; \& c'elt à ce peuple qu'il a dû tous fes fuccès, beaucoup plus qu’au courage de fes troupes.)

Les Indiens du Chili attendent leur ennemi en rafe campagne, \& en ordre de bataille régulier; ils attaquent avec valeur. En général ce font les plus courageux de tous les Américains. On peur voir les détails d'Ovalle, de Lorenzano dans Robertfon. L'Efpagne a toujours échoué contre les Peuples du Chaco. ( C'eft mal juger de ces Peuples, que de leur reprocher de la lâcheté devant des armes, aufi effrayantes que les nôtres pour toutes les Nations qui les ont vues la première fois, \& fur lefquelles elles affurent toujours l'avantage. L'Indien eft aujourd'hui fort timide fous le joug qu'il porte : peut-il être hardi fans armes? ou sil a intention de l'être dans l'un ou l'autre moment, n'eft-il pas arrêté par la crainte de la force majeure de l'ennemi contre lequel il ne peut avoir que des fuccès fans fuite. Mais l'Indien libre n'eft pas timide, puifqu'au moindre fujet il prend les armes, \& fair de l'infulte dun particulier la caufe de toute une Peuplade. 
Obfervations \& additions:

Sil prend la fuite dès qu'une fois un parti a enttamé l'armée de l'ennemi, il a une très-bonne raifon pour fe fauver; c'eft que la plupart de ces Peuples, ou égorgent fans pitié les prifonniers fur les autels de leurs Idoles, ou les mangent. Quelle armée Européenne ne fuiroir pas, étant une fois entamée, fi elle s'attendoit à un pareil (ort?)

Quelques Nations, dit notre Auteur, font dans l'ufage de fe percer les oreilles \& de fe les aggrandir, en y paffant des corps très-gros \& très-lourds. On aura à ce fujet des détails plus étendus dans le Voyage de notre Auteur, dans Gumilla, de la Condamine. Blumenbach a dit des chofes affez curieufes fur la forme de ces énormes oreilles dans le magafin de Gottingue; nous nous contentons de ces indications.

Quant aux mariages des Indiens de la province de Quito, \& au changement qu'ils font des femmes, on aura des détails fuffifans dans le Voyage de D. Ulloa : mais on fera plus fatisfait des remarques que Robertfon a faites fur la vie domertique des Indiens, \& fur le fort des femmes en Amérique.

(En général ces Peuples ont été peu attachés à leurs femmes, qu'ilstraitent encore tous comme des efclaves; aufi ne le fentent-elles que trop: il y a même des Nations chez lefquelles deux 
412

Objervations \& additions:

vieilles femmes accompagnent la future époufe le jour de fon mariage, en pleurant réellement; fe lamentant, \& lui criant fans ceffe : ma fille, que vas-tu faire, tu vas te précipiter dans le plus grand des malizeur. C'elt cer état affreux qui les décide très-fouvent à étouffer leurs filles en naiffant, pour leur éviter d'être aufli malheureufes qu'elles. Quoique l'adultère y foit puni, même en quelques endroits par la mort de la femme, cetre loi n'elt favorable qu'aú mari qui defire prendre une ou plufieursautres femmes, ou jouir où bon lui femble avec les filles qui la plupart ont une pleine liberté avant de fe marier. La fatigueque les jeunes femmes ont ì efluyer, groffes ou non, pour fuivre leurs maris à la chaffe, à la pêche, préparer le boire \& le manger, avoir foin des enfans, dont le père ne s'inquiète guère, $\&$ autres malheureufes circonltances, font de l'état du mariage, chez la plupart de ces Nations, un état affreux, quand on penfe que la femme eft née pour faire les délices de l'homme, \& que l'homme ent né pour lui rrouver à vivre. Il y a cependant quelgues Nations où les pères aiment leurs enfans mâles; mais cette amitié eft moins fondée fur une tendreffe naturelle que fur le befoin que la Nation a d'individus mâles. C'étoir ce principe qui guidoir un Indien, à qui un Prélat Efpagnol repréfentoit le défordre de 
la polygamie. “Je ne puis, dit-il à l'Evếque, avoir alfez d'enfans avec une femme. "Le ta bleau que Gumilla feul nous préfente de l'état des femmes chez les Peuples où il a été pendant nombre d'années, eft bien capable de faire gémir une ame fenfible, lorfqu'il voit l'efpèce humaine dégradée à ce point; \& cependant elle l'eft encore moins là que dans d'autres parties du Globe.)

La manière dont les Indiens cultivent les champs en commun au Pérou, l'art d'arrofer \& de fertilifer les terres par des canaux, \& de les fumer, font des inftitutions dont ils font redevables aux Incas. Ces Princes avoient établi ces ufages conformément au génie de leurs fujets. Les Efpagnols les ont fagement maintenus; d'ailleurs on ne pouvoit imaginer rien de mieux que ces Chacos, ou Communautés de travail. Herrera (Decad. V, Liv. IV.c. 2.) \& de la Vega' (Liv.

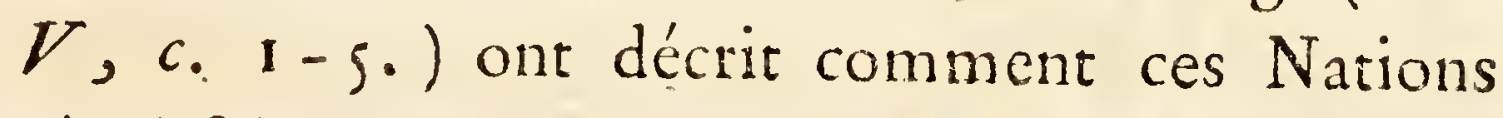
réuniffoient leurs forces, lears chanfons, leur mufique, pour s'occuper des travaux de l'agriculture. D. Ulloa a fait connoîre dans fon Voyzge ce qui concerne leurs canaux.

On fume les terres avec les excrémens humains dans les plars-pays de Cuzco \& dans ceux des montagines. Mais fur toure la côte de la mer, depuis Arequequa jufqu'a Tarapaca, on fume avec la fienre d'une efpèce d'oifeaux de mer qui 
414 Obfervations \& additions.

fe tiement dans une ifle déferre, \& qui n'en eft pas éloignée. Dans d'autres contrées, comme d̀ Malla, Chilca, Atica, Atitipa, Villacori, on emploie, pour fumer, les têtes des fardines. On peut voir fur cet objet Acofta, Liv. IV; de la Vega, Liv. $V$; le Voyage de notre Auteur, \& Frćzier. Les oifeaux que notre Auteur appelle Guanaès viennent fur ces côtes, pour prendre une efpèce d'harengs ou d'anchois, qui fe trouvent en immenfe quantite fur les côtes des environs de Lima.

Quant aux mitas ou corvées que les Indiens font obligés de faire pour les travaux des fabriques de Quito, outre celles qu'on exige d'eux pour les mines, D. Ulloa s'eft étendu à ce fujet dans fon Voyage; mais on n'y lit pas les plaintes qu'il préfente dans cer Ouvrage-ci fur les mauvais traitemens qu'on fait effuyer aux Indiens, malgré les Ordonnances précifes des Rois d'Efpagne. (J'ajouterai que, d'après d'autres Voyageurs, ces plaintes ne font que trop bien fondées. On peut voir ce que Corréal avoir détaillé à ce futjet, \& le portrait quil fait de la conduite de fes compatriores en Amérique. Ce morceau eft dans Prévôt, d'une éloquenee digne des D'́mofthène \& des Cicéron. Je fouhaite avec fincérité que ce tableau, qui ne préfente affurément pas les vues du Gouvernement, fe trouve faux au- 
Objervaîions E additions:

jourd'hui; car il eft affreux, fur-tout fait par un Efpagnol. Voyez Hiftoire Générale des Voyages, Tom. XII, pag. , $82-587$.

OBSERVATIONS \& Additions fur la Religion des Indiens.

I f faut revoir, au dix-neuvième Difcours de notre Auteur, ce qu'il a dit à ce fujet dans difrens paffages de cer Ouvrage, On remarquera enfuite, dans le vingtième Difcours, que le culte du Dieu Pachacamac, \& le temple qui y étoit deftiné, fubfiftoient déja dans la Vallée avant que les Incas fe foumiffent cette contrée. Il faut donc attribuer la conftuction de re temple à Cuifmann qui régnoit dans cette contrée, ou à fes ancêtres. Mais quant à la grandeur, l'ordre \& la fructure de l'édifice, tel qu'il a enfuite exifté, tout y étant femblable aux autres bâtimens \& monumens que les Incas ont fait élever, il y a lieu de croire que le temple dont on voit encore les ruines, a été au moins aggrandi par les Incas, s'il n'a pas été bâti de nouveau.

Les Incas rendoient hommage à Pachacamac; comme au premier \& au plus grand des Dieux; mais cet hommage n'étoit qu'intérieur. Ils rendoient au contraire un culte extérieur \& public 


\section{Obfervations \& additions.}

au Soleil \& à la Lune, dont ils éprouvoient rous les jours les influences bienfairantes. D. Ulloa explique ce mot par le Dieu Juprême, invifible, inconnu, ou le Créaciur. C'eft ce qu'il répètề encore dans le vingt-unième Chapitre, où il ajoute que les Péruviens, préfentoient des offrandes en actions de graces, mais fans avoir d'objer fenfible de leur hommage, ou autrément fans avoir dans leur temple aucune repréfentation du Soleil; qu'on n'y trouvoit que des peintures on images imitées de figures informes \& fort laides des nations Indiennes.

Garcilaffo de la Vega explique le mot Pachacamac par l'ame du monde, prenant ce mot de Pacha monde, \& de Camac, participe préfent du verbe Camar ou Camor, animer, doriner vie.

C'elt-là, dir-il, le vrai fens de ce mor compofé. On pourroit trouver l'analogue \& peut-être le même dans les langues de l'Orient; car le mot Bach, dans un de ces dialectes, fignifie une totalité, une grande réunion de chofes. Les Latins rendoient cette idée par compages, en parlant du monde: nous difons l'univers. Le mor cama, anmar ou charnar, fignifie, dans ces dialectes, former, faire fermenter, échauffer. Mais c'elt en vain chercher du jour dans une nuit aufí obfcure. L'explication de Garc. de la Vega revient à l'idée dées Anciens: Mens agitat molem, \& magno fe corpore 
Observations \& additions. mifcet, dir Virgile. En ce cas, cette idée n’auroir rien de bien remarquable. Cicéron raifonnoit mieux lorfqu'il difoir dans fon Timée, dont il nous refte quelque chofe, celui qui écoit (is qui erat) a répandu dans toute la nature cet efprit ou certe force qui l'anime. La divinité pa. roît dans ce paffage; \& l'on ne voit, dans le fens de la Vega, que le Dien de Pline, natura potentia, ou certe force énergique de Virgile, mais qui n'eft pas la Divinité. Les Incas n'avoient donc aucune idée de Dieu. C'eft donc bien gratuitement qu'on la fuppofe chez ces Princes.

Acofta, Liv. D, chap. 4, nous préínte la Divinité connue au Pérou, fous le nom de $V i$ racocha: mais $G$. de la Vega a fuffínment réfuté cette dénomination mal fondée, $L . X I$, ch. I, 6. Il convient que les Indiens n'avoient bâti fous Cuifmann qu'un temple à la Divinizé, où ils lui rendoient leurs hommages. Cependant il prétend que la connoiffance de certe Divinité ne leur eft venue que des Incas, par la tradition qui s'en répandit.

A quatre lienes de Pachacamac, on rencontre la vallée de Rimac, mot qui, dit-o,n, fignifie celui qui parle là. $\mathrm{L}_{a}$ dénomination de certe vallée eft venue d'un temple qui y étoit, \& où l'on adoroit une idole fous forme humaine : on alloit auffi la confulter comme les Grecs alloient Tome 11 .

$\mathrm{D} d$ 
demander avis à leurs oracles, \& les If́aćlizes

à leurs Voyans ou Prophères.

Quant aux repréfentations fenfibles du Soleil, que D. Ulloa dit formellement n'avoir jamais exifté au Pérou, voici ce que G. de la Vega dir du temple de Cuzco. "Sur le grand autel on voyuir la. figure du Soleil, faite de même fur une plaque d'or plus maffive du doublè que les autres. Cetre figure, qui étoir toute d'une pièce, avoit le vifage rond, environné de rayons \& de flammes, de la même manière que les Peintres ont accoutumé de la repréfenter. Elle éroit fr grande, qu'elle s'érendoit prefque d'une muraille à l'aurre, où l'on ne voyoir que cette feule idole, parce que les Indiens n'en avoient point d'autres, ni dans ce temple ni ailleurs, \& quils n'adoroient point d'autres Dieux que le Soleil, quoiqu'en difent quelques Auteurs ". Miais Acolta parle encore de trois flarues du Soleil \& du Tonnerre. Ces deux Hiftoriens, qui étoient plus près du tems de la conquête que D. Ulloa, peuvent avoir été mieux inftuits : ou il faut convenir que l'hifoire de ces révolutions mérice bien pen d'attencion.

Ce que l'Autent nous dit du culte fuperfirieux actuel ou de la religion que fuivent les Indiens foumis du Pérou \& de leurs Mochaderos, feroit croire qu'il n'a pas bien examiné. 
Obfervations \& additions.

cet objet, \& qu'il a, fans le favoir, donné une fauffe idée d'une partie de leur ancien culte auquel ils reviennent tonjours autant qu'il leur eft poffible. Je ne puis juger de la dérivation plus ou moins exacte que l'Auteur nous donne du mot mochaderos, qui, dit-il, vient peut-être de muchar qui fignifie baifer. Cependant voici un autre mot pris de la langue de la province de Tarama au Pérou, \& qui probablement eft la racine de mochaderos. De Laët nous produit, d'après Pedro de Cieza, le mot mocha qui fignifie Soleil.

(M. Schneider devoit donc achever, \& demander fi ces mochaderos, où les Indiens vont encore adorer fur les montagnes, ne feroient pas relatifs an culte du Soleil. On fait que les Ifraélites idolâtres alloient, comme les autres peuples qui les environnoient, adorer le Soleil ( 1 ) ou Bahal fur les montagnes. Or, cer attache des Indiens pour le culte de cet aftre, prouve une idée bien anciennie \& bien gẹ́nérale dans l'efprit d'une nation. Les Carchaginois, qui adoroient le Soleil fous le nom de Saturne, comme les Phéniciens fous celúi d'Hercule, étoient pareillement $f i$ attachés à ce culte, qu'un traité formel, qui les obligeoir à ne plus immoler des victimes

(I) Voyez le Liv. IV. des Rois felon la Vulgate, chap. 22, 23.

$D d 2$ 
620

Obfervations \& additions.

humaines à cet aftre, ne put le leur faire oublier, $\&$ ils recommencèrent leurs facrifices horribles. Il en eft de même, quant au culte, parmi les Indiens du Pérou, \& dans d'autres contrèes de l'Amérique, où ce culte fut prefque généralement accompagné de facrifices humains. ERt-jl venu de l'Afie? Cela doit être, foir directement, foit indirectement) ( $\mathrm{I}$ ).

Quant à la comparaifon que fait D. Ulloa des tas de pierres des Indiens avec les Mercures de l'antiquité de nos continens, c'eft un article fur lequel Acohta peut jetter un grand jour. " Les Indiens, dit Acofta, Liv. IV , ch.s, rendent des hommages aux fources, aux fleuves, aux vallées, aux rochers, aux groffes pierres, aux monticules, aux cimes des montagnes quils appellent Apachitas, ubjers qui leur paroifrent dignes de leur adoration. En un mot, ils adorent tout ce qui leur frappe les yeux \& l'imagination, comme sils y reconnuiffoient une divinité particuliète. On me montra près de Caxamalca, un monticule affez grand formé de fable, qui avoir éré un principal lieu de fépulture

(I) On fait qu'à l'origine même de Rome Tatius fit bâtir un Temple au Soleil. En Crête, en Arcadie, en Perfe, en Egypte, \&c., le Soleil avoit fon culte \& fes prêrires. 
du tens des anciens Indiens. Demandant ce qu' il y avoit donc là de divin, ces gens me répondirent : “ $\mathrm{La}$ merveille de voir ce mont de fable " au milieu des autres qui font de picrre ". Ce mont méritoir en effer beaucoup d'attention. 'Ils adorent aufin les ours, les tigres, les lions, les ferpens, afin qu'ils ne leur faffent pas de mal ". “ C'eft d'après ces rapports de leurs Dieux qu'ils fe règlent dans le culte qu'ils leur rendent; \& qu'ils en choififfent les offrandes. Sils fe mettent en route, ils ont coutume de jetter aux chemins qui fe croifent, fur les côteaux, \& furtout à la cime des montagnes, qu'ils appellent Apachitas, de vieilles fandales, des plumes, de la coca mâchée; \& s'ils n'ont rien, ils jettent au moins une pierre. Toutes ces chofes font autant d'offrandes qu'ils font pour obtenir de la force \& un heureux voyage. Voilà pourquoi l'on trouve fur les chemins de ces contrées de gros tas de pierres, qu'ils ont ainfi accumulées, \& des autres chofes que nous venons de citer. " *

"Les Anciens préfentoient auffi de femblables homñages à leur: Metcure; en jettant des pierres dans les carrefours ou chemins croifés : ils les appelloient des Hermès, ou Hermakès, c'eft-ìdire, des Mercures. On troivera fans doute aufin fingulière l'offrande qu'ils font de leurs fourcils, des cils quilis préfentent au foleil, aux côteaux,

$$
\mathrm{Dd}_{3} \text {. }
$$


422

\section{Objervations \& additions:}

aux apachites, aux vents, \& à d'autres objets qu'ils craignent.

(Il n'y a fans doute rien qui étonne dans la condurte de ces Indiens, lorfqu'on voit les Romains élever des autels à une divinité cacatoire. Qu'on juge de-là combien il devoit y avoir chez eux de Dieux différens depuis leur Jupiter altitonans jufqu'à une femblable divinité. Tout étoit érigé en divinité chez ces conquérans de l'univers, les vices comme les vertus, \& l'ordure comme l'aftre du jour. A peine avoient-ils conquis un pays qu'ils en confacroient chez eux les cultes religieux, quelqu'abfurdes qu'ils fuffent: ainfi, quand Athénée nous dit qu'on retrouvoit de fon tems à Rome toutes les villes de la terre, il avoit raifon, ne fut-ce qu'à cet égard. Les Dieux des pays conquis du Pérou étoient aufi transférés à Cuzco.

M. Schneider devoit dire ici quelque chofe de l'origine de ces Mercures, ou tats de pierres connus dans l'auriquité de nos continens. Il en eft formellement parlé dans les proverbes de Salomon; c'elt la plus ancienne date qui. en exifte: mais les Kuébreux tenoient cet ufage de plus loin. Ce qui fe pratique encore chez les Sauvages de l'Amérique, lorfqu'ils veulent retrouver leur chemin, montre que c’eft la néceflité qui y a donné lieu: ces gens, qui font quelquefois des courfes 


\section{Obfervations \& additions:}

très-longues dans des forêts où jamais perfonne n'a paffé avant eux, abattent, chemin faifant, des branches d'arbres, qui font autan̨t d'indices de la route qu'ils ont tenue, quelquefois même ils placent des pierres par intervalle. Les premiers hommes qui avoient à parcourir une terre où il n'y avoit aucun fentier, fur tout dans les montagnes, avoient pareillement foin de ramaffer des pierres qu'ils jettoient par intervalles, ou ils en élevoient de groffes; les chemins ayant été enfuire plus fréquentés, les tas de pierres y groffirent. On faifoit auffi des vœux à Mercure; angelus, ou guide, comme ces Indiens, pour avoir un henretix voyage : de-là l'origine de la fuperftition, dont ces pierres font devenues les objets. D'une idée abfurde l'efprit humain une fois égaré, donne bientôt dans une autre, \& ces tas de pierres devinrent enfuite le Dieu conducteir que chacun mit même devant fa maifon. Nous voyons qu'il $y$ en avoit à Athènes, nonfeulement dans toutes les rues, mais même devant les portes de nombre de citoyens. L'Hiftoire ne permet pas d'en douter, lorfqu'elle nous dit que tel jour on trouva que les Mercures de tels \& tels avoient été renverfés pendant la nuit. Les Mercures ou pierres qu'oin plaçoir aux chemins croifés dans les campagnes, \& qui indiquèrent les différentes routes, avoient le furnom de trivius,

$\mathrm{Dd}_{4}$ 


\section{Obfervations \& additions:}

quadrivius, \&c., felon le nombre des chemins qui 1e rencontroient. Mercure conduifoit auffi tantôt les Múfes, tantôt les Graces, \&' ce fut lui qui mena les trois Dé effes nues devant le Berger Pâris, pour y être jugées fur le mérite de leurs charmes. Les Romains, maîtres d'une graride partie de l'Ancien-Monde connu, fuppléèrent à ces pierres brutes par les bornes quilils placèrent à des diftances régulières, \& nous les avons imités, fans penfer que nous avons rappelié les Mercures de l'antiquité, ou ces pierres quarrées qu'on plantoir fur les routes: Telle eft la plus faine idée qu'on puiffe fe former de ces tas de pierres; \& des Hemakès de l'antiquité; ainfi je ne m'arrêterai pas à réfuter les fentimens que d'autres ont eus fur leur origine: mais, quelles que puifent être les vues de ces Indiens, jai bien de la peine à foupconner même qu'il y ait quelque rápport - entre les idées de ces tas de pierres, \& celles que les Grecs avoient des leurs.)

L'explication que donne Acofta, dit M.Schn., ent contredite par les dérails que préfente G. de la Vegaj comme fon paflage jetre du jour fur ce que dit notre Aureur, le voici : "Poulr expli" quer le terme apachitas, que les Efpagnols "atrribuent aux ertres élevés, \& quills, font "parter pour les Dieux des Indiens, il faut fa"voir qu'apachec eft un participe du tems préfent 


\section{Obfervations \& additions:}

" qui frgnifie celut qui fait fupporter, fans dire " ni quoi, ni qui il eft, \& ce participe fait an " génitif arachecpa, \& aul datif apachecta; de

". forte qu'à prendre ce mot fuivant la manière ") commune de parler des Indiens, c'étoir la même " chofe que s'ils avoient dit : rendons de trèsb) humbles hations de graces a celui qui nous ddonne autant de vigueur quilil nous en faut " pour monter jufqu'au fommer de ces lieux $\mathrm{ft}$ is élevés \& fi raboteux, paroles quils n'em3) ployoient jarnais qu'après avoir gagné le haut w de la colline; ce qui a fait croire aux Hifto2.3. riens Efpagnols quils en appelioient le fommer 3) apachitas. Mais toutes les fois que les. Indiens " éclairés de la lumière naturelle ufoient de ces ') termes, leur intention étoit de montrer qu'ils (s) devoient rendre graces \& faire quelque offrande " ̀̀ Pachacamac, ou au Dieu inconnu qu'ils ado"roient mentalement, pour les avoir aidés à " furmonter certe farigue. Aufin lorfqu'ils étoient "arrivés au fommet de la colline, ils pofoient " leur fardeau, s'ils en avoient, \&zaprès avoir " élévé les yeux au ciel, ils les baiffoient vers " la terre, \& ils donnoient les mêmes marques "d'adoration quilis avoient accoutumé de pra" tiquer à l'égard de Pachacamac. Outre cela, ils " répétoient deux ou trois fois le datif apachecta; " enfuice, par une efpèce doffrande, ils fe ti- 
"roient le poil des fourcils, \&, foit qu'ils en " arrachaffent on non, ils fouffloient en l'air,

" comme s'ils les eufient voulu envoyer au ciel:

. ils prenoient auffi dans la bouche d'une hicrbe 's) qu'ils eftiment beancoup, appellée coca, qu'ils

" jettoient aufi en l'air, comme pour dire qu'ils " offroient à Pachacamac ce quils avoient de " plus précieux. Leurs fuperftitions alloient même " jufqu’à hii offrir de petits éclats de bois, ou " des pailles, sils ne trouvoient rien de meil" leur, ou bien quelque caillou, \& à faute de "s cela, une poignée de terre. On voyoit même " de ces grands monceaux fur le fommer des " collines. Quanả ils faifoient ces cérémonies ils "ne regardoient jamais le Soleil, parce que ce "n'étoir pas à lui, mais à Pachacamac, que leur "adoration s'adreffoit. Je parle comme témoin " oculaire, \& pour avoir été plufieurs fois avec " eux en pareille occafion. "

L'explication que donne ici G. de la Vega fur les ufages finguliers des Indiens, \& qui fe retrouvent en partie chez d'autres Nations groflières du Globe, paroît aufli empruntée que ce culte intérieur par lequel il prétend, comme D. Ulloa, diftinguer Pachacamac du Soleil. Paw dit tout fimplement que Pachacamac \& le Soleil n'étoient qu'un même objet pour ces. Peuples : c'eft ce que je laifre à décider à d'autres. 
Obfervations \& additions:

( $L a$ queftion n'eft pas fi difficile à décider. De quelque objet.que l'on puiffe parler à ces Indiens, ils ne connoiffent rien de comparable au Soleil : c'elt à ce terme qu'ils reviemnent toujours dans leurs difcours, lorfquilils veulent défigner quelque chofe de grand, de majeftueux, de fublime. Leurs Princes fe difoient fils du Soleil, comme les anciens Rois de l'Orient: tout le culte extérieur étoir rapporté au Soleil ; tontes les idées d'adoration tournées vers ce feul objer: c'étoir-là le miroir dans lequel on leur faifoit voir la divinité, \& fans autre cérémonie impofante, que le facrifice de quelques animaux, s'il eft vrai qu'on n'immolât point de victimes humaines au Pérout. Jamais leurs Prêtres n'étoient occupés à leur donner d'infructions relatives à aucun autre objet; comment donc prétendre qu'ils en aient eu une idée, \& fur-tout une idée auffi méraphyfique que celle d'un Être diftingué de tous les êtres créés? L'état de leur ignorance, \& les bornes actuelles de leur efprit, dans lequel it eft impolfible d'imprimer l'idée de la divinité telle qu'on veut qu'ils l'aient connue, montrent fuffifamment qu'ils n'ont jamais eu cette idée. De la Vega en prouvant trop, n'a rien prouvé, \& Paw a ine fois raifon, en foutenant que Pachacamac \& le Soleil n'étoient qu'un pour ces Peuples. Les offrandes 
quils faifoient fur les cimes des montagnes étoient 'un. refte de l'ufage des Nations primitives, qui ayant toujours habité des éminences, y rendoient leurs hommages au Dieu qu'elles recommoiffoient. En defcendant peu-à-peu dans les plaines, 'elles n'ont pas perdu de vue ces lieux élévés confacrés au culte qu'elles rendoient; \& c'eft : fur-tout dans les montagnes qu'elles ont continué leurs hommages \& leurs offrandes. D'ailleurs, tout culte fuppofant néceffairement quelque chofe de grave \& de relevé, on a préféré ces lieux, où l'on fe croyoir plus près de la divinité, \& dont la retraite infpiroit une crainte religieufe. Quclques hommes plus hardis que les autres, osèrent $f e$ dire infpirés par le Dieu qu'on adoroit. La fourberie étoit intéreffée à cacher fes rufes \& fes ftratagêmes : où pouvoit-elle mieux le faire que fur ces éminences, dans des bois épais, des antres ? L'igo. rance autorifa des miniftres de la divinité; lidole eut fon Prêtre; le culte fe perpétua ainfi; \& voila l'origine des plus grands maux de l'humanité. Homme cruel, qui as ofé le premier te dire infpiré, que n'es-tu à jamais refté dans le néant! ou que ne puifies-tu voir le fang que tu as fait couler! tu offrirois peut - être le tien pour expier tant de crimes! Mais cet ufage d'adorer un Dieu quelconque fur les montagnes; 
Obfervations \& additions.

prouve la haute antiquité des Nations du Pérou. )

Robettfon, dit M. Schneider, a montré quelles devoient être les fuites du culte du Soleil, $\&$ fon influence fur la forme du Gouvernement \& les mour des habitans. Mais je remarquerai en paffant, contre Robertfon, qu'il eft faux qu'il n'y ait pas eu dans la Langue Péruviennne un nom propre pour défigner l'Être fusprême, \& que ces Indiens ne fe foient pas repréfenté cet $\hat{E} t r e$ comme le Créateur \& le fouverain Maître de l'Univers. Acofta convient qu'il n'y a pas de nom propre comme Theos, Deus, Dieu; \&rc. pour défigner la Divinité; mais il foutient que l'on reconuoiffoit au Pérou Viracocha conme le Maîre fuprême, le Créateur de tout, \& qu'on lui donnoir le nom majeftueux de Pachacamac, on Pachayachachic, c'eft-à-dire Créateur du Ciel \& de la Terre. Ainfr, quoique les Péruviens n'euffent pas de nom propre \& fimple, ils en employoient un compofé pour exprimer leur idée. Je voudrois que Robertfon eût fait attention à cela, \& qu'il fe fût expliqué fur le culte intérieur de ce Dieu étranger, qu'on avoit adopté dans ces contrées.

( Ces réflexions de M. Schneider font affez fingulières dans un homme auffi inftruit que lui. Il a déjà produit G. de la Vega, pour prouver 
$4 ; 0$

Obfervations \& additions.

que le nom de Viracocha n'étoit pas celui de la Divinité au Pérou. Il eft d'ailleurs prouvé par l'hiftoire vraie ou faufe, que les Rois de cette contrée prenoient ce nom; mais on fait aufli que Pachacamac éroit le nom de l'idole que Cuifman avoit placée dans le temple de lá vallée où fes peuples l'adoroient. Qu'on donne le fens qu'on voudra à ce mot, il eft conftant que c'éroir celui d'une idole : le peuple aufi ignorant, \& même encore plus que le rôtre ne lentans les campagnes, ne portoit pas fes idées plus loin. C'étoir cette idole qui avoit créé le Ciel \& la Terre, ii tel eft le fens du mot Pachacammac. En vain veut - on faire de ce Peuple une république de Philofophes: nous devons le juger par le nôtre, \& par ce qu'eft le periple fur toute la furface de la terre, lorfqu'il n'a qu'un fpectre pour s'inftuire, \& qu'on lui préfente en lui difant comme Roboam aux Juifs : Ifraël, voilà ton Dieu. Ainfi l'on peut affurer fans" rifque, que les temples bâtis au. Soleil chez les Incas, \& celui de Cuifman c' l'honneur de: l'idule Pachacamac, n'étoient rotifs quà un feul \& même objet: d'ailleurs étoite avoir vraiment une idée abrtaite de la Divinité, que de remercier le Soleil des bienfaits que la Divinicé feule accordoit par le moyen de cet antre nécellité dans fes opérations. 
Tout ce qu'on peut conclure des récits des Hiftoriens du tems de la conquête, c'eft que le merveilleux, ou plutôt l'enthoufiafme, les a guidés plus que les connoiffances qu'ils avoient de la vérité. On s'eft d'abord plus occupé de pofféder l'or du pays, que d'en connoître les Dieux, \& ceux qui ont écrit, l'ont fait quand les monumens qui pouvoient inftuire, avoient été dérruits, \& les Prêtres égorgés: ou voulant rendre leurs écrits plus curieux, ils ont mêlé avec quelques faits pofitifs, tout ce quils croyoient pouvoir lier le peu de connoiffance qu'ils avoient de la Religion de ces contrées. D'ailleurs la langue leur étoit inconnue, \& ce n'eft pas en peut de tems qu'on vient à bout de polféder le fyrtême religieux \& politique d'une contrée fur-tout auffi étrange que celle-là devoit l'être pour eux. Cette vérité eft fi frappante, que D. Ulloa lui-même dit dans fon Voyage, qu'il ne fait à quoi s'en tenir, lorfqu'il lit ces Hiftoriens, \& confidère l'état d'abrutiffement où font tous les Indiens de ces contrées. On lui a répondu que les fujets peuvent toujours avoir été fort grofliers, quoique conduits par des maîtres éclairés. C'eft donc convenir que ces peuples n'avoient ni de la Divinité, ni de la Religion, les idées faines qu'on leur prête : ainfi La réflexion fenfée de D. Ulloa, celle de Ro- 
432 Objervations \& additions. bertfon reftent dans tumte leur force, \& l'on peut hardiment conclure, qua au-delà de lidée du Soleil, ces Indiens, ni leurs maitres, ne connoiffoient pas Dieu.)

\section{ODSERVATIONS \& Additions fur les Guacas, ou Tombeaux des Indiens.}

ON peut rappeller ici ce que D. Ulloa dit des fépulcres de Quito dans fon Voyage. Les Indiens, dit-il, faifoient des ouvrages qu'ils confacroient à la poftérité, \& done ils ont rempli toute la contrée de Quito. Ils en ont fait dans les endroits habités de même que dans les plaines, fur les côteaux \& lès montagnes de moyenne élévation : car ils fe faifoient inhumer, en général, comme les Egyptiens, dans des lieux remarquables, ou près des grands édifices. Les Egyptiens élevoient à cet effer des colonnes pointues, \& l'on y plaçoir au centre les corps de ceux à qui elles ćtoient deftinées. Les Indiens dépofoient leuirs morts dans le lien où ils devoient refter, fans l'enterrer, y. réuniffoient plufieurs pierres dont ils faifoient un monument fépulcral, en y joignant de grolles briques crues. Tous les parens ou alliés du mort amonceloient de la terre fur ce tombeau \& à fes côtés, afin d'en former un monticule qu'ils 


\section{Objervations \& adilitions.}

qu'ils appelloient Huaca, ou Guaca. Ces tertres n'étoient pas tout-à-fait en pyramide; il femble qu'on ait voulu imiter daus leurs formes celle que la Nature donne aux monragnes. L'ćlévation. ordinaire de ces tombeaux eft de huit à dix toifes, ou de vingt-trois varas, la longueur de vingt à vingt-cing toifes, \& la largeur un peu moindre.

On en trouve cependant de beaucoup plus grands. Ces monumens font affez répandus çà \& là dans le pays; mais c'eft firr-tout près du village de Cayambé qu'on en voir le plus grand nombre: les champs en font remplis. Il paroît que c'eft à caufe d'un ancien Oratoire, on d'un de leurs principaux Temples quils avoient là, ou parce que les campagnes des environs étoient regardées comme facrées. Les Rois \& les Caciques de Quito, de même que tous les Habitans des Villages ou Bourgs voifms, vouloient être enterrés.

Comme ces monumens font de différente grandeur, on a lieu de penfer qu'on fe régloir dans leur étendue par la dignité on l'opulence de ceux à qui ils étoient deftinés. Sans doute que le monument d'un Cacique qui avoit beaticoup de fujets devoit cerre plus grand, plus élevé que le vulgaire, qui avoit contribué à éléver ce monument, au lieu que ceux du Peuple na'étant bâtis ou ćlévés que par les alliés ou les parents des Tome 1 . Ee 
$4 \$ 4 \quad$ Objervations \& additions. particuliers, ne pouvoient avoir autant de grandeur. On enterroit avec le cadavre (comme en Grèce \& en Sibérie) tont ce qui avoit fervi à lhomme pendant fa vie, comme fes vafes d'or, de cuivre, de pierre; de terre, \& autres uftenfiles.

Bonguer nous parle des tombeaux qu'il a vus à Cochefqui, \& qui font d'une grandeur \& d'une hauteut prodigieufe; il en fixe la confruction au règne de Huyenna-Capac. Ces monumens font des monticules de terre, parmi lefquels il y en a qui ont quarante pieds de haut fur foixante-dix brafles de long, \& quarante de large : ils font percés de très-longues galeries par lefquelles on arrive aux tombeaux, en defcendant fans prefque s'en appercevoir. Le nombre de ces monumens en conídérable.

Les Hiftoriens font mention d'un palais que les Incas avoient fait bâtir daus cette contrée : mais on n'en voit plus aucuns reftes. Les tombeaux dont perfonne n'avoit fait mention avant Bayer, y fubliftent encore en partie. Voici ce qu'il dit des Guacas de Cuzco. "On voit pareillement, en nombre d'endroits, fur de petites éminences des Guacas qui, par leur forme majeftueure, paroifrent avoir éré les tombeaux des Indiens de qualité. Ils font bâtis de pierres quarrées affemblées avec art, \& ont, de tous côtés, trois ou quatre aunes de large, trois ou fix en 


\section{Olfervations \& additions.}

hauteur, \& font couverts (I) de pierres plattes. Il y a une petite porre ouverte du côré du Soleil levant, par où l'on mettoit les corps dans une efpèce de niche.

La plupart de ces guacas ont été fouillés \& bouleverfés par les Efragnols qui y ont cherché de l'or \& de largent, ou pour en prendre les belles pierres qu'ils ont employées à des bâtimens.

Bayer décrit encore les tombeaux qui fe trouvent dans quelques vallées fituées vers les côtes du Pérou. Ils font faits de terre taflée très-fortement, \& dans leur entier. Depuis cinq cens ans qu'ils font abandonnés, on n'y voit aucune atteinte. Peut-être ne les a-t-il pas bien examinés,

Mais Frezier parle de quelques circonfances que l'on peut revoir ici avec avantage. $P$ ag. 31 ; "On voit, dit-il, des malheurs plus touchan de cette pauvre nation auprès d'Arica, \& tout le long du rivage jufquà la pointe de Coles: c'eft une infinité de tombeallx où ils fe font enterrés tout vifs, avec leurs familles \& leurs biens. D'où vient qu'en creufant encore aujourd'hui on tronve des corps prefque tout entiers, avec leurs habits, \& fouvent des vafes d'or 8 d’argent. Ceux que j’ai vus font creufés dans le

(I) Tels font ceux des Grands de la Chine.

$\mathrm{E} e 2$ 


\section{$436 \quad$ Olfervations \& additions:}

fable, de la hauteur d'un homme, \& environnés de murailles de pierres fèches. Ils font couverts d'une claie de cannes, fur laquelle ef un lit de terre, \& du fable par-deffus, afin qu'on ne s'apperçut pas du lieu où ils étoient".

"Il fe trouve des Efpagnols qui n'atribuent pas à la terreur de ces peuples l'invention de ces tombeaux. Ils difent que comme ils adoroient le Soleil, ils le fuivoient dans fa courfe, s'imaginant pouvoir en approcher; \& qu'enfin arrêtés par la mer qui les bornoit au couchant, is s'enterroient au rivage, pour le voir avant que de mourir, jufqu'au moment oì il femble fe cacher dans les eaux. La coutume des Grands qui ordonnoient, en mourant, quon les portât au bord de la mer, eft une preuve de ce fentiment; mais la plus commune opinion eft, qu'ils furent tellement épouvantés lorfqu'ils appritent que les conquérans n'avoient pas même épargné leur Roi Acahualpa, quils crurent tous périr. Pour échapper aux mains des Efpagnols, ils fe fauvèrent le plus loin qu'ils purent au couchant; mais arrêtés par la mer, ils fe cachèrent fur fes bords, pour implorer la mifericorde dil Soleil, quils croyoient avoir grandement offenfé, puifqu'il leur envoyout de fi cruels ennemis qui fe difoient auti defcendre du Soleil ".

"Il faut faire une grande difference entre ces 
tombeaux volontaires d'avec ceux qu'ils dreffoient à des gens de confidération. Ces derniers font hors de terre, bâtis de briques crues \& en rond comme de petits colombiers de cinq à fix pieds de diamètre, de douze a quatorze de haut, \& voûtés en cul-de-four, dans lefquels on les affeyoit, puis on fermoit les murailles. En voyageant dans ces terres, on en trouve quantité qui fubfitent, même dès avant la conquêre des Efpagnols. "

( $C e$ que dit ici Frezier de la crante queurent ces Indiens, \& qui, felon ce quil appelle la plus commune opinion, leur fit prendre le parti de s'enfevelir tout vifs à l'occident, eft une fable indigne même d'être rapportée. D'ailleurs il y a une contradiction manifefte dans le récit de Frezier. Sil étoic d'ufage que les Grands fulfent inhumés fur le bord de la ner, pourquoi le peuple, qui avoit comme cux un préjugé de la plus ancienne date, \& plus général qu'on ne le croit, n'auroit-il pas voulu être enterré du même côté? car lhiftoire nous apprend que quelques peuples de la Grèce toumoient toujours la tête des morts à l'occident. C'étoit l'emblême de la mort, comme l'orient étoit celui de la vie. Or, ces ufages tiemnent à une origine de la plus haute antiquité. D'ailleurs, il y a trop d'art dans ces tombeaux, quelques fimples quilis foient, pour avoir ćté faits par des gens au dé.

$$
E \subset z
$$


fefpoir. On en a trouvé de femblables dans nombre de hutres éloignées de la mer : c'étoit done un ufage qui n'avoit rien de particulier. Un Hiftorien ne doit avancer rien fans preuve; \& tout ce qui n'elt pas prouvé dans l'hiftoire eft néceffairement fufpect. Que nombre d'Indiens fe foient fauvés au hafard, tués, précipités, fi l'on veut, après le malheur de leur prince, cela eft très-poffible; mais qu'ils aient conftruit un fi grand nombre de tombeaux, \& avec réflexion, c'eft ce qui n'eit pas vraifemblable. Numance, Calaguris, Sagonte, font des exemples de défefpoir. Les habitans étoient enfermés, \& ne vouloient pas périr par le glaive de l'ennemi qui les tenoit inveftis. Les Indiens pouvoient fuir; ils l'ont fait, mais non pour s'enterrer tout vifs : cela eft très-fûr. L'hiftoire de ces tems-là nous a confervé le nom de plufieurs peuples fugirifs, \& celui des provinces où ils fe font retirés alors. Si D. Ulloa paroît avoir eu lui-même quelque doute, c'eft qu'il n'a pas fait affez de réflexion fur ces circonfances. Cependant il dit, comme Frezier, que luafage de ces fépultures étoit for commun. Quant à ces tombeaux de terre amoncelée dont parle Bayer, l'ufage n'en eft pas inconnu à la Chine. Ceux du peuple font de dix ì douze pieds de haut, faits en pyramide. Les Grands font couvrir cetre pyramide de terre avec des 
pierres plattes, afin que l'eau n'y trouve aucun dommage. On le retrouve aufli en Grèce. Le tombeau d'Epytus tué par un ferpent, étoit fait en pyramide avec une terre amoncelće, \& garni d'une bordure de pierre ì fa bafe. Mais le tombeau du Melfénien Lycus étoit un monticule de terre feule. Voilì donc la forme des tombeaux Indiens dont parle D. Ulloa. Les tombeaux des amans de Sémiramis étoient aufli faits de terre amoncelée; mais une autre circonfance vient à l'appui de ce que dit le même fur ces colonnes fépulcrales que M. Schneider a révoquées en doute. L'ufage des habitans de Sicyone, la plus ancienne ville de la Grèce, étoit de placer d'abord le corps dans le trou deftiné à le recevoir. Enfuite on ćlevoit une bâtiffe de pierres qu'on furmontoit d'une colonne. Or, Sicyone touche aux premiers âges du Globe habité depuis le déluge. Je pourrois réunir ici plus de circonfances analogues fur cet objer; mais ce n'eft pas une Differtation que j'écris; je venx feulement montrer combien l'on peut diliper de doutes avec un peu de lecture. V. Gualter fur Parata, \& Paranias.

Mais Frezier fair une réflexion qui devoit encore arrêter M. Schneider. Ces Indiens, dit-il, fe cachèrent fur le bord de la mer ( felon la tradition, pour implorer la miféricorde du Soleil, \&c. Ce n'eft donc plus à un antre Etre que

E e 4 


\section{$44^{\circ}$ Obfervacions \& additions.}

le Soleil, à un Dieu Pachacamac qu'ils s'adreffent, ou il faut convenir que ces deux objets n'en faifoient qu'un pour eux, comme je l'ai déjà dit, \& cela eft vrai. Le Soleil étoit leur Dieu, de même que celui des premiers habitans de la Grèce, où cet aftre avoit fes ftatues comme à Cuczo, à Mexico, fes autels, fes prêtres \& fon culte particulier, même lorfque la Grèce avoit admis d'autres Dieux, Paulanias feul en donne la preuve).

Le calcul que fait D. Ulloa, d'après le nombre des cadavres qu'on a trouvés dans les tombeaux dont il s'agit dans cet Ouvrage-ci, eft fort ingénieux. C'étoit chercher, ávec efprit, la première époque à laquelle ces vallées avoient été habitées, au moins celle à laquelle ces nations avoient fubi le joug des Incas. Mais il falloir autre chofe pour donner à ces calcuis la vraifemblance, fans laquelle ils deviennent inttiles pour fon but. Cette vraifemblance ne pouvoit être fondée que fur la connoiffance certaine (fauf quelques à-pen-près) du nombre des anciens habitans de ces mêmes contrées, du rapport des naiffances aux morts; ce qui, fans doute, ne peut fe déterminer d'après ce qui fe paffe dans nos climats.

La fepulture, oa plitôt les lieux deftinés à la pourriture des cadavres dans la Louyfrane, \& 
Obfervations \& additions.

441

les autres ufages funèbres, s'accordent jufqu'à la moindre circonftance avec ce que les Anglois nous ont appris de la fépulture des habitans de Taït, comme on peut le voir dans la Collecsion d'Hawkefworth, qui en donne même la figure. Quand la chait eft tombée des os, en pouirriture, on y nettcie les os en les grattant, $\&$ on les enterre ou dans un morai ou dehors. Morai eft une efpèce de temple ou d'oratoirè.

Après ces détails rrès-étendus fur la ftrncture des tombeaux, le Lecteur, qui ignore les autres ufages, eft fans donte curieux de favoir comment on plaçoit les morts dans ces monticules \& ces efpèces de niches; \& par quel appareil on diftinguoit les perfonnes de qualité opulentes, ou d'un mérite particulier. Voici ce que quelques Auteurs nous appremnent à ce fujet. Acolta dit, Li\%. $V, c .6$, que les Péruviens étoient curienx de conferver avec foin les corps de leurs Rois \& des Grands, \& qu'ils les gardoient pendant deux cens ans, fans qu'ils euffent la moindre atteinte de pourriture \& fans ancune puanteur. Ce fut ainfi qu'on trouva les Incas à Cuzco, chacun dans leur caveau. Le Marquis de Cagnette en fit retirer trois ou quatre qu'on tranfporta à Lima, \&: l'on fut extrêmement étonné de la fraicheur des traits du vifage dé ces radavres. Une partie des tréfors que laifoit le 
442. Obfervations E addicions:

Roi à fa morr étoit deftiné aux frais requis pour entretenir le caveau où le corps étoit dépofé, \& pour toute la famille \& les Domeftiques qui devoient avoir foin des cérémonies annuelles qui fe faifoient à leur tombeau. Outre cela, l'Inca faifoit faire $f_{a}$ figure en pierre pendant fa vie. On l'appelloit Huaciqui, qui veut dire frère. (Dans les langues de l'Orient, Akhik ou Akh fggnifie la même chofe). On rendoit à cette figure les mêmes honneurs qu'on avoit rendus à i'Inca pendant fa vie. On la portoit à la guerre, en proceffion quand on faifoir des prières publiques pour obtenir le tems convenable, \& on lui confacroit des fêtes \& des offiandes. On voyoir beaucoup de ces figures à Cuzco \& dans le voifinage. Mais les honneurs qu'on leur rendoit ceffèrent dès que le Vice-Roi Polo les ent découverts. Acofta dit encore que Pizarre ayant découvert le corps de l'Inca Viracocha à Xaquixaguana, le fit brûler. Les Indiens en ramafsèrent les cendres dans un vaiffeau, \& témoignèrent la plus gande vénération à ces reftes d'un de leurs Somverains. On trouva les corps des autres Incas embatimés.

Le corps de l'Inca Yupangui fut découvert; aufii bien confervé : il étoir préparé avec une ré́ne qui lui ayoit maintenu les traits, au point q̨u'on l'eut cru vivant; les yeux étcient faits d'tum 
petit tiffu d'or, ( telillla de oro; font-ce plutôt de petites lames d'or; ) \& placés avec tant d'art, qu'ils fembloient naturels : on voyo:t fur fon front la cicatrice d'une bleffure quil avoit reçue à la guerre; il avoit les cheveux gris, un air aufi frais que s'il venoit de mourir. Ce cadavre étoit cependant là depuis foixante ou quatre vingt années. Tous ces cadavres furent apportés dans l'Hôpital de Saint-André de Lima, où nombre d'Efpagnols les ont vus; mais ils font actuellement mutilés $\&$ corrompus.

C'eft fans doute fur ces circonftances qu'ert fondée la fuite des figures des Souverains du Pérou, que D. Ulloa a publié dans fon Voyage, d'après une gravure en cuivre qui en avoit été faite autrefois à Limn. Il ne parle, il eft vrai, que de modèles d'argile, faits en relief ou demirelief, d'après lefquels les Indiens ont repréfenté les figures de ces Souverains, foit en or, foit en pierre, \& qui ont fervi à la gravure quion en avoir faite : mais il eft probable que ces cadavres ayant été découverts, ont été utiles à cet ouvrage.

De la Vega raconte quétant à Cuzco, dans la maifon du Juge Paul Oudegardo de Salamanque, en I 560 , il y avoit val le corps de cinq Incas, fi bien confervés, qu'il ne leur manquitoit ni un cheveu ni un poil des fourcils; ils avoient les mệmes habits que pendant leur vie, \& le Llautu 


\section{$444 \quad$ Objervations \& additions.}

fur la tête, ce qui étoit la marque de la dignité royale. Les mains étoient croifées fur la poirrine, \& les yeux dirigés vers la terrè. Quant aux yeux artificiels, dit-il, dont parle Acofta, je ne les ai pas remarqués lorfque j'ai vu le corps; fi j’avois penfé alors à écrire une Hiftoire du Pérou, je les aurois examinés avec plus d'attention, \& jaurois auffi tâché de découvrir l'art de l'embaumement de ces corps, car les Indiens n'ont jamais voulu le découvrit aux Efpagnols. Cet art eft peut - être actuellement perdu pour jamais, comme bien d'autres que connoiffoient ces Indiens : pour moi je n'ai remarqué de réfine à aucuin de ces cadavres : je ne doute cependant pas qu'on 11'em. ployât pour cela certains aromates, afin de les conferver fans les décharner. Ils metroient pentêtre les corps morts dans de la neige pour lis faire deffécher, \& y ajoutoient enfuite de la neige. Je fonde cette idée fur l'ufage où l'on eft, dans les contrées du Nord des Indes, de conferver les viandes en les metrant feulement fécher à l'air, fans employer ni fel, ni aucun autre moyen. C'eft ainfi quon préparoit les provifions de viandes pour les armées des Incas. Les cadavres fufdits étoient fi légers, que le plus foible Indien pouvoit les porter fans peine fous les bras ou fur le dos.

( M. Schneider avoit ici le parallèle des 
Guanches à citer : l'art avec lequel ils embaumoient les corps les rendoit également légers $\&$ incorrupribles. La conjecture que préfente la Vega fur l'effet du froid qui pouvoit conferver les cadavres dans cer étar, ne peut avoir lieu ici, parce que cet effot doit-néceffairement ceffer, dès gue les viandes font atteintes de l'impreffion d'une rempérature plus chaude, ou de la chaleur. Les viąndes gelées, dont la Vega \& norte Auteur fait mention, prouvent le fait, puifque l'eau chaude les faifoit dégeler. C'étoit donc l'embaumement même qui confervoit les cadavres des Incas au Pérou, comme aux Canaries ceux des Guanches. Il paroît auffi par l'effet des baumes, que l'art devoit être le même.)

Quant à la manière dont on conferve les viandes par l'effer du froid, c'eft une chofe qui fe pratique encore aujourd'hui. Notre Auteur en parle dans fon Voyage, \& l'on a vu ce qu'il dit à ce fujet dans cet Ouvrage-ci. La Barbinais nous dit qu'il a vu fur la place de la Capitale de Pachacamac, des cadavies qui n'avoient pas la moindre marque de corruption; il attribue cela aux qualités particulières de l'air \& du fol : les rraits y étoient encore reconnoiffables, la peau étoit feulement plus blanche, plus tendue qu'elle ne l'eit ordinairement chez les Indiens. Il trouva aufi dans la province de Chinca, un tombeau où il y 
$44^{6}$ Objervations Es additions:

avoit deux cadavres d'homme \& de femme, e peu corrompus, qu'on y diftinguoit encore la différence des parties fexuelles; on vit aufi dans le tombeau des vaiffeaux de terre, deux chiens, \& quelques morceaux d'argent.

(Sans aller en Amérique, on a à Pétersbourg du poifon qui refte gelé, \& qu'on coupe à coups de hache à celui qui veut en acheter; enfuite nous comoifons en Europe des caveaux \& des rerreins où l'on a trouvé dés cadavres inhumés depuis long-tems, \& fans la moindre atteinte de corruption. Je connois une cave dans une Eglife, où je vis, il y a environ rrente ans, neuf à dix cadavres fur leurs jambes, \& appuyés contre le mur; on les avoit exhumés defféchés, \& ils y font reftés tels. Si l'on avoit donc dit que les corps des Incas avoient été confervés par des circonftances analogues, plus de dificulté; mais les raifonuemens de la Vega, \& ceux des Auteurs que cite M. Schneider, devenoient inutiles.)

Zarate s'explique ainfi à ce fujer, Liv. I, c. I2. On portoit les Caciques \& les principaux du Pérou, après leur mort, dans un endroit voûté, \& on les haffoit-là aflis avec les plus riches paiures quils avoient eues. On enterroitaufi avec eux quelques-unes de leurs femmes, de leurs ferviteurs, les ufenfles \& inftrumens qui leur avoient fervis. Les parents du mort répandoient fur le 
Obfervations \& additions.

tombeau de la chica, qu'on faifoit couler dans fabouche avec un tuyaul. On plaçoir auffi fa figure en bois fur le haut du monument. ( Quiconque comparera tous ces ufiges \& ceux qui fuivent avec ceux des peuples de la Chine \& de la Tartarie, y verra beancoup de rapports.) Quant aux gens du peuple, on fe contentoit de mettre auprès d'eux leurs outils, \& fur le tombeau la repréfentation de leur métier. Les Guerriers fur-tout avoient ces honneurs. Le même Ecrivain dit encore que les gens de qualité de la province de Pachacamac, fe faifoient enterrer près du temple de cette Divinité fi vénérable pour eux, à quuatre lieves de Lima.

On voit par ces paffages pourquoi D. Ulloa dit : "Quelques perfonnes s'en rapportent à la bonne-foi d'un feul temoin; mais en rémniffant \& comparant ce que ces différens Ecrivains nous apprennent, il paroît démontré que l'on enterroit les Grands dans des tombeaux de pierre élévés, au lieu que cenx du vulgaire étoient faits de terre, d'argile ou de bíques crues. On les plaçoir embaumés ou defféchés, accroupis dàns une niche, ou affis fur' un fiège; on mettoit auprès d'eux quelques provifions de bouche, tant pour boire que pour manger, différens joyaux, des ferviteurs, \& aux Rois quelques femmes pour compagnie. 


\section{Obfervations \& additions.}

Mais perfonne ne notis apprend où étoit $l a$ fépulture particulière des Rois. De la Vega dit, Liv. VI, c. S, quion les plaçot dans le temple de Cuzco devant l'image du Soleil, \& qu'on leur préfentoit-là des offrandes; du refte il ne fait pas connoitre où ils étoient enfuite tranfportés, ou. s'is refoient-là : il affure cependant qu'on en confervoit les entrailles dans un temple de Tampu. Nous favons par le vingt-deuxième Chap. de fon Liv. III, que les corps embaumés des Rois étoient placés dans le temple de Cuzco, des deux côtés de l'image du Soleil, allis chacuin fur un trône d'or, les yeux baifés fur la terre. A l'arrivée des Efpagnols, les Indiens les emportc̀rent, dit-il, avec les autres tréfors, \& les cachèrent de mánière qu'on ne trouva jamais que les cinq que le ViceRoi Polo découvrit en 1599. Mais Lopès de Gomara nous rapporte les circonftances fuivantes daus fon Hiftoire générale des Indes, imprimće $₫$ Anvers en I $14, p .170$. Les pauvres \& le peuple de Cuzco éroient enterrés tous fort fimplement : on mettoit fur le tombeau de chacun d'eux les atrriburs de lenrs mériers ou de leur commerce. Quant anx Incas, on pratiquoit pour etix des caveaux voûtés, que l'on garnifioit de tapis oì l'on attachoit beaucoup de joyaux, des armes \& des plumes : on y mertoit auffi des vaiffeaux d'or avec de l'eal, des liqueurs \& des

alimens. 
Objervations \& additions:

alimens. On joignoit à cela quelques-unes de leurs femmes les plus chéries, \& des ferviteurs pour leur compagnie \& le fervice : mais ces derniers n'y alloient pas volontiers. Tout étoit recouvert de terre, \& l'on verfoit continnellement de la chica pardeffus. Le même dit encore, $p .264$ : les Péruviens fe font enterrer fous terre, quelquesuns font embaumés. Pour cet effet on injecte dans le corps par la gorge des fucs d'arbres aromatiques, \& on les oint extérieurement avec de la gomme. Quant aux habitans des montagnes, le froid y conferve les corps; auffi l'on y trouve quantité de momies, ( corps defféchés). Pag. 267, il dit que les Caciques de Panama éroient defféchés aul feu, \& mis en terre de cette manière : mais nombre d'entr'eux fe faifoient porter dans les champs au moment de leur mort, y expiroient, \& n'avoient que le ventre des animaux pour tombeau.

Notre Auteur \& Bayer ont fait graver des figures de tombeaux; on les confultera. On nous a auffi donné dans plufieurs Voyages les figures de plufieurs inftrumens \& des parures des Indiens, qu'on trouvera en partie dans l'Hiftoire générale des Voyages. On peut dire qu'en général la fépulture de ces peuples étoit, comme à la Chine \& ailleurs, plus ou moins diftinguée felon le rang \&. la richeffe des perfonnes.

Tome II.

F $€$ 


\section{$45^{\circ} \quad$ Objervations $\&$ additions.}

Nous remarquerons que $D$. Ulloa dit que les Indiens du Pérou n'emploient le tabac que pour fumer: mais de la Vega nous apprend qu'ils le prenoient autrefois par le nez, pour fe décharger le cerveau : la plante s'appelle Sayri dans le pays. Ce que dit D. Ulloa de l'habitude où font les femmes du Pérou, d'avoir toujours un rouleau de rabac à la bouche, doit fans doute ne s'entendre que des Efpagnoles.

OBSERVATIONS E Additions fur les Monumens. anciens des Indiens.

M. Schneider commence à parler de l'anti= quité des Indiens, en s'arrêtant fur leur manière de bâtir leurs huttes, \& dir que ces orgueilleux Efpagnols ont appris d'eux à conftruire leurs édifices, fur le modèle $\&$ avec les mêmes matériaux qui étoient en ufage avant eux au Pérou. 11 pouvoit fe difpenfer de cette apoftrophe, qui n'eft pas honnête; d'ailleurs, elle eft dénuée de toute raifon. Avec quoi veut-il que l'on bâtiffe, fi ce n'eft avec les matériaux qu'on a à fa difpofition? Les Efpagnols fe fervent d'adoves, ou de briques crues : mais que peuvent-ils employer de mieux, puifqu'il eft prouvé par de très-anciens reftes du P'érou, que ces matériaux réfiftent à toutes les 
Obfervations \& additions.

injures du tems peindant des fiècles. Autant vaut-ii reprocher à l'Impératrice de Ruflie, de n'avoir en Sibérie que des fortereffes de bois, parce qu'on y a ces matériaux fous la main. Quant à la maniere dont les Efpagnols bâtiffent dans ces contrées Occidentales, felon la defcription qu'il cite de Frézier, $T . I I, p .460-469$ \& autres, ces paffages feuls devoient lui prouver l'énorme diffém rence qu'il y a entre cetre ftucture \& celle des Indiens. Les Efpagnols n'avoient pas non pius befoin des modèles des Indiens pour faire cess Tapias, ou murs de terre battue avéc de la paille hachée \& mife entre deux planches ou entre des claies. L'Europe connoiffoit cette ftructure de toute antiquité, \& j'en ai vu dans mes voyages en plufieurs endroits. Pline, qui fervit de guice aux Efpagnols pour l'exploitation des mines, Virruve même, pouvoient leur apprendre à bâtir, comme ils étoient contraints de le faire, \& M. Schneider n'ignoroit pas les avis de ces deux grands Ecrivains. Il fait peut-être auffi que les premières maifons des Bourgades que Théfée raffembla pour former la ville d'Athènes, étoient bâties de même; je lui citerai même fon propre pays, (l'Allemagne,) où les payfans, fans avoir été en Amérique, couvrent leurs murs de boue, avec de longues planches horifontales.

Mais fuivons à préfent M. Schneider. Les In-: $F f_{2}$ 
452

Objervations \& additions:

diens appellent tica ce que les Efpagnols nomment adove. On pêtrit de l'icho haché avec l'adove ou la terre qu'on employe, \& cette terre ainfi pêtrie eft mife dans des moules : on la laiffe bien fécher. De la Vega dir aufli que les Péruviens mêlent une argile rouge avec certe efpèce de jonc, dont ils font des adoves de différentes grandeurs : cet ufage étoit anciennement connu en Italie \& ailleurs. “ C'eft ainfi, dit Pline, qu'on " élève en Afrique \& en Efpagne ces murs qu'on " appelle formaceos, parce qu'on taffe ou farcit " plutôt ces murs entre deux tables qui forment " le contour, qu'on ne confruit. Cela dure des " fiècles, fans être altéré par les pluies, les vents, " le feu même, \& c'eft plus folide que tous les " autres matériaux. On voit encore en Efpagne " les tourelles des fentinelles d'Annibal, élevées "ainfi fur les montagnes; mais on fait aufli 2. qu'on employoit des claies recouvertes de boue „) pour former des maifons. Liv. XXXV. "Pline apprend enfuite que les Romains formoient aufi des briques \& des tuiles avec de l'argile \& de la paille hachée, ou la balle des grains. On verra la même obfervation dans Virruve.

Quant aux maifons de joncs qui font en ufage, Frézier en donne une idée qui éclaircira la chofe : "Les maifons d'Arica ne font la plupart que des fafcines d'une forte de glayeul appellé tozora 2 


\section{Obfervations Es additions.}

liées de bout les unes contre les autres avec des éguillettes de cuir, fur des cannes qui fervent de traverfe; ou bien elles font faites de cannes pofées de bout, dont les intervalles font remplis de terre. L'ufage des briques crues eft réfervé aux églifes, \& aux maifons les plus magnifiques: comme il n'y pleur jamais, il n'y a d'autre couverture qu'une natte, ce qui donne aux maifons un air de ruine. T. 1, p. $26 \mathrm{I}$.

Acofta dit que le totora eft une efpèce de jonc; qui croît abondamment dans le lac Titicaca. Les Indiens l'employent à divers ufages, pour le donner en fourrage à leurs chevaux ou aux porcs, ou pour leurs huttes, leurs radeaux, enfin pour combuftible. Bouguer décrit aufli en détail les maifons de joncs de Manta, que les Efpagnols font de jonc feul à la manière des Indiens. Ulloa nous parle auffi de ces maifons dans fon Voyage.

Ce que cet Ecrivain nous dit de la pofition des anciens Villages dés. Indiens, fe concevra plus facilement par la lecture de ce qu'il rapporte concernant les reftes d'une pareille habitation dans la vallée de Quachipa, à trois lieues de Lima. Voyez fon Voyage. Les rues en étoient étroites; les maifons, fans couverture, étoient faiter des tapias dont nous avons parlé, \& diftribuées de manière qu'il s'y trouvoit quatre pe$\mathrm{F} \mathrm{f}_{3}$ 


\section{Obfervations \& additions.}

vites pièces quarrées : les portes qui donnoient fur la rue n'avoient pas la hauteur d'un homme; les murs étoient élevés à trois varas environ. Parmi toutes ces maifons, qui donnent lieu de croire qu'il y avoit un gros Village au bas de la montagne, on en diftingue une, dont les murs plus élevés que les autres paroiffent avoir été la demeure du Cacique de ce canton; car les ruines ne permettent pas d'y fuppofer un autre ufage. Il faut encore remarquer que toutes ces huttes étoient bâties fur la terre même, fans aucun plancher fur le fol: ces huttes ont réfinté depuis. fi long-tems à l'injure de l'air, tandis que les. édifices des Efpagnols, folides en apparence, ne tardent pas à tomber en ruines. Ces huttes des. Indiens ne fe font altérées que parce qu'elles ont été abandonnées quand ils ont pris la fuite, \& fe font retirés chez d'autres Nations du continent : les Marchands de beftiaux les ont auff beaticoup endommagées.

Quant aux temples, aux palais des Incas, à la fortereffe de Pachacamac \& d'Herbai, on peut joindre à ce qu'en dir notre Auteur les détails qu'il a donnés dans fon Voyage. On trouvera d'ailleurs dans un affez grand nombre d'Écrivains. de quoi fe fatisfaire à cet égard; HHiftoire génćrale des Voyages en fournit aulli plufieurs def- 
criptions. Acofta, G. de la Vega, Bouguer, de la Condamine, fuppléeront à tout, en les comparant avec D. Ulloa.

Tous ces édifices, où l'on admire autant les efforts, ou des bras, ou des machines inconnues de nos jours, que la patience incroyable des Indiens, font en même tems la preuve du peu de goût \& de génie des conftructeurs : ils n'avoient aucune idée de conftruction en charpente, ne favoient même pas engrainer deux pièces de bois l'une dans l'autre, \& n'avoient pas l'idée des voûtes. Cependant il ne faut pas les juger auffi précipitamment que Paw l'a fait : Raynal paroît plus judicieux que cet Ecrivain, qui outre toujours les chofes; mais Robertfon mérite fur-tout attention. On convient affez généralement qu'il y a dans plufieurs de leurs anciens monumens des chofes abfolument incompréhenfibles, \& inexplicables, quand on les confidère fans préjugés. Ainfil l'on ne doir pas juger de l'état primitif de ces Peuples par celui où ils font actuellement, gémiffant fous les fers de la plus trifte fervitude, ( Malgré les ordres précis des Souverains de l'Efpagne, ordres que Frézier lui-même a cités, \&z qui prouvent que l'intention du Gouvernement n'étoit pas de les réduire à la condition des Nègres, ou, ce qui eft encore plus criant, à une fervitude mille fois plus dure. Quand donc les Ef- 
456 Obfervations \& additions.

pagnols nous peignent ces Peuples comme des hommes qui ont à peine la moindre intelligence, ils devroient nous peindre les malheurs de la Nation, \& l'on fentiroir auffi tôt la caufe de cet abrutiffement. Frézier, qui les a peints tels qu'ils font en eifet, ne leur refufe cependant pas de l'induftrie, de l'intelligence; $\&$, ce qui prouve qu'ils en ont, dit-il, c'eft l'art avec leauel ils favoient prendre le niveau des eaux pour les conduire par-tout où ils en avoient befoin. On verroit un grand nombre d'Européens très-embarraffés pour faire la même chofe. On pourroir produire d'autres preuves de leur ancienne induftrie.

Mais pour faire voir à quel degré ces gens auroient porté la beauté des édifices s'ils avoient entrepris de ceintrer, difons deux mots de la perfection de leur maçonnerie, qui furpaffe tout ce qui noils refte en ce genre dans les plus beaux monumens de l'antiquité. L'ouvrage du palais de Latacunga eft de pierres prefque noires, auffi dures que la pierre à fufil, \& fi bien jointes, qu'il eft impoffible de faire entrer la pointe d'un couteau entre deux pierres. Les jointures ne femblent paroître que pour faire juger que toute la maffe n'eft pas d'une feule pierre. On n'y remarque ancune liaifon de ciment ou de mortier; elles font convexes en dehors, \& plattes à lentrée des portes. On voit de linégalité non-fels. 


\section{Objervations E addicions.}

lement dans les rangs des pierres, mais dans les pierres mếmes, \& l'ouvrage en eft plus fingulier; car une petite pierre étant immédiatement fuivie d'une grande affez mal quarrée, celle de deffus ne laiffe pas d'être accommodée à ces deux inégalités, comme aux faillies \& aux irrégularités de leurs faces; $8 z$ de quelque côté qu'on les regarde, on les voit jointes dans la même perfection. Quant à leurs ouvrages en briques crues, les reftes du temple de Cayambé montrent encore l'excellence de leur art. Quoique quelques écrivains aient avancé qu'on ne voyoit rien de rond dans les ouvrages des Indiens, ces reftes font preuve du contraire. Ce temple eft rond, \& peut avoir quarante-cing ou fix pieds de diamètre. Les briques y font jointes avec la même terre détrempée dont on les a formées, \& la maffe reftante fait un mur auffi folide que s'il étoit de la pierre la plus dure. En effet elle a bravé, depuis plufieurs fiècles, les injures du tems \& des faifons. On voit donc que les Indiens favoient tirer une courbe, \& que sils n'ont pas ceintré le comble de leurs grands édifices, c'eft qu'ils n'avoient peut-être pás ofé le faire, ne fachant pas arrêter la pouffée d'une voûte élevée, fans nuire en dehors à la forme de leurs édifices : car il eft certain que quelquesmins des caveaux de leurs tombeaux, préfentent 


\section{Obfervations \& additions:}

des voûtes, (bovedas) felon le rapport des Hiftoriens, \& que la forme étoit en cul-de-four, dit Frezier. D'ailleurs les pierres du palais de Latacunga ont toutes une forme convexe en dehors. Ils fivoient donc leur donner une forme courbe. Les voûtes fouterraines de la fortereffe de Cuzco font ceintrées. Üne autre raifon me perfuade que la forme fupérieure de leurs édifices. tenoit à un ufage ancien, auquel ni M. Schneider ni d'autres n'ont penfé : car il eft permis d'avoir des conjectures lorfque les Hiftoriens fe taifent. Tous les grands édifices de 'l'antiquité étoient couverts par une platte-forme ou terraffe fur laquelle on avoir la liberté de monter, \& nous voyons, par l'Hiftcire Juive, qu'un fils fût affez infâme pour violer les femmes de David fon père fur la terraffe ou le comble de fon palais, à la face di Soleil, dit l'Hiftorien, afin de rendre l'injure plus outrageante. Nombire de maifons font encore ainfi couvertes dans l'Orient, \& le Temple de Jérufalem n'éroit pas couvert autrement. C'eft donc cet ancien ufage qui avoit réglé leur conftruction, \& non le défaut de génie fuffiant pour imaginer un ceintre. Le temple d'Hercule en Efpagne, \& tous les anciens édifices analogues de la Grèce, étoient également terminés par tune platte-forme. Rome même n'eut que des édifices femblables pour fes. 
Obfervations E' adiditions.

Dieux pendant plus de cinq cens ans. Elle n'a ceffé d'être barbare à cet égard que lorfque la Grèce ne l'étoit plus, \& qu'elle cri eût vu les édifices. Si les. Péruviens terminoient leurs portes par des linteăux en les rétréciffant un peu, certainement cette forme étoit moins défagréable gue les cintres pointus des. Goths que nous avons fil long-tems confervés à nos grandes portes; \& ce n'eft que depuis peu que nons avons eu la hardieffe de ceintrer prefqu'à plat, comme on l'a fait, en ménageant les points d'appui dans $1 a$ coupe même des pierres. Mais combien ne nous a-t-il pas fallu de fiècles pour parvenir là! Convenons donc que fi ce n'elt qu'après tant d'années que nous avons eu cette hardieffe, avec les plus profondes connoiffances dans la géométrie, les Incas, en moins de quatre cens ans, avoient porté l'art de la conftruction infiniment plus loin que tonte l'Europe ine le fît en mille ans après tha chûte de l'Empire Romain, quoiqu'elle eût Rome \& Conftantinople pour modèles. Le génie n'a donc pas manqué aux Péruviens, au moins à la Cour des.Princes, mais le tems, qui ne fait avancer les arts quavec la progrefion la plus lente, \& qui enfevelit pour jamais des connoiffances qu'on ne voir reparoûtre que par d'heureux hafards. Les Péruviens avoient déjà déterminé la révolution de l'aunće de la manière la 
$460 \quad$ Obfervations \& additions. plus régulière; \& au bout d'une période fixe; fe retrouvoient, fans erreur, fans nos fuppofitions, nos intercalations, nos calculs; au lieu que la Grèce, du tenss de Platon, ne favoit ellcore à quoi s'en tenir fur le cours du Soleil. Leur amée, dit-on, commença d'abord en Janvier, $\&$ fut ramenée, pour le premier jour, au mois de Décembre. Pachacutec, auteur de cette réforme; avoir ainfr rappellé l'année à l'époque de fes fêtes primitives. C'étoit alors qu'on voyoir au Pérou une ombre de ces fêtes fi facrées pour l'antiquité, quand tous les grains, les fruits, le vin étoient recueillis. Ces Saturnales, fi faintes dans leur inftitution, étoient confacrées à rendre à l'Auteur de la Nature les actions de graces qu'on lui devoit. On jouiffoit de tous ces biens : on s'en envoyoit réciproquement; de-là les étrennes, \& les fêtes fe renouvelloient jufqu'à l'équinoxe de Mars. Ce fut dans ces momens de joie qu'on réitéra tous les ans dans les anciens Continens, ces Saturnales, où l'efclave même, après la dégradation de l'efpèce humaine, recouvroit une ombre de liberté. On en revêtoit un des plus riches habits de fon maitre; il commandoir à toute la maifon avec les égards requis; il étoit roi, $\&$ nous avons perpétué ce jour par le jour des Rois, où l'on tire à la fève celui qui aura cette prérogative. C'étoit auff daris ce trimętre que fe célébroit Îa 


\section{Obfervations \& additions.}

fềre des lampes, que l'Eglife a confacré à un ufage plus religieux le jour de la Chandeleur; mais on ne célébroit ces fêtes qu’après avoir offert, par toute la terre habitée, les facrifices ollaires pour les morts du monde anti-diluvien, \& c'eft auffi ce même ufage que nous fuivons encore fans le favoir, le jour des Morts, que nous avons placé avant la Saint-Martin ou avant la fête que célébroit l'antiquité le jour que l'on ouvroit les tonneaux pour goûter les fuccès de la vendange. Pachacutec n'avoit affurément pas repris l'époque de Décembre fans en favoir la raifon, \& les fêtes qui fe célébroient alors au Pérou le prouvent. Ces détails paroîtront finguliers fans doute; mais il n'en eft pas moins vrai que l'ancien monde eft encore nouveau dans nos ufages, dont bien des gens ignorent l'origine.

En voici une autre preuve. On célébroit auffi au Mexique la fête des Marchands, comme fe célébroit dans les Gaules la fête de Mercure. On engraiffoit un homme qu'on promenoit enfuite dans une cage, \& on le facrifioit. J. Cé$\mathrm{far}, \&$ une de nos anciennes chroniques, nous parlent de cette cérémonie; mais les Gaulois faifoient la cage d'ofier avec la forme d'un géant. On y plaçoit l'homme que l'on promenoit avec la plus grande pompe, \& on le brûloit avec la cage ou le fpectre. Si nous ne faifons plus 
462

Objervations \& additions.

le facrifice, nous en avons au moins confervé la mémoire dans le prétendu Suiffe de la rue aux Ours, dont on pronène le fpectre partout Paris. Nous fommes donc encore à l'époque de l'ignorance des Mexicains. Je pourrois prouver que l'antiquité avoit des fêtes qui répondoient à toutes celles que nous célébrons pendant toute l'année.

OBSERVATIONS \& Additions fur les armes, les inftrumens, les vafes, les uftenfiles, les ufages, Eco des Indiens du Ptrou.

HEs Indiens foumis à l'Efpagne ont prefque totalement renoncé à l'ufage de leurs anciennes armes, comme l'arc \& la flèche, \&c. Ils ne font même plus affez adroits pour les manier avec avantage. Ils ne font pas non plus capables d'en faire. On peut en dire autant de tout ce qui concerne l'ufage domeftique \& la parure, \& dont on trouve de tems à autre des échantillons dans les Huacas ou tombeaux.

D. Ulloa ne parle pas, dans fon voyage, avec autant de détails des haches des Indiens. Il les nomme feulement comme des outils dont ils $\mathrm{fe}$ fervoient pour tailler, hacher; mais il n'en fait pas mention comme de marques diftinctives du rang, de la qualité des Officiers, encore moins 
Obfervarions \& additions.

comme d'atrributs de la dignité royale. Cependant de la Vega femble autorifer ces affertions, L.VI, 6. 27. La dernière marque de diftinction qu'on donnoit au Prince étoit un javelot d'une aune de long, \& une hache d'armes, dont le fer (la lame de cuivre fans doute) étoit d'un côté comme celui d'un couteau large, \& de l'autre en pointe de diamant, \& reffembloit à-peu-près à une pertuifanne. Les Incas portoient aufil une hache, dans la figure que $D$. Ulloa en a fait graver dans fon voyage.

Ces haches étoient ou de cuivre ou de pierre de Gallinace, ou d'une autre efpèce femblable à la pierre à feu, mais non auffi dure, auffi tranfparente que l'autre. Ils faifoient auffi des lancettes de ces pierres, \& l'on en trouve dans les. Huacas. On verra dans les gravures qui accompagnent le Voyage de notre Auteur différentes efpèces de coignées avec lefquelles ils travaile. loient à leurs ouvrages mécaniques, une hache de pierre à feu, avec laquelle ils tailloient les autres pierres, une hache d'armes avec ( $\mathrm{I}$ ) un man-

(1) Les haches du Pérou ont un œil pour y introduire le manche : mais celles des autres Sauvages s'enmanchoient bien différemment. On fendoit un jeune arbre fur pied. pour y introduire la tête de la hache de pierre, \& on laiffoit croître encore quelque tems l'arbre, dont les fibres 
464 Objervations \& additions:

che de bois, \& la figure de l'inftrument avec lequel ils s'arrachoient la barbe.

L'Auteur ne dit rien dans fon Voyage des haches étoilées; mais il préfente trois efpèces d'aiguilles \& d'agraffes, dont une a une tête de cette forme. Les Indiens de la Guiane appellent le cafle-tête Buta: c'eft avec cela qu'ils frappent la tête de l'ennemí. On diroit une règle d'un pouce d'épais environ, \& large de trois ou quatre pouces à chaque bout. Dans fa longueur, qui eft de deux pieds, il fe rétrécit au milieu : on fait ordinairement cette arme avec du fer, ou de toute autre matière très-dure. Voyez Barère, Voyage à la Guiane.

Garcilaffo de la Vega a confacré le vingthuitième Chapitre de fon Liv. III. prefque tout entier à la defcription des outils des Indiens; mais ce qu'il dit cft fi vagtie \& fi obfcur, qu'on ne peut faire aucun ufage de fes détails. Parmi les outils dont les, Indiens fe fervoient pour tailler la pierre, il en nomme un fait d'un caillou noir, que les Indiens appelloient Hihuana. Il paroît qu'ill'entend de la pierre de Gallinace,

ligneufes fe refferroient fur cette pierre: alors on coupoit larbre au-deffus de cette infertion, \& plus bas, felon la longueur qu'on vouloit donner all manche. On voit par-là combien une hache dcmandoit de tems \& de peine : mais le Sauvage ne compte pas fon tems. 
Obfervations \& additions:

qui, felon le rapport de notre Auteur, a pris ce nom de la conleur de l'oifeáu Gallinazo, autrement Aura, \& dans Linné, Vultur aura. Cette pierre eft noire, fort dure, \& caffante comme la pierre à fufil. Elle fervoit en outre, de même que la pierre d'Incas, à faire des miroirs dont on a trouvé quelques - uns dans les tombeaux. (Ces miroirs font travaillés des deux côtés, \& très-bien arrondis : ils font percés par le haut, comme pour y mettre une attache \& les fufpendre : le poli de ceux de Gallinace, ne céde en rien à celui de la pierre d'incas. On en voit de cette dernière pierre auffi polis, \& auff parfairement travaillés, que fi les Indiens avoient eu les outils les plus parfaits, \& connu les règles les plus précifes de l'Optique : on en voit aufli de convexes.)

G. de la Vega ne parle que de miroirs d'argent ou de cuivre. La pierre de Gallinace, dit $\mathrm{Paw}$, n'eft autre chofe qu'une lave fine jettée par les volcans du Pérou. On voir que la pierre obfidiane de notre continent, eft l'analogue de la Gallinace. Quant à la pierre des Incas, c'eft une efpèce de pyrite blanche, arfénicale, luifante comme de l'étain, ou du fer recuit, dont l'analogue eft connue dans notre continent; mais on a auffi regardé cette pierre. comme une compofition. Un Efpagnol nommé Tome II. 
Alzate, décrit dans le Voyage de Chape d'Anteroche, $p .62$, des morceaux d'un verre noir naturel, nommé Gallinace, \& qui, felon la conjecture de Bergmann, doit être femblable à l'agate d'Irlande. Bergmain doit avoir eu fous les yeux avec Paw, un endroit qui m'eft inconnu dans le Voyage de la Condamine. Cet habile Chymitte dit dans fa Defcription Phyfique de la Terre, édit. $2^{\mathrm{e}}$, p. 175 : "une " pierre virreufe fort belle, qu'on appelle là "Piedra de Gallinaz̧o, eft probablement une ¿lave : elle fait feu contre l'acier, coupe le "ver, prend un poli, gît en gros blocs, \& "reffemble à la pierre obfidiane:" il nomme caillou la pierre d'Incas. Le même Alzare eft fans doute celui dont il eft fait mention dans le Journal des Savans de 1773 , au mois de Juin, au fujer d'une addition à l'Hiftoire Naturelle da Mexique.

On trouve auffi dans les tombeaux des Indiens, des vafes à boire de différentes formes. Ces vaiffeaux y ont été mis au moment de la fépulture; voilà pourquoi on les appelle Guaqueros, ou fépulcraux. Il y en avoit de terre noire \& de grife, de rouge, de brune; d'autres approchent beaucoup du bleu. On ne fait pas -encore où ils prenoient ces belles terres. Il y a une grande aralogie entre ces vaiffeaux \& ceux des 
Objervations \& additions:

Guanches de Canarie, avec cette différénce, qu'ils font d une texture fi compacte, qu'il eft trèsdifficile de brifer ceux-ci : ces vafes avoient nombre de formes. Les plus ordinaires du Pérou pour 12 forme, font ceux dont Frezier a donné la figure tant fimples, que doubles. Mais on en a rapporté dernièrement un très - grand nombre d'autres ; dont le Public pourra fans doure bientôt fe récréer la vue au Cabinet du Roi: Ainfi nous n'anticiperons fur perfonne, quoique nôts ayons vu toure cetre collection.

D. Ulloa parle encore dans fon Voyage: d'autres antiquités de ces Indiens, comme des chaines de cou, de bras, des nageoires, des pendans d'oreilles, des figures d'idoles, \& des éméraudes artiftement travaillées. Nous avons. à Paris nombre de ces curiofités dans quelques cabinets, pour ne rien dire de ce qu'on a rapporté dernièrement du Pérou.

(Les idoles font les objets qui méritent une attention particulière. M. Schneider devoit obferver ce que l'Auteur en dit dans cet Ouvrage. 11 n'elt donc pas fûr que ce qu'on prend pour des idoles, en foit vrainent, puifqu'on ne voir pas les Indiens rendre de cultè à ces figures de rerre, de cuivre, \& même d'or, dont les unes longues de denx pouces, ont toute l'apparence des Momies d'Egypte, \& les autres repréfentent

G $\mathrm{g}_{2}$ 


\section{Obfervations \& additions:}

tout le corps. Ces petites momies d'or \& les autres figures, font creufes \& fi minces, qu'on en prendroir la matière pour une feuille d'or. On n'y voit aucune foudure : il faut donc qu'elles aient été faites en fonte, \& toutes d'un jet; mais on ne conçoit pas trop comment ces Indiens ont dî s'y prendre, pour fe faire des moules fi délicats. Voilà ces prétendus barbares qui embarraffent notre: génie: ils l'embarrafferoient fur bien d'autres objets, fi l'avidité de l'or n'avoit fait ruiner tous leurs travaux. Ces figures, de même que celles de terre \& de différens (1) cuivres, paroiffent plutôt avoir été des fymboles, des emblêmes bifarres, ou des jeux de l'imagination, que des idoles. La,plupart des Auteurs qui ont traité de l'idolâtrie \& des cultes religieux des anciens Peuples, ont fouvent pris pour des idoles ce qui n'étoit que fymbolique dans les diverfes théories de ces anciens Peuples : il eft même plus que probable quil y a eu moins de vraie idolâtrie qu'on ne le penfe en général, chez les Nations où la raifon a paru la plus égarée. Mais

(x) Quoiqu'on ait découvert en Amérique des cuivres de différentes coulcurs rouges, il eft cependant vrai que les Indiens pouvoient varier les nuances dont parle notre Auteur, avec des plantes de différentes efpèces. Ce fecret ignoré de nos laborieux Chymiftes, eft une chofe extrê.rnement fimple. 
Obfervations $\mathcal{G}$ additions.

469

le vrai fens des fymboles, qui n'étoit pas d'abord équivogue, ayant été de plas en plis ignoré, à mefure qu'on s'éloignoit de l'origine, le Peuple n’a plus comnu que la figure: de-là l'origine des fables, d'autant plus bifarres, qu'on cherchoit plus à les expliquer fans pouvoir remonter à la fource. Mais ces fymboles étoient devenus ( 1 ) facrés; on les a donc confervés avec. refpect, \& même tiès-long-tems, fans les comprendre, \& fans être idolâtre : c'elt ainfi que Laban confervoit les fymboles ou les emblêmes qui fervoient à éclairer fans doute les gens de fa maifon, fans idolâtrie. Jacob, qui adoroit le vrai Dieu, n'auroit pas pris une femme payenne: la conduite de fon père $\&$ de fa mère le prouve. Les Péruviens pouvoient donc avoir de pareilles figures fans les adorer: d'ailleurs ils avoient le Soleil pour objet de leur culte. On ne voit pas qu'on ait jamais trouvé l'image du Soleil dans leurs tombeaux : elle n'ćtoit que dans leurs temples. J'ai dit que ces figures pouvoient aufi être en partie des jeux de l'imagination, \& les Hiftoriens en conviennent. Mais quand un homme qui fe mêle d'écrire l'Hiftoire, vient nous dire que c'étoir le démon qui fe plaifoit à leur fug-

(I) C'elt ce qu'on peut prouver par un paffage do Macrobe, \& un autre de Paufanias.

$$
\text { G g }
$$


gérer les figures hideufes qu'ils faifoient, pour devenir lui-même l'objer de leur culte, je ne vois chez lui qu'une imbécillité qui né mérite plus d'être entendue, au moins fur cet article. Je crois donc que $D$. Ulloa a mieux vu l'objet de ces figures, qu'Acofta, \& mềme que la Vega, quoique ce dernier ait quelques idées affez faines fur plufieurs articles.)

(Ces Indiens, dit notre Auteur, fe plaifent à fe couvrir de mafques d'une forme fi laide, fi abfurde, qu'à peine peut-on s'en former l'idée. Si nous ne voyous pas de mafques auffi laids chez nous dans les jours de carnaval, c'eft qu'on ne peur pas les imaginer; mais les divertiffemens de ces Indiens font fans doute moins abfurdes, que les Proceffions où l'on voit en Europe des gens métamorphofés en diables, accompagner le Saint-Sacrement, fous la forme la plus ridicule : ne faifons-nous pas ce que les Indiens faifoient le jour de la fête du Soleil ? Voila donc leur ufage établi chez nous, les mêmes abfurdités chez nous devant le foleil d'or qui porte le Pain confacré, auquel on prétend que répondoit lidée que ces peuples avoient de Pachacamac, ou du Créateur de l'Univers. Loin de tourner ici la Religion en ridicule, je veux au contraire montrer que, dans la pratique, notre Peuple n'en a pas d'idées plus faines que ces 
Obfervations \& additions.

Indiens, \& qu'il fuit, fans le favoir, une coutume de la plus haute antiquité ; car c'étoir dans le même tems que la fête du Soleil fe célébroit chez prefque tous les Peuples, \& ils s'accordent encore tous fur le jour des feux de la SaintJean, qui ne font qu'un refte des feux allumés à Rome le jour des Palilia.

(Malgré ce que les premiers Hiftoriens de la conquête, ont dit de l'état où étoient les arts \& le génie des Péruviens au moment de la conquête, quelques Ecrivains de nos jours ont prétendı que ces $^{`}$ Peuples étoient encore à l'enfance des arts; mais on a oublié volontairement que ces Peuples ont eux-mêmes détruit, brûlé tout ce qu'ils avoient de plus précieux dans les palais de leurs Princes, dont ils avoient auffi emporté les tréfors. Ce qu'ils ont laiffé çà $\&$ là dans les différentes contrées, ne pourroit donc être que des ouvrages grofliers \& de peu d'importance, tels que ceux qui refteroient dans les villages de nos Provinces, fi nos grandes villes fubiffoient le même fort que Cuzco \& autres. Or ne feroit-ce pas une abfurdité de juger dans deux cens ans de nos arts $\&$ de notre induftrie par ces reftes qu'on trouveroit alors.

On a cru auffi pouvoir juger da génie des anciens habitans du Pérou, par l'état où l'on a trouvé leurs langues dans ces dernier's tems;

$$
\mathrm{Gg} 4 \text {, }
$$


472 Obfervations \& additions:

mais c'étoit une feconde abfurdité : autant vauteil juger du génie du fiècle d'Augufte, par l'état où fe trouvoit la Langue Latine, lorfqu'elle étoit devenue la feule langue des campagnards, \& n'avoir plus que le nom de ruftica. La Langue Péruvienne, forcée de céder aux idiomes barbares des Peuples qui ont fuccédé à l'anéantiffement de l'Empire des Incas, ne peut done plus repréfenter dans fes foibles rettes, cette Langue qui étoit devenue celle de tour l'Empire fous ces Princes. Sans avoir de termes propres pour chaque chofe, on peut y fuppléer par des expreffions figurées, ou des circonlocutions qui n'en font pas moins énergiques, $8 z$ ne défignent pas moins les objets. A quel degré n'avoit - on pas poulfé les Arts \& les Sciences fous Louis XIV! cependant notre Langue étoit alors la plus pauvre de l'Europe, \& d'un autre côté, l'état de nos Arts eft beaucoup inférieur à celui de ce fiècle, qui a éclairé toute l'Europe, tandis que nous avons une Langue infiniment plus riche. C'elt donc une fingulière méprife que de vouloir juger des Airs d'un Peuple par l'état de fa Langue. La Langue Grecque n'a fait que saltérer depuis Homère, qui vivoir dans un âge où la Grèce étoit encore prefque toute barbare. Mais pour ne pas nous écarter, lifons avec attention les premiers détails de la conquête du Pérou, 
Obfervations \& additions.

nous verrons de la grandeur, de l'élévation dans la feule eutreprife de ces grands-chemins que les Incas avoient fait faire dans toute l'étendue de leur Royaume. Ceux des Romains ne préfentent rien de plus parfait que ce qu'on voit encore dans les reftes des chemins du Nouveau-Monde. Un Peuple barbare ou ignorant, fe contente comme nous, jufqu'au commencement de ce fic̀cle, de traverfer le pays dans des chemins tels que ceux que nous avions encore à la mort de Louis XIV. Mais de telles entreprifes ne fe font pas fans de grandes vues dans un Gouvernement, \& elles fuppofent néceffairement un ordre civil des plus perfectionné. Les fimples befoins des habitans les ayant difpenfés de cet appareil onéreux dont nos demeures font remplies, ils n'ont cherché qu'à fatisfaire le befoin; mais cela ne prouve pas un défaut de génie. Les huttes des habitans des premiers âges avoient été changés en maifons de pierres dans les villes du Pérou, fous les règnes des Incas, \& l'on voit que fỉ leurs bâtimens n'avoient pas l'appareil des nôtres, il y avoit des compartimens pour toutes les commodités, \& que tout y étoir propre, même très-orné, felon le befoin \& la fimplicité du luxe de ces tems-là. Qu'on jette les yeux fur les habitations ruftiques de prefque toutes nos Provinces, dans quel état 
474 Obfervations \& additions:

les verra-t-on? moins commodes, plus fales; plus infectes que ne l'étoient celles des Péruviens. Et nots ne fommes pas barbares? Et nous avons des arts, du génie? Soyons donc plus juftes envers nous-mêmes, \& convenons que pour juger un Peuple, il ne faut pas le voir après une dévaftation générale. Jugerons - nouis l'ancienne Grèce par l'état où font actuellement les Grecs fous la domination du Turc? c'eft cependant le paralogifme dans lequel nous tombons à l'égard du Pérou. Ainfi nions qu'A thènes ait été une fi grande, li fuperbe ville, parce quil ne refte plus que quelques traces de fon enceinte, \& qui cependant protvent qu'elle devoit être plus grande que notre capitale.

OBSERVATIONS É Additions fur la découverte. de l'Amérique, É les lieux par où elle a pu être peuplée.

LEs notes de (i) l'édition Allemande de cet Ouvrage, ne préfęnrant aucuns détails fur ces articles, je vais y fuppléer à certain point. $D$.

(I) J'avois fupprimé ces détails, me contentant de ce que j’avois dit fur cet objet dans ma Préface; mais plufieurs perfonnes qui les ont lus m'ont fait un reproche de les. fupprimer: Lifez-les après le Difcours $22^{\mathrm{eme}}$ de l'Auteur. 


\section{Obfervations \& additions.}

Ulloa penfe que le midi de l'Amérique, \& même le continent, peut avoir été peuplé par des Navigateurs que le vent $y$ porta des ifles qui font à l'oueft de l'Afrique. Les raifons qu'il produir, me paroiffent des mieux fondées. Ces ifles étoient peuplées de très-ancienne date, puifque Ptolomée nomme même l'ifle Canarie. Or, plufieurs Navigateurs ou habitans de ces ifles, ont pu être jettés fur les côtes du. NouveauMonde, comme il eft arrivé au Navigateur d'après les inftructions duquel Colomb entreprit fon premier voyage. Les débris d'un vaiffeau que Colomb apperçut fur les côtes où il aborda, prouvent encore que d'autres $y$ avoient été jettés avant le Navigateur auquel il dût toute la gloire de fes découvertes. Si lon examine. enfuite avec impartialité les détails que $M$. Reinhold Forfter $(\mathrm{r})$ a produits il $\mathrm{y}$ a peu de tems au fujet des anciens voyages maritimes des Vénitiens, on fera forcé de convenir qu'ils conhoiffoient les Antilles, \& y naviguoient : c'eft ce qui eft démontré par une Carte (2) marine de

(I) Hiftoire des découvertes faites dans le Nord par zous les Navigateurs.

(2) On voit fur cette ancienne Carte manufcrite une Ine qui ne peut être que Saint-Domingue, au point où elle eft marquée. 
476

Objervaitons \& additions.

1436 , que M. le Comte Carlo Carli dit, dans fes lettres fur l'Amérique, avoir vu à Venife. Ainfi tout fe réunit pour confirmer le fentiment de D. Ulloa.

D'autres réuniroient ici les paffages que préfentent plufieurs Anciens au fujer de l'Atlantide; d'autant plus qu'il y avoit en Amérique plufieurs habitations \& une ville même, près du Mechoacan, qui fe nommoient Atlan. On a auffi cru reconnoître le nom d'Antée, contemporain d'Atlas, dans le nom d'Antilles \& d'Andes. Laiffons ces conjectures pour ce qu'elles valent. J'ai vu avec peine que M. Filfon \& $M$. le Comte Carlo Carli, s'étoient trop arrêtés à ces paffages des Anciens, qu'on a pris dans $l_{a}$ favante differtation de Cellarius, \& fans le citer. Mais Reisk en a fait voir l'infuffifance dans fes notes fur Cluvier. Théopompe cité par Elien \& Plutarque, méritent feuls quelqu'attention, lorfqu'ils nous difent, l'un, qu'au-delà de notre hémifphère, il exifte un grand continent; l'autre, qu'au-delà des ifles Atlantiques on trouve un grand continent. Mais ces paffages bien appréciés ne défignent rien.

Le rapport de plufieurs ufages feroit préfumer d'un côté, que ces peuples du Pérou font venus des inles qui font à l'oueft de l'Afrique; de l'autre, qu'ils font originaires de la Chine: 


\section{Obfervations E additions:}

aindi l'on ne pent encore rien conclure. Cependant il eft probable que les Mexicains font d'origine Phénicienne, \& d'une race tonte différente de celle des'Péruviens. Si je n'étois convaincu par la connoiffance d'un affez grand nombre de langues, que les Dictionnaires fone infuffifans pour en déduire l'origine \& l'analogie des langues, je dirois que les Péruviens \& les Mexicains tenoient à une origine commune dans les tems les plus reculés: car nombre de mots comparés avec les idiômes que je connois, m'ont perfuadé que le fond de leur langue eft le même. Mais ils ont cela de commun avec tous les peuples de la terre, dont les langues: nous rappellent manifeftement un idiôme primitif. Quel eft-il ? Je n'ofe l'affurer. Ce n'eft affurément pas l'Hébreu, qui fe préfente comme une langue dans laquelle il fe trouve trop de mots compofés ou modifiés, pour être primitifs.

Mais paffons à d'autres objets. D. Ulloa croit à peine que le nord-eft de l'A fie air pu fournir des habitans à l'Amérique. Lés voyages du. célèbre Cook, \& la fuite d'une Colonie fauvage, Américaine qui, pour éviter fa deftruction totale, fe fauve fur le continent de l'Afie, prouvent que D. Ulloa eft mal fondé dans fon opinion. Le paffage eft aujourd'hui connu. Il l'étoit 


\section{Obfervations \& additions:}

même des Anciens, fil l'on peut s'en rapporter à Pline, à qui l'on rend avec raifon, plus de juftice que par le paffé. Ses prétendues fables deviennent peu-à-peu des vérités certaines. $\mathrm{Ce}$ qui montre que s'il the faut pas croire fans preuves, il ne faut pas tout rejetter légèrement. Cet habile Naturalifte nous dit donc qu'il avoit paru dans les mers de la Germanie, des vaiffeaux venus des Indes par le Nord. Pourquoi ces. vaiffeanx n'auroient-ils pas pu faire ce voyage, puifque dans le dixième \& onzième fiècle, les habitans du Nord alloient par mer en Amérique, \& en revenoient fans s'égarer? C'eft ce que M. Reinhold Forfter à prouvé.

Leif, nous dit-il , fils d'Erick Raude, équipe " un vaiffeau, prend avec lui Biorn, fils d'un "Iflandois Herjolf. Il part avec trente hommes "pour aller à la découiverte. Ils arrivent dans " un pays pierreux, ftérile, qu'ils appellent "Helleland: Un autre où ils découvrent des "bois, eft appellé Marckland. Deux jours "après ils voyent un notiveail pays, \& à fa " partie Septentrionale tune ifle, ou il y avoit " un Aleuve qu'ils remontent. Les buịfons por. " toient des baies d'une faveur douce. Enfin ils " arrivent à un lac d'où le fleuve fortoit. Dans " les plus courts jours ils n'y virent le Soleil " que huir heures far lhorifon. Ce pays devoir 
" donc être all $49^{\circ}$. degré, latitude feptentrio\nale, au Sud de Groënland, \& ainfr la baie ¿ des exploits, ou une autre côte de la rivic̀re " de Saint-Laurent. Leif appella ce pays $W^{i n-}$ » land, parce qu'il y trouva du raifin. Le Prin" tems fuivant il revint en Groënland. Tho"wald, frère de I-eif, y retourna avec le 3 même monde, \& y mourut des bleffures - qu'il reçut dans un combat contre les natu"rels du pays. Thorftins, troifième fils d'Erick"Raude, paffa la même année à Winland avec i) fa femme, fes enfans \& fes domentiques; " en tout, vingt-cing perfonnes. Il mourut. $\mathrm{Sa}$ "veuve époufa Thorfin, illuftre Iflandois; ce" lui-ci y mena foixante-cinq hommes, \& cinq "femmes; \& y fonda une colonie. Il com"mença à trafiquer avec les Skallingers, habi$\Rightarrow$ tans du lieu, ainfi appellés à caufe de leur " petite taille. Ce font fans doute les Efqui3. maux, même peuple que celui de Groën" land. Les defcendans de ces Normands qui " fe fixèrent en Amérique, s'y font maintenus " long-tems; quoique depuis le voyage de l'E. "vêque Illandois Erick, en Winland, l'an " I 2 I; on n'en ait plü entendu parler s. Telle eft une partie de l'extrait que je donnai de l'ouvrage de $M$. R. Forfter, en 1785 . M. Filfon qui dit aufli deux mots de ces évènemens, ajoute 


\section{iso Obfervations \& additions.}

que des troubles furvenus en Danemarck, firent oublier le Winland. L'Ouvrage de M. R. Forfter eft écrit avec cette tête froide, \& ce grand fens fi nécelfaires lorfqu'il s'agit de marquer la limite des évènemens douteux ou invraifemblables, \& cependant vrais. On verra dans les lettres du Comte Carlo Carli, comment \& à quelles époques fuivant lui, des peuples de l'Afie ont paffé dans le Notiveau-Mionde. Ces lettres aufi érudites qu'agréables (Florence 1780 ), \& que l'Auteur appelle lui-même fes fonges, préfentent une foule de faits intéreffans, gu'on chercheroit envain dans un affez grand nombre de volumes. Paffons-lui fes hyporhères chronolo-

- giques, \& nous ferons très-fatisfaits d'avoir connu fes fonges. Il eft donné à peu de perfonnes de rêver d'une manière auffi érudite.

Voyons comment d'autres peuples de l'Europe ont paffé en Amérique 322 ans avant Colomb. On parloit déjà, le fiècle dernier, d'une Colonie Galloife, partie de l'Angleterre, pour fe fixer en Amérique, fous la conduite de Madoc, fils d'Owen-Gueyned. Cette émigra. tion étoit connue par des Notices hiftoriques affez certaines dans le pays de Galle, \& entr'autres, par quatre vers Gallois, que Powel a publiés dans fa Chronique ou fes Antiquités Bretonnes. La Reine Elifabech chargea même Raleigh 
Objervations छे additions:

Raleigh de chercher ces Emigrans à qui l'on avoir entendu dire fur la côce de Virginie, haa houi iach, " comment vous portez-vous " ce qui eft le falut même de nos. Celtes de la Baffe-Brotagne. Raleigh malheureux, ne pur les découvrir. Mais la chofe n'en étoit pas moins certaine pour le pays de Galle. Voyons d'abord ce qu'en dit M. Filfon dans fon excelsente Hiftoire de Kentuke; je donnerai enfuite la preuve de ce quil avance.

"L'an r170, Madoc, fils d'Owen-Gwyn"nedh, Prince de Galles ( $\mathrm{I}$ ), mécontent de la 2). Fituatien des affaires de fon pays, abandonna "fa patrie, comme le rapportent les Hiftoriens "Gallois, pour chercher de nouveaux établiffe" mens. Laiffant l'Irlande au Nord, il avança " à l'oueft, jứqu'à ce qu'il rencontrât une con" trée fertile, où ayant laifé une colonie, il "retourna chez lui, perfuada à plufieurs de le " fuivre, partit de nouveau avec dix navires, "fans qu'on (2) ait entendu parler de lui de-

(I) La vraie caufe, felon d'autres, étoit qu'il avoit tue par mégarde fon Grand-père : cependant fa généalogie eft rapportée différemment par d'autres Hiftoriens; nous le verrons plus loin.

(2) Selon d'autres, Madoc fit trois voyages en Europe, \& s'en retournoit emportant avec foi tous les inftrumens de fer néceffaires aux métiers \& à l'agriculture.

Tome II. Hh 
482 Obfervations \& additions.

" puis cette époque. Ce récit a plufieurs fois " excité l'atiention des Savans. Mais comme

" on n'a point trouvé de veltiges de ces (I)

"Emigrans, on a conclu peut-être trop légè-

" rement que c'étoir une pure fable, ou au

" moins, qu'il n'exiftoit aucune trace de cette

" colonie. En dernier lieu néanmoins les habi-

"tans de l'oueft ont entendu parler d'une na-

" tion qui habite à une grande diftance fur le

"Miffouri, femblable aux autres Indiens pour

" les mœurs \& l'extérieur, mais parlant la

• langue Galloife, \& confervant quelques céré.

"monies de la Religion Chrérienne : ce qui à

"la fin a été regardé comme un fait conf-

"tant “.

"Le Capitaine Abraham, Chapelain de

". Kentuke, homme fur la véracité duquél on

" peut compter, a affuré à l'Auteur (M. Filfon)

" que, dans la dernière guerre, étant avec fa

" compagnie à Kaskasky, il y vint quelques In-

"diens, qui parlant la langue Galloife, furent

" parfaitement entendus de deux Gallois qui

" étoient dans fa compagnie, avec lefquels ils

" converfèrent beaucoup; \& qu'ils leur parlè-

'g) rent d'une manière parfaitement conforme,

ss à ce qu'en rapportent les habitans de l'oueft ".

(1) L'Aiuteur eft dans lerreur. 


\section{Obfervations 'E, additions.}

"L'Auteur n’ignóre pas le ridicule que ç r" taines perfonnes vaines \& bouillantes, pour" ront jetter fur ces récits; mais comme la vé"rité feule a guidé fa plume, peul lui inporte ' ce quón dira : \& il fe flatte quen excitant " de nouveau la curiofiré publique, il pourra "donner occafion à des recherches plus exactes " pour découvrir la veritée “.

C'êt ainf que parle $M$. Filfon dans la traduction de fon hiftoire. Il cite d'anciénnes ruines, des reftes de fortifications, avec des retranchemens, des battions ( 1 ), des tombeatix d'une ftricture toute différente de ceux des Sauvages, \& préfume que ce peut êrre quẹlques reftes des anciens ouvrages des Gallois. II le penfe dautant plus volontiers, que les Salivages n'áyant pas l'ufage du fer, ne pouvoient entreprendre ces ouvrages. Ce raifonnement n'eft pas concluant : car nums favons que le cuivire a été le métal que les anciennes nations ont le plus générálement employé pour leurs outils \& leurs armes, dans toutes les parties du globe.

(I) Ces baftions prouveroient que ces ouvrages font très-nouveaux; car du tems de Madoc aucune ville de l'Europe même n'en préfentoit. Les tombeaux méritent plüs d'attention.

\section{$\mathrm{H} \mathrm{h}_{2}$}


Je laiffe de côté d'autres circonftances qu'on pourra voir dans l'Hiftoire même de M. Filfon, $\&$ le récit du Capitaine Ifaac Steward, qui eft ì la fin, pour faire mention d'un ouvrage dont il auroit pu parler. Il eft même étonnant quil ne l'air pas connu.

Le nommé Benjamin Beaty, Miniftre Anglican, Méthodifte, lui-même Gallois, fe trouvant en Virginie, \& voulant repaffer dans la Caroline, fut rencontré par une troupe de Sauvages, lorfqu'il cherchoir à éviter les ennemis. Ceux-ci l'ayant reconnu Anglais, l'arrêtèrent avec fes compagions, les attachèrent à des arbres, \& fe difpofoient à les percer de fleches. Près de mourir il fe recommanda à Dieu, dit fon Pater, \&c. tout haut dans fa langue. Ces Sauvages étonnés qu’il parlât leur langue, accourent à lui, l'appellent frère, le délient lui \& les autres, \& les mènent à leur village, où ils arrivèrent après quelques jours de marche. Il y vit une peuplade toute Galloife, où fe confervoit encore la tradition du paffage de Madoc. On le conduifit enfuite à l'oratoire, où on lui mit en main un rouleau de peau, dans lequel étoit foigneufement confervé un manufcrit de la Bible en langue Galloife. Beaty revint à Londres avec quatre de ces Gallois, pour demander des Miniftres de la Religion, \& publia cet évè 
Obfervations \& additions.

nement dans un petit ouvrage, intitulé Journal of Two months, journal de deux mois. M. le Brigant, notre favant Celte, de qui je tiens ce récit, me dit s’être trouvé à Londres peu de tems après le retour de Beary, \& la publication de ce Journal, dont il s'eft procuré un exemplaire. Il y elt aufli parlé d'un nommé Sutton, qui ayant été fait prifomnier par ces Sauvages, eut occafion de connoître cette peuplade Galloife. Les habitations y font bien mieux conftruites que celles de tous les autres Sauvages. On voit partout de l'art, \& une nation qui n'a rien de commun avec les peuples voifins par la manière d'être.

Je ne fais que rappeller ici que le célèbre Cook a trouvé au nord de la Californie, une partie de l'ancienne Colonie Galloife, refoulée par les autres Sauvages, comme la maffe de la peuplade a été forcée de quitter fon ancien local lorfque les Efpagnols s'emparèrent du Mexique, \& je paffe à un monument publié à Londres en $1777,8^{\circ}$. par M. Owen, le jeune, dans un Recueil d'antiquités Bretonnes, pag. 103 : j'en traduirai littéralement l'effentiel.

“Ces préfentes attefteront à toute perfonne quelconque, qu'en 1669 , étant alors habitant de la Virginie, \& Chapelain du Major-Général

$\mathrm{Hh}_{3}$. 
Bennet, M. William Berkeley envoya deux vaiffeaux pour découvrir le lieu qu'on appelloit alors Port-Royal, mais maintenant Sud-Caroline, qui eft à foixante lieues au Sud du Cap-Fair, \& i'y fus envoyé avec eux pour en être le Miniftre. ,

“ Nous partimes le 8 Avril pour la Virginie, \& arrivâmes à l'embouchure du Port de PortRoyal, le 19 du même mois. Nous y attendîmes. le refte de la Hotte qui devoit venir de Barbadoes $\&$ des Bermudes, avec le nommé $\mathrm{M}$. Weft, envoyé pour être Député-Gouverneur de ladite Place. Aunitôt que la flotte fut entrée, les petits vaiffeaux qui étoient avec nous remontèrent la rivière, jufqu'à l'endroit appellé Oyfter Point; car nous n'ofâmes pas monter avec les gros vaiffeaux, à caufe de la barre que le fable formoic à l'entrée du Port.

Nous nous y arrêtames fept à huit mois, c'eftà-dire jufqu'au so Novembre fuivant. Epuifé pour-ainfi-dire par une faim preflante, faute de vivies nécelfaires, moi \& cing autres nous allâmes battre les champs, voyageant dans un défert, \& nous vînmes enfin dans la contrée de Tufcorara, où les Indiens du pays nous arrêtèrent, \& nous firent prifonniers, parce gue nous leurs dîmes que nos vaifleaux étoient chargés 


\section{Obfervations \& additions.}

pour Roanoake : or ils étoient en guerre avec les Anglois à Roanoake. Ils nous conduifirent donc dans leur peuplade cette nuit-là, nous enfermèrent feuls dans une maifun. Le jour fuivant ils tînrent un Macchcomoco (ou Confeil) à notre fujer, \& après la délibération, l'Interprête vint nous dire de nous préparer à mourir le lendemain. Confterné de cette décifion, je m'écriai dans ma Langue Bretonne: " N'ai-je donc évité tant de dangers que pour mourir affommé comme un Chien! "A ces mots un Indien vint à moi; (Il me parut enfuite être un des Capitaines de guerre du Chef des Doegs, dont l'origine me femble devoir être rapportée aux Gallois.) cet Indien me prit par le milieu du corps, \& me dit en Breton : non, tu ne mourras pas. Sur le champ il alla trouver le Chef des $T$ ufcoraras, pour traiter de ma rançon \& de celle de mes compagnons: il la paya le lendemain. Après cela ils nous conduifitent à leur ville, nous traitèrent avec affabilité pendant quatre mois. Je parlaı avec eux de nombre de chofes en Langue Bretonne, \& je leur fis trois prêches par femaine. Ils fe faifoient un plaifir de me communiquer leurs affaires les plus difficultueufes, \& quand nous les quitrâmes, ils agirent à notre égard avec beaucoup de civilité \& de bonté. Ces Sauvages ont leur habitation fur la rivière Pantigo, non loin du Cap-Atros. Tel H h 4 
eft le récit de mon voyage chez. les Indiens Doëgs.

A New-Yorck, 1.0 Mars I 68.5.

Morgan Jones, fils de John Jones, de Bafleg, près de Newport, dans la province de Monmouth.

P. S. Je fuis prêt à conduire tout Gallois, ou autres, qui defireront une plus ample inftruction.

\section{Tres-honorabie Cousin.}

Telle eft la copie du papier que mon cher frère T. K. m'envoyá de New-York en Amérique; je vous avois promis de vous en domner copie, d'autant plus que vous defriez la montrer à l'Evêque de Saint-Afaph : ma longue abfence m'a empèché de vous fatisfaire, mais pour vous éclaircir un peu les chofes, de même qu’à ce docte Antiquaire, permettez-moi de vous préfenter quelques détails à ce fujet.

Mon frère \& moi nous nous entretinmes, il y a quelques années, avec le coufin Thomas. Price de Llauvilling, fur cette matière, \& il nous dir qu'un homme de Brecknock fe trouvant, il y a environ trente ans, plus ou moins, fur les côres de l'Amérique fur un vaiffeau Hollandois, 
l'équipage voulut defcendre pour prendre des rafraîchiffemens; les Naturels approchèrent, \& fe difpofoient à les emmener de force, lorfque cet homme dit aux Matelots fes compagnons qu'il entendoit le langage de ces Sauvages. Les Hollandois lui dirent de parler à ces gens : aufitôt ils devinrent très-honnêtes, \& fournirent tout ce qui fut en leur pouvoir. Ces Sauvages dirent entr'autres, chofes à celui qui les comprenoit; qu'ils étoient venus d'une contrée appellée Gwynedd en Prydam-Fawr. Voilà en fubstance ce que je me rappelle de cette circonftance : c'étoit, à ce que je penfe, entre la Virginie \& la Foride, ou le Mexique. Olivier Humphreys, Marchand, dernièrement décédé, \& dont la veuve étoit il y a peu de tems à Saint-Afaph, me dit qu'étant à Surinam, il eut occafion de fréquenter un Corfaire Anglois, qui, faifant radoubler fon vaiffeau près de la Floride, y apprit un peu la Langue des Indiens : or cette Langue, me dit Humphreys eft abfolument la même que celle du pays de Galles. Mais, pour laiffer de côté des rapports: incertains $\alpha$ des conjectures, je dirai que Thomas Herbert touche, eu paffant, ce fujet au dernier feuillet de fon livre de Voyages aux Indes Orientales; il cite même la chronique du Docteur Powel, ou plutôt fon Commentateur H. Lloyd de Denbigh, pour confirmer ce fait. 
L'un ou l'autre, ou tous les deux, ont extrait leut récit de la vie d'Owen-Gwynedd, ou de fon fils. David, écrite par Gytto de Glyn; car je n'ai pas ce livre fous la main, l'ayant laiffé daris. la contrée d'Hereford.

"Or il eft dit, que cing ou fix vaiffeaux partirent d'Anglefey, faifant route au fud-oueft, \& laiffant l'Irlande à droite. Que ces vaiffeaux abordèrent dans le pays mentionné, \& que Madoc de retour chez fes comparriotes, les. engagea autant qu'il pût à quitter les armes avec lefquelles ils s'égorgeoient mutuellement pour un pays défert. Qu'il en avoit trouvé un, où il n'y avoit que peu ou point d'habitans : enfin, que certains nombre de Bretons s'étant décidés fur fes inftances, il partit une flotte de onze vaiffeaux pleins d'Emigrans, dont on n'ayoit jamais en rendu parler depuis.

"Mon frère ayant apris ce récit, \& rencorrtrant ce Jones à New-Yorck, le pria de le lui écrire chez lui même. Ce fut pour mobliger, ainfi que mon coufin Thomas Price, quil m'en envoya l'original. Ce Jones avoit fa demeure à douze milles de New-York, \& avoit été en même-tems que moi à Oxford. Il étoit du Collège de Jefus, \& fe nommoit Jones Senior, pour être mieux diftingué. Les noms propres ne font pas écrits felon l'orthographe moderne, 
nais j'ai dit à mon copifte de les écrire comme ils y étoient tracés. L'Evêque de S. Afaph faura. les corriger.

$\therefore$ si je puis dire mon fentiment furces noms, les Indiens Doegs n'ont eu ce nom que de la fyllabe finale du mot Madog ou Madoc, le CapÁtros doit-être le Cap Hatcerash, près du CapFair, dans la Caroline. Car obfervez quil dit que ces Indiens Bretons habitoient fur la rivière Pantigo près du Cap-Atros. Pantigo eft peut-être un ancien nom, qui au refte à un fon Breton. Il nomme le Cap-Fair, \& non Feir. Voyez fi ce feroit la même chofe. Il nomme Port-Royal qui eft actuellement dans la Caroline. En outre il dit qu'il s'échappa vers la Virginie. Les Indiens Tufcoraras \& Doegs font placés là dans les nouvelles Cartes des Domaines Britanniques. Je préfume que fa fuite $\& \cdot \sqrt{a}$ délivrance inattendue chez des compatriotes qu'il n'efpéroit pas trouver là, peuvent être fixées au tems de la révolte de Bacon en Virginie, vers 1669 , tems où fe paffèrent les chofes qu'on eut à démêler avec les Indiens. Ce Jones prometsoit d'en amener quelques-uns fous un moins, \& $c_{0}$

Votre très-obligé ami \& parent,

$$
\text { Charles Lloyo. }
$$

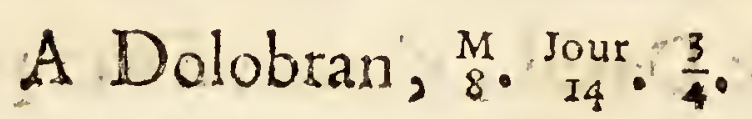


492 Objervations \& additions.

Telle eft la date de ceite lettre. Je n'y vois pas l'année: le huirième nзois eft Août. Enfuite c'eft le 14 de ce mois. Que veut dire $\frac{3}{4}$ ? Je ne le vois pas. Seroit-ce fix heures du foir, ou les trois quarts de ce jour. "Cette émigration d'une colonie Bretonne s'eft faite, ajoute l'Auteur, vers le tems de Guillaume le Roux 3 ou de Henri I, Roi d'Angleterre “

Copie du récit du Docteur Ploct Jü le même fujet.

“. L’Auteur de la lettre (Morgan Jones, \&c.) n'ayant pas imaginé, ni tait préfumer comment la Colonie Galloife peut avoir été portée \& comprife dans une contrée fi éloignée, je penfe que ce feroit obliger la Société, que d'éclaircir ce problême. Voici donc ce que je puis offrir au Public à ce fujet, foumettant tout à l'examen le plus impartial. Ainfi j'efpère procurer quelque fatisfaction, fi je puis au moins préfenter quelques degrés de probabilité.

" Je trotve dans les Annales Bretomes que le Prince Madoc, fils d'Owen-Gwynnedd, fils de Gryffith, fils du Conan, rendoit hommage pour certaines terres, en Angleterre, à Guillaume le Conquérant. Fatigué de la guerre civile qui s'étoit allumée enrre fes frères Jorwerth, Howel \& David, chacun d'eix prétendant avoir 
Objervations \& additions.

493

part dans les domaines de leur peère, felon la coutume du Gavel-Keind, (V. Blackftones.) il s'apperçut en inême-tems que les Normands, leurs nouveaux voifins, étoient près de leur enlever tout. Il s'y prir donc par toures les voies praticables pour mettre la paix entr'eux, mais il ne fut pas écouté. Ses bons offices le rendirent même l'objet de leur furie. Ainfi cherchant à fe conferver, \& ne voyant pas qu'il pût être tranquille dans fon pays, il réfolut de chercher un afyle dans quelque partie éloignée du Globe, tant pour lui que pour fa poftérité. Il fit fes: préparatifs \& s'embarqua en 1170 , la feizième année de Henri II. Ayant mis à la voile par un vent favorable, il paffa en quelques femaines du pays de Galles dans une nouvelle terre qu'il découvrit à l'oueft. A fon arrivée', il y trouva tous les vivres dont il avoit befoin, de l'eau douce, un air falubre \& frais, de l'or, \& tout ce qu'il pouvoit raifonnablement defirer. Madoc s'y arrête, y établit ceux qu'il avoit amenés (vers la Floride ou le Canada, comme mes Auteurs le penfent; ce qui s'accorde on ne peut mieux avec ma nouvelle relation ). Après y avoir paffé quelque tems pour mettre tout en ordre, \& élever les fortifications nécelfaires à une défenfe affurée, il fe décida à retourner 
494 Obfervations \& additions.

dans fa parrie, pour en amener un plus grand nombre de Colons, \& fe fournir de toutes les provifions néceffaires. Il partit donc, laiffant cent-vingt hommes à fa nouvelle habitation, Comme Cynvrick, fils de Grono, Meredith fils de Rice, Gaten, Owen, \& plufieurs autres l'atteftent. Dirigé par la Providence, qui eft la meilleure bouffole, \& par la vue de l'étoile polaire, il arriva heureufement an pays après un long voyage; raconta les fuccès étonnans quili avoit eus, la fertilité du fol, la fimplicité des Sauvages, l'abondance qu'il y avoir trouvée, \& combien il étoit facile de s'affurer la conquête de ce pays. Il engagea donc nombre de fes compatriotes à partir avec lui. Tous fe mettent en mer fur des barques chargées de provifions, \& ils arrivèrent heureufement à la colonie. Madoc n'y retrouva en vie qu'un petit nombre de ceux quill y avoit laiffés. Les uns étoient morts par leur excès dans le manger, d'aurres par la perfidie des Barbares. Mais les nouveaux Colons qu'il amena, ayant étendu \& confidérablement fortifié fa peuplade, il difpofa tout de manière à n’avoir plus à craindre aucun ennemi. L'abondance, la fécurité, un contentement parfait, firent bientốt oublier le fouvenir de l'ancienne patrie. Perfonne n'y retourna ; \& après 
Obfervations \& additions.

quelques générations, ce fut un fait qui tomba dans un oubli total.

"Herbert remarque Lib. 3 cap. ultim. que les Efpagnols trouvèrent quelques veftiges de cette émigration, lorfqu'ils arrivèrent en Amérique. Les Mexicains n'avoient pas encore oublié que vers l'époque à laquelle Madoc paffa en Amérique, des étrangers y étoient arrivés fur des vaiffeaux. C'eft ce qu'atteftent Colomb, François, Lopez", \& autres. Ces étrangers y avơient répandu quelque connoiffance de Dieu, montré l'ufage des chapelets, des reliaues, du crucifix, \&c. : \& Lopez de Gomara affure qu'on en trouva dans ces contrées, quand on y arriva. Il faut aufi faire attention à ce que Cortez rapporte. Obfervant que les Indiens avoient nombre de cérémonies, il demanda à Motezuma, père de Quabutino, dernier Roi du Mexique, doù ils les tenoient. Motezuma répondit, qu’il y avoit nombre d'années qu'une nation étrangère avoit débarqué dans la contrée : que l'honnêteté, la piété exemplaire de cette nation, l'a. voir fait recevoir favorablement; mais qu'il ne pouvoir dire ni d'où elle venoit, ni comment elle s'appellọit. Dans une autre circonftance, Motezuma remerciant les Efpagnols de quelque faveur, leur dir que la principale raicon pour laquelle il avoit affectionné leur na- 
rion, étoit qu'il avoit entendu fon grand-père affurer, d'après une tradition conftante, que (peu de générations avant lui), fes ancêtres y étoient arrivés comme étrangers \& par hafard, ayant avec eux un homme de qualité. Que cet homme étant parti peu de tems après, revint, mais trouva morts la plupart de ceux qu'il avoit laiffés : qu'au refte c'éroit de lui ou d'eux, qu'ils croyoient eux-mêmes defcendre. Ce récit fi conforme aux circonfances de Madoc, prouve que (I) c'étoit plutôt des Gallois qu'ils defcendoient que des Efpagnols, ou de tout autre peuple. D'ailleurs les écrits qui contarent ce voyage, les vers des Poëtes Gallois, les Généalogiftes, décident la queftion. La vérité eft encore plus fenfible, lorfqu'on fait combien il refte dans ces contrées-là de mots Bretons. Tels font par exemple, Penguoin, tête blanche, noms donnés à un oifeau qui a la tête blanche, ou aux pointes nues des roches; gwyn-dw, blanche eall; bara, pain; mam, mère; tad, père; clugar, coq de bruyère; liynog, un renard; wy, cuf; calaf, thyau de plume; trwyn, nez, ou trogne en François;

$F$ (i) Les facrifices humains \& autres rits religieux prouvent l'erreur de Motézuma : fa race ou celle des anciens Rois du Mexique étoir très-probablement Phénicienne.

Neaf, 


\section{Obfervations \& additions:}

Weaf, le Ciel, \&c, \&c; mots connus égale-, ment dans l'Armorique.

"Mais la lettre de Jones eft un monument. qui fournit une preuve inconteftable. Un homme qui a été quatre mois parmi ces Sauvages, qui a prêché trois fois par femaines dans fa langue; que ces gens entendoient, à qui ils faifoient part de leurs affaires dans la langue qu'il leur parloit, étoit certainement de la même nation; quelque léger changement que le tems en̂t opéré dans l'idiôme. Il eft donc plus que probable que ces Indiens Doëgs, font les defcendans de la colonie de Madog ou Madoc. Ce ne font donc plus Colomb, Vefpuce, Magellan, qui ont découvert ce continent que l'Angleterre, ou les Gallois, connoiffent 322 ans avant eux. Le Nouveau-Monde, ainfi appellé très-mal à propos,; doit donc être nommé Madocia \& non Amérifca, \&c. »

Je fuprime le refte. Le Docteur Robert Plott plaide ici une mauvaife caufe. Car les habitans du Nord ont une date plus ancienne en leur faveur ; \& l'Amérique devroit plutôt être appellée Leifia, puifque ce fut dans le dixième fiècle que les Normands y paffèrent, fous la conduite de Leif.

C'eft affez de cette plaifanterie. Pour réfumer Tome II, 


\section{$498 \quad$ Obfervations \& additions.}

je dis qu'il eft actuellement prouvé que l'exiftence des Gallois en Amérique n'elt plus une chimère. Qu'ils y ayent paffé fans bouffole, $j$ 'ai peine à le croire. Mais étoit-elle connue à cette époque? Je le crois. Albert-le-Grand, né vers la fin du même fiècle que Madoc, parla de la bouffole dans le fuivant comme d'une chofe trèsconnue. Il fait même dire à Ariftote, que les Marins fe fervoient d'un fer aimanté qui fe tournoit vers le pole feptentrional. Voyez fon Traité des Métaux. Si cet ufage a été connu d'Ariftote, ou au moins du tems d'Albert-le-Grand, peuton croire qu'on l'ait ignoré du tems de Madoc? Peut-on même préfumer qu'un homme s'en ira au hafard avec une grande fuite, fans avoir au moins quelque notions vagues du pays qu'il alloit chercher? jai peine à le croire. Colomb n'a penfé à l'Amérique, qu'après les notions que fon Pilote lui avoit données. Il faut en dire anrant de Madoc. Sans doute qu'il fubfiftoit encore de ce tems-là quelques idées vagues de ce continent, où d'autres avoient été jettés par ha: fard, \& d’où ils avoient eu le bonheur de revenir comme le Pilote qui infruifit Colomb. Ce qu'il y a de très-probable, c'ent que les côtes de Terre-Neuve étoient fréquentées avant Colomb. Suivoit-on les indications de l'aimant? 
Objervations \& addicions:

je n'en fais rien : mais le paffage d'Albert-leGrand, prouve que (I) Kircher \& Blancan (2) fe font trompés, \& que cette invention étoit connue avant I302. D'autres ont encore eu plus de tort de l'attribuer à Marc-Paul. Elle étoit connue avant lui en Orient \& parmi les Chinois, fur-tout comme l'a prouvé il y a cinq ou fix ans un jeune Italien, dans une Differtation très-intéreffante fur l'origine de la foie, \& fur fes différentes efpèces.

Voilà ce que j’ai cru devoir ajouter de vrai ou de probable à cet Ouvrage, au fujet de la découverte de l'Amérique.

\section{Lefebvie de Villebrune.}

(1) De arte magnet.

(2) Chronol. matkematicor.

Fin du Second E dernier Dolume. 



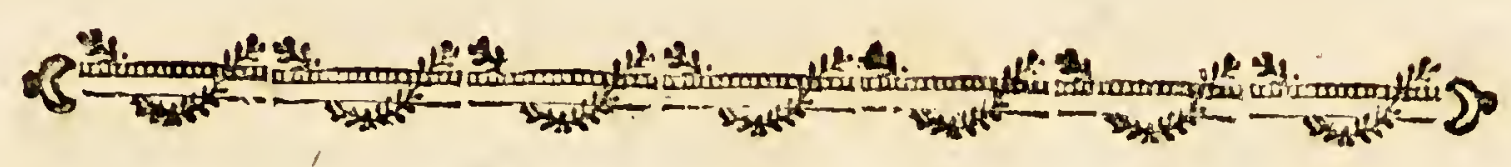

\section{T A B L E}

DES Chapitres contenus dans ce fecond Volume.

(Nota.) Voyez à la fin de ce Volume, des Obfervations \& Additions importantes à chacun des Difcours fuivans. La Table de ce fecond Volume indique ces Obfervations \& Additions, qui font Supplément.

\section{DISCOURS DIX-SEPIÈME.}

1 Es Indiens indigènes des deux parties de l'Amérique, de leurs mours, coutumes $\& u$ Jages,

Disc. XVIII. Continuation des détails relatifs au caractère E aux maurs des Indiens. Comparaifon des uns $E$ des autres,

Disc. XIX. De la Religion des Indiens Occidentaux, de leurs fépultures, de leur diminution, $\varepsilon$ des Cafzes des Mérifs,

Disc. XX. De l'antiquité des Indiens Occidentaux, É des chofes qui s'y font confervées, 66

Disc. XXI. Des différens Ouvrages dictés par la nécelfité, Es de plufieurs figures d'Idoles, ou d'Amulettes,

Disc. XXII. De la langue des Indiens; du juTome II. 
gement qu'on peut porter de la premiere popio lation de l'Amérique,

Obfervations fur le Difcours II d'Ulloa, concernant la pofition des terreins de l'Amérique, 137 Objervations É Additions aux Difcours III, IV Eै $\mathrm{V}$, concernant les températures, climats, \&c. des divers terreins de l'Amérique, \&c. I 37 Obfervations Jur les Garvas $\mathcal{E}$ les Paramos, dont il eft fait mention daus les Difcours V E VIII,

I 6

Obfervations fur le Difcours X, concernant les Lacs \& les Fleuves,

I 66

Objervations \& Additions au Difcours VI, concernant le Règne Végétal,

Objervations \& Additions aux Difcours VII, VIII \& IX, concernant le Règne Animal, les. particularités relatives aux Volatiles $\mathcal{E}$ aúx Poiffons,

Objervations \& Additions aux Difcours XII, $\mathrm{XIII}, \mathrm{XIV} \& \mathrm{XV}$, concernant les Mines de l'Amérique Efpagnole,

253

Objervations \& Additions au Difcours XVI, concernant les Folfiles \& les Pétrifications , 346 Objervations \& Additions au Difcours XVII E XVIII, concernant les Indiens de l'Amérique Méridionalé. Leurs maurs, leurs ufages, leur caractère, 


\section{TABLE DES CHAPITRES.}

iil $\hat{j}$

Objervations \& Additions au Difcours XIX, concernant la Religion des Indiens,

Obfervations \&s Additions au Difcours XX, concernant les Huacas, ou tombeaux des Indiens,

Obfervations E Additions au Difcours XX, concernant les monumens anciens des Indiens, 450 Objervations \&, Additions au Difcours XXI, concernant les armes, les inftrumens, les vajes, les uftenfiles, les ufages, \&x. des Indiens du Pérou,

Objervations E Additions au Difcours XXII, concernant la découverte de l'A mérique, El les lieux par où elle a pu être peuplée,

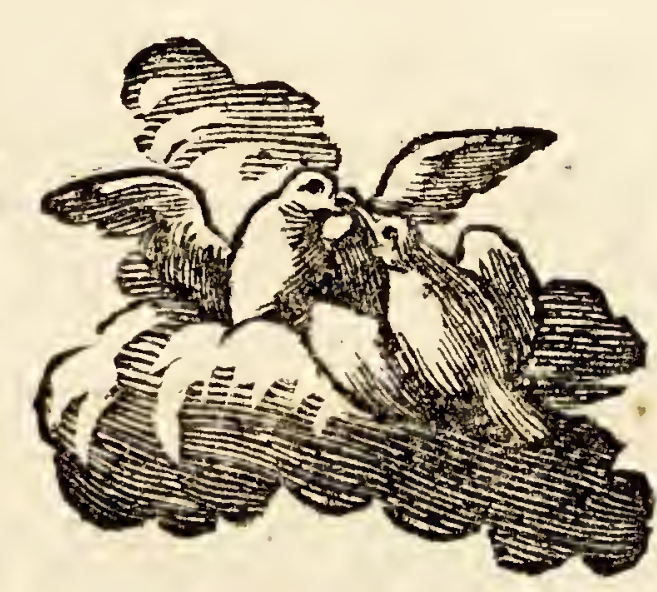

$\mathrm{Kk}_{2}$ 
iv

\section{T A B L E}

DEs principales matières contenues dans ce fecond Tolume.

ABAQUE des Romains \& des Chinois. Acérado, ou Efpeiado: efpèce de Minérai d'argent, 288 Adoves, ou Briques crues : leur emploi,

Voyez aufi Temple \& Palais des Incas. Afrique : fes pyramides, 385 E Suiv. Air dangereux des hantes cimes du Pérou, I $38-$ I 56 Amalgame: opération préliminaire \& fubféquente felon Acofta; quantité de Mercure employé, $29.3-298$ - fes procédés, felon Frézier, 298-304 procédés différens felon Bayer \& de Laëte , 304-306 fon ancien procédé, Celon Carreri, 3I3-

fon origine eft-elle due aux Efpagnoles? fon époque incertaine; pratiquée des anciens, $\quad 328-337$ Amérique: de quel côté les premiers Habitans y ont-ils palfé ?

I 12 -I 34 depuis quand les eaux ont-elles quitté fa furface; révolutions qu'elle a fubies, fréquentée par les Européens avant Colomb. Voyez. Gallois,

Année : fa révolution fixée au Pérou, Animal: règne; animaux principaux dont il eft parlé dans

l'Auteur,

Apachitas. Voyez Hermès, I 98-252 Argent purifié: fon titre, 
Armes : les mêmes chez toutes les Nations anciennes, 88 .

- à feu, introduites chez les Indiens par les Anglois

\& les François, $\quad 89$

Atlantide: fauffes idées qu'on a eues de cette Ine, 387

Aviadors, $\quad 26 \mathbf{I}$

Balance \& poids en ufage chez les Indiens, $\quad$ iøo \& fuiv. Barbe : poil; les Indiens n'en ont poine, I I

pinces pour l'arracher, os

Bois pétrifié, 390

Buytrons,

$295-299$

Cadavres accroupis dans les tomb̆eaux, $\quad 447$

447
avant d'être enfevelis; ou jettés dans les champs, 449

Cailloux : leurs giffemens font-ils une preuve du Déluge en Amérìjue?

js8 \& Juiv.

Calumé: fon urage, 58

Cafje-tête, 92

Caftillan : poids,

Catafalques : leur origine, leur forme originaire chez nos anciens Francs; leur conformité avec les fépulcres pyramidaux,

384

Cause première, ou Etre fuprême étoit-il connu chez les Indiens du tems des Incas?

Caxas, ou réceptacle: terme de Mineur,

Caxon: efpèce de mefure de Minérai,

2.98

Cayambé : Structure de fon temple; beauté de fes reftes, leur Colidité,

Caylloma: fes Mines, fa Caiffe Royale; 457 \& fuiv. Chandeleur: origine de cette fête, 256 Cheveux: manière dont les Indiennes les arrangent, $\mathrm{KS} 3$

$46 \mathrm{I}$ 
vi T A $\quad$ B $\quad$ L $\quad E$

Chine: (la) conformité de fes fépultures \& de celles du Pérou,

Chucuito: Mines de cette Province,

Chica: boiffon des Indiens,

Cinabre : fon ufage pour fe peindre chez les Indiens,

Cobo, ou vingtième denier de l'or, $404 \mathbb{\xi}$ fuiv.

Cobriffo : efpèce de Minérai d'argent, ingrat, 260

Colonies Efpagnoles : les blancs y dédaignent les travaux, 65 Corréal : fes plaintes fur l'abus de lautorité, 414 Couleurs différentes des habitans de l'Amérique,

rouge dont fe peignent les Indiens; leur art, \& leur affectation dans leur manière de fe peindre, 5-8 des différens Indiens de l'Amẹrique; forme de leur vifage; caules des variérés qu'on y remarque , $397^{-}$

404

Cuivre: Con ufage chez les anciens Indiens. Ses différentes couleurs,

$90-94$

moyens de lui donner différentes couleurs, 468 Cuerpo : ce qua c'elt,

Culture des terres faite en commun, 4 I 3 Déluge: Arche; Colombe de Noé; tradition qui s'en. éroit confervée en Amérique, $348 \cdot 350$ - de Deucalion, 378

Diftribution des appartemens des Indiens, $7 \mathrm{I}$ Droit de Quint \& de Cobo, 260

Eau qui le convertit en pierre; réflexions à ce fujet,

Edifices anciens ruinés par la cupidité, $338-342$ 104 - des anciens Indiens, préfentent des dificultés infolubles,

Embaumemens des Péruviens, inconnus, analogues à celui des Guanches, 
Efpagnols : leur modération à l'égard de leurs efclaves,

Efsai de l'argent: comment il fe fait,

Femmes : leur état malheureux chez les Indiens, 4 II Fêtes en ufage chez toutes les anciennes Nations, 460 E $\int$. Feu de la Saint-Jean; fon origine,

Figures métalliques \& de pierres; induftric qu elles fuppofent, 26. Vertus que les Indiens leur atribuoient, ibid.

$\vec{F}$ ortereffes des Incas, leur forme, 72

Fofples \& pétrifications; additions à ce fujet,

Gallinace : pierre,

Gallois : leur paffage en Amérique dans le douzième fiècle, prouvée par des monumens aukhentiques, $274 \& \int$. Garvas: obfervation fur ce phénomène, I $56-$ I 60 Géants, $393-39^{6}$

Gérie: il nª pas manqué aux Péruviens; mais le tems,

Gouvernement Efpagnol : rageffe de fa conduite à l'égard des Indiens,

Granitos: eft-ce une pierre primitive?

378

Granize, 392.

Guayac très-difpofé à la pétrification, itid. Guanta: fes Mines, Fabitations des Mdiens : leur différence, 69. Lieux où elles étoient,

Habits: Leur couleur; épingles; parures des femmes trouvées dans les tombeaux,

Haches : de cuivre \& de pierre de différentes formes, \& autres infrumens de métal, 90-93 marque de dignités chez les Indiens du Pérou, 
obfervations ultérieures fur ces inftumens; étoient-elles des marques de dignités? manière dont ils les emmanchent,

Herbet: (Palais de)

$462-464$

Huanta-Joya: fes Mines,

Hermiès, ou Mercures, ou tas de pierres; les connoiffoiton aul Pérous?

Idoles hideufes des Indiens,

apparentes; crreur où l'on eft tombé à ce fujet,

Incas: durée de leurs règnes, $467-470$

- tradition fabuleufe fur l'origine de leur Empire, $366-368$
Empire,
340

hommage qu'ils rendoient à PEtre fuprême, 4Is - fils du Soleil, comme les Rois de l'Orient, 427 - époque de leurs règnes, fixée par le nombre des cadavres; ce calcal eft-il juffe?

- découverte de leurs cadavres, $44^{I-443}$

- ornemens de leurs tombeaux, 448. Femmes \& EFclaves qu'on leur donnoit pour compagnie,

Indiens indigènes de l'Amérique; leurs mœurs, leurs coutumes \& leurs ufages,

foumis; leurs habits; leur penchant à l'ivreffe, 1 4:20

leurs rufes, leur perfidie \& leur lâcheté; leurs cruantés, $2 I-32$ borne de leur intelligence, $32-35$ leur longue vie,

leurs grandes oreilles; leur changement de femme, $36-37$

leurs huttes $\&$ leurs habitations, $38-40$ lcurs affemblées dangereufes, 
DES M A TIERES. i leur efpèce ne diminue pas par les travaux des. Mines, mais par les mauvais traitemens, $\quad 4 \mathrm{I}-44$ - leurs pareffe; leurs femailles en commun ; leur préfomption; leur inclination au menfonge; dangers de leur donner de l'eau-de-vie, $44-48$ leur Religion, 49 caufes de leur diminution, 60-62 différence qu'il faut faire entre leur induftrie méchanique \& leur intelligence, $84-87$ les premiers quii pafsèrent en Amérique, étoientils en grand nombre?

102 moins timide que l'Auteur ne le dit, 409 fe font-ils enterrés tout vifs au moment de la conquête?

Ingénios: machines à bocarder, Inhumanité de tous les Indiens, $435-438$ 294-298 IO-I I Infenfibilité des Indiens,

I 2-14 \& courage des Indiens dans les douleurs. Exemple,

400

Inteiligence \& induftrie des Indiens, prouvées par leurs ouvrages,

$45^{6}$

Lacs \& Fleuves: obfervations, $166-172$ Langue des anciens Indiens; a-t-elle du rapport avec l'Hébreu?

Llipta : épice de Minérai d'argent, IOS-109 286 Larecaxa: fes Mines, 256

Latacunga: ftructure de fon Palais; art que l'on y remarque,

Lieux hauts conffacrés aux cultes religieux,

Loi Salique, citée,

Louifranne: nature de fon fol, 428 384 Lucanes: 'leurs Mines d'argent, I 7 I 256 
Madoc, Prince de Galle, paffe en Amérique dans le douzième fiècle, 474 \& fuiv. Maifon de jone, $45^{2}$ Machacado: Mines d'argent, ou de cuivre natif, 253 Maladies des ouvriers dans les Mines de Mercure, $\quad 327$ Manto: nom d'une efpèce de Mines, $\quad 257$. Marbre, \& pierre feuilletée dans la même maffe, 390.

Masques hideux des Indiens, $32.2=$

abus qu'en font les Chrétiens, 98

Métaux : les Indicns ch connoilfoient le mélange; ufage. quiils en faifoient,

Mercure : ( Dieu) conducteur, $93-94=$ à quel prix il fe livre acuellement, 423 comment en évitei les pertes dans le traitement des Mines?

quantité tranfportée à la Caiffe Royale de Pca tofi, jufquen 1638 ,

détails de fa mine à Guancavelica; circonftance de fa découverte, de fon expioitation \& fes produits,

3 I $5-327$

fes Mines dans le corrégiment de Cuenca, 342 Mers : leur profondeur eft dans le rapport du Plan plus ou moins obliques des côtes,

Mefures : les Indiens en avoient-ils pour le Commerce?

Io2

Méxique: forme des tombcaux,

Fines de l'Amérique Elpagnole; leur immenfé produit; quint attribué au Roi, d'or ; privilégiées,

les travaux y Cont-ils préjudiciables à la fanté des Indiens? 
D E S M A T I E R E S.

d'argent, leur ancien traitement felon Acolta, $291-293$

Avantages faits à celui qui en découvre, felon Carreri,

309

comment on $y$ defcend, \& comment on en vuide les eaux,

comment on les fuit, 308-3 II

Hefrs efpeces, leurs couleurs, \& leurs richefles,

$28,-289$

d'argent; comment on le traite felon Carreri,

Miroirs de veriec, ont-ils eté connu des anciens? 3 II

Miroirs de verre, ont-ils été connu des anciens? $\quad 338$

de Gallinace, 465

Miffsfipi : fa fource felon Carver, I 66

Mitas, ou corvée; ordonnance du Roi à cet égard,

$262-263$

pour les travaux des Fabriques,

414

Mochadéros: lieux de dévotion des Indiens,

418

Monumens : antérieurs à la conquête du Pérou, 67

Morts: refpect qu'on avoit pour eux,. $\quad 385$

- encerrés hors des murs des villes, 386

- (jour des) origine de cette fête, 461

Murs: de quelle nature on les faifoit chez les Indiens,

$72-74$

- faits de terre \& de paille hachée entre deux claies; ulage connu de toutes les anciennes nations, 45 I

Navarros: fa Mine; \$ु fuiv.

Nègres: origine de leur coulcur, 309

402

Négrillo: efpèce de Minérai d'argent,

Normands paffent en Amérique dans-ie onzième fiècie. Voyer Gallois,

Oifiveté de tous les Indiens, 
xis

'T A B L E

Onftions des Indiens \& des Habitans des anciens continens; leur origine,

Oreilles: ufage de fe les aggrandir, 4 II

Opas, ou figures hideufes que les Indiens confultoient, $96-98$

Pptique: fes règles bien obfervées dans les miroirs des Indiens,

465

Oruro: les Mines,

256

Or: fon alloi,

259

Os, \& crânes humains dans les ruines des anciens édifíces,

Offemens d'une grandeur prodigieufe, $393-395$

Outils \& inftrumens des Indiens; oblervations ultérieures à ce fujer,

Pachacamac: (vallée de)

462

(Edifice de)

$4 \mathrm{I} 5$ nom de l'Etre fuprême, nom de lidole de Quifman, confonduavec le nom de l'Erre fuprême,

Pachacutec rappelle le premier jour de l'année au mois de Décembre,

460

Palais, temples \& fortereffes, leur matière \& leur forme, 74-78. Qui en eft l'auteur?

Paca : efpèce de Minérai d'argent, 285

Pella: terme de Mineur; ce que c'elt, $296^{\circ}$

Péruviens anciens, mal jugés par les Européens, 47 I-

Pérou: civilifation de fes anciens habitans, $67-68$

Pétrifucations de l'Amérique, $368-377$

Perfes \& Grecs anciens; leurs figures hideufes en allant à? l'armée, 102 Pierres peintes, 379 
Pignes paffées en contrebande; comment on les effaie, $26 r$

- de quoi on les forme, \& comment on les effaic aux Caiffes Royales,

Polvérina: efpèce de Minérai d'argent, riche, 288 Population nombreufe des Indiens avant la conquête; 79 Potofi : defcription de cette fameufe Mine. Comment elle a été découverte; fes fouilles, fes travaux, fourneaux de fonte, 268-285

_ Produits immenfes de cette Mine, jufqu'en J.638.

Pyramides de la plaine de Zucara,

290 380 fépulcrales, 383

Plata-Blanca: ce que c'eft,

Plates-formes, ou terraffes en ufage chez toutes les anciennes nations pour couvrir les édifices,

Platine :- réflexions fur la nature de ce minéral, 343-345.

Papas-d'argent,

Paramos : ce que c'eft; air dangereux de ces hautes cimes; leur influence fur les degrés de chaleur, I $62-166$ Plomboronco : efpèce de Minérai d'argent, , 286 Quichua: langue générale du Pérou, I $10-112$ Quipos: ce que c'eft; leur ufage pour l'Hiftoire, 358 363. Voyez aufi, 364-366 Race différente des habitans de l'Amérique, $\quad$ 63-64 Relaves : terme de Mineur, 296.

Religion: lieux confacrés chez les Indiens, SI religion des Indiens, 4 Is - religion ancienne du Pérou; incertitude à ce fujet, 
sit

Refatador,

$$
\text { T A B L E }
$$

Rimac: fens de ce mot; temple oi l'on adosoit un

Rocou: fon ufage pour fe peindre le corps, 4.17

Rois : (fête des). Con origine,

Rofjzcler: efpèce de Minérai d'argent; riche,

Saint-Martin : origine de cette fête,

Santa-Cruq: fa Mine,

$S$ chite avec une apparence ligneufe,

Sémiramis: tombeaux de fes amans, leur forme, 385

405

460

287

461

309

Sépulcre des Indiens notables, non pyramidaux, 382

Sépulture des anciens Indiens; fuperfition à cet égard; ce qu'on trouve dans leurs tombeaux,
- particulière des Rois du Pérou, 448
Celle du Peuple, des Caciques,
Sombreros: efpèce de veine métallique;
Soroche: efpèce de Minérai d'argent,

Soufre, ou peau jaunâtre fur les eaux après les phies; fa caufe,

Soleil adoré chez les Indiens,

but des offrandes qu'on lui faifoit, 
Texos;

Tombeaux, ont eu la même forme chez toutes le anciennes nations, $438-440$ des Indiens; leur forme, leur emplacement, lieux où ils les conftruifoient,

La Trinité: fa Mine, 310

Vaiffeaux des anciens Indiens \& des modernes; leur différence \& leur matière, 99-100

Vapeurs dangereufes des Mines de Mercure, 327 $V$ afes de terre tirés des tombéaux, des anciens Indiens, leur forme, 466

Végétat : règne. Plantes principales dont il eft parlé dans l'Auteur, I73-I 98 Viandes confervées par le feul effet de l'air \& du froid, $444 \div 446$ Villages des anciens Indiens; leur pofition \& leur forme,

Vilcas-Guamen: fes Mines; 453 Virreyno: fes Mines, 253

Voûtes: les anciens Indiens les connoiffoient; pourquoi a'en voit-on pas dans leurs grands édifices ? 447 É Juiv.

Fin de la Table du fecond Volume. 






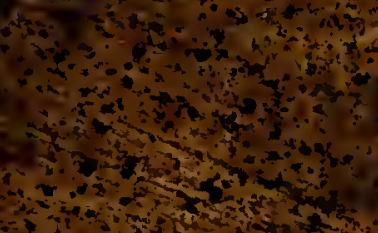

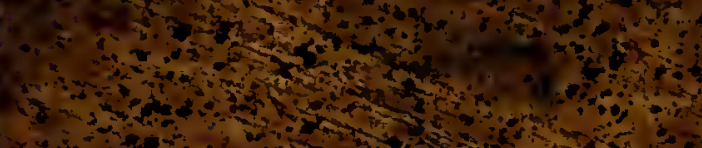

(n)

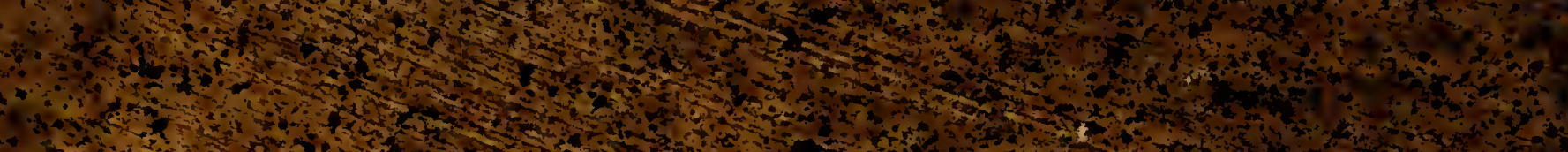

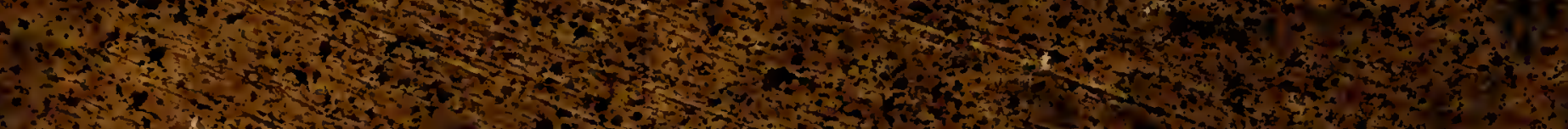

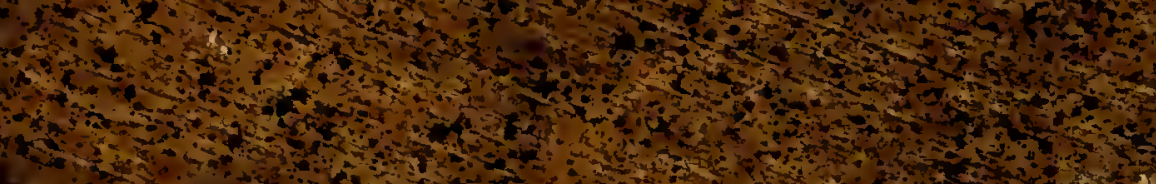

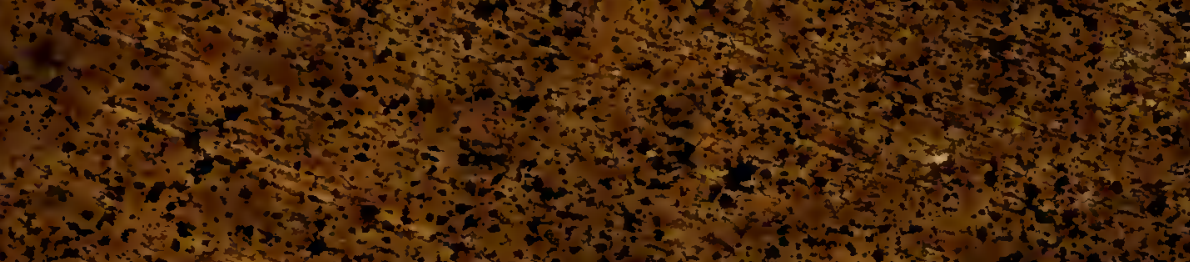

H.

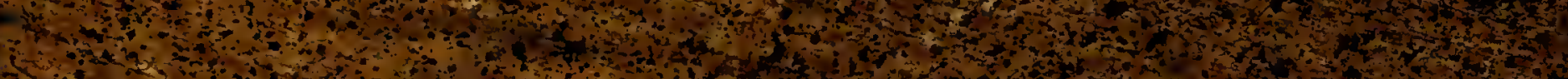

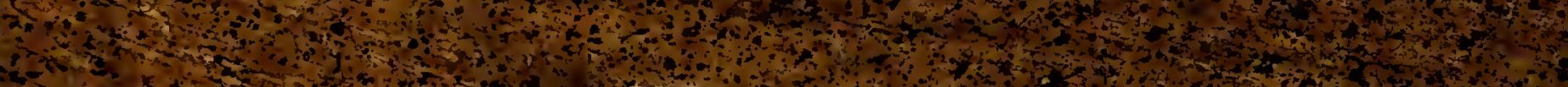

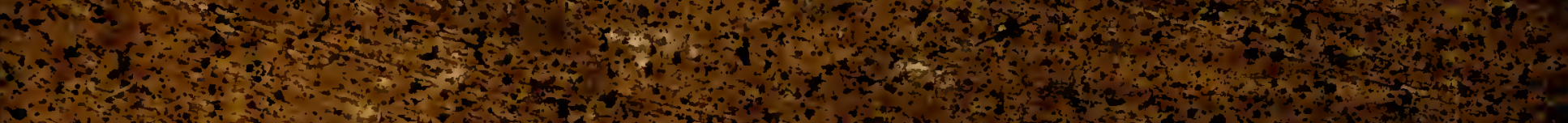

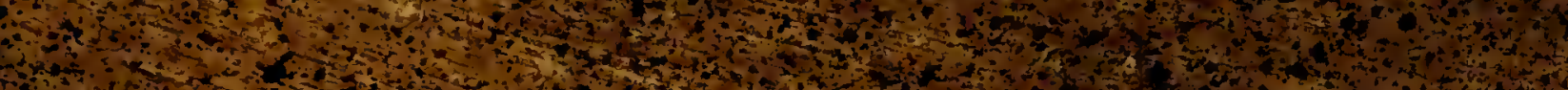

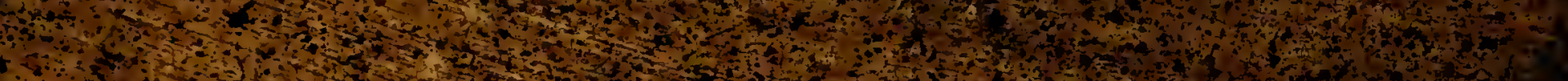

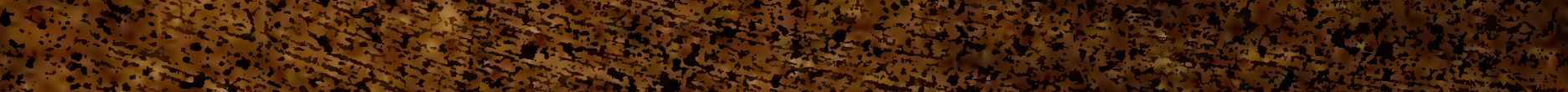

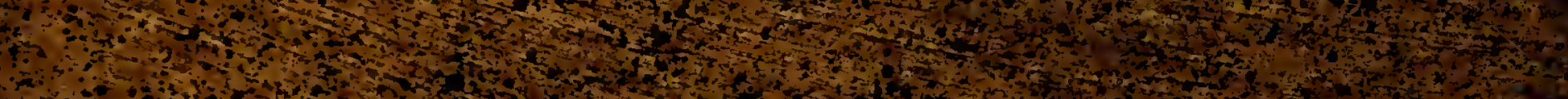

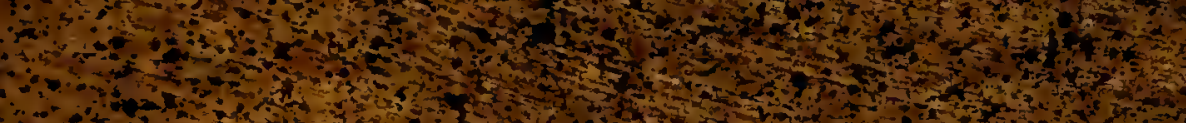

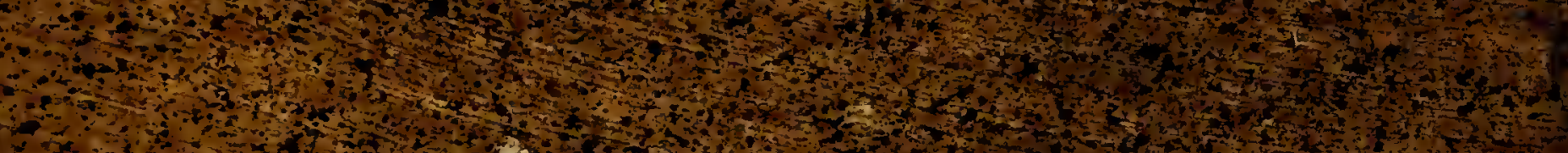

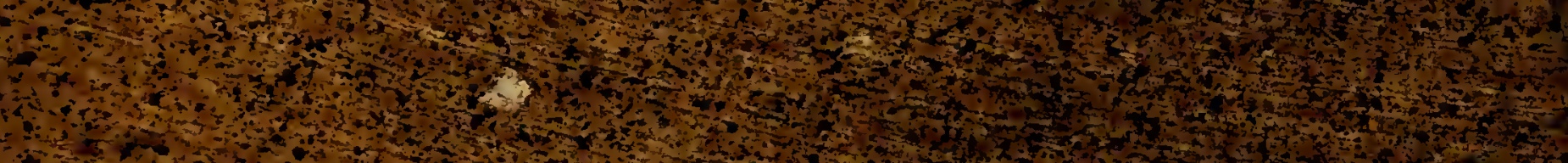

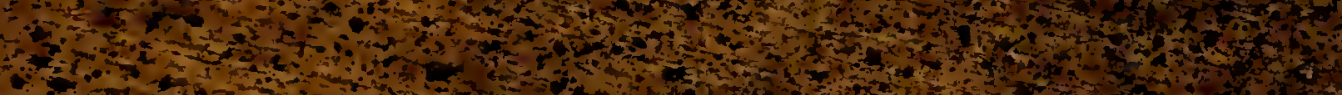

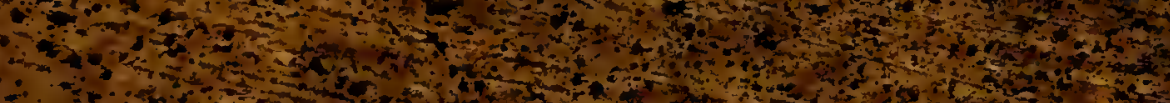

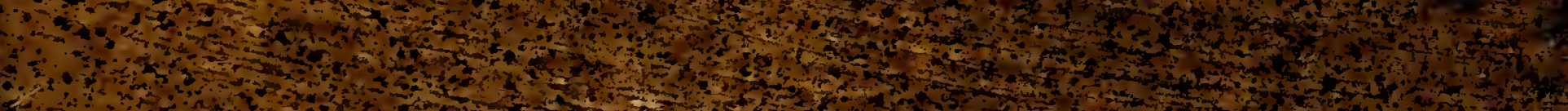

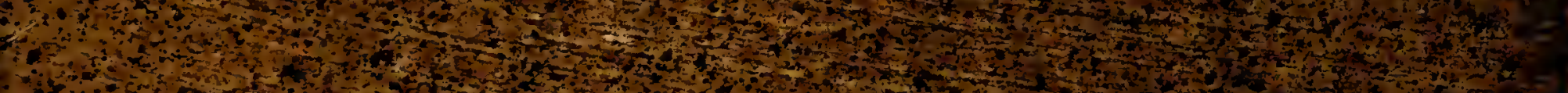

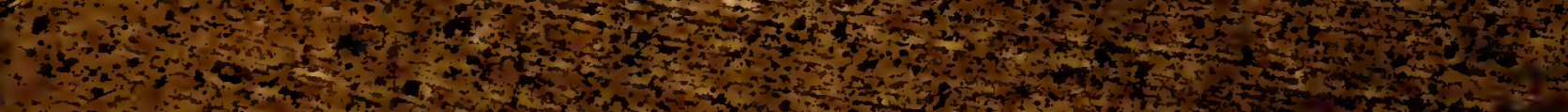

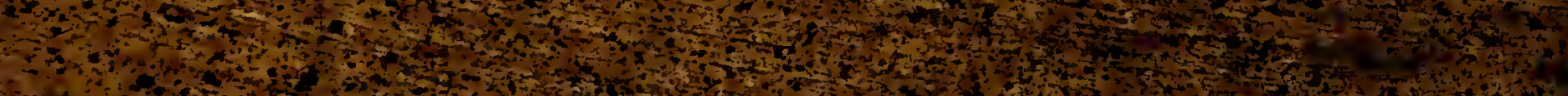

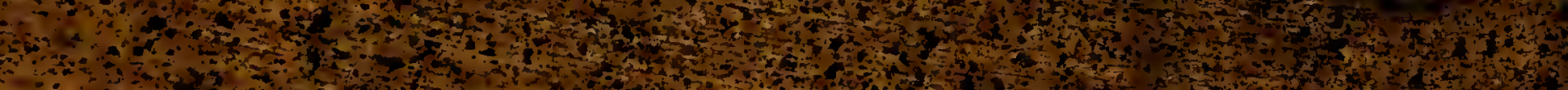

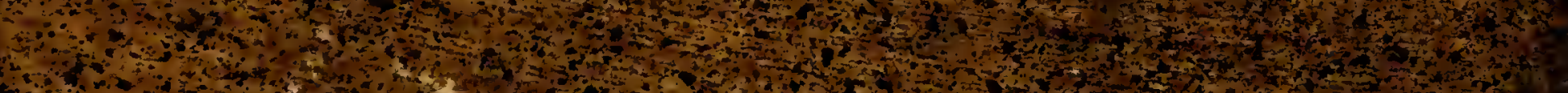

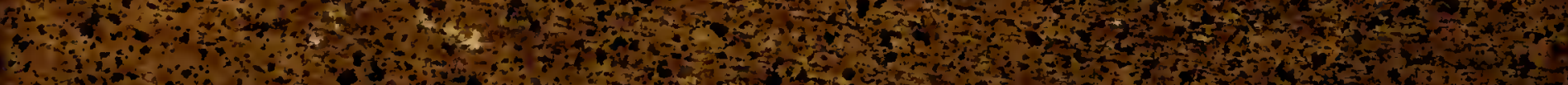

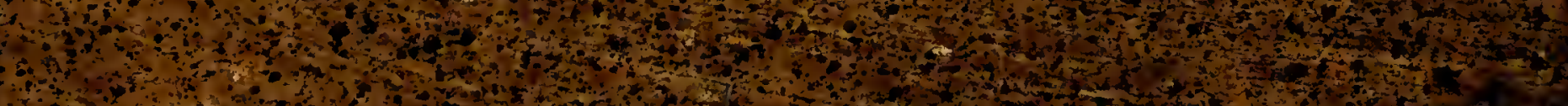

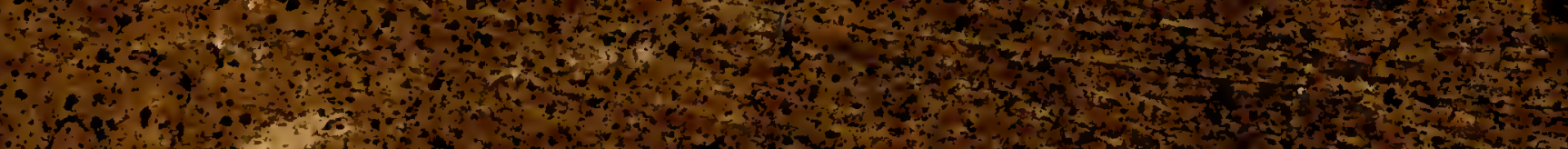

$n$
3

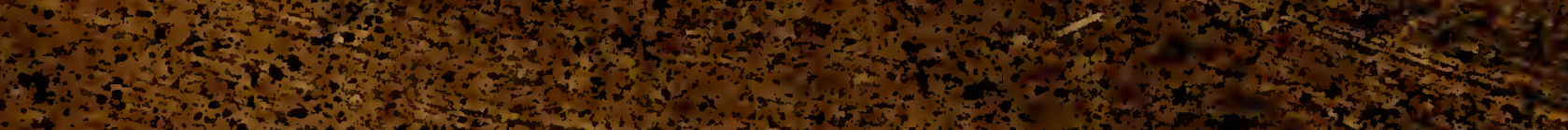

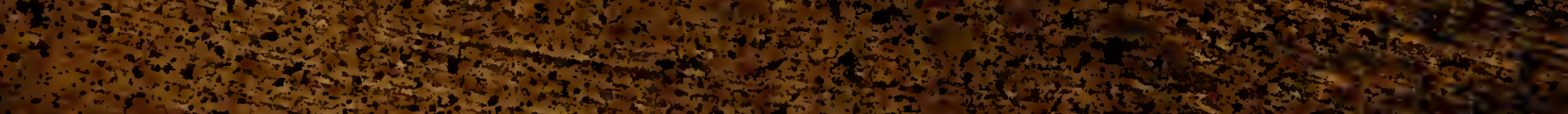

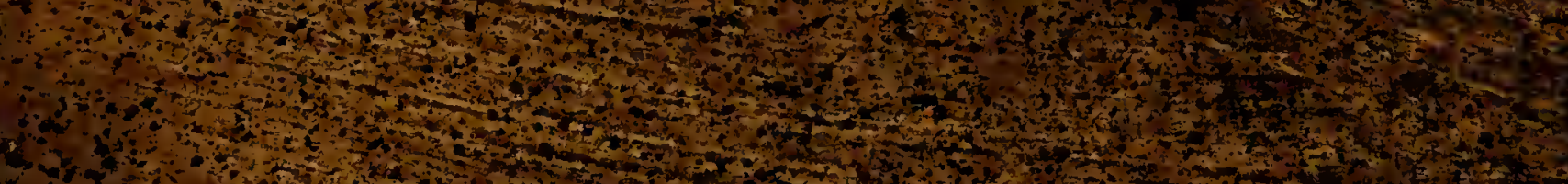

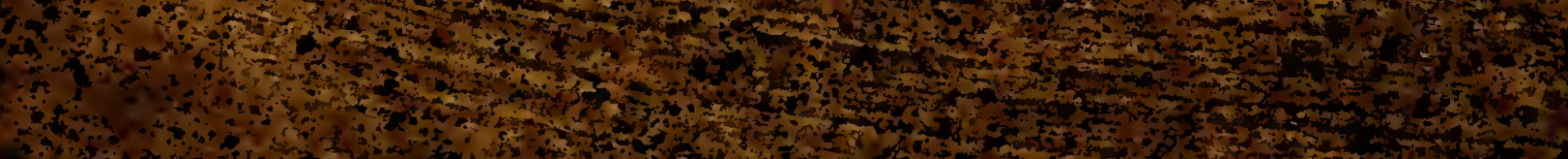

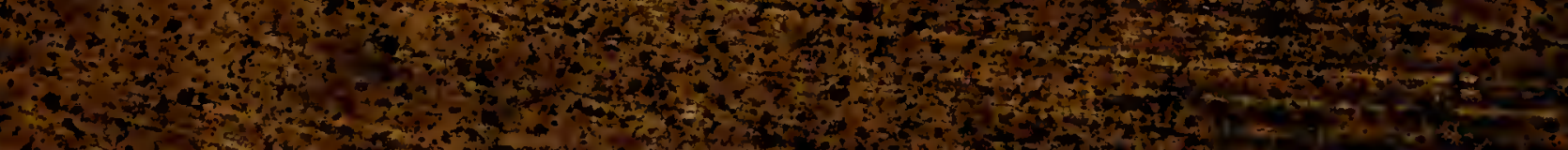

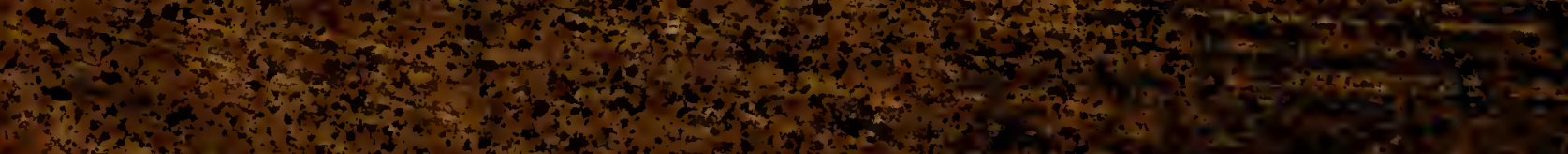

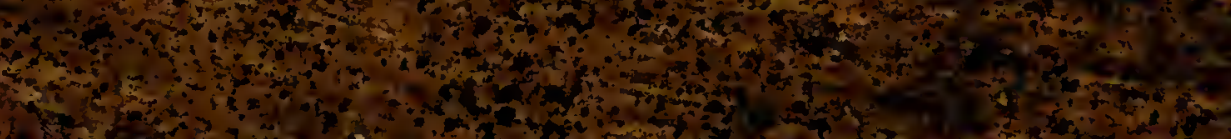

